㱐 


\section{Akten zur Auswärtigen Politik der Bundesrepublik Deutschland}

Herausgegeben im Auftrag des Auswärtigen Amts vom Institut für Zeitgeschichte

Hauptherausgeber

Hans-Peter Schwarz

Mitherausgeber

Helga Haftendorn, Klaus Hildebrand, Werner Link, Horst Möller und Rudolf Morsey

R. Oldenbourg Verlag München 1996 


\section{Akten zur Auswärtigen Politik der Bundesrepublik Deutschland}

\section{5}

Band I: 1. Januar bis 31. März 1965

Wissenschaftlicher Leiter

Rainer A. Blasius

Bearbeiter

Mechthild Lindemann und Ilse Dorothee Pautsch

R. Oldenbourg Verlag München 1996 
Die Deutsche Bibliothek - CIP-Einheitsaufnahme

Akten zur auswärtigen Politik der Bundesrepublik Deutschland / hrsg. im Auftr. des Auswärtigen Amts vom Institut für

Zeitgeschichte. - München : Oldenbourg.

Früher mehrbd. begrenztes Werk

1965.

Bd. 1. 1. Januar bis 31. März 1965. - 1996

ISBN 3-486-56071-9

(C) 1996 R.Oldenbourg Verlag GmbH, München

Das Werk einschließlich aller Abbildungen ist urheberrechtlich geschützt. Jede Verwertung außerhalb der Grenzen des Urheberrechtsgesetzes ist ohne Zustimmung des Verlages unzulässig und strafbar. Das gilt insbesondere für Vervielfältigungen, Übersetzungen, Mikroverfilmungen und die Einspeicherung und Bearbeitung in elektronischen Systemen.

Umschlaggestaltung: Dieter Vollendorf

Gesamtherstellung: R. Oldenbourg, Graphische Betriebe GmbH, München

Gedruckt auf säurefreiem, alterungsbeständigem Papier

ISBN: 3-486-56071-9 


\section{Inhalt}

Vorwort $\ldots \ldots \ldots \ldots \ldots \ldots \ldots \ldots \ldots \ldots \ldots \ldots \ldots \ldots \ldots, \quad$ VII

Vorbemerkungen zur Edition $\ldots \ldots \ldots \ldots \ldots \ldots \ldots \ldots, \quad$ VIII

Verzeichnisse $\ldots \ldots \ldots \ldots \ldots \ldots \ldots \ldots \ldots \ldots \ldots \ldots \ldots \ldots, \quad \mathrm{XV}$

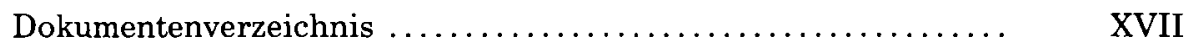

Literaturverzeichnis ................................... CCXI

Abkürzungsverzeichnis .............................. CCXIX

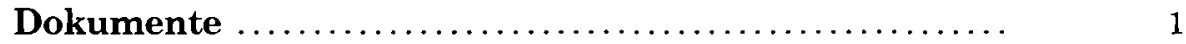

Band I (Dokument 1-158) ........................... 3

Band II (Dokument 159-338) .......................... $\quad 645$

Band III (Dokument 339-480) ........................ $\quad 1397$

Personenregister ................................... $\quad 1981$

Sachregister.................................... $\quad 2037$

Organisationsplan des Auswärtigen Amts vom Oktober 1965 ..... $\quad 2093$ 



\section{Vorwort}

Mit den Jahresbänden 1965 wird zum dritten Mal eine ausführlich kommentierte Sammlung von Dokumenten aus den Beständen des Politischen Archivs des Auswärtigen Amts unmittelbar nach Ablauf der dreißigjährigen Aktensperrfrist veröffentlicht. Das bewährte Editionskonzept der in den beiden letzten Jahren bereits publizierten ,Akten zur Auswärtigen Politik der Bundesrepublik Deutschland 1963“ und „Akten zur Auswärtigen Politik der Bundesrepublik Deutschland 1964" ist beibehalten worden.

Das Erscheinen der vorliegenden Bände gibt Anlaß, allen an dem Werk Beteiligten zu danken. So gilt mein verbindlichster Dank dem Auswärtigen Amt, insbesondere dem Politischen Archiv sowie den Damen und Herren in den Referaten, die beim Deklassifizierungsverfahren zur Offenlegung der Dokumente beigetragen haben. In gleicher Weise zu danken ist dem Bundeskanzleramt für die Erlaubnis, unverzichtbare Dolmetscheraufzeichnungen einbeziehen zu können. Desgleichen danke ich Frau Brigitte Schröder für die Genehmigung, einige Schriftstücke aus dem Nachlaß des Bundesministers a.D. Dr. Gerhard Schröder im Archiv für Christlich-Demokratische Politik in St. Augustin abdrucken zu dürfen.

Besonderer Dank gebührt ferner den Kollegen im Herausgebergremium, die sich ihrer viel Zeit in Anspruch nehmenden Aufgabe in bewährter Kollegialität gewidmet haben. Ferner sei die tadellose Zusammenarbeit mit den zuständigen Persönlichkeiten und Gremien des Instituts für Zeitgeschichte dankbar hervorgehoben. Gedankt sei auch dem präzise arbeitenden Verlag R.Oldenbourg.

Das Hauptverdienst am Gelingen der drei Bände gebührt den Bearbeitern, Frau Dr. Mechthild Lindemann und Frau Dr. Ilse Dorothee Pautsch, zusammen mit dem Wissenschaftlichen Leiter, Herrn Dr. Rainer A. Blasius. Ihnen sei für den großen Einsatz und für die erbrachte Leistung nachdrücklichst gedankt.

Weiter genannt sei Herr Dr. Daniel Kosthorst, der durch Kommentierung der Monate Juli und Oktober 1965 wesentlich zur pünktlichen Fertigstellung der Edition beigetragen hat. Nicht vergessen seien schließlich die Damen des Sekretariats, Frau Andrea Bock und Frau Melanie Stuch.

Die Jahresbände für 1966 und 1967 befinden sich in Arbeit. Sie sollen im vorgesehenen Rhythmus erscheinen. 


\section{Vorbemerkungen zur Edition}

Die „Akten zur Auswärtigen Politik der Bundesrepublik Deutschland 1965“ (Kurztitel: AAPD 1965) umfassen drei Bände, die durchgängig paginiert sind. Den abgedruckten Dokumenten gehen im Band I neben Vorwort und Vorbemerkungen ein Dokumentenverzeichnis, ein Literaturverzeichnis sowie ein Abkürzungsverzeichnis voran. Am Ende von Band III finden sich ein Personen- und ein Sachregister sowie ein Organisationsplan des Auswärtigen Amts vom Oktober 1965.

\section{Dokumentenauswahl}

Grundlage für die Fondsedition der Akten zur Auswärtigen Politik der Bundesrepublik Deutschland im Jahr 1965 waren die Bestände des Politischen Archivs des Auswärtigen Amts (PA/AA). Besonderes Gewicht wurde auf die zentralen Bestände „Ministerbüro“ und „Büro Staatssekretär“ gelegt. Angemessene Berücksichtigung fanden aber auch die einzelnen Abteilungen und Referate des Auswärtigen Amts. Schriftstücke aus anderen Bundesministerien, die in die Akten des Auswärtigen Amts Eingang gefunden haben, wurden nur zur Kommentierung herangezogen und lediglich in Fällen von besonderer außenpolitischer Bedeutung als Dokumente aufgenommen. Fast ausnahmslos haben dagegen die im Auswärtigen Amt vorhandenen Aufzeichnungen über Gespräche des Bundeskanzlers mit ausländischen Staatsmännern und Diplomaten Aufnahme gefunden. Als notwendige Ergänzung dienten die im Bundeskanzleramt überlieferten Gesprächsaufzeichnungen.

Entsprechend ihrer Herkunft belegen die edierten Dokumente in erster Linie die außenpolitischen Aktivitäten des Bundesministers des Auswärtigen. Sie veranschaulichen aber auch die Außenpolitik des jeweiligen Bundeskanzlers. Die Rolle anderer Akteure, insbesondere im parlamentarischen und parteipolitischen Bereich, wird beispielhaft dokumentiert, sofern eine Wechselbeziehung zum Auswärtigen Amt gegeben war.

Die ausgewählten Dokumente sind nicht zuletzt deshalb für ein historisches Verständnis der Außenpolitik der Bundesrepublik Deutschland von Bedeutung, weil ausschließlich Schriftstücke veröffentlicht werden, die bisher der Forschung unzugänglich und größtenteils als Verschlußsachen der Geheimhaltung unterworfen waren. Dank einer entsprechenden Ermächtigung wurden den Bearbeitern die VS-Bestände des PA/AA ohne Einschränkung zugänglich gemacht und Anträge auf Herabstufung und Offenlegung von Schriftstücken beim Auswärtigen Amt ermöglicht. Das Bundeskanzleramt war zuständig für die Deklassifizierung von Verschlußsachen aus den eigenen Beständen. Kopien der offengelegten Schriftstücke, deren Zahl diejenige der in den AAPD 1965 edierten Dokumente weit übersteigt, werden im PA/AA zugänglich gemacht (Bestand B 150). 
Nur eine äußerst geringe Zahl der für die Edition vorgesehenen Aktenstücke wurde nicht zur Veröffentlichung freigegeben. Hierbei handelt es sich vor allem um Dokumente, in denen personenbezogene Vorgänge im Vordergrund stehen oder die auch heute noch sicherheitsrelevante Angaben enthalten. Von einer Deklassifizierung ausgenommen war Schriftgut ausländischer Herkunft bzw. aus dem Bereich multilateraler oder internationaler Organisationen wie etwa der NATO. Unberücksichtigt blieb ebenfalls nachrichtendienstliches Material.

\section{Dokumentenfolge}

Die 480 edierten Dokumente sind in chronologischer Folge geordnet und mit laufenden Nummern versehen. Bei differierenden Datumsangaben auf einem Schriftstück, z.B. im Falle abweichender maschinenschriftlicher und handschriftlicher Datierung, ist in der Regel das früheste Datum maßgebend. Mehrere Dokumente mit demselben Datum sind, soweit möglich, nach der Uhrzeit eingeordnet. Erfolgt eine Datierung lediglich aufgrund sekundärer Hinweise (z.B. aus Begleitschreiben, beigefügten Vermerken usw.), wird dies in einer Fußnote ausgewiesen. Ein Dokument, bei dem nur der Entstehungsmonat bekannt ist, wird am Ende des betreffenden Monats eingereiht. Bei Aufzeichnungen über Gespräche oder Besprechungen ist das Datum des dokumentierten Vorgangs ausschlaggebend, nicht der Zeitpunkt der Niederschrift.

\section{Dokumentenkopf}

Jedes Dokument beginnt mit einem halbfett gedruckten, stets gleich gestalteten Dokumentenkopf, in dem wesentliche formale Angaben zusammengefaßt werden. Auf Dokumentennummer und -überschrift folgen in kleinerer Drucktype ergänzende Angaben, so rechts außen die Datumsangabe. Links außen wird, sofern vorhanden, das Geschäftszeichen des edierten Schriftstücks einschließlich des Geheimhaltungsgrads (zum Zeitpunkt der Entstehung) wiedergegeben. Das Geschäftszeichen, das aus der Kurzbezeichnung der ausfertigenden Arbeitseinheit besteht sowie aus weiteren Elementen wie dem gemäß Aktenplan inhaltlich definierten Aktenzeichen, der Tagebuchnummer einschließlich verkürzter Jahresangabe und gegebenenfalls dem Geheimhaltungsgrad, läßt Rückschlüsse auf den Geschäftsgang zu und eröffnet die Möglichkeit, zugehöriges Aktenmaterial zu ermitteln. Dokumentennummer, verkürzte Überschrift und Datum finden sich auch im Kolumnentitel über dem Dokument.

Aus den Angaben im Dokumentenkopf, vor allem aus der Überschrift, läßt sich die Art des jeweiligen Dokuments erschließen. Aufzeichnungen und Vermerke des internen Schriftverkehrs im Auswärtigen Amt sind eine in der Edition besonders häufig vertretene Dokumentengruppe. Der Verfasser wird jeweils in der Überschrift benannt. Läßt sich ein solcher weder unmittelbar noch mittelbar nachweisen, wird die ausfertigende Arbeitseinheit (Abteilung oder Referat) angegeben.

Eine weitere Gruppe von Dokumenten bildet der Schriftverkehr zwischen der Zentrale in Bonn und den Auslandsvertretungen. Diese erhielten ihre Infor- 
mationen und Weisungen in der Regel mittels Drahterlaß, der fernschriftlich oder per Funk übermittelt wurde. Auch bei dieser Dokumentengruppe wird in der Überschrift der Verfasser genannt, ein Empfänger dagegen nur, wenn der Drahterlaß an eine einzelne Auslandsvertretung bzw. deren Leiter gerichtet war. Anderenfalls werden die Adressaten in einer Fußnote aufgeführt. Bei Runderlassen an sehr viele oder an alle diplomatischen Vertretungen wird der Empfängerkreis nicht näher spezifiziert, um die Anmerkungen nicht zu überfrachten. Ebenso sind diejenigen Auslandsvertretungen nicht eigens aufgeführt, die nur nachrichtlich von einem Erlaß in Kenntnis gesetzt wurden. Ergänzend zum Geschäftszeichen wird im unteren Teil des Dokumentenkopfes links die Nummer des Drahterlasses sowie der Grad der Dringlichkeit angegeben. Rechts davon findet sich das Aufgabedatum und - sofern zu ermitteln die Uhrzeit der Aufgabe. Ein Ausstellungsdatum wird nur dann angegeben, wenn es vom Datum der Aufgabe abweicht.

Der Dokumentenkopf bei einem im Auswärtigen Amt eingehenden Drahtbericht ist in Analogie zum Drahterlaß gestaltet. Zusätzlich zu Datum und Uhrzeit der Aufgabe wird hier auch der Zeitpunkt der Ankunft festgehalten, jeweils in Ortszeit.

In weniger dringlichen Fällen verzichteten die Botschaften auf eine fernschriftliche Übermittlung und zogen die Form des mit Kurier übermittelten Schriftberichts vor. Beim Abdruck solcher Stücke wird im Dokumentenkopf neben der Überschrift mit Absender und Empfänger das Geschäftszeichen und das Datum genannt. Eine Sonderform des Schriftberichts stellt das sogenannte Privatdienstschreiben dar, mit dem außerhalb des offiziellen Geschäftsgangs zu einem Sachverhalt Stellung bezogen werden kann; darauf wird in einer Anmerkung aufmerksam gemacht.

Neben dem Schriftwechsel zwischen der Zentrale und den Auslandsvertretungen gibt es andere Schreiben, erkennbar jeweils an der Nennung von Absen. der und Empfänger. Zu dieser Gruppe zählen etwa Schreiben der Bundesregierung, vertreten durch den Bundeskanzler oder den Bundesminister des Auswärtigen, an ausländische Regierungen, desgleichen auch Korrespondenz des Auswärtigen Amts mit anderen Ressorts oder mit Bundestagsabgeordneten.

Breiten Raum nehmen Niederschriften über Gespräche bzw. Besprechungen ein. Sie werden als solche in der Überschrift gekennzeichnet. Hervorzuheben sind innerhalb dieser Dokumentengruppe Gesprächsaufzeichnungen der Dolmetscher. Für deren chronologische Einordnung ist das Gesprächs- oder Besprechungsdatum ausschlaggebend, während Verfasser und Datum der Niederschrift - sofern ermittelbar - in einer Anmerkung ausgewiesen werden.

Die wenigen Dokumente, die sich keiner der beschriebenen Gruppen zuordnen lassen, sind aufgrund individueller Überschriften zu identifizieren.

Die Überschrift bei allen Dokumenten enthält die notwendigen Angaben zum Ausstellungs-, Absende- oder Empfangsort bzw. zum Ort des Gesprächs oder der Besprechung. Erfolgt keine besondere Ortsangabe, ist Bonn stillschweigend zu ergänzen. Hält sich der Verfasser oder Absender eines Dokuments 
nicht an seinem eigentlichen Dienstort auf, wird der Ortsangabe ein „z.Z.“ vorangesetzt.

Bei den edierten Schriftstücken handelt es sich in der Regel jeweils um die erste Ausfertigung oder - wie etwa bei den aufgrund festgelegter Verteiler vervielfältigten Drahtberichten - um eines von mehreren gleichrangig nebeneinander zirkulierenden Exemplaren. Statt einer Erstausfertigung mußten hin und wieder ein „Durchschlag als Konzept“, ein Durchdruck, eine Abschrift oder eine Ablichtung herangezogen werden. Ein entsprechender Hinweis findet sich in einer Fußnote. In wenigen Fällen sind Entwürfe abgedruckt und entsprechend in den Überschriften kenntlich gemacht.

\section{Dokumententext}

Unterhalb des Dokumentenkopfes folgt - in normaler Drucktype - der Text des jeweiligen Dokuments, einschließlich des Betreffs, der Anrede und der Unterschrift. Falls die Textvorlage eine inhaltlich substantielle Überschrift aufweist, wird diese mitabgedruckt. Die Dokumente werden in der Regel ungekürzt veröffentlicht. In wenigen Ausnahmefällen sind geringfügige Auslassungen vorgenommen worden; sie werden durch [...] gekennzeichnet und in einer Fußnote erläutert. Textergänzungen der Bearbeiter stehen ebenfalls in eckigen Klammern.

Offensichtliche Schreib- und Interpunktionsfehler werden stillschweigend korrigiert. Eigentümliche Schreibweisen bleiben nach Möglichkeit erhalten; manchmal erwies sich jedoch eine Vereinheitlichung bzw. Modernisierung als sinnvoll. Dies trifft teilweise auch auf fremdsprachige Orts- und Personennamen zu, deren Schreibweise nach den im Auswärtigen Amt gebräuchlichen Regeln wiedergegeben wird.

Selten vorkommende oder ungebräuchliche Abkürzungen in der Textvorlage werden aufgelöst. Typische Abkürzungen von Institutionen, Parteien etc. werden allerdings übernommen. Hervorhebungen in der Textvorlage, also etwa maschinenschriftliche Unterstreichungen oder Sperrungen werden - sofern sie nicht überwiegend formaler Natur sind - kursiv wiedergegeben. Darüber hinaus dient der Kursivdruck dazu, bei Gesprächsaufzeichnungen die Sprecher voneinander abzuheben. Im äußeren Aufbau (Absätze, Zentrierungen usw.) folgt das Druckbild der Textvorlage, soweit dies unter Berücksichtigung der satztechnisch bedingten Gegebenheiten möglich ist.

Mit Ausnahme der dem Namen hinzugefügten Dienstbezeichnung, die der Überschrift eines Dokuments zu entnehmen ist, wird eine Unterschriftsformel vollständig wiedergegeben. Ein handschriftlicher Namenszug ist nicht besonders gekennzeichnet, eine Paraphe mit Unterschriftscharakter aufgelöst (mit Nachweis in einer Fußnote). Findet sich auf einem Schriftstück der Name zusätzlich maschinenschriftlich vermerkt, bleibt dies unerwähnt. Ein maschinenschriftlicher Name, dem ein "gez." vorangestellt ist, wird entsprechend übernommen; fehlt in der Textvorlage der Zusatz „gez.“, wird er in eckigen Klammern ergänzt. 
Unter dem Dokumententext wird die jeweilige Fundstelle des Schriftstücks in halbfetter Schrifttype nachgewiesen. Bei Dokumenten aus dem PA/AA wird auf die Angabe des Archivs verzichtet und nur der jeweilige Bestand mit Bandnummer genannt. Dabei ist, soweit möglich, der aktuelle Stand der Verzeichnungsarbeiten im Politischen Archiv berücksichtigt. Dokumente aus VSBeständen sind mit der Angabe „VS-Bd.“ versehen. Bei Dokumenten anderer Herkunft werden Archiv und Bestandsbezeichnung angegeben. Da alle edierten Dokumente für die wissenschaftliche Benutzung bisher nicht oder nur in eingeschränktem Maße zur Verfügung standen, erübrigte sich eine systematische Suche nach Vor- oder Teilveröffentlichungen.

\section{Kommentierung}

In Ergänzung zum Dokumentenkopf enthalten die Anmerkungen formale Hinweise und geben Auskunft über wesentliche Stationen im Geschäftsgang. Angaben technischer Art, wie Registraturvermerke oder standardisierte Verteiler, werden nur bei besonderer Bedeutung erfaßt. Wesentlich ist dagegen die Frage, welche Beachtung das jeweils edierte Dokument auf den verschiedenen Ebenen des Auswärtigen Amts bzw. außerhalb dieser Behörde gefunden hat. Dies läßt sich an den Paraphen maßgeblicher Akteure sowie an den - überwiegend handschriftlichen - Weisungen, Bemerkungen oder auch Reaktionen in Form von Frage- oder Ausrufungszeichen ablesen, die auf dem Schriftstück selbst oder auf zugehörigen Begleitschreiben und -vermerken zu finden sind. Die diesbezüglichen Merkmale sowie damit in Verbindung stehende Hervorhebungen (Unterstreichungen oder Anstreichungen am Rand) werden in Anmerkungen nachgewiesen. Auf den Nachweis sonstiger An- oder Unterstreichungen wird verzichtet. Abkürzungen in handschriftlichen Passagen werden unter Kennzeichnung durch eckige Klammern aufgelöst.

In den im engeren Sinn textkritischen Anmerkungen werden nachträgliche Korrekturen oder textliche Änderungen des Verfassers und einzelner Adressaten festgehalten. Unwesentliche Textverbesserungen sind hiervon ausgenommen. Ferner wird auf einen systematischen Vergleich der Dokumente mit Entwürfen ebenso verzichtet wie auf den Nachweis der in der Praxis üblichen Einarbeitung von Textpassagen in eine spätere Aufzeichnung oder einen Drahterlaß.

Die Kommentierung soll den historischen Zusammenhang der edierten Dokumente in ihrer zeitlichen und inhaltlichen Abfolge sichtbar machen, weitere Aktenstücke und anderweitiges Schriftgut nachweisen, die unmittelbar oder mittelbar angesprochen werden, sowie Ereignisse oder Sachverhalte näher erläutern, die dem heutigen Wissens- und Erfahrungshorizont ferner liegen und aus dem Textzusammenhang heraus nicht oder nicht hinlänglich zu verstehen sind. Dem erstgenannten Gesichtspunkt tragen jene rück- oder weiterverweisenden Anmerkungen Rechnung, die Bezüge zwischen einzelnen Dokumenten in den vorliegenden drei Bänden offenlegen und auf die AAPD 1963 und 1964 bzw. auf die in Vorbereitung befindlichen AAPD 1966 verweisen. Das Auffinden von Dokumenten zu einem bestimmten thematischen Schwerpunkt ist mit Hilfe des Sachregisters möglich. 
Besonderer Wert wird bei der Kommentierung darauf gelegt, die Dokumente durch Bezugsstücke aus den Akten der verschiedenen Arbeitseinheiten des Auswärtigen Amts bis hin zur Leitungsebene zu erläutern. Zitate oder inhaltliche Wiedergaben sollen die damaligen Entscheidungsprozesse erhellen. Dadurch wird zugleich Vorarbeit geleistet für eine vertiefende Erschließung der Bestände des PA/AA. Um die Identifizierung von Drahtberichten bzw. -erlassen zu erleichtern, werden außer dem Verfasser und dem Datum die Drahtberichtsnummer und, wo immer möglich, die Drahterlaßnummer angegeben.

Findet in einem Dokument veröffentlichtes Schriftgut Erwähnung - etwa Abkommen, Gesetze, Reden oder Presseberichte -, so wird die Fundstelle in einer Anmerkung nach Möglichkeit genauer spezifiziert. Auszüge aus den Bezugsstücken oder inhaltliche Zusammenfassungen sollen zum Verständnis der Dokumente beitragen. Bei Anmerkungen oder Anmerkungsteilen, deren Zweck die knappe Erläuterung eines Sachverhalts oder Ereignisses ist, erfolgen keine systematischen Hinweise auf archivalische oder veröffentlichte Quellen. Sekundärliteratur wird generell nicht in die Kommentierung aufgenommen.

Angaben wie Dienstbezeichnung, Dienststellung/Funktion, Dienstbehörde und Nationalität dienen der eindeutigen Identifizierung der in der Kommentierung vorkommenden Personen. Die genannten Merkmale werden dabei erforderlichenfalls in Kombination oder auch im Wechsel dem Namen hinzugefügt. Bei Bundesministern erfolgt ein Hinweis zum jeweiligen Ressort nur im Personenregister. Eine im Dokumententext lediglich mit ihrer Funktion genannte Person wird nach Möglichkeit in einer Anmerkung namentlich nachgewiesen. Davon ausgenommen sind der jeweilige Bundespräsident, der Bundeskanzler bzw, der Bundesminister des Auswärtigen.

Die Bezeichnung einzelner Staaten wird so gewählt, daß Verwechslungen ausgeschlossen sind. Als Kurzform für die Deutsche Demokratische Republik kommen in den Dokumenten die Begriffe SBZ oder DDR vor und werden so wiedergegeben. Der in der Forschung üblichen Praxis folgend, wird jedoch in der Kommentierung und in den Regesten der Begriff DDR verwendet. Das Adjektiv „deutsch“ findet nur bei gesamtdeutschen Belangen oder dann Verwendung, wenn eine eindeutige Zuordnung gegeben ist. Der westliche Teil von Berlin wird als Berlin (West), der östliche Teil der Stadt als Ost-Berlin bezeichnet. Im übrigen orientiert sich die Edition bei der Benutzung geographisch-politischer Begriffe an der Sprache der Quellen.

Für häufig benutzte Publikationen wie Editionen, Geschichtskalender und Memoiren werden Kurztitel oder Kurzformen eingeführt, die sich über ein entsprechendes Verzeichnis auflösen lassen. Der Platzersparnis dienen ebenfalls die Rückverweise auf bereits an anderer Stelle ausgeführte Anmerkungen.

Wie bei der Wiedergabe der Dokumente finden auch in den Anmerkungen die im Auswärtigen Amt gebräuchlichen Regeln für die Transkription fremdsprachlicher Namen und Begriffe Anwendung. Bei Literaturangaben in russischer Sprache wird die im wissenschaftlichen Bereich übliche Transliterierung durchgeführt. 


\section{Verzeichnisse}

Das Dokumentenverzeichnis ist chronologisch angelegt. Es bietet zu jedem Dokument folgende Angaben: die halbfett gedruckte Dokumentennummer, Datum und Überschrift, die Fundseite sowie eine inhaltliche Übersicht in Form eines Regests. Um die Einheitlichkeit der Regesten in ihrem notwendigerweise verkürzenden Charakter zu wahren, steht bei der Zusammenfassung des Dokumenteninhalts nicht die Aufzählung aller angesprochenen Themen im Vordergrund, sondern die Aufmerksamkeit gilt wesentlichen Schwerpunkten oder neuartigen Gedanken. Die Regesten können und sollen lediglich einer ersten Orientierung dienen. Hinsichtlich ihrer formalen Gestaltung wird auf die vorangehenden Ausführungen zur Kommentierung verwiesen.

Das Literaturverzeichnis enthält nur solche Publikationen, die häufig zur Kommentierung herangezogen und mit Kurztiteln oder Kurzformen versehen wurden. Diese sind alphabetisch geordnet und werden unter Angabe der notwendigen bibliographischen Daten aufgelöst.

Das Abkürzungsverzeichnis führt - mit Ausnahme der erwähnten Kurzformen die im Dokumententeil vorkommenden Abkürzungen auf, es sei denn, sie sind so gebräuchlich, daß sich eine Auflösung erübrigt. Nicht aufgenommen werden Abkürzungen, die in einer Fußnote erläutert sind.

\section{Anhang}

Im Personenregister werden in der Edition vorkommende Personen unter Nennung derjenigen politischen, dienstlichen oder beruflichen Funktionen aufgeführt, die im inhaltlichen Zusammenhang der Dokumente wesentlich sind. In der Regel wird nur die maßgebliche Funktion im Jahr 1965 angegeben. Zu den im Auswärtigen Amt gebräuchlichen deutschen Funktionsbezeichnungen für ausländische Diplomaten werden in Einzelfällen die entsprechenden Termini in der jeweiligen Landessprache in Klammern hinzugefügt. Steht ein Dokument in seiner Gesamtheit in Beziehung zu einer Person, so wird im Register statt der betreffenden Seitenzahlen die halbfett gedruckte Dokumentennum. mer ausgeworfen.

Das Sachregister ermöglicht einen thematisch differenzierten Zugriff auf die Dokumente. Auch hier wird in den Fällen, in denen sich ein Schlagwort auf ein Dokument in seiner Gesamtheit bezieht, die halbfett gedruckte Dokumentennummer anstelle von Seitenzahlen aufgeführt.

Der Organisationsplan vom Oktober 1965 zeigt die Struktur des Auswärtigen Amts und orientiert über die Namen der Leiter der jeweiligen Arbeitseinheiten. 


\section{Verzeichnisse}





\section{Dokumentenverzeichnis}

Die Vorlage befaßt sich mit den Waffenlieferungen der Bundesrepublik an Israel, die die Beziehungen zu den arabischen Staaten belasten. Die Unterstützung des Alleinvertretungsanspruchs der Bundesrepublik durch die arabischen Staaten sei aber "von entscheidender Bedeutung" für die Haltung der blockfreien Staaten in der Deutschland-Frage. Ein Austausch amtlicher Vertretungen mit Israel bei gleichzeitiger Fortsetzung der Waffenlieferungen lasse sich gegenüber den arabischen Staaten nicht begründen. Es wird daher vorgeschlagen, nur noch bereits eingegangene bindende Lieferverpflichtungen an Israel abzuwickeln.

Carstens legt vier Notizen aus den Jahren 1961 bis 1963 mit Informationen der Amtsspitze des Bundesministeriums der Verteidigung über israelische Wünsche und tatsächlich geleistete Waffenlieferungen an Israel vor. Bereits am 11. Juli 1962 wurde Bundesminister Strauß im Beisein des stellvertretenden israelischen Verteidigungsministers Peres darauf hingewiesen, da $\beta$ bei einer Lieferung von 15 Panzern „keine Geheimhaltung möglich sei", während Bundesminister Schröder am 19. Juli 1963 jegliche Verantwortung für Waffenlieferungen abgelehnt und sich gegenüber Bundesminister von Hassel grundsätzlich gegen „militärische Beziehungen“, und zwar „weder mit den Ägyptern noch mit den Israelis“ ausgesprochen habe. amerikanischen Botschafter McGhee

McGhee bittet um Stellungnahme zu den Anregungen des amerikanischen Außenministers Rusk, in New York eine Konferenz der Außenminister der drei Westmächte und der Bundesrepublik abzuhalten und den am Rande der NATO-Ministerratstagung vom 15. bis 17. Dezember 1964 von Schröder vorgetragenen Gedanken einer neuen Deutschland-Initiative in der Bonner Vierergruppe zu beraten. Der Bundesminister äußert sich zurückhaltend und bekräftigt seinen Wunsch, die angeregte Deutschland-Initiative auf Regierungsebene $\mathrm{zu}$ behandeln. Amerikanische Bedenken, daß mit dem Vorschlag eines VierMächte-Gremiums zur Deutschland-Frage der UdSSR die Möglichkeit gegeben werden könnte, „sich in die innerdeutschen Angelegenheiten einzumischen", hält er für unbegründet; vielleicht ließen sich durch Einsetzung gesamtdeutscher Kommis- 
sionen unter einem „Vier-Mächte-Dach“ gewisse Fortschritte erzielen. Selbst bei sowjetischer Zurückweisung sei ein gemeinsamer Vorschlag des Westens schon für sich „eine eminent politische Tatsache“. Abschließend weist Schröder auf den in der Öffentlichkeit entstandenen Eindruck eines nachlassenden Interesses der USA an der geplanten MLF hin.

Der von Carstens unterbreitete Vorschlag für eine DeutschlandInitiative sieht vor, daß die Bundesrepublik mit den früheren Kriegsgegnern des Deutschen Reiches Teilabkommen über bislang ungeregelte Fragen wie die künftigen deutschen Grenzen und Wiedergutmachungsleistungen abschließen solle. Zur Festlegung des künftigen militärischen Status eines gesamtdeutschen Staates können eine Friedensvertrags-Vorkonferenz einberufen und parallel dazu Verhandlungen der Bundesrepublik mit den Vier Mächten über eine Wiedervereinigung Deutschlands aufgenommen werden. Mit einer solchen Initiative werde auch der Vorwurf der Alliierten entkräftet, daß die Bundesregierung wichtigen Fragen wie dem Grenzproblem ausweiche. Zudem könne der UdSSR, die derartige Vorschläge wegen einer Nichtzulassung der DDR zu den Gesprächen und wegen des Alleinvertretungsanspruchs der Bundesrepublik zurückweisen werde, "das Odium der Ablehnung einer westlichen Initiative“ zugeschoben werden. Möglichen Einwänden über eine Bereitschaft der Bundesregierung, auf ehemals deutsche Gebiete zu verzichten, lasse sich mit dem Hinweis auf das notwendige spätere gesamtdeutsche Plebiszit sowie mit dem Argument begegnen, daß die Wiedervereinigung Deutschlands als großes nationales Ziel „ein Opfer wert" sei. japanischen Botschafter Narita

Der Bundesminister erläutert, daß die Konsultationen mit den Westmächten über die von der Bundesregierung vorgeschlagene neue Initiative zur Deutschlandfrage fortgesetzt werden. Von amerikanischer Seite gewünschte Positionsbestimmungen in den Fragen der Sicherheit, der Abrüstung und der deutschen Grenzen seien jedoch als ,ziemlich theoretisch“ zu betrachten, da die UdSSR diese Themen nicht in Verbindung mit der Wiedervereinigung diskutieren und überhaupt noch für einen langen Zeitraum kaum gesprächsbereit sein werde. In Äußerungen des amerikanischen Außenministers Rusk, bei veränderter militärischer Lage könnte eine Überprüfung der amerikanischen Truppenpräsenz in der Bundesrepublik erfolgen, sieht Schröder keinen Anlaß zur Sorge. Hinsichtlich der MLF teilt er mit, die Bundesregierung halte eine Verbindung dieses Projekts mit dem britischen Vorschlag einer „Atlantic Nuclear Force“ (ANF) 
für denkbar. Wesentlich sei allerdings die von Großbritannien bisher abgelehnte gemischtnationale Bemannung der Überwasserschiffe. Auch müsse ein späterer Beitritt, mindestens aber eine Zusammenarbeit Frankreichs möglich sein. Bezüglich der Europapolitik vertritt Schröder die Auffassung, daß mit dem Aufbau einer politischen Union ,einschließlich gewisser institutioneller Abmachungen" zu beginnen sei. Dabei könnten solange die NATO nicht beeinträchtigt werde - auch Fragen der Verteidigung einbezogen werden. Lindenberg

Meyer-Lindenberg nimmt zum italienischen Entwurf einer Europäisierungsklausel im angestrebten Abkommen über eine integrierte NATO-Atomstreitmacht Stellung. Weil der Entwurf davon ausgehe, daß der Kreis der Teilnehmerstaaten an einer MLF deckungsgleich mit dem einer europäischen politischen Union sein werde, schlägt er Umformulierungen vor. Auswärtige Amt

Knappstein hält aus einem Gespräch mit dem amerikanischen Außenminister den Hinweis fest, daß die Empfindlichkeit in der Bundesrepublik hinsichtlich der Deutschland-Frage inzwischen "eine amerikanische Gegenempfindlichkeit“ erzeuge. Rusk betonte, die USA stünden, wie bisher, jederzeit für eine Verhandlungsinitiative zur Verfügung. Es müsse jedoch klar gesehen werden, daß die UdSSR nicht gesprächsbereit sei; außerdem könnte sie etwa mit der Forderung nach einem Abzug der amerikanischen Truppen aus Berlin (West) sogar eine neue Krise entfachen. Ferner stelle sich das Problem der Grenzen Deutschlands und der Verknüpfung einer Wiedervereinigung mit Fragen der europäischen Sicherheit. Schließlich müsse eine gemeinsame westliche Verhandlungsposition vorhanden sein. Knappstein folgert, daß die amerikanische Regierung nur umfassende Verhandlungen über Mitteleuropa wünsche; das „relativ entspannte“ Verhältnis zur UdSSR solle nicht durch einen Vertrag belastet werden, der sich lediglich auf eine Dachorganisation der Vier Mächte für innerdeutsche Kontakte beschränke. Sollte es der Bundesregierung nicht gelingen, insbesondere Staatspräsident de Gaulle für ein realistisches Verhandlungsprogramm zu gewinnen, würde eine Initiative zurückgestellt, um angesichts der vor allem in Südostasien bestehenden Probleme "nicht ohne zwingenden Grund ,schlafende Hunde zu wecken "“. 

Auswärtige Amt

Der Botschafter faßt Teile eines Gesprächs mit dem amerikanischen Außenminister zusammen. Rusk betonte die Notwendigkeit, in der Frage einer integrierten NATO-Atomstreitmacht Einvernehmen zwischen Großbritannien, Italien und der Bundesrepublik herzustellen oder zumindest ein deutsch-italienisches Konzept unter Berücksichtigung des britischen Vorschlags einer „Atlantic Nuclear Force" zu entwickeln. Er regte an, in der NATO einen „Exekutivausschu $\beta^{\prime \prime}$ des Ausschusses für Nuklearfragen zu bilden, der „die Tür für Frankreich offen ließe“. Knappstein erwähnte die Nachteile einer ANF, darunter vor allem die Verpflichtung zur Nichtverbreitung von Kernwaffen, mit der „eine wesentliche Verhandlungsposition“ zur Lösung der Deutschland-Frage preisgegeben würde. Rusk entgegnete mit dem Hinweis auf die Revisionsklauseln, die u.a. den Fall einer Wiedervereinigung beträfen. Im übrigen habe der sowjetische Außenminister Gromyko erklärt, daß die Schaffung einer MLF eine Lösung der Deutschland-Frage erschweren, ein Verzicht gleichwohl nicht zu Verhandlungen über eine Wiedervereinigung führen würde. Lindenberg

Meyer-Lindenberg erläutert die Probleme der Beziehungen zum Nahen Osten. Die Waffenlieferungen an Israel würden von den arabischen Staaten als einseitige Parteinahme gewertet. Das von Bundestagspräsident Gerstenmaier im November 1964 in Kairo in Aussicht gestellte Waffenembargo sei daher wesentlicher Bestandteil eines "Arrangements“ mit dem ägyptischen Präsidenten. Darüber hinaus müsse Nasser während seines geplanten Staatsbesuchs in Bonn ein Ausgleich für die noch abzuwickelnden Lieferungen an Israel angeboten werden, entweder auf dem Gebiet der Rüstung oder im Bereich der Wirtschaftshilfe. Vor einer solchen Regelung sei es nicht möglich, auf die Einstellung der Tätigkeit deutscher Rüstungsexperten in der VAR zu drängen. Die Anwendung des „Prinzips der gleichen Behandlung" im Nahen Osten bedeute „logischerweise“ auch die Aufnahme amtlicher Beziehungen zu Israel. Meyer-Lindenberg geht allerdings davon aus, daß sich die arabischen Staaten nur mit der Errichtung einer Handelsvertretung der Bundesrepublik in Israel abfinden würden; die Aufnahme diplomatischer Beziehungen hätte jedoch unabhängig vom „persönlichen Willen und Verständnis Präsident Nassers“ die Anerkennung der DDR durch die arabischen Staaten zur Folge. 
Gerstenmaier bedauert, daß trotz der bereits im November 1964 getroffenen Absprachen mit dem ägyptischen Präsidenten noch keine formelle Einladung zu einem Besuch in der Bundesrepublik ergangen sei, obwohl Nasser aufgrund der schwierigen politischen und wirtschaftlichen Verhältnisse auch „verzweifelte Versuche nicht scheuen" würde, aus der Klemme zu kommen. In einem Schlußprotokoll anläßlich eines Staatsbesuchs in Bonn könnte festgestellt werden, daß „Waffenhilfe“ der Bundesrepublik in Zukunft nur noch im Rahmen der NATO erfolgen dürfte; daneben sollte die Zusage für eine wirtschaftliche Unterstützung der VAR konkretisiert und präzisiert werden. Als politische Gegenleistung für einen solchen Kompromiß müßte Klarheit darüber geschaffen werden, wie die VAR und die Arabische Liga auf eine Aufnahme diplomatischer Beziehungen zwischen der Bundesrepublik und Israel reagieren würden; verbale Proteste seien dann ohne weiteres hinzunehmen.

Carstens berichtet über eine Unterredung mit dem kanadischen Botschafter. Er hob gegenüber Starnes hervor, daß das sowjetische Interesse an einer weiteren Verpflichtung der Bundesrepublik über den Nichterwerb von Kernwaffen - trotz des Verzichts von 1954 auf die Produktion von ABC-Waffen - für Fortschritte in der gemeinsamen westlichen Deutschlandpolitik genutzt werden müsse. Dann erläuterte er die deutsche Haltung zur MLF bzw. zur ANF und stellte als positive Elemente des britischen Vorschlags die "Unwiderruflichkeit des Beitrages" sowie die starke Betonung des Gedankens einer Integration der Verteidigung Europas und der USA heraus. Als „weniger überzeugend" bezeichnete er die britischen Vorstellungen hinsichtlich eines Vetorechts der Mitgliedstaaten sowie die Überlegung, eine eigene nukleare Kommandobehörde zu bilden, während doch Kanada und die Bundesrepublik die Unterstellung einer integrierten Nuklearstreitmacht unter SACEUR befürworteten.

Carstens gibt den Inhalt eines Gesprächs mit dem amerikanischen Botschafter wieder. McGhee betonte die grundsätzliche Bereitschaft, der UdSSR die Einsetzung eines Vier-Mächte-Gremiums zur Deutschland-Frage vorzuschlagen. Jedoch müßten sich die Westmächte und die Bundesrepublik über die weitere Vorgehensweise einig sein. Allerdings beruhe der Vorwurf, die USA verlangten, ,jetzt auf die deutschen Ostgebiete zu verzichten“, ebenso auf einem Mißverständnis wie das Gerücht, daß sie an einer integrierten Nuklearstreitmacht der NATO kein Interesse mehr zeigten. Bedenken von McGhee, die Bundesrepublik 
könnte „aus Mißstimmung“ über die amerikanische Haltung eine Beteiligung an der Force de frappe anstreben, wies Carstens zurück. Der Staatssekretär erläuterte abschließend die Haltung zu einem Abkommen über die Nichtverbreitung von Kernwaffen. McGhee bezweifelte allerdings, ob sich das sowjetische Interesse an einem Beitritt der Bundesrepublik für Fortschritte in der Deutschland-Frage nutzen lasse.

Carstens hält ein Gespräch mit dem britischen Botschafter aus Anlaß des bevorstehenden Besuches des Premierministers Wilson in der Bundesrepublik fest. Roberts zeigte sich beunruhigt über Pressemeldungen, wonach die Bundesrepublik „um jeden Preis" ein verteidigungspolitisches Arrangement mit Frankreich anstrebe und auch am MLF/ANF-Projekt nicht mehr interessiert sei. Der Staatssekretär bekundete die grundsätzliche Übereinstimmung mit Großbritannien über die Notwendigkeit einer integrierten atlantischen Nuklearverteidigung. Schwierigkeiten bereite jedoch u.a. der britische ANF-Vorschlag zur Einbringung von V-Bombern und zum Veto-Recht bei einer Freigabe des Einsatzes der geplanten Streitmacht: Werde dies zu vielen europäischen Staaten eingeräumt, dann sei die Glaubwürdigkeit der MLF in Frage gestellt. Der Gesamtkomplex der MLF/ANF solle in der - eventuell um Kanada erweiterten MLF-Arbeitsgruppe beraten werden, nicht jedoch im Ständigen NATO-Rat, da einige NATO-Partner „das Verhandlungsziel als solches" ablehnten und Frankreich Bedenken gegen eine Erörterung anmelden würde. Im Zusammenhang mit dem deutschbritischen Devisenausgleich erwähnte der Botschafter die Möglichkeit eines Kaufs des britischen Flugzeugs BAC 1-11 durch die "Lufthansa“.

Carstens informiert über die Mitteilung des türkischen Botschafters Müezzinoglu, daß die Türkei künftig nicht mehr zu einer Mitarbeit an der MLF-Arbeitsgruppe bereit sei. Als Gründe seien die Kosten, die Fraglichkeit des militärischen Nutzens und der Wandel, den das Projekt durch den britischen Vorschlag einer ANF mittlerweile erfahren habe, genannt worden. Der Staatssekretär bat darum, die Entscheidung nicht vor einer Rücksprache mit der Bundesregierung zu veröffentlichen. Eine sofortige Bekanntgabe würde auch den "sicherlich falschen" Eindruck hervorrufen, der Entschluß stünde in Zusammenhang mit dem gerade beendeten Besuch einer sowjetischen Delegation in Ankara. 

amerikanischen Botschafter McGhee

Schröder zeigt sich befriedigt über die in einem Schreiben des amerikanischen Außenministers Rusk bekräftigte positive Haltung zu der geplanten MLF. Davon müsse jetzt vor allem auch die Öffentlichkeit in der Bundesrepublik überzeugt werden, nachdem der Eindruck einer von Rücksichten auf Frankreich bestimmten amerikanischen Distanzierung und damit „eine verteufelte Lage“ entstanden sei. Der Bundeskanzler benötige die nun schriftlich vorliegende Zusicherung einer unveränderten amerikanischen Deutschland- und Verteidigungspolitik, da er bei der bevorstehenden Begegnung mit dem französischen Staatspräsidenten „mit sehr andersartigen Ansichten konfrontiert werde“. Erhard stehe - was de Gaulle sehr wohl wisse wegen der Bundestagswahlen unter dem Druck, deutsch-französische Friktionen zu vermeiden. McGhee warnt allerdings davor, dem französischen Staatspräsidenten ein Vetorecht über die deutsche Nuklearpolitik zuzugestehen. Abschließend bestreitet der Botschafter jede Absicht der USA, ihre Beziehungen zu Frankreich auf Kosten der Bundesrepublik zu verbessern und danach „die Deutschen fallen zu lassen“. (Entwurf)

In Vorbereitung der Reise des Bundesministers Scheel nach Tansania erläutert Böker die Verhandlungsziele. Von Präsident Nyerere müßte die Zusage erreicht werden, die DDR zum Verzicht auf jegliche Vertretung in Daressalam zu veranlassen. Die Existenz der DDR-Botschaft auf Sansibar gelte als „Erbschaft aus der Zeit der „Volksrepublik Sansibar“ und stelle zunehmend ein „Kuriosum“ dar. Demgegenüber würde die Einrichtung einer DDR-Handelsvertretung in Daressalam eher als ein "Neuanfang“ angesehen werden, der sich in weiten Teilen Afrikas „verhängnisvoll“" auswirken könnte. Als weiteres Verhandlungsziel nennt Böker eine allmähliche Herabstufung der DDR-Botschaft auf Sansibar, notfalls mit der zeitweiligen Zulassung eines sich nur auf die Insel beschränkenden Konsulats als „letzte Rückzugslinie“. Im Gegenzug könnte von der Bundesregierung in Aussicht gestellt werden, alle Entwicklungshilfe-Projekte der DDR zu übernehmen. amerikanischen Botschafter McGhee

Erhard und McGhee stimmen in der Einschätzung der geplanten MLF überein. Erhard betont die Verbundenheit mit den USA: die NATO, der „nukleare Schutz Amerikas“ und die Anwesenheit amerikanischer Truppen seien für die Bundesrepublik unabdingbar. McGhee steht der von Erhard entwickelten Vor- 
stellung positiv gegenüber, ein gemeinsames nukleares Verteidigungskonzept auszuarbeiten, in das die Force de frappe eingebracht würde, aber in einem "gewissen Umfang " unabhängig bliebe. Allerdings bezweifelt er die französische Bereitschaft zu einer solchen Lösung, da Staatspräsident de Gaulle „die absolute Kontrolle" behalten und entscheiden wolle, "wann wohin geschossen werde“. Zu einer etwaigen Europa-Reise des amerikanischen Präsidenten erklärt Erhard, daß Johnson „aus Höflichkeitsgründen mit Paris anfangen könne". McGhee pflichtet dem Bundeskanzler bei, daß die MLF einer ANF vorzuziehen sei, da letztere keine Europäisierungsklausel habe.

18 15.01. Botschafter Groepper, Moskau, an das Auswärtige Amt

Groepper teilt mit, daß sich die sowjetische Regierung mit der baldigen Aufnahme von Wirtschaftsverhandlungen einverstanden erklärt habe. Der Stellvertretende Außenhandelsminister Kusmin sei jedoch nicht auf den Wunsch der Bundesregierung eingegangen, über den Geltungsbereich des seit 1958 bestehenden Warenabkommens und damit über die Einbeziehung von Berlin (West) zu sprechen. Lediglich der Umfang des beiderseitigen Handels sowie das Warenangebot stünden zur Diskussion. Groepper spricht sich jedoch gegen die Fortschreibung der bestehenden Warenlisten und statt dessen für Neuverhandlungen aus, um auf die Gestaltung des Handels mit der UdSSR, insbesondere durch Kreditgewährung, Einfluß nehmen zu können. Anderenfalls könnte sich die zunehmende wirtschaftliche Verflechtung der westlichen Bündnispartner Großbritannien und Frankreich mit der UdSSR nicht nur kommerziell, sondern auch politisch nachteilig auf die Deutschland-Frage auswirken.

Mirbach stellt fest, daß die Tschechoslowakei während der bis zum Vortage in Bonn geführten Verhandlungen eine Einbeziehung von Berlin (West) in ein Handelsabkommen abgelehnt habe. Die zwischen der Bundesrepublik und vier anderen Ostblock-Staaten bereits gefundene vertragliche Lösung sei nach tschechoslowakischer Ansicht nicht mehr möglich, nachdem "deutsche Politiker trotz der vereinbarten Vertraulichkeit zu häufig und zu deutlich in der Öffentlichkeit darauf hingewiesen hätten". Unklar sei auch der Status der zukünftigen Vertretung. Weil die Bundesregierung dem Wunsch nach konsularischen Befugnissen nicht zugestimmt habe, werde die Tschechoslowakei nur noch eine Handelsvertretung zur Durchführung des Abkommens gewähren und deren Wirkungsmöglichkeit vermutlich vom ersten Tag an bewußt ,sehr stark einschränken“. Dies könnte zu erheblicher Kritik in der Öffentlichkeit der Bundesrepublik führen. 
Krapf faßt den deutschen Standpunkt zu einer integrierten Nuklearstreitmacht der NATO zusammen. Die von den USA vorgeschlagene MLF könne den Rahmen für eine „unauflösbare Verknüpfung“ der Verteidigung der USA mit derjenigen Westeuropas bilden, während sich weder mit einer europäischen Atomstreitmacht noch mittels einer Beteiligung an der Force de frappe Einfluß auf das „entscheidende amerikanische Potential nehmen ließe. Die an der MLF interessierten Staaten wollten ein neues Waffensystem aufbauen und dadurch die NATO stärken. Demgegenüber strebe Großbritannien mit der ANF lediglich eine Umgruppierung der in der NATO vorhandenen bzw. geplanten Kernwaffen unter einem "Sonderregime" außerhalb der NATO-Befehlshierarchie an, nicht zuletzt um die Kompetenzen von SACEUR zu verringern. Daneben sollten nach britischen Vorstellungen die ANF-Staaten eine Verpflichtung zur Nichtverbreitung bzw. zum Nichterwerb von Kernwaffen eingehen, um eine bessere Voraussetzung für eine Ost-West-Entspannung zu schaffen. Krapf empfiehlt, bei den bevorstehenden Gesprächen anläßlich des Besuchs von Premierminister Wilson in Bonn möglichst viel vom Projekt der MLF zu bewahren und auf die besondere Bedeutung einer Nichterwerbsverpflichtung von Atomwaffen für die Deutschlandpolitik hinzuweisen.

Die Bundesregierung stellt fest, daß ein unverzichtbarer Bestandteil des britischen Vorschlags vom 11. Dezember 1964 für eine Atlantische Nuklear-Streitmacht eine Überwasserflotte von wenigstens 20 Schiffen sein müsse, da nur auf diese Weise eine wirksame Beteiligung der nicht-nuklearen NATO-Mitglieder sichergestellt werden könne. Sie regt an, daß alle Einheiten der ANF dauerhaft zugeteilt werden sollen, daß die Streitmacht in gemeinsamem Eigentum sowie unter gemeinschaftlicher Leitung der Mitgliedstaaten stehen und gemischt bemannt sein soll. In der Frage der Bemannung wie auch hinsichtlich einer Unterstellung unter SACEUR und des Vetorechts bei der Einsatzfreigabe vertritt die Bundesregierung jedoch einen von der britischen Position abweichenden Standpunkt. Sie schlägt zudem die Aufnahme von Revisionsklauseln vor, welche eine Änderung des ANF-Vertrags im Falle einer Wiedervereinigung Deutschlands, einer europäischen politischen Union und wesentlicher abrüstungspolitischer Fortschritte erlauben würden. Die im ANF-Konzept enthaltene Regelung über die Nichtverbreitung von Kernwaffen wird zwar grundsätzlich befürwortet, jedoch müsse dieses Problem im weltweiten Rahmen gelöst werden. Ferner sei zu bedenken, ob das sowjetische Interesse an einer weiteren nuklearen Verzichtserklärung der Bundesrepublik nicht besser für deutschlandpolitische Fortschritte genutzt werden könne. 

präsident de Gaulle in Rambouillet

Erhard erörtert seine Vorstellung über eine „stärkere politische Zusammenarbeit" der EWG-Staaten. Er schlägt regelmäßige Treffen der Außenminister und Regierungschefs vor, die sich an das im deutsch-französischen Vertrag vom 22. Januar 1963 vorgesehene Verfahren anlehnen könnten. De Gaulle ist bereit, eine entsprechende Initiative mitzutragen. Die Gesprächspartner einigen sich auf ein erstes Außenministertreffen im Mai 1965, dem etwa am 1. Juli 1965 eine Konferenz der Staats- und Regierungschefs folgen könne. Hinsichtlich der DeutschlandFrage regt der Bundeskanzler eine Initiative an, die „die VierMächte-Verantwortung wieder einmal sichtbar werden" ließe, obwohl die UdSSR gegenwärtig nicht zu einem Gespräch bereit sei. De Gaulle sieht in der deutschen Teilung eine „europäische Frage par excellence“. Bei der Suche nach einer Lösung glaube er nicht an eine Einigung zwischen den USA und der UdSSR. Er sei vielmehr überzeugt, daß die UdSSR - „oder deren Nachfolger" - und die anderen Ostblock-Staaten langfristig eine Wiedervereinigung hinnähmen, wenn sie darin den Vorteil einer „Entente vom Osten bis zum Westen" finden würden. Der Bundeskanzler gibt zu bedenken, daß die „Ungeduld der Herzen“ in Deutschland eine absehbare und "erlebbare Hoffnung" erfordere. Daher brauche das deutsche Volk die „Willensbezeugung auf seiten der Alliierten“. Der Staatspräsident entspricht schließlich der Bitte, auf seiner Pressekonferenz am 4. Februar 1965 für eine Lösung der Deutschland-Frage im europäischen Kontext einzutreten. Dagegen werde er nicht auf die Gespräche der Vier Mächte eingehen, deren Ausgang er noch nicht absehen könne. in Paris

Die Unterredung der Außenminister ist zunächst Fragen der Ostpolitik gewidmet. Auf Bitte von Bundesminister Schröder erklärt sich der französische Außenminister Couve de Murville bereit, in Jugoslawien von einem Besuch des Staatspräsidenten Tito nach Ost-Berlin abzuraten, der auch die französische Entspannungspolitik störe. Dann berichtet er über den Aufenthalt des ungarischen Außenministers in Paris. Peter habe die französische Regierung gebeten, nach der völkerrechtlichen Anerkennung der Volksrepublik China nunmehr auch die DDR anzuerkennen. Schröder erläutert den Stand der unterbrochenen Verhandlungen mit der Tschechoslowakei über den Austausch von Handelsvertretungen und nennt als entscheidende Streitpunkte das Münchener Abkommen von 1938 und die Frage der Einbeziehung von Berlin (West) in ein Handelsabkommen. In der Europapolitik sind sich beide Gesprächspartner einig, daß vorsichtige Schritte - etwa durch eine Außenministerkonfe- 
renz der Sechs - in Richtung auf eine politische Union eingeleitet werden könnten. Im Hinblick auf die EWG besteht Übereinstimmung, ein Arbeitsprogramm für die weitere Harmonisierung vorzubereiten. Zur Deutschland-Frage betont der Bundesminister, daß der Vorschlag einer Initiative keineswegs nur innenpolitisch motiviert sei. Der französische Außenminister weist darauf hin, daß man sich „keine Illusionen über den zu erwartenden Erfolg" machen dürfe. rats I. Klasse Bassler

Der Leiter des Referats „Süd- und Ostasien“ faßt die Gespräche zusammen, die der pakistanische Außenminister u.a. mit Bundespräsident Lübke, Bundeskanzler Erhard, Bundesminister Schröder und Staatssekretär Carstens führte. Bhutto erläuterte die Annäherung Pakistans an die Volksrepublik China; beide Staaten hätten das gleiche Interesse an einer Normalisierung ihrer Beziehungen gehabt. Aus der Mitgliedschaft in den für die westliche Verteidigung gebildeten Organisationen SEATO und CENTO habe Pakistan keinen Nutzen gezogen; die Abkühlung der Beziehungen zu den USA und Großbritannien erkläre sich aus deren Waffenlieferungen an Indien. Bhutto hob hervor, daß Pakistan sich stets für die Interessen der Bundesrepublik eingesetzt und auch im Gegensatz zu Indien die Errichtung einer Handelsvertretung der DDR abgelehnt habe. Trotzdem erhalte Indien eine größere Entwicklungshilfe, und auch bezüglich der Ausrüstungshilfe an Pakistan werde „eine unnötige Rücksicht auf indische Empfindlichkeiten" genommen. Die gewünschten 15000 Maschinengewehre würden für die Verteidigung gegen Indien dringend benötigt, das Waffen „in größtem Umfang“ von den USA und von der UdSSR erhalten habe. Mit Bhutto wurden Möglichkeiten erörtert, die Maschinengewehre „über ein drittes Land" wie die Türkei oder Italien zu liefern. Auswärtige Amt

Walther berichtet über ein Gespräch mit dem Generalsekretär im türkischen Außenministerium. Er legte Bayülken dar, daß der türkische Vorschlag, Zypern für unabhängig zu erklären und eine Föderalverfassung zu geben, sich nachteilig für die türkische Seite auswirken könnte, wenn er bereits vor einer Behandlung der Zypern-Frage in der UNO erfolgen würde. Dann müsse nämlich mit einer "gereizten Reaktion“ von griechischer Seite gerechnet werden. Zu den Föderationsplänen führte Bayülken aus, daß ein Fünftel des Territoriums für die türkische Bevölkerung vorgesehen werde und alle Bodenschätze und Industrien auf griechischer Seite lägen. Die Zentralregierung mit einem griechischen Präsidenten und einem türkischen Vize- 
präsidenten an der Spitze solle für Außen- und Militärpolitik sowie Strafjustiz zuständig sein. Der Generalsekretär bat um eine formlose mündliche Zustimmung zu dem türkischen Plan, damit im Parlament in Ankara ohne nähere Angaben allgemein auf den Rückhalt bei den „Freunden und Alliierten der Türken“ und nicht nur auf die Unterstützung durch die UdSSR verwiesen werden könne. präsident de Gaulle in Rambouillet

De Gaulle faßt das Gespräch mit Erhard vom Vortag zusammen und signalisiert seine Bereitschaft, der UdSSR gemeinsam mit Großbritannien und den USA einen Vorschlag zur DeutschlandFrage zu unterbreiten. Allerdings störe die Diskussion um eine nukleare Mitsprache der Bundesrepublik in der NATO eine „Prüfung der Wiedervereinigung“. Der „bloße Anschein“, daß die Bundesrepublik Zugang zu atomaren Waffen erhalte, sei für „fast alle Europäer unerträglich“. Erhard erörtert sodann die innenpolitischen Schwierigkeiten, die gegen einen baldigen Abschluß der MLF-Verhandlungen sprächen. Der Bundeskanzler hebt besonders den Wunsch hervor, nicht vor die Notwendigkeit einer Wahl zwischen der Freundschaft mit Frankreich und der Freundschaft mit den USA gestellt zu werden. Allerdings müßten die USA davon überzeugt werden, bei einem sowjetischen Angriff auf Europa sofort die nuklearen Waffen ,in Rußland und nicht nur bei den armen Ostdeutschen" einzusetzen. De Gaulle weist darauf hin, daß Frankreich Atomwaffen baue, um in einem solchen Fall selbst „ etwas Nukleares zum Abschuß bringen zu können“. Der Auffassung, daß die Bundesrepublik "das amerikanische Protektorat" akzeptiert habe, widerspricht Erhard mit dem Hinweis, Deutschland sei dankbar für den Schutz durch die USA. Beide Gesprächspartner sind sich darin einig, daß auf dem Gebiet der Technologie und Forschung die Zusammenarbeit vertieft werden sollte, um den amerikanischen Vorsprung zu verringern und den „Aderla $\beta$ an Intelligenz“ in die USA zu bremsen. präsident de Gaulle in Rambouillet

Der französische Staatspräsident bekräftigt seine Zustimmung zu den Vorschlägen der Bundesregierung für eine politische Fortentwicklung Europas, äußert aber Bedenken gegen den vorgesehenen „Rat der Weisen“. Er nimmt ferner die Anregung auf, durch die Außenminister der Sechs eine Konferenz der Regierungschefs vorbereiten zu lassen, die nach einer Regelung der verbliebenen Agrarfragen zur Jahresmitte zusammentreten 
könnte. Der Bundeskanzler hebt die Bedeutung eines europäischen politischen Zusammenschlusses hervor, der mit Rücksicht auf die öffentliche Meinung und die Bundestagswahlen nicht hinausgezögert werden solle. Hinsichtlich der DeutschlandFrage hält de Gaulle langfristig eine „Wiedervereinigung der beiden Zonen" in gesamteuropäischem Rahmen für möglich; sollten sich jedoch wider Erwarten die USA und die UdSSR über das deutsche Problem einigen, so käme es zu „einer Lösung à la Jalta", also zum Schaden Deutschlands und Europas. Kontakte zwischen den drei Westmächten und der Bundesrepublik zur Vorbereitung einer Wiedervereinigungsinitiative werde er unterstützen. Allerdings sei das zeitgleiche Streben der Bundesrepublik nach Beteiligung an der nuklearen Verteidigung in Form der MLF ,inopportun“. Der Bundeskanzler hebt die besondere psychologische Bedeutung einer deutschlandpolitischen Unterstützung durch die Westmächte hervor. Den Wunsch nach Mitsprache in Nuklearfragen rechtfertigt er mit der Bedrohung, der die Bundesrepublik ausgesetzt sei, wenngleich ihm jeder militärische Aktivismus nach den leidvollen Erfahrungen der Vergangenheit fernliege. Finke-Osiander

Finke-Osiander gibt eine Unterredung vom 14. Januar 1965 mit dem stellvertretenden Abteilungsleiter im tschechoslowakischen Außenministerium, Rezek, wieder. Dieser führte aus, daß eine Erklärung der Bundesregierung, das Münchener Abkommen von 1938 sei „von Anfang an nichtig“ gewesen, zwar keine Voraussetzung für einen Austausch von Handelsvertretungen, wohl aber für eine volle Normalisierung der Beziehungen darstelle. Belastend für das bilaterale Verhältnis sei auch die Forderung nach Heimatrecht für die Sudetendeutschen. Dem wurde entgegnet, die Bundesregierung halte generell die „gewaltsame Aussiedlung von Volksgruppen für einen völkerrechtlichen Unrechtstatbestand" und trete lediglich für das menschliche Grundrecht des einzelnen auf Heimat ein. Das Münchener Abkommen sei gültig zustande gekommen und erst im März 1939 „von Hitler selbst zerrissen“ und damit nichtig geworden. Aufgrund der weitreichenden Konsequenzen für die Sudetendeutschen in Fragen der Staatsangehörigkeit, des Eigentumsrechts und der Entschädigung könne die gewünschte Erklärung allenfalls im Rahmen einer „umfassenden bilateralen Regelung" abgegeben werden. Anschließend wurde die tschechoslowakische Seite gebeten, die Anträge auf Familienzusammenführung schneller zu bearbeiten sowie der deutschen Volksgruppe einen Minderheitenstatus zu gewähren. 


\section{z. Z. Bonn}

Walther gibt ein Gespräch mit dem polnischen Botschafter in Ankara wieder, das am Vormittag in der türkischen Hauptstadt stattfand. Gebert übermittelte die Reaktion auf das Ende Dezember 1964 unterbreitete Angebot, Sondierungsgespräche über den Abschluß eines Nichtangriffsabkommens zu führen. Als Voraussetzungen habe die polnische Regierung gefordert, daß die Bundesrepublik die Oder-Neiße-Linie anerkenne, jetzt und zukünftig keine territorialen Forderungen erhebe, ,ordentliche diplomatische Beziehungen" zu Polen aufnehme und die Existenz „zweier Deutschlands" nicht in Frage stelle. Walther betonte gegenüber seinem polnischen Kollegen, daß die OderNeiße-Frage bekanntermaßen erst in einem Friedensvertrag geregelt werden könne. Gebert, der sich selbst „betroffen“ über die Weisung seiner Regierung zeigte, räumte ein, daß die polnische Antwort eine „klare Absage“ bedeute. Carstens

Der Botschafter berichtet über ein Gespräch mit dem ägyptischen Außenminister. Riad sagte zu, sich der Terminfrage für einen Besuch des Präsidenten Nasser in Bonn anzunehmen; allerdings müßten die Präsidentschaftswahlen im März 1965 abgewartet werden. Er befürwortete die Fortsetzung des von Bundestagspräsident Gerstenmaier im November 1964 begonnenen Gedankenaustausches über das Verhältnis zwischen Israel und der Bundesrepublik und erklärte, daß über die Konsequenzen einer Aufnahme diplomatischer Beziehungen verschiedene Meinungen in der Arabischen Liga bestünden. Federer empfiehlt eine Kontaktaufnahme mit Generalsekretär Hassouna, um dem „Teufelskreis gegenseitiger Erpressung“ zu entkommen. Ein Verzicht der Bundesregierung auf weitere Waffenlieferungen an Israel würde eine gute Basis für ein solches Gespräch schaffen.

31 22.01. Gespräch des Bundeskanzlers Erhard mit dem britischen Botschafter Roberts

Erhard berichtet über die Gespräche am 19./20. Januar 1965 in Rambouillet. Er hebt die Bereitschaft des französischen Staatspräsidenten hervor, eine Deutschland-Initiative der Drei Mächte mitzutragen und auch die politische Zusammenarbeit in Europa fortzusetzen. Zwar äußere sich de Gaulle sehr skeptisch über eine Beteiligung der Bundesrepublik an der MLF, verknüpfe diese Frage aber nicht mit den Europa-Plänen und der Wiedervereinigung. Hinsichtlich der Haltung Großbritanniens zur EWG erläutert Roberts, daß eine Mitgliedschaft „zur Zeit nicht an erster Stelle rangiere“. Gleichzeitig betont er das briti- 
sche Interesse, an den Besprechungen über eine europäische politische Zusammenarbeit beteiligt zu werden. Der Botschafter zeigt volles Verständnis für die Deutschland-Politik der Bundesrepublik und sichert britische Unterstützung zu. Er weist die Befürchtung des Bundeskanzlers, daß Großbritannien in der Frage der Denuklearisierung und des Disengagements „nicht immer die richtige Haltung einnehme", zurück. Lediglich die Verbreitung nuklearer Waffen solle verhindert werden.

In der Stellungnahme zur Entwicklungshilfe an Israel und die arabischen Staaten wird festgestellt, daß die Fortsetzung der Waffenlieferungen an Israel, die auf lange Sicht ebensowenig geheim bleiben könnten wie die Kreditgewährung, sowie die angestrebte Konsolidierung der Beziehungen zu Israel nur bei "entsprechenden Gegenleistungen" von den arabischen Staaten hingenommen werde. Dabei müsse den tatsächlichen wirtschaftlichen und geographischen Gegebenheiten des arabischen Raums und Israels ausgewogener als bisher Rechnung getragen werden. Eine Störung der Beziehungen zu den arabischen Staaten sei im Hinblick auf die „labile Lage“ im Südabschnitt der westlichen Allianz sehr abträglich; zudem müsse die ungestörte Ölzufuhr aus diesem Raum gewährleistet werden. Die zugesagte Entwicklungshilfe an die arabischen Staaten sei bislang wegen des Prinzips der Projektbindung erst zu knapp 40 Prozent ausgeschöpft worden. Grundsätzlich sollte die Hilfe mit Blick auf Größe und Einwohnerzahl „mindestens dreimal so viel betragen" wie die an Israel. Das Auswärtige Amt schlägt daher die Bereitstellung von Sondermitteln für die elf entwicklungsbedürftigen arabischen Staaten vor und weist dabei besonders auf die von der DDR angebotene Entwicklungshilfe an die VAR hin. Zur Durchsetzung der politischen Ziele der Bundesrepublik sei es notwendig, über die Leistungen der DDR hinauszugehen.

Carstens hält Überlegungen zum Vorschlag des Auswärtigen Amts vom 19. Januar 1965 fest, mit Israel Handelsmissionen auszutauschen. Er erwartet, daß Israel den Wunsch nach Aufnahme diplomatischer Beziehungen äußern werde, weil es sich durch eine Handelsmission in Bonn protokollarisch schlechter gestellt sähe als durch die bisherige Israel-Mission in Köln. Als Alternative könne daher erwogen werden, die Rechtsgrundlage der Israel-Mission über das auslaufende Wiedergutmachungsabkommen hinaus zu verlängern und auf eine Vertretung der Bundesrepublik in Israel zu verzichten. Dies erleichtere auch die Politik gegenüber den arabischen Staaten, die auf den Austausch von Handelsvertretungen mit Israel eventuell mit der Eröffnung von Handelsvertretungen in der DDR reagieren würden. 
Pauls legt Zielsetzung und Grundsätze der Ausrüstungshilfe für Entwicklungsländer dar. Der Westen stehe auf diesem Gebiet in Konkurrenz zum Ostblock, der erkannt habe, daß für die jungen Nationalstaaten Streitkräfte und Polizei ein „Kristallisierungskern des fehlenden Nationalbewußtseins" seien. Daher sei der Ostblock bestrebt, dem Westen zuvorzukommen und durch Ausrüstungshilfe seinen politischen Einfluß zu stärken. Ein Engagement der Bundesrepublik in diesem Bereich werde von den Entwicklungsländern ebenso erwartet wie von den Verbündeten. Zudem biete die Gewährung von Ausrüstungshilfe politische Vorteile: Über die damit verbundene Ausbildungshilfe werde einem zwar kleinen, aber einflußreichen Teil der Bevölkerung der Empfängerländer ein positives Deutschlandbild vermittelt. Auch die Volkswirtschaft der Bundesrepublik profitiere von Material- und Ersatzteillieferungen an Entwicklungsländer. Der Ministerialdirigent skizziert die Richtlinien für die Ausrüstungshilfe: Sie werde nur auf Antrag der fremden Regierung gewährt und sei von der zivilen Entwicklungshilfe zu trennen; ausgeschlossen seien Lieferungen in Spannungsgebiete. Die Hilfsprogramme würden mit den Verbündeten abgestimmt und müßten vom Bundesverteidigungsrat genehmigt werden. Abschließend weist Pauls darauf hin, daß auch der Verkauf von ausgemustertem Material der Bundeswehr sowie kommerzielle Verkäufe von Rüstungsfirmen unter dem „strengen Maßstab politischer Zweckmäßigkeit" geprüft werden müßten. Mannesmann

Der Vorsitzende des Arbeitskreises China im Ostausschuß der Deutschen Wirtschaft berichtet von einem Gespräch mit dem chinesischen Handelsrat Mo Cheng-kuei am 21. Januar 1965 in Bern. Hufnagel erläuterte den Wunsch der Industrie nach einem erweiterten Warenaustausch auf der Basis einer "wie immer gearteten Vereinbarung, auch in loser Form“. Mo Chengkuei führte dagegen aus, daß die Verhandlungen vom Vorjahr über ein offizielles Abkommen gescheitert seien, da von deutscher Seite lediglich eine inoffizielle Übereinkunft auf der Ebene der Industrieverbände gewünscht worden sei und China dies ablehne. Zudem sei die Volksrepublik nicht in der Lage, eine Berlin-Klausel, wie sie "die anderen sozialistischen Länder" angenommen hätten, zu akzeptieren. Mo Cheng-kuei bezeichnete die "unfreundliche“ Haltung der Bundesrepublik gegenüber der Volksrepublik China, die den Wirtschaftsbeziehungen abträglich sei, als „Kernfrage“ des bilateralen Verhältnisses. Hufnagel hält eine Vereinbarung über den Ausbau des Handels zum augenblicklichen Zeitpunkt für unrealistisch. 
Carstens übermittelt eine Stellungnahme zum irischen Resolutionsentwurf über die Nichtverbreitung von Kernwaffen. Die Initiative wird grundsätzlich befürwortet, aber es wird darauf hingewiesen, daß die Bundesrepublik bereits 1954 auf die Herstellung atomarer Waffen verzichtet habe. Angeregt wird, das sowjetische Interesse an einem Nichtverbreitungsabkommen für Gegenleistungen in der Deutschland-Frage zu nutzen. Aus sicherheitspolitischen Erwägungen komme ein solches Abkommen für die Bundesrepublik erst nach der Verwirklichung einer integrierten NATO-Atomstreitmacht in Betracht. Zudem müsse die Teilnahme möglichst aller bereits existierenden und potentiellen Nuklearmächte sichergestellt sein. Da das Abkommen allen Staaten offenstehen solle, müsse die Bundesrepublik eingehend konsultiert werden, um einer Aufwertung der DDR "durch eine geeignete Disclaimer Clause“ entgegenwirken zu können.

Aus einem Gespräch mit den Botschaftern der drei Westmächte hält Carstens fest, daß die - ihm selbst nicht bekannte - Äußerung des Bundesministers Mende vor der Presse kritisiert worden sei, eine Sitzung des Bundestages in Berlin (West) notfalls auch gegen die Bedenken der Alliierten stattfinden zu lassen. Die Botschafter bedauerten ferner, daß eine Zusammenkunft des Bundeskabinetts in Berlin stattgefunden habe, ohne daß zuvor ihre Einwilligung eingeholt worden sei. Weiterhin beanstandeten McGhee, Roberts und de Margerie, daß zwei Generale der Bundeswehr an einer Sitzung des Verteidigungsausschusses in Berlin teilgenommen hätten, ohne daß die Westmächte die Transitreise genehmigt hätten. Im Wiederholungsfall seien "erhebliche" Komplikationen mit der UdSSR zu befürchten. Abschließend wurde bemängelt, daß die Bundesregierung ohne vorherige Konsultation gemäß der Entscheidung der NATOStaaten über die Ausstellung von Temporary Travel Documents einer Anzahl von Rentnern aus der DDR Bundespässe ausgestellt habe. Carstens bestritt die Zuständigkeit der Westmächte in dieser rein innenpolitischen Angelegenheit. Carstens

Federer hat den Eindruck, daß die ägyptische Regierung die Folgen eines Besuchs des Staatsratsvorsitzenden der DDR in Kairo unterschätze und nur mit einem formalen Protest der Bundesregierung rechne. Er sieht sowohl die Nahost- als auch die Deutschlandpolitik der Bundesrepublik an einem „Scheideweg“ und plädiert dafür, in einem „package deal" einen Widerruf der Einladung an Ulbricht gegen eine Einstellung der Waffenlie- 
ferungen der Bundesrepublik an Israel zu vereinbaren. Andernfalls bleibe nur die Möglichkeit, mit den „Konsequenzen der Hallstein-Doktrin in all ihren Schattierungen" zu drohen.

Carstens informiert über die Entscheidung des Bundeskanzlers Erhard vom Vortage, „mit sofortiger Wirkung“ keine neuen Verpflichtungen zu Waffenlieferungen an Israel einzugehen und nach Möglichkeit die noch ausstehenden Lieferungen, insbesondere von 90 Panzern, zu unterbinden oder zu reduzieren. Federer soll nun auf Präsident Nasser einwirken, um den angekündigten Aufenthalt des Staatsratsvorsitzenden der DDR in der VAR zu verhindern und den ägyptischen Präsidenten zu einer Reise in die Bundesrepublik zu veranlassen. Käme der Besuch von Ulbricht trotzdem zustande, werde dies nicht nur zu einer "Überprüfung der getroffenen Entscheidung“ über die Waffenlieferungen an Israel führen, sondern sich auch ungünstig auf die von der Bundesregierung erwogene „namhafte Wirtschaftshilfe " auswirken. Abschließend teilt Carstens mit, daß er die Aufnahme diplomatischer Beziehungen zu Israel momentan "für ausgeschlossen" halte.

Carstens faßt die Ergebnisse der Kabinettssitzung vom 27. Januar 1965 zusammen. Bundesminister Schröder beantragte, die Waffenlieferungen an Israel einzustellen, die Wirtschaftshilfe fortzusetzen sowie den Austausch von Handelsvertretungen oder eventuell sogar die Errichtung einer neigenen Mission in Jerusalem" anzubieten. Er empfahl, den arabischen Staaten eine Wirtschaftshilfe in dreifacher Höhe der an Israel geleisteten Zahlungen zu gewähren und Präsident Nasser in der Bundesrepublik zu empfangen. Carstens hält fest, daß eine Mehrheit der Anwesenden die Fortsetzung der vereinbarten Waffenlieferungen an Israel befürwortete; einige Kabinettsmitglieder zeigten sich zudem nicht mit der Absicht des Bundeskanzlers Erhard einverstanden, keine neuen Lieferverpflichtungen einzugehen. Überwiegend negativ war auch die Haltung zu einer Gesetzesinitiative mit dem Ziel, generell keine Waffen außerhalb des NATO-Gebiets zu liefern.

Krapf befaßt sich mit den möglichen Reaktionen auf den angekündigten Besuch des Staatsratsvorsitzenden der DDR, Ulbricht, in der VAR. Wegen der Wirkung auf die übrigen blockfreien Staaten müsse die Bundesregierung alles tun, um den Besuch zu verhindern. Er schlägt deshalb vor, Präsident Nasser 
einen "package deal“ anzubieten, in den auch das ,in seiner Erpressungstaktik nicht hinter der VAR" zurückstehende Israel einbezogen sein müßte. Um ägyptische Forderungen zu befriedigen, seien ein sofortiger Stopp der Waffenlieferungen an Israel und ein vorläufiger Verzicht auf den Ausbau der amtlichen Beziehungen zu erwägen; um israelischen Forderungen nachzukommen, seien Maßnahmen zur Unterbindung der Tätigkeit von Rüstungsexperten aus der Bundesrepublik in der VAR und eine Verlängerung der Verjährungsfrist für die Verfolgung von nationalsozialistischen Gewaltverbrechen in Betracht zu ziehen.

Vor dem Hintergrund der politischen Annäherung einer Reihe blockfreier Staaten an die DDR befürchtet Krapf für die Bundesrepublik in absehbarer Zeit einen „Einbruch" in die Politik der Nichtanerkennung. Um dieser Entwicklung entgegenzuwirken und vor der Weltöffentlichkeit klarzustellen, daß sich die Bundesregierung ihre Politik nicht, won der SBZ oder dritten Staaten durch Erpressung aufzwingen" lasse, solle sie sich darauf einrichten, ,jederzeit“ diplomatische Beziehungen zu osteuropäischen Staaten wie Rumänien, Ungarn, Bulgarien und eventuell auch Jugoslawien aufzunehmen. Durch eine solche Initiative würde die Bundesregierung genügend außenpolitischen Handlungsspielraum gewinnen, um auf die mögliche Anerkennung der DDR durch blockfreie Staaten nicht mehr unter allen Umständen mit dem Abbruch der diplomatischen Beziehungen antworten zu müssen, sondern „ein anderes Strafmaß" auf dem Gebiet der Kreditgewährung und der Entwicklungshilfe anwenden zu können. an das Auswärtige Amt

Sahm berichtet von der Diskussion über den irischen UNOResolutionsentwurf zur Nichtverbreitung von Atomwaffen. Der Vorschlag stie $ß$ im Politischen Ausschuß der NATO auf breite Zustimmung; von britischer Seite wurde jedoch angeregt, einen Appell an alle Nichtnuklearstaaten, ihren Verzicht auf Kernwaffen zu erklären, einzufügen. Der Vertreter Italiens schlug vor, eine Verpflichtung der Atommächte zur Nichtweitergabe aufzunehmen. In besonderem Maße befürworteten die USA den Entwurf, der der UdSSR Gewißheit verschaffe, daß die angestrebte NATO-Atomstreitmacht nicht zu einer Weiterverbreitung von Kernwaffen führen würde. Die seitens der Bundesrepublik vertretene Ansicht, eine Nichtverbreitungsregelung dürfe nicht die Weitergabe von Atomwaffen an „Staatengruppen", wie zum Beispiel an eine MLF oder ANF, verhindern, wurde von den Vertretern Kanadas, Dänemarks, Griechenlands 
und der Niederlande unterstützt. Abschließend hob die niederländische Seite hervor, daß einem Abkommen nur zugestimmt werden könne, wenn es weltweite Gültigkeit besitze. an das Auswärtige Amt

Sahm berichtet über die Diskussion im Ständigen NATO-Rat vom Vortag über die im März 1964 revidierten Richtlinien für die Ausgabe von Temporary Travel Documents. Dabei wurden zwei unterschiedliche Haltungen deutlich: Die Mehrzahl der NATO-Staaten unterstützte die Auffassung des niederländischen Botschafters, daß die Anwendung einzelner TTD-Bestimmungen noch flexibler gehandhabt werden sollte. Boon plädierte vor allem dafür, mehr Personen die Einreise unter der Kategorie 1 („Trade“) zu ermöglichen. Im Gegensatz dazu verwies der französische Botschafter darauf, daß die Zeit seit März 1964 zu kurz gewesen sei, um die Handhabung der TTD-Richtlinien zu überprüfen. Eine Lockerung würde einen propagandistischen Erfolg der Ostblock-Staaten darstellen. Dem „brillianten Plädoyer" von Seydoux schlossen sich der britische, der amerikanische, der türkische und griechische Vertreter wie auch Botschafter Grewe an. Letzterer hob hervor, daß die Auslegung der bestehenden Bestimmungen nicht zu einer Aufwertung der DDR führen dürfe; hohen Funktionären „Pankows“ sei daher die Einreiseerlaubnis zur Führung von Handelsgesprächen zu verweigern. tansanischen Außenminister Kambona

Schröder äußert sich besorgt über die im Zuge der Vereinigung von Tanganjika und Sansibar vorgesehene Errichtung eines Generalkonsulats und einer Handelsvertretung der DDR in der tansanischen Hauptstadt. Kambona erläutert, daß wegen der seit Januar 1964 bestehenden diplomatischen Beziehungen zwischen Sansibar und der DDR nun ein Kompromiß innerhalb der Unionsregierung unumgänglich gewesen sei. Dabei habe Präsident Nyerere die Nichtanerkennung der DDR durchgesetzt. Die Verlegung der Vertretungen der DDR von Sansibar nach Daressalam rechtfertigt er mit der besser zu gewährleistenden Kontrolle. Schröder weist demgegenüber darauf hin, daß es der DDR gelungen sei, Sansibar als „Sprungbrett" zu benutzen. Daher sei er in großer Sorge hinsichtlich der weiteren Entwicklung der wirtschaftlichen Beziehungen und der "Gewährung von Hilfe auch auf anderen Gebieten“. 

bei der NATO in Paris

Krapf empfiehlt Zurückhaltung gegenüber dem britischen Änderungsvorschlag zum UNO-Resolutionsentwurf über die Nichtverbreitung von Kernwaffen. Während sich nach der irischen Vorlage nur diejenigen UNO-Mitglieder, die für die Resolution stimmten, zu ihrer Einhaltung verpflichten würden, sehe die geänderte Fassung einen Appell an alle Nichtnuklearmächte zu Verzichtserklärungen auf die Herstellung von Atomwaffen bzw. auf die nationale Verfügungsgewalt vor. Krapf hebt hervor, daß die Bundesregierung einem solchen ohne Einschränkungen formulierten Appell nicht zustimmen und daher keine verbindliche Erklärung abgeben könne. Ein derartiger Aufruf würde jedoch einen "fast unwiderstehbaren Druck“ in Richtung auf einen vorbehaltlosen Beitritt zu einem Nichtverbreitungsabkommen erzeugen. minister Wilson in London

Wilson bezeichnet einen britischen Beitritt zur EWG als gegenwärtig „nicht aktuell“, bekundet aber nach wie vor Interesse am Gemeinsamen Markt und an den Diskussionen über eine europäische politische Union. Erhard berichtet von seinen Gesprächen mit Staatspräsident de Gaulle am 19./20. Januar 1965 in Rambouillet, der - ohne die Kritik an der NATO zurückzunehmen - seine „Worte des Mißtrauens" gegen Großbritannien und die USA nicht wiederholt habe. Zudem habe er sich weder kategorisch gegen eine Beteiligung der Bundesrepublik an der MLF ausgesprochen, noch sich gegenüber der Europa-Initiative der Bundesregierung vom 4. November 1964 verschlossen gezeigt. Wilson bestätigt die Ähnlichkeit der deutsch-britischen Interessen in der Frage der nuklearen Verteidigung, bezweifelt aber die französische Bereitschaft zur Kooperation. Hinsichtlich der Deutschland-Frage sagt er zu, die Politik der Bundesregierung zu unterstützen und die „absolut kategorische "Haltung in der Berlin-Frage beizubehalten. Schließlich bittet er um Unterstützung bei den Stationierungskosten für die Rheinarmee und spricht den möglichen Ankauf des britischen Flugzeugs BAC 1/11 durch die „Deutsche Lufthansa“ sowie gemeinsame Forschungsvorhaben an. Erhard verweist nochmals auf die Unterredung mit de Gaulle. Auch wenn er dessen Skepsis über die Erfolgsaussichten einer Initiative der Drei Mächte in der Deutschland-Frage teile und die Aussichten einer Mitarbeit der UdSSR „äußerst gering“ seien, hält er es für wichtig festzustellen, „ob die Viermächteverantwortung wieder sichtbarer gemacht werden könne". 
Der Botschafter berichtet über ein Gespräch mit dem ägyptischen Präsidenten vom Vortag. Nasser erklärte, daß der Staatsratsvorsitzende der DDR, Ulbricht, am 24. Februar 1965 nach Kairo kommen werde. Hinweisen auf mögliche schwerwiegende Folgen begegnete Nasser mit dem Vorwurf, daß die Bundesrepublik „durch dick und dünn mit Israel verbunden“ sei. Außerdem behielt er sich eine spätere Anerkennung der DDR vor, wenn die Waffenlieferungen der Bundesrepublik an Israel fortgesetzt würden. Federer zieht aus der Wirkungslosigkeit seiner Einwände den Schluß, daß Nasser bereits „fest gebunden war". Er vermutet, daß dabei der Aufenthalt des sowjetischen Stellvertretenden Ministerpräsidenten Schelepin vom 18. bis 29. Dezember 1964 in Kairo eine entscheidende Rolle gespielt habe. Auswärtige Amt

Knappstein teilt mit, die amerikanische Regierung wolle dem Eindruck entgegenwirken, daß sich ihr Interesse an einer integrierten NATO-Atomstreitmacht seit Dezember 1964 verringert haben könnte. Tatsächlich befürworte sie weiterhin den britischen Vorschlag einer MLF/ANF als die beste Lösung des Problems der nuklearen Mitsprache in der Allianz. Der in der Diskusssion "verloren gegangene Impetus" müsse allerdings von den europäischen Verbündeten ausgehen. Daher versuchten die USA, interessierte Staaten wie die Bundesrepublik, Großbritannien, Italien und die Niederlande zu einem „Fortschreiten auf zunächst bilateralem Wege “ zu ermutigen. Jedoch dürfe die Bundesregierung nicht als treibende Kraft auftreten oder den Anschein eines möglichen deutsch-amerikanischen Alleingangs erwecken. Werde keine gemeinsame europäische Basis gefunden, sei es sehr fraglich, ob die USA sich weiter um das Zustandekommen einer MLF/ANF bemühen würden. Ausschlaggebend für die Haltung des Präsidenten Johnson gegenüber dem Projekt werde in jedem Fall die Teilnahme Großbritanniens und die „Überwindung oder Milderung des französischen Widerstandes“ sein. syrischen Botschafter Khabbaz

Khabbaz zeigt sich beunruhigt über die „Hinwendung“ der Bundesrepublik zu Israel und äußert Zweifel an ihrem Willen, den vereinbarten Bau des Euphrat-Staudamms durchzuführen, der von großer wirtschaftlicher Bedeutung für Syrien sei. Erhard verweist auf Probleme bei der Finanzierung des Projekts. Er macht auf die moralische Dimension der deutsch-jüdischen Beziehungen aufmerksam, deutet aber gleichzeitig auch die 
Einstellung der unentgeltlichen Waffenlieferungen nach Israel an. Der Bundeskanzler sichert zu, sich weiterhin für das Euphrat-Projekt einzusetzen.

\section{Klasse Schirmer}

Schirmer gibt den Inhalt eines Gesprächs mit dem ägyptischen Geschäftsträger wieder. Karim zeigte sich bestürzt über die Reaktion der Bundesregierung auf den geplanten Besuch des Staatsratsvorsitzenden der DDR in Kairo. Schirmer wies auf die Bedeutung hin, die Ulbricht „für jeden Deutschen als Symbol der Unterdrückung “ habe. Karim betonte, daß Präsident Nasser mit der Einladung nicht länger habe warten können, zumal sich die VAR auf einen bewaffneten Konflikt mit Israel einstellen müsse. Mit den Waffenlieferungen an Israel handele die Bundesrepublik gegen ihre eigenen Interessen, da einer Anerkennung der DDR durch die VAR innerhalb von sechs Monaten 30 weitere Staaten folgen würden. Nachteilige politische Konsequenzen müsse Nasser also ebensowenig fürchten wie wirtschaftliche Rückschläge, weil für den Fall einer Aufkündigung der Wirtschaftshilfe durch die Bundesrepublik bereits britische und französische Firmen mit der ägyptischen Regierung über eventuell freiwerdende Kontrakte verhandelten. Karim schlo $\beta$ mit der Aufforderung, die Waffenlieferungen an Israel umgehend einzustellen. Noch könne eine „äußerst gefährliche politische Entwicklung“ verhindert werden.

Krapf berichtet, daß in der Politischen Abteilung II des Auswärtigen Amts die Vorbereitungen zur Aufnahme diplomatischer Beziehungen mit den osteuropäischen Staaten angelaufen seien. Um die Folgen des wohl nicht mehr zu verhindernden Besuchs des Staatsratsvorsitzenden der DDR, Ulbricht, in Kairo gering zu halten, rät er davon ab, mit einem Abbruch der Beziehungen zur VAR oder etwa einer diplomatischen Anerkennnung Israels zu reagieren. Krapf rät vielmehr zur sofortigen Einstellung aller Waffenlieferungen an Israel, um Präsident Nasser die Anerkennung der DDR zu erschweren. Selbst für den Fall, daß es nicht zu einer Aufnahme diplomatischer Beziehungen zwischen der VAR und der DDR kommen werde, empfiehlt er einen möglichst umgehenden Botschafteraustausch zwischen den osteuropäischen Staaten und der Bundesrepublik. Diese Vorgehensweise werde die außenpolitische Bewegungsfreiheit erweitern und die Bundesregierung schließlich in die Lage versetzen, „die Israel-Frage zu lösen“, ohne daß dies als Reaktion auf ein Scheitern ihrer Nahost-Politik erscheinen werde. 
Angesichts der Stellungnahme des Bundesministers Bucher, die während des Jahres 1965 ablaufende Verjährungsfrist für nationalsozialistische Gewaltverbrechen nicht zu verlängern, macht Krapf auf die Folgen aufmerksam, die sich aus einer solchen Haltung für die Deutschlandpolitik der Bundesregierung ergeben könnten. In jüngster Zeit sei es zusätzlich zu etlichen Rückschlägen in der Alleinvertretungspolitik - so im Verhältnis zur VAR, zu Indonesien und zu Tansania - durch die ,Agitation“ in der Frage der Verjährungsfristen sogar zu einer Isolierung der Bundesrepublik gegenüber der Öffentlichkeit befreundeter Staaten gekommen. Ohne eine Korrektur des bisherigen Verhaltens in der Verjährungsfrage werde die Bundesrepublik ihre "moralische und politische Stellung“ in der Deutschland-Frage nicht halten können.

Erhard äußert sich besorgt über die Absicht einiger Großfirmen aus der Bundesrepublik, sich an der Leipziger Frühjahrsmesse $1965 \mathrm{zu}$ beteiligen. Da bisherige Bemühungen, die Firmen zu einer größeren Zurückhaltung zu bewegen, gescheitert seien und der Teilnahme eine besondere politische Bedeutung zukomme, bittet er Schröder, zusammen mit Bundesminister Schmücker auf die Konzerne einzuwirken.

Middelmann hält ein Gespräch zwischen Staatssekretär Lahr und dem portugiesischen Botschafter fest. Homem de Mello zeigte sich überzeugt, daß der ins Auge gefaßte Verkauf von Flugzeugen der Bundesluftwaffe aus kanadischer Produktion an Portugal nicht unter die in der deutsch-kanadischen Vereinbarung von 1956 vorgesehene Regelung über die Zustimmung Kanadas zu einer Weiterveräußerung falle. Demgegenüber teilte Lahr mit, die kanadische Regierung bestehe auf einer präziseren Fassung der Endverbleibsklausel. Während Homem de Mello darauf beharrte, ein Einsatz der Maschinen in den afrikanischen Kolonien stehe nicht im Widerspruch zu der 1963 ausgehandelten Endverbleibsklausel, entgegnete Lahr, deutscherseits sei damals auf die von Portugal gewünschte „flexible Formel" in dem Glauben eingegangen worden, daß über ihre Auslegung Einvernehmen bestehe. Eine Klärung sei erforderlich, um eine Verstimmung zwischen der Bundesrepublik und Portugal zu vermeiden. 

Roschach

Der Leiter des Planungsstabs stellt Überlegungen zur Deutschlandpolitik an. Für den Fall, daß die VAR oder ein einzelner nichtkommunistischer Staat Botschafter mit der DDR austauschten, müsse die Bundesrepublik, um andere Regierungen von einem solchen Schritt abzuschrecken, mit dem Abbruch der diplomatischen Beziehungen antworten; darüber hinaus solle auch die Entwicklungshilfe eingestellt werden. Sollte jedoch eine ganze Gruppe nichtkommunistischer Staaten die DDR diplomatisch anerkennen, würde ein Abbruch der Beziehungen einer politischen „Selbstverstümmelung“ gleichkommen; die Bundesrepublik könnte dann lediglich Gegenmaßnahmen wie z. B. die Einstellung der Entwicklungshilfe ergreifen. Zudem sollte differenziert werden, inwieweit die Anerkennung der DDR Ausdruck der Haltung in der Frage des Selbstbestimmungsrechtes sei. So könne von Sanktionen abgesehen werden, wenn ein Staat, der Botschafter mit der DDR ausgetauscht hat, sich öffentlich und verbindlich zum Selbstbestimmungsrecht für alle Deutschen bekennen würde. Diese Vorschläge, so MüllerRoschach, sollten die politische Bewegungsfreiheit der Bundesregierung auch nach einem Zusammenbruch der Politik der Hallstein-Doktrin sichern, keinesfalls bedeuteten sie einen Verzicht auf die „exemplarischen abschreckenden Sanktionen im nichtkommunistischen Bereich“. in Washington

Carstens informiert über ein Gespräch des Staatssekretärs Lahr mit dem Leiter der Israel-Mission am 4. Februar 1965. Shinnar sei mitgeteilt worden, daß nach dem Bekanntwerden der Waffenlieferungen an Israel deren Fortsetzung nicht möglich sei. Intern schlage Lahr nun ersatzweise eine Geldzahlung an Israel vor. Der amerikanische Botschafter McGhee sei davon bereits in Kenntnis gesetzt worden und habe zugesagt, seine Regierung zu unterrichten, damit die Position der Bundesrepublik gegenüber Israel unterstützt werde. Carstens weist Botschafter Knappstein an, in diesem Sinne tätig zu werden. Auswärtige Amt

Knappstein berichtet, daß er dem amerikanischen Außenministerium die Entscheidung der Bundesrepublik in der Frage der Waffenlieferungen an Israel übermittelt habe. Er informiert zudem über die Proteste dreier großer jüdischer Verbände in den USA gegen den geplanten Lieferstopp. Er habe seine Gesprächspartner darauf hingewiesen, daß für die Bundesrepublik "das Alleinvertretungsrecht auf dem Spiele stehe", dem alle anderen 
Überlegungen untergeordnet werden müßten. Knappstein erwartet weitere Interventionen, zeigt sich aber zuversichtlich, diesen wirkungsvoll entgegentreten zu können.

Allardt gibt Informationen über ein Gespräch des spanischen Vermittlers in der Nahost-Krise, Marques de Nerva, mit dem ägyptischen Ministerpräsidenten in Kairo wieder. Danach habe Sabri darauf hingewiesen, daß die VAR bislang die Position der Bundesrepublik in der Frage der Nichtanerkennung der DDR voll unterstützt, im Gegenzug aber keine entsprechenden Hilfen erhalten habe. Indem die Bundesrepublik durch MilitärhilfeAbkommen „de facto-Beziehungen“ zu Israel wie ,zwischen Alliierten" unterhalten habe, sei mit "der arabischen Welt ein doppeltes Spiel getrieben" worden. De Nerva habe daraufhin vorgeschlagen, den Besuch des Staatsratsvorsitzenden der DDR in Kairo zu verschieben, damit die Bundesrepublik ihr Verhältnis zu Israel überprüfen könne. Sabri habe ein Einlenken für den Fall angedeutet, daß die Bundesregierung unverzüglich und unmißverständlich eine andere Haltung gegenüber Israel einnehme. Dann sei die VAR bereit, die DDR nicht anzuerkennen und den Besuch von Ulbricht als eine „reine Courtoisie-Geste“ zu behandeln. amerikanischen Botschafter McGhee

Erhard korrigiert die seiner Meinung nach falsche Auslegung der Äußerungen des französischen Staatspräsidenten am 4. Februar 1965 vor der Presse. De Gaulle habe keineswegs die Wiedervereinigung Deutschlands als ausschließlich europäische Angelegenheit bezeichnet, sondern sich dafür ausgesprochen, die Viermächte-Verantwortung wieder deutlicher hervortreten zu lassen. Mit Blick auf die amerikanischen Bemühungen um eine Intensivierung des Handels mit osteuropäischen Staaten versichert McGhee, daß die DDR nicht von dieser Politik profitieren werde. Hinsichtlich der internationalen Währungssituation und der amerikanischen Zahlungsbilanzprobleme wendet sich Erhard gegen die Vorschläge des französischen Staatspräsidenten für Kontrollmaßnahmen und eine Rückkehr zum Goldstandard. Kritische Stimmen gebe es zwar auch zum Eindringen von amerikanischem Kapital auf den deutschen Markt; jedoch könne dieses Problem nur durch eine Steigerung der europäischen Wettbewerbsfähigkeit gelöst werden. Der Bundeskanzler äußert die Befürchtung, daß Präsident Johnson durch die Äußerungen von de Gaulle ein falsches Bild von den Europäern bekommen könne. Er betont, „Europa wolle sich nicht einigen, um isoliert dazustehen, sondern vielmehr, um ein stärkerer Bündnispartner in der westlichen Allianz zu sein“. 

an Staatssekretär Carstens

Müller berichtet von der Sondersitzung des obersten Führungsgremiums der Arabischen Sozialistischen Union unter Vorsitz des Präsidenten Nasser. Nach ersten Presseberichten habe das Gremium den Abbruch der diplomatischen Beziehungen mit der Bundesrepublik für den Fall beschlossen, daß die Waffenlieferungen an Israel fortgesetzt würden. Mit dieser „letzten Warnung" wolle die VAR offensichtlich die Bundesrepublik für die gespannten Beziehungen verantwortlich machen und den geplanten Besuch des Staatsratsvorsitzenden der DDR, Ulbricht, in Kairo „zu einer Bagatelle herunterspielen“. AbschlieBend nimmt Müller zu der beabsichtigten Entsendung von Sonderbotschaftern der Bundesrepublik in die arabischen Hauptstädte Stellung und warnt vor einer „sehr heftigen“ Reaktion von Nasser. Dieser werde nämlich vermuten, daß die Bundesrepublik „die Araber auf Kosten der gesamtarabischen Sache gegeneinander ausspielen" wolle.

Klaiber berichtet von einem Gespräch des Vorsitzenden der CDU/CSU-Fraktion mit dem französischen Staatspräsidenten. Barzel dankte für die Äußerungen von de Gaulle vor der Presse zur Deutschland-Frage und erläuterte, da $\beta$ auch in der Bundesrepublik davon ausgegangen werde, daß die Wiedervereinigung erst nach „einer Auflockerung des Ostblocks im europäischen Rahmen" verwirklicht werden könne. De Gaulle erklärte sich bereit, eine Deutschland-Initiative in Moskau zu unterstützen, obwohl mit Fortschritten in Richtung auf eine Wiedervereinigung nicht gerechnet werden könne. Solange Europa von den USA "völlig abhängig" sei, werde der Weg zur Wiedervereinigung im europäischen Rahmen „blockiert" bleiben. Zur Sicherheitsfrage führte er aus, daß Frankreich kein Mißtrauen mehr gegen die Bundesrepublik hege, die die ihrem wirtschaftlichen und militärischen Potential entsprechende "Großmachtstellung“ einnehmen könne. Weder der Westen noch der Osten würden es jedoch zulassen, daß sich die Bundesrepublik zu einer Atommacht entwickele; ein solcher "Ehrgeiz" würde daher die Wiedervereinigung gefährden.

Böker gibt den Inhalt zweier Gespräche mit dem tunesischen Botschafter wieder. Ayed erklärte, er sei wegen der gespannten Beziehungen zwischen der Bundesrepublik und der VAR kurzfristig zu Konsultationen nach Tunis zurückberufen worden. Präsident Bourguiba, der sich noch vor dem Staatsratsvorsitzenden der DDR, Ulbricht, in Kairo aufhalten werde, wolle mäßigend auf Präsident Nasser einwirken. Voraussetzung seien 
allerdings Zusicherungen der Bundesregierung hinsichtlich der Einstellung der Waffenlieferungen an Israel und ihrer entwicklungspolitischen Planungen für den arabischen Raum außerhalb der VAR. Böker deutete an, daß die Bundesregierung bei der Entwicklungshilfe künftig stärker die „zuverlässigen Freunde“, wie etwa Tunesien, bedenken wolle als die „unsicheren Kandidaten à la Nasser". Gleichzeitig warnte er vor den Folgen, wenn die Bundesrepublik auf Grund einer „Kurzschlußreaktion“ der arabischen Staaten aus dem Nahen Osten „herausmanövriert" würde. an Bundesminister Schröder

Der Botschafter gibt ein Gespräch mit dem amerikanischen Präsidenten wieder. Knappstein wies darauf hin, daß die währungspolitischen Äußerungen des französischen Staatspräsidenten auf der Pressekonferenz vom 4. Februar 1965 nicht mit der Bundesregierung abgesprochen waren. Gleichzeitig trug er Bedenken wegen des starken Kapitalexports aus den USA vor. Sodann dankte er für die mehrfach öffentlich geäußerte Solidarität in der Deutschland-Frage. Johnson äußerte sich skeptisch über die von de Gaulle geforderte Europäisierung der DeutschlandFrage. Er bekräftigte die Bereitschaft, jeden Vorschlag zur Wiedervereinigung zu prüfen und jeder Konsultation unter den vier westlichen Regierungen zuzustimmen. Auf eine mögliche amerikanische Distanzierung von dem Projekt einer integrierten NATO-Atomstreitmacht angesprochen, verwies Johnson auf sein eindeutiges Plädoyer für eine MLF/ANF gegenüber Premierminister Wilson. Der amerikanische Präsident vertrat jedoch die Auffassung, daß die Initiative von den europäischen Staaten ausgehen müsse.

Carstens notiert über ein Gespräch mit dem Leiter der IsraelMission, daß die israelische Regierung eine Modifizierung der Absprachen über Waffenlieferungen ablehne und allenfalls zu einer beschleunigten Abwicklung der Panzerlieferungen bereit sei. Shinnar habe auf die wiederholten Kriegsdrohungen des Staatspräsidenten Nasser hingewiesen und versichert, daß Israel selbst seine Nachbarn niemals angreifen werde. Allerdings könne es nicht hinnehmen, daß kurz vor seiner Grenze das Jordanwasser abgegraben werde. Der Botschafter schloß mit der Bitte, eine Entscheidung über die Waffenlieferungen bis zu einem Gespräch des Bundeskanzlers Erhard mit Ministerpräsident Eshkol offenzulassen. Carstens zeigte sich enttäuscht und wies auf die Probleme für die Deutschlandpolitik der Bundesregierung hin, die sich aus dem Bekanntwerden der Waffenlieferungen ergäben. An eine beschleunigte Abwicklung sei 
nicht zu denken, eher an eine Unterbrechung. Zudem werde von Bundesregierung und Bundestag gefordert, den Grundsatz, keine Waffen in Spannungsgebiete zu liefern, zukünftig strikt zu befolgen. Auf die Andeutung von Shinnar, einen Botschafteraustausch anzustreben, ging Carstens nicht ein.

Krapf betont, daß die restriktive Kreditpolitik gegenüber der UdSSR nur gegen politische Gegenleistungen aufgegeben werden solle. Für eine Ausschöpfung des in der Berner Union vorgesehenen Spielraums könne etwa ein Entgegenkommen hinsichtlich der Berlin-Klausel, der Repatriierung von Volksdeutschen oder der Freilassung der Studenten Naumann und Sonntag erwartet werden. Kredite mit einer Laufzeit von mehr als fünf Jahren sollten jedoch nur bei „fühlbaren“ Konzessionen, etwa der Gewährung größerer Freiheiten für die Bevölkerung in der DDR, vergeben werden.

Knoke informiert über die vom Abteilungsleiter im französischen Außenministerium, Puaux, geäußerte Bitte um Überlassung eines Durchdrucks des deutschen Antwortmemorandums auf den britischen ANF-Vorschlag vom 11. Dezember 1964. Puaux begründete das Ersuchen mit widersprüchlichen Presseberichten über die Antwort der Bundesregierung und verwies auf die im deutsch-französischen Vertrag vom 22. Januar 1963 geforderte Konsultationsverpflichtung.

Der Bundeskanzler weist darauf hin, daß der Vorschlag des tansanischen Präsidenten, ein Generalkonsulat und einen Handelsbevollmächtigten der DDR in Tansania zuzulassen, den Interessen des deutschen Volkes zuwiderlaufe. Es komme nicht nur darauf an, eine diplomatische Anerkennung der DDR zu vermeiden, sondern es müsse vor allem jegliche Aufwertung "des in der SBZ eingesetzten Regimes" verhindert werden. Daher könne sich die Bundesregierung auch nicht mit dem „Kairoer Modell“ - der Tolerierung eines DDR-Generalkonsulats ohne Exequatur - einverstanden erklären. Erhard macht darauf aufmerksam, daß ein solches Vorgehen das freundschaftliche Verhältnis zwischen der Bundesrepublik und Tansania „schwer belasten" würde. 

amerikanischen Botschafter McGhee

Auf die Frage von McGhee, ob die Bundesregierung nicht wenigstens die bestehenden Abmachungen mit Israel über die Lieferung von Waffen erfüllen könne, erwidert Schröder, eine Durchführung der Vereinbarung sei nach deren Bekanntwerden unmöglich geworden. Er hoffe jedoch auf eine "vernünftige“ Regelung über eine Ablösung der Waffenlieferungen. Der amerikanische Botschafter kritisiert die Ausführungen des ehemaligen Bundeskanzlers Adenauer gegenüber der Tageszeitung "The New York Times" zur amerikanischen Politik in Europa und äußert die Erwartung, die Bundesregierung werde sich bemühen, die „Auswirkung dieses Interviews zu beheben“. Schröder zeigt sich skeptisch bezüglich rascher Fortschritte bei den Verhandlungen über eine europäische politische Union. Hinsichtlich einer Initiative zur Deutschland-Frage erwähnt er die Notwendigkeit bilateraler Vorgespräche und die Möglichkeit einer Behandlung in der Washingtoner Botschaftergruppe. Mit Blick auf die Pressekonferenz des Staatspräsidenten de Gaulle vom 4. Februar 1965 unterstreicht McGhee, daß im amerikanisch-französischen Verhältnis - anders als zwischen der USA und der Bundesrepublik - große Differenzen bestünden. Bundesministers Westrick mit dem Leiter der Israel-Mission, Shinnar

Westrick erklärt, daß die ausstehenden Waffenlieferungen an Israel nicht durchgeführt werden könnten, nachdem mit dem Ende der Geheimhaltung auch die "Geschäftsgrundlage" entfallen sei. Es könnten nicht die Lebensinteressen der Bundesrepublik riskiert werden, nur „um eine geschenkweise Zusage abgewrackter Waffen zu erfüllen". Die bestehenden Absprachen sollten jedoch "in honoriger Weise" abgelöst werden. Shinnar, der am folgenden Tag zu Gesprächen nach Israel zurückkehren soll, bittet dagegen darum, die Lieferungen so schnell wie möglich durchzuführen und eine öffentliche Verlautbarung zum Lieferstopp noch zurückzuhalten. Insbesondere dürfe eine solche Entscheidung in keinem erkennbaren Zusammenhang mit der Politik des Präsidenten Nasser stehen. Westrick lehnt dies ab, „da dies ja der Sinn des Lieferungsstopps sei“. Bundeskanzler Erhard bekräftigt den Willen zu einer "einvernehmlichen Lösung“ mit Israel, schließt aber ebenfalls eine Durchführung der ausstehenden Waffenlieferungen aus. Allerdings wolle er hinsichtlich der Verlängerung der Verjährungsfrist für Gewaltverbrechen in der Zeit des Nationalsozialismus „etwas tun“, das zeige, daß ihm an einem guten Verhältnis zu Israel gelegen sei. 
Walther informiert über ein Gespräch mit dem türkischen Ministerpräsidenten über die Zypern-Frage. Erkin berichtete, daß Gespräche der drei am Konflikt beteiligten Parteien an der ablehnenden Haltung der Vertreter der zyprischen Bevölkerung gescheitert seien. Da eine Abstimmung in der UNO wohl nicht mehr zustande kommen werde, die Situation für eine Durchsetzung des türkischen Föderalkonzepts jedoch günstig sei, habe er um eine entsprechende gemeinsame sowjetisch-amerikanische Initiative gegenüber der zyprischen Regierung gebeten. Dies hätten jedoch die USA abgelehnt. Walther zieht den Schluß, daß die Türkei weiterhin an westlicher Unterstützung zur Durchsetzung ihrer Pläne interessiert sei, sich aber voraussichtlich stärker auf die UdSSR stützen werde, wenn sich der Westen nicht zu einer „eindeutigen“ Haltung entschließen könne. Er regt an, entsprechend auf die amerikanische und die britische Regierung einzuwirken.

Amt

Schwörbel berichtet von einem Gespräch mit dem Generaldirektor im ceylonesischen Außenministerium, der mitteilte, daß demnächst eine Delegation aus der DDR in Colombo eintreffen werde, um das seit einem Jahr angebotene Kredithilfeabkommen über 80 Millionen Rupien abzuschließen. Peiris wies darauf hin, daß sich das ceylonesische Außenministerium bislang erfolgreich bemüht habe, alles zu vermeiden, was Schlüsse auf eine "weitergehende Aufwertung" der DDR zuließe. Nun werde sich aber der Abschluß eines formellen Abkommens nicht mehr umgehen lassen. Die Lage Ceylons sei seit der Einstellung der Wirtschaftshilfe aus den USA und der Bundesrepublik „so verzweifelt", daß jedes Hilfsangebot angenommen werden müßte. Somit habe das Verhalten der Bundesrepublik „zwangsweise ${ }^{\text {" zu }}$ einer weiteren Aufwertung der DDR beigetragen. sches Außenministerium

De Nerva schildert die vom 4. bis 10. Februar 1965 in Kairo geführten Vermittlungsgespräche. Der ägyptische Ministerpräsident habe sich von der Warnung, die Bundesrepublik werde bei einem offiziellen Empfang des Staatsratsvorsitzenden der DDR die diplomatischen Beziehungen abbrechen, zunächst wenig beeindruckt gezeigt. Sabri habe betont, nur bei einer "sofortigen Änderung in der Haltung und Handlungsweise Bonns" könne auf eine Anerkennung der DDR verzichtet werden. Erst nachdem eine Instruktion der Bundesregierung die Zusicherung ermöglicht habe, daß ab sofort keine Waffen mehr 
an Israel geliefert würden, habe Sabri zugesagt, daß der Aufenthalt von Ulbricht nur als Höflichkeitsbesuch anzusehen und ein Gegenbesuch des ägyptischen Präsidenten ausgeschlossen sei. Nasser selbst habe Sympathie für das deutsche Volk bekundet, die Vermittlung durch Spanien begrüßt und erklärt, „die Situation wäre jetzt vollkommen normal". Carstens dankt de Nerva für seine Bemühungen, weist jedoch darauf hin, daß die Reise von Ulbricht unverändert bevorstehe. Sie werde in der Bundesrepublik „einen tiefen Schock“ bewirken. an Staatssekretär Carstens

Der Botschafter berichtet von der beim Unterstaatssekretär im amerikanischen Außenministerium vorgetragenen Bitte, die Bundesrepublik bei den Bemühungen um eine Ablösung ihrer Waffenlieferungen an Israel durch Geldzahlungen zu unterstützen. Harriman erwiderte, daß die USA selbst vor schwierigen Verhandlungen über israelische Rüstungsanforderungen stünden und aus politischen Gründen vermeiden müßten, als Lieferant aufzutreten. Gerade im Fall der zugesagten Panzer sei es deshalb „sehr unwillkommen“, wenn die Bundesrepublik ihre Verpflichtungen nicht einhalte. Wie Harriman bestätigte, sei Israel seinerzeit auch von amerikanischer Seite darauf hingewiesen worden, daß die Lieferungen im Falle ihres Publikwerdens eingestellt werden würden. Dabei sei jedoch an eine Bekanntgabe von israelischer Seite gedacht worden, während nun allem Anschein nach die Indiskretion von „irgendeiner Seite in Bonn" ausgegangen sei. ägyptischen Botschafter Mansour

Schröder legt nachdrücklich die Besorgnis über den bevorstehenden Aufenthalt des Staatsratsvorsitzenden der DDR in Kairo dar. Wegen der Signalwirkung für andere blockfreie Staaten komme dem Besuch von Ulbricht mehr als nur bilaterale Bedeutung zu. Es werde damit „die Axt an die Wurzel der deutschen Politik angelegt“. Mansour rechtfertigt die ägyptische Haltung als Reaktion auf die Waffenlieferungen an Israel, die für die VAR eine „Frage auf Leben und Tod" bedeuteten. Wenn auch von deutscher Seite eine "Gewissensschuld" gegenüber den Juden empfunden werde, so rechtfertige dies doch nicht, daß hierfür „die Araber den Preis“ zahlen müßten. Der Botschafter zieht eine Parallele zwischen der Nichtanerkennung der DDR als Staat und der Tatsache, daß es nach ägyptischer Auffassung „kein Israel“ gebe. Schröder verwahrt sich gegen diese Gleichsetzung, der jede historische Grundlage fehle. Zu den Waffenlie- 
ferungen erläutert er, daß die noch ausstehenden Verbindlichkeiten auf andere Weise abgegolten und neue Vereinbarungen nicht geschlossen würden.

Krapf äußert sich zustimmend zu dem britischen Vorschlag, die künftigen Verhandlungen über eine NATO-Atomstreitmacht multilateral auf Abteilungsleiter-Ebene zu führen und dieses Verfahren der amerikanischen Regierung noch vor dem Besuch des Premierministers Wilson am 7./8. März 1965 in Bonn vorzuschlagen. Die Gründe für diese Initiative sieht Krapf im britischen Interesse an einer Nichtverbreitung von Kernwaffen, die im Rahmen des von britischer Seite vorgeschlagenen ANF-Projekts geregelt werden soll, in der Befürchtung, der amerikanische Vorschlag einer MLF könne wieder in den Vordergrund treten, im Wunsch nach einer verstärkten Zusammenarbeit mit den USA in Südost-Asien sowie in der britischen Innenpolitik. Er gibt seinen Eindruck wieder, Großbritannien sei zu Konzessionen in der Frage des Aufbaus einer NATO-Atomstreitmacht bereit, sofern eine Vereinbarung über die Nichtverbreitung von Kernwaffen zustande komme. Lindenberg

Meyer-Lindenberg weist darauf hin, daß die widersprüchlichen Äußerungen, die zur Einstellung der Waffenlieferungen an Israel durch den spanischen Vermittler in der Nahost-Krise, Marques de Nerva, einerseits und Bundeskanzler Erhard andererseits abgegeben worden seien, in Kairo als Versuch bewußter Irreführung angesehen werden könnten. Bisherige Verhandlungen über eine Umwandlung der Waffenlieferungen seien jedoch in Israel wie in den USA auf Ablehnung gestoßen; gerade die amerikanische Regierung wolle die Bundesrepublik weiter „vorschieben“, um nicht selbst als Waffenlieferant auftreten zu müssen. Zur Wahrung der Interessen der Bundesrepublik empfiehlt Meyer-Lindenberg eine sofortige Beendigung der Waffenlieferungen an Israel. Mit einer Abgeltung der noch ausstehenden Leistungen durch Geldzahlungen oder durch die Lieferung von nichtmilitärischem Material könne die Bundesrepublik einen Beweis ihres guten Willens erbringen, zu dem sie rechtlich nicht verpflichtet sei. Gegenüber der VAR rät Meyer-Lindenberg in erster Linie zu wirtschaftlichen Sanktionen. Damit werde sowohl das notwendige Exempel statuiert als auch verhindert, daß Präsident Nasser durch eine „Überspitzung der Maßnahmen" dazu gebracht werde, in einer „Kurzschlußreaktion" doch noch die DDR anzuerkennen. 

Auswärtige Amt

Böker teilt mit, er habe dem jordanischen König das Schreiben des Bundespräsidenten Lübke übergeben und darauf hingewiesen, daß die Bundesregierung auf den Aufenthalt des Staatsratsvorsitzenden der DDR in Kairo mit der Einstellung der Wirtschaftshilfe an die VAR reagieren werde. Hussein sicherte zu, während seines bevorstehenden Besuchs bei Präsident Nasser vermittelnd tätig werden zu wollen, verhehlte aber nicht seine Enttäuschung über die Waffenlieferungen an Israel. Gerade Jordanien fühle sich „betrogen“, weil die Bundesregierung eine erbetene Lieferung alter amerikanischer Panzer unter Hinweis auf das Spannungsgebiet Naher Osten abgelehnt habe. Der König warnte vor einer Aufnahme diplomatischer Beziehungen zwischen der Bundesrepublik und Israel; dies würde die arabischen Staaten zu Gegenmaßnahmen zwingen. In einem weiteren Gespräch mit Außenminister Nuseibeh wies Böker darauf hin, daß eine protokollarische Herabstufung des Besuchs von Ulbricht nicht genüge, um Gegenmaßnahmen der Bundesregierung zu verhindern; allenfalls „ein offenes Bekenntnis von Nasser zum deutschen Selbstbestimmungsrecht in Gegenwart Ulbrichts" könne noch von politischem Wert sein. Böker stellt abschließend fest, daß eine für Jordanien befriedigende Regelung der noch ausstehenden Waffenlieferungen an Israel die Voraussetzung für die Isolierung des ägyptischen Präsidenten in der „Ulbricht-Frage“ sei.

Knoke berichtet über ein Gespräch mit dem Abteilungsleiter im französischen Außenministerium, Soutou. Dieser riet davon ab, auf die Einladung des Staatsratsvorsitzenden der DDR nach Kairo mit einem Abbruch der diplomatischen Beziehungen zur VAR zu reagieren, da sich dann alle arabischen Staaten gezwungen sehen würden, ihre Botschafter aus Bonn abzuberufen. Sinnvoller wäre es, wenn die Bundesregierung während des Besuchs von Ulbricht erklärte, diplomatische Beziehungen zu Israel aufnehmen zu wollen. Falls daraufhin Präsident Nasser die Beziehungen abbräche, so würde, nach der Überzeugung von Soutou, nur eine Minderheit der arabischen Staaten seinem Beispiel folgen. Die gemäßigten arabischen Staats- und Regierungschefs, die ohnehin „höchst unglücklich" darüber seien, daß die Bundesregierung bisher das „Spiel Nassers" gespielt habe, würden dagegen den ägyptischen Präsidenten für die Aufnahme diplomatischer Beziehungen zwischen der Bundesrepublik und Israel verantwortlich machen. Eine solche Vorgehensweise würde daher die VAR politisch isolieren. Ferner sei es wahrscheinlich, daß Israel unter diesen Umständen einer Umwandlung der noch ausstehenden Waffenlieferungen zustimmen würde. 

sekretär Cattani, italienisches Außenministerium

Aus seinen Gesprächen mit dem französischen und dem belgischen Außenminister teilt Cattani mit, daß Couve de Murville und Spaak bereit seien, an den Vorbereitungen einer politischen Zusammenarbeit der sechs EWG-Staaten mitzuwirken. Couve de Murville lehne allerdings weiterhin „übernationale Konstruktionen" ab und damit auch den in der Europa-Initiative der Bundesregierung vom 4 . November 1964 vorgesehenen beratenden Ausschuß. Er habe sich jedoch mit einem „Dialog zwischen den Regierungen und dem Europäischen Parlament" einverstanden erklärt. Spaak habe als ersten Schritt ein formloses Treffen der Außenminister in Brüssel vorgeschlagen, auf dem Weisungen für die Vorbereitung einer offiziellen Konferenz erarbeitet werden sollten. Die Notwendigkeit einer Zusammenkunft der Verteidigungsminister, an der Frankreich besonders interessiert sei, habe der belgische Außenminister dagegen in Frage gestellt. Carstens äußert sich positiv zum französischen Einverständnis, durch die Einbeziehung des Europäischen Parlaments ein „Element kommunautären Charakters“ zu akzeptieren. Eine britische Teilnahme an den Gesprächen sei zur Zeit kaum möglich, jedoch solle über die WEU eine „laufende Unterrichtung" sichergestellt werden. sekretär Cattani, italienisches Außenministerium

Carstens und Cattani stellen eine weitgehende Übereinstimmung der deutschen und der italienischen Haltung zum britischen Vorschlag einer integrierten NATO-Atomstreitmacht fest, deren Anbindung an die NATO allerdings noch diskutiert werden müsse. Carstens weist darauf hin, daß die britische Regierung mit der $A N F$ versuche, mehrere schwer zu vereinbarende Dinge, wie Festigung der Allianz und Abrüstung, gleichzeitig zu verwirklichen. Die Mitwirkung der Bundesrepublik werde die Chancen für eine Wiedervereinigung nicht beeinträchtigen; vielmehr sei denkbar, die Teilnahme an der Streitmacht in der Zukunft als deutschlandpolitisches Verhandlungsobjekt gegenüber der UdSSR einzusetzen. Weiterhin erläutert Carstens, Probleme bereiteten zur Zeit eine mögliche Einladung des Staatsratsvorsitzenden der DDR nach Indonesien, die voraussichtliche Errichtung eines Generalkonsulats der DDR in Daressalam sowie der wohl nicht mehr zu verhindernde Besuch von Ulbricht in Kairo. Die Bundesregierung wolle im Sinne einer "Eskalation" zunächst die Wirtschaftshilfe für die VAR einstellen, erwäge aber auch den Abbruch der Beziehungen im Fall einer diplomatischen Anerkennung der DDR. 
82 17.02. Botschafter Grewe, Paris (NATO), an das Auswärtige Amt

Grewe gibt Informationen über Gespräche des polnischen Außenministers mit seinem belgischen Amtskollegen Spaak in Brüssel wieder. Rapacki habe betont, Hauptziel des Gromykound Rapacki-Planes sei die Verhinderung der Weitergabe von Atomwaffen in Europa, besonders an die Bundesrepublik und an die DDR. Die angestrebte europäische Konferenz über militärische, politische und wirtschaftliche Fragen sollte durch einen Meinungsaustausch interessierter Staaten „beider Blöcke" vorbereitet werden. Das europäische Sicherheitsproblem müsse bereits vor einer Wiedervereinigung Deutschlands oder allenfalls parallel dazu gelöst werden; die umgekehrte Reihenfolge sei nicht akzeptabel.

Knoke berichtet von einem Gespräch mit dem Abteilungsleiter im französischen Außenministerium, Soutou. Dieser beurteilte die vom Auswärtigen Amt beabsichtigte Reaktion auf die Zulassung eines DDR-Generalkonsulats in Tansania - die Einstellung der Ausrüstungs-, Kapital- und weitgehend auch der technischen Hilfe - als ,zu scharf“. Inwieweit eine weitere Aufwertung der DDR in Afrika und Asien verhindert werden könne, hänge vor allem von der Vorgehensweise der Bundesregierung gegenüber der VAR ab. Tansania befinde sich in einer „sehr prekären“ Lage, in der es leicht „restlos östliches Einflußgebiet“ werden könne. Zudem werde der Eindruck entstehen, daß die Bundesregierung Tansania für ein Verhalten bestrafe, das sie im Falle der VAR schon seit Jahren toleriere. Dies könne Folgen für die gesamte westliche Position in Afrika haben.

Vor dem Hintergrund der Einladung des Staatsratsvorsitzenden der DDR, Ulbricht, nach Kairo bittet Carstens die Botschafter in Washington, London und Paris, sich bei der jeweiligen Regierung darum zu bemühen, daß die Position der Bundesrepublik unterstützt und israelischen Protesten bzw. Bestrebungen zum Boykott deutscher Waren entgegengetreten wird. Carstens erläutert die Politik gegenüber Israel seit den fünfziger Jahren und verweist auf die „sehr großen Aufwendungen“ im Bereich der Wiedergutmachung. Die durch militärische Zusammenarbeit mit Israel eingetretene Verschlechterung der Beziehungen zu den arabischen Staaten habe die Bundesregierung nun veranlaßt, ,ihre Politik der Nichtlieferung von Waffen in Spannungsgebiete wieder strikt durchzuführen“. Der Staatssekretär informiert über den Gesamtumfang der Waffenlieferungen von etwa 280 Millionen DM, über den „völlig abwegige Nachrichten" verbreitet worden seien. Für die noch ausstehen- 
den Leistungen in Höhe von 50 Millionen DM sei eine Geldzahlung angeboten, allerdings nicht akzeptiert worden. Weitere Probleme ergäben sich aus der möglichen Eröffnung eines Generalkonsulats der DDR in Tansania bzw. eines indonesischen Generalkonsulats in Ost-Berlin. In beiden Fällen sei die Einstellung der Entwicklungshilfe angedroht worden. Auswärtige Amt

Der Botschafter berichtet, daß er dem amerikanischen Außenminister die Bitte vorgetragen habe, die Position der Bundesregierung gegenüber Israel zu unterstützen. Da mittlerweile öffentlich bekannt sei, daß die Waffenlieferungen an Israel weitgehend auf amerikanische Initiative zurückgingen, bestehe im Falle ausbleibender Hilfe bei der Umwandlung der restlichen Lieferungen die Gefahr einer "schweren Enttäuschung" im deutsch-amerikanischen Verhältnis. Knappstein fragte, ob die USA bei der israelischen Regierung nicht wenigstens eine ruhigere Betrachtung der Probleme erreichen und in ähnlichem Sinne auch auf die tansanische und die indonesische Regierung einwirken könnten. Rusk kündigte an, daß die USA demnächst einen Großteil des „Feuers“ auf sich ziehen würden, und sagte weitere Hilfe zu. Allerdings habe die amerikanische Regierung fast keinen Einfluß mehr auf die VAR, Tansania und Indonesien. Knappstein empfiehlt, die mit der Nahost-Krise zusammenhängenden Probleme nicht in der Washingtoner Botschaftergruppe, sondern bilateral mit der amerikanischen Regierung zu behandeln. Lindenberg

Meyer-Lindenberg greift die von italienischer und belgischer Seite vorgebrachte Anregung zu einem formlosen Treffen der EWG-Außenminister über Fragen der europäischen politischen Zusammenarbeit auf, um eine Arbeitsgruppe aus Beamten zur Vorbereitung einer Außenministerkonferenz und einer nachfolgenden Zusammenkunft der Staats- und Regierungschefs einzusetzen. Für eine solche Zusammenkunft biete sich die EWGMinisterratstagung am 2./3. März 1965 in Brüssel an. MeyerLindenberg erwartet keine Bedenken gegen eine Aufnahme der Gespräche, obwohl in keinem der „fünf Partnerländer zur Zeit eine große Begeisterung spürbar" sei. Vom inhaltlichen Standpunkt her komme die Europa-Initiative der Bundesregierung vom 4. November 1964 einem Kompromiß zwischen den divergierenden Auffassungen der EWG-Staaten am nächsten. Das Zustandekommen von offiziellen Verhandlungen werde allerdings „wesentlich von der deutschen Regierung, ihrem Willen und ihrer Überzeugungskraft abhängen“. 

von Mirbach, z. Z. Prag

Carstens weist darauf hin, daß ein langfristiges Warenabkommen mit der Tschechoslowakei - auf das vor allem die tschechoslowakische Regierung Wert lege - nicht ohne eine Übereinkunft über den Austausch von Handelsvertretungen abgeschlossen werden dürfe. Eine solche Verknüpfung könne entweder durch ein gemeinsames Mantelprotokoll oder aber dadurch erreicht werden, da $B$ als Aufgabe der Handelsvertretung die Durchführung des Abkommens über den Waren- und Zahlungsverkehr definiert werde. Auf diese Weise könne auch die Einbeziehung von Berlin (West) in den Geltungsbereich der Vereinbarung über die Handelsvertretung gewährleistet werden. Carstens schlägt vor, anzudeuten, daß nur bei Zustimmung zu einer Handelsvertretung der Bundesrepublik in Prag eine weitere Duldung des tschechoslowakischen Handelsbüros in Frankfurt/ Main erwartet werden könne.

Carstens legt dar, da $\beta$ auf einer Ressortbesprechung am 20. Februar 1965 im Bundeskanzleramt der Beschluß gefaßt worden sei, festzustellen, ob die 60 aus der Bundesrepublik nach Italien verladenen Panzer bereits in Israel angekommen seien und ob eventuell die USA bereit wären, die weiteren Lieferungen zu übernehmen. Während der Chef des Presse- und Informationsamtes, von Hase, auf die „Kampagne des Weltjudentums" hinwies, nach der Israel ein "verbürgtes Recht auf Waffenhilfe" habe, verlangte Bundesminister Scheel die sofortige Einstellung, da er andernfalls nicht mehr bereit sei, "den ganzen Komplex öffentlich zu decken“: „,keine Schraube dürfe mehr versandt werden “. Weiterhin wurde beschlossen, daß der CDUAbgeordnete Blumenfeld in Rom über einen Mittelsmann, der enge Beziehungen zu Ministerpräsident Eshkol unterhalte, die Möglichkeiten zu einer einvernehmlichen Regelung mit Israel ausloten solle. Zudem solle die letzte Annuität nach dem deutsch-israelischen Abkommen von 1952 nicht, wie vorgesehen, am 22. Februar, sondern erst am 9. März 1965 unterzeichnet werden. Hinsichtlich möglicher Sanktionen, mit denen auf den Besuch des Staatsratsvorsitzenden Ulbricht in Kairo reagiert werden könne, wies Bundesminister Schröder darauf hin, daß nichts geschehen dürfe, was die "schwachen Sicherungen“, die noch gegen eine Anerkennung der DDR durch die VAR bestünden, „durchschlagen würde“. 

amerikanischen Botschafter McGhee

McGhee berichtet von den amerikanischen Bemühungen um eine Entschärfung der Nahost-Krise. Die ägyptische Regierung sei eindringlich vor einer Verschlechterung der Beziehungen zur Bundesrepublik gewarnt worden. Der Botschafter räumt ein, daß der amerikanische Verteidigungsminister McNamara am 12. Juni 1964 Bundeskanzler Erhard zugesagt habe, die Waffenlieferungen an Israel könnten im Falle ihres Bekanntwerdens eingestellt werden. Auf die Frage von Schröder nach amerikanischer Unterstützung bei der Umwandlung der noch ausstehenden Leistungen weist McGhee darauf hin, daß hier „gewisse Grenzen“ gegeben seien. Die USA wollten das „prekäre Gleichgewicht" zwischen Israel und den arabischen Staaten aufrechterhalten sehen. Dennoch bestünden Anzeichen für eine mögliche Intervention bei der israelischen Regierung. Der Bundesminister macht auf die Gefahr einer „schweren Belastung“ des Verhältnisses zu den USA aufmerksam, wenn sich der Eindruck verfestige, daß die amerikanische Regierung, die die Bundesrepublik in diese "schwierige Situation gebracht" habe, jetzt zur Hilfeleistung „nicht willens oder nicht fähig“ sei. amerikanischen Botschafter McGhee

Erhard bezeichnet die ,jüdischen Boykotts“ gegenüber deutschen Waren in den USA und die Behandlung der Nahost-Krise in der amerikanischen Presse als "miserabel“ für die deutschamerikanischen Beziehungen. Er bittet die amerikanische Regierung, sich ,sehr deutlich und positiv zur Deutschland-Politik" zu äußern. Als hilfreich werde sich wohl eine Entscheidung des Bundestages zugunsten einer Verlängerung der Verjährungsfristen für Gewaltverbrechen in der Zeit des Nationalsozialismus erweisen. Der Bundeskanzler ist überzeugt, daß im Falle eines Einvernehmens mit Israel über die Ablösung der noch ausstehenden Waffenlieferungen Präsident Nasser "wohl kaum die arabische Allianz zusammenhalten“ könne. Nach „privaten und offiziösen“ Informationen gebe es Anzeichen für eine israelische Verhandlungsbereitschaft. Der Botschafter teilt mit, Israel sei darauf aufmerksam gemacht worden, daß mit der Geheimhaltung auch die Geschäftsgrundlage für die Waffenlieferungen entfallen sei. Auf den Hinweis von Erhard, die britische Regierung werde auf den Empfängen für den Staatsratsvorsitzenden Ulbricht in Kairo nicht vertreten sein, zeigt sich McGhee überzeugt, daß der amerikanische Botschafter Battle ebenso verfahren werde. 
91 22.02. Gespräch des Bundeskanzlers Erhard mit dem französischen Botschafter Seydoux

Erhard führt die Nahost-Krise darauf zurück, daß die sowjetische Regierung von Präsident Nasser als Gegenleistung für finanzielle Hilfen die Einladung des Staatsratsvorsitzenden der DDR nach Kairo verlangt habe. Seydoux bezweifelt dies, da Ministerpräsident Chruschtschow Ulbricht „nie gemocht“ habe. Der Bundeskanzler bittet die französische Regierung, gemeinsam mit den USA und Großbritannien Israel davon zu überzeugen, eine Regelung über die Ablösung der noch ausstehenden Waffenlieferungen zu akzeptieren. Außerdem müsse gegenüber Nasser dargelegt werden, daß sich dessen Politik nicht nur gegen die Bundesrepublik, sondern gegen die deutschlandpolitischen Verpflichtungen der Drei Mächte richte. Frankreich könne darüber hinaus in den Maghreb-Staaten die Warnung aussprechen, daß im Falle einer Anerkennung der DDR die im EWG-Rahmen geleistete Entwicklungshilfe eingestellt würde. Erhard bat ferner um das Fernbleiben der französischen diplomatischen Vertreter von offiziellen Empfängen anläßlich des Besuchs von Ulbricht in Kairo.

Carstens notiert über eine Ressortbesprechung mit Bundeskanzler Erhard, daß von den 60 für Israel bestimmten Panzern bereits 40 an ihrem Bestimmungsort angekommen seien und die restlichen 20 in Italien zur Umrüstung mit amerikanischen Waffen bereitständen. Carstens schlug vor, den Standpunkt einzunehmen, daß das Panzergeschäft nicht direkt zwischen der Bundesrepublik und Israel, sondern nur auf dem Wege deutscher und israelischer Erklärungen gegenüber den USA zustandegekommen sei. In diesem Fall wäre die Äußerung des amerikanischen Verteidigungsministers McNamara vom 12. Juni 1964 über die Geheimhaltungspflicht der Transaktion Bestandteil der Absprache, und die Bundesregierung könnte die Auffassung vertreten, da $\beta$ das Geschäft aufgrund der vorgefallenen Indiskretionen beendet sei. Damit jedoch seitens des Auswärtigen Amts dieses Argument verwendet werden könne, müsse in Erfahrung gebracht werden, „was zwischen den Israelis und den Herren des Verteidigungsministeriums abgesprochen worden sei“. Carstens riet daher „dringend“, die „in Frage kommenden Beamten und Offiziere" Aufzeichnungen über ihre Gespräche mit israelischen Stellen anfertigen zu lassen. britischen Botschafter Roberts

Die Gesprächspartner erörtern Ablauf und Themen für den bevorstehenden Besuch des Premierministers Wilson in Bonn. Roberts bedauert, daß bislang erst ein Drittel des deutsch-briti- 
schen Devisenausgleichsabkommens erfüllt und insbesondere der Kauf britischer Flugzeuge durch die „Deutsche Lufthansa“ gescheitert sei. Anders als der Botschafter sieht Erhard keine Chance für eine spätere Mitwirkung Frankreichs an einer NATO-Atomstreitmacht. Selbst wenn für den französischen Staatspräsidenten ein "Prunkstuhl“ reserviert würde und alle anderen auf „Küchenhockern" säßen, würde de Gaulle „doch nein sagen". Hinsichtlich der Nahost-Krise sichert Roberts die diplomatische Unterstützung der Position der Bundesrepublik zu. Er erkundigt sich nach dem Stand der Gespräche über eine europäische politische Union und erwähnt, daß sich in Großbritannien die Stimmen für eine Annäherung an die EWG mehrten. Schließlich weist Roberts auf die britische Bereitschaft hin, mit der Bundesrepublik sowie mit Frankreich und den USA über eine neue Deutschland-Initiative zu sprechen. Voraussetzung seien jedoch substantielle Vorschläge der Bundesregierung, die dann von der Washingtoner Botschaftergruppe erörtert werden müßten. Schröder

Der Botschafter informiert über seine erste Unterredung mit dem neuen sowjetischen Ministerpräsidenten, bei der er eine offizielle Einladung zu einem Besuch in Bonn übermittelte. Kossygin zeigte sich überrascht und erklärte, daß vor einer Beantwortung interne Beratungen erforderlich seien. Er bezeichnete den Vorschlag jedoch als „freundlichen Akt“. Groepper zieht daraus den Schluß, daß Kossygin wegen der seinerzeitigen Pressespekulationen um die Einladung des ehemaligen Ministerpräsidenten Chruschtschow in die Bundesrepublik bewußt vorsichtig agiere und eine Entscheidung nicht allein verantworten wolle. Es komme ihm offensichtlich darauf an, im Gegensatz zu seinem Amtsvorgänger das Prinzip der kollektiven Führung auch nach außen hin zu betonen. Um jede negative Präjudizierung zu vermeiden, empfiehlt der Botschafter, über den Inhalt des Gesprächs nichts verlauten zu lassen. wärtige Amt

Lilienfeld berichtet über ein Gespräch mit dem Abteilungsleiter im amerikanischen Außenministerium, Tyler. Dieser lehnte eine Lockerung der Bedingungen der Berner Union für die Kreditvergabe an Ostblock-Staaten ab, bevor nicht alle Möglichkeiten ausgeschöpft seien, wieder eine „einheitliche westliche Praxis" zu erreichen. Dies werde sich jedoch voraussichtlich aufgrund der britischen Haltung als schwierig erweisen. Daher überlege die amerikanische Regierung, die Laufzeiten der Kredite von fünf auf sieben bis acht Jahre auszudehnen, obwohl sie 
sich der Gefahr bewußt sei, daß auf diese Weise die Fristen „ins Rutschen" kommen könnten. Tyler zeigte Verständnis für die Haltung der Bundesregierung, künftig bei der Kreditvergabe gegenüber der UdSSR den durch die Berner Union gegebenen Spielraum auszunutzen, um so eine größere politische Bewegungsfreiheit zu erreichen. Eine einseitige Verlängerung der Kreditfristen für andere osteuropäische Staaten sei dagegen "bedenklich und würde die amerikanische Regierung in eine schwierige Lage bringen“. Auswärtige Amt

Knappstein berichtet über ein Gespräch des Vorsitzenden der CDU/CSU-Fraktion im Bundestag, Barzel, mit dem amerikanischen Präsidenten. Johnson würdigte die Hilfeleistungen der Bundesrepublik an Israel und bedauerte die Schwierigkeiten, die aus dem Bekanntwerden der Waffenlieferungen entstanden seien. Als Zeichen seiner Unterstützung der Deutschlandpolitik der Bundesregierung führte er an, daß die amerikanischen Truppen allein auf deutschen Wunsch hin in vollem Umfang in der Bundesrepublik stationiert blieben, auch wenn er selbst der Ansicht sei, daß ihre Zahl verringert werden könnte. Hinsichtlich des MLF-Projekts empfahl Johnson Gespräche mit der britischen Regierung, betonte aber, er stünde „zur MLF genauso fest wie zur Wiedervereinigung und der Notwendigkeit, in Deutschland Truppen zu stationieren". Schließlich griff der Präsident den Vorschlag eines Erfahrungsaustauschs über das Konzept der "großen Gesellschaft" auf und regte persönliche Kontakte von Fachleuten aus den Parlamenten beider Staaten an.

Bach informiert über eine Unterredung mit dem iranischen Ministerpräsidenten. Hoveida sicherte ihm im Auftrag des Schah Reza Pahlevi die Unterstützung der Position der Bundesrepublik in der Nahost-Krise zu und betonte, eine Anerkennung der DDR käme für den Iran nicht in Frage. Sodann kam er auf die Wirtschaftshilfe zu sprechen und fragte an, ob nicht über eine Verwendung der ursprünglich für ein Stahlwerk vorgesehenen 350 Millionen DM Hermes-Plafonds für andere „erfolgversprechende Projekte“ verhandelt werden könne. Da außerdem der iranischen Regierung die Kreditbedingungen zu hart erschienen, bat Hoveida um eine Senkung des Zinssatzes. Bach unterstützt die vorgetragenen Wünsche, da sich der Iran bislang stets als „aufrichtiger Freund“ erwiesen habe. 

Auswärtige Amt

Schroeder teilt mit, daß in Tansania der plötzliche Abzug einer Militärberater-Gruppe aus der Bundesrepublik als Folge des tansanischen Beschlusses, ein Generalkonsulat der DDR zuzulassen, mit Bestürzung aufgenommen worden sei. Es werde gemutmaßt, daß die Bundesrepublik ihre „Wut und Ohnmacht gegenüber Nasser" an Tansania auslasse. Präsident Nyerere werde nun vermutlich einem Vorschlag des Präsidenten Nasser zustimmen, eine Konferenz afrikanischer Staatschefs zur Behandlung der Deutschland-Frage einzuberufen. Der Botschafter hält die Entscheidung der Bundesregierung für grundsätzlich richtig, weist jedoch darauf hin, daß die Form der Durchführung, insbesondere die dabei an den Tag gelegte Eile, dem „Image bei den Afrikanern nicht zuträglich“ gewesen sei. Die Beendigung der Militärhilfe werde allerdings keine Auswirkungen auf die Haltung der tansanischen Regierung gegenüber der DDR haben. Um darüber hinaus die westliche Orientierung Tansanias nicht ganz zu gefährden, rät Schroeder dazu, hinsichtlich der weiteren Gewährung von Entwicklungshilfe „großzügig“ zu sein. Budapest, an das Auswärtige Amt

Brückner teilt mit, daß die ungarische Regierung „konzentriert und systematisch“ jegliche Tätigkeit der Handelsvertretung der Bundesrepublik in Budapest behindere, die über die Wahrnehmung rein wirtschaftlicher Interessen hinausgehe. Offenbar sollten die während des letzten Halbjahres geknüpften Verbindungen weitgehend unterbunden, zumindest aber nicht erweitert werden. Der Leiter der Handelsvertretung führt dies auf den Einfluß der UdSSR und der DDR zurück. Da die ungarische Regierung dennoch Interesse an konsularischen und kulturellen Kontakten zur Bundesrepublik zeige, vermutet Brückner, daß die Bundesregierung dazu veranlaßt werden solle, von sich aus Verhandlungen über eine Erweiterung der bilateralen Beziehungen vorzuschlagen und somit zur „Aushöhlung“ der Hallstein-Doktrin beizutragen. amerikanischen Botschafter McGhee

Über die Sondierungen des amerikanischen Sonderbotschafters Harriman in Tel Aviv teilt McGhee mit, daß die israelische Regierung nicht bereit sei, für die noch ausstehenden Waffenlieferungen der Bundesrepublik Finanzleistungen zu akzeptieren. Auf die Frage, ob mit Israel nicht vereinbart worden sei, die Lieferungen im Falle ihres Bekanntwerdens zu beenden, erklärt Schröder, keine Kenntnis über die Details der Abmachungen zu 
besitzen, die auf Wunsch der USA durch das Bundesministerium der Verteidigung getroffen worden seien. Die Gesprächspartner stimmen überein, daß eine Verstärkung des kommunistischen Einflusses im arabischen Raum, mit der bei einem Abbruch der diplomatischen Beziehungen zwischen der Bundesrepublik und der VAR gerechnet werden müsse, nach Möglichkeit vermieden werden sollte. Schröder weist in diesem Zusammenhang darauf hin, daß der Einstellung der Waffenlieferungen an Israel entscheidende Bedeutung zukomme. Hinsichtlich der Beziehungen zu Tansania erläutert der Bundesminister, die Bundesregierung prüfe noch, wie auf eine Intensivierung des Verhältnisses zur DDR zu reagieren sei.

Carstens faßt die Ergebnisse einer Ressortbesprechung im Bundeskanzleramt zusammen. Bundeskanzler Erhard stellte die Frage, ob auf den Besuch des Staatsratsvorsitzenden Ulbricht in Kairo nicht mit dem Abbruch der Beziehungen zur VAR reagiert werden müsse. Darauf erwiderte Bundesminister Schröder, die USA legten „größten Wert“ darauf, daß die Position der Bundesrepublik in der VAR und auch in Tansania erhalten bleibe. Carstens schloß sich der Empfehlung von Schröder an, sich auf wirtschaftliche Maßnahmen gegen die VAR zu beschränken, da mit einem Abbruch der diplomatischen Beziehungen die grundsätzlichen Schwächen der Nichtanerkennungspolitik keineswegs behoben werden könnten. Zur Lösung der Probleme mit Israel schlug Schröder vor, die Waffenlieferungen einzustellen, aber an den Zahlungen der Aktion „Geschäftsfreund" festzuhalten und Israel den Austausch von Generalkonsulaten oder Handelsmissionen anzubieten.

In Vorbereitung des Besuchs des britischen Premierministers in Bonn faßt Krapf Überlegungen der Bundesregierung zum Projekt einer ANF zusammen. Gegenüber Wilson soll dargelegt werden, daß eine integrale NATO-Streitmacht die bestehende „Abschreckungslücke“ gegenüber der UdSSR wirkungsvoller schließen würde als eine ANF. Zudem könnte durch eine MLF den sowjetischen Mittelstreckenraketen ein vergleichbares Abschreckungspotential entgegengesetzt werden. Darüber hinaus würde die gemeinsame Verantwortung für die Atomwaffen die Einheit der atlantischen Allianz festigen. Abschließend äußert Krapf Bedenken gegen die in dem britischen Vorschlag vorgesehene Selbstverpflichtung der Nichtnuklearstaaten, „für alle Zeiten" auf den Erwerb von Kernwaffen zu verzichten. Das Problem der Nichtverbreitung sei nur in weltweitem Rahmen zu lösen. 


\section{Klasse Schirmer}

Schirmer bilanziert die bestehenden Verbindungen und die bislang erbrachten Leistungen der Bundesrepublik gegenüber Israel. Er betont, daß viele Abmachungen ohne Beteiligung des Auswärtigen Amts von einzelnen Bundesministerien ausgehandelt worden seien und dies eine „sinnvolle Planung und Abstimmung" der politischen Beziehungen zu den Staaten des Nahen Ostens verhindert habe. Er referiert jüngste arabische Vorwürfe wegen geheimer Abmachungen zwischen der Bundesrepublik und Israel und vermutet, Präsident Nasser werde auch diese Informationen gegen die Bundesrepublik verwenden. Abschließend unterstreicht Schirmer die Notwendigkeit, das Auswärtige Amt über die laufenden Projekte zu informieren und es bei allen künftigen Kontakten mit Israel von vornherein zu beteiligen. Auswärtige Amt

Müller informiert über den Besuch des Staatsratsvorsitzenden der DDR vom 24. Februar bis 2. März 1965 in der VAR. Ulbricht habe für die DDR den Alleinvertretungsanspruch reklamiert. Auf das Bedauern des Präsidenten Nasser über die „künstliche Demarkationslinie" in Deutschland habe er mit der Bemerkung geantwortet, es handele sich um die Grenze zwischen beiden deutschen Staaten. Die Bundesregierung habe er als „hinter den Kräften der Aggression und Erpressung“ stehend angegriffen. Müller regt an, bei der ägyptischen Regierung wegen dieser „ungeheuerlichen Ausfälle“ zu protestieren, sobald das Bundeskabinett die Haltung zum Ulbricht-Besuch in der VAR endgültig festgelegt habe.

\section{Lindenberg}

Meyer-Lindenberg faßt Überlegungen zusammen, welche Maßnahmen die Bundesrepublik im Anschluß an den Besuch des Staatsratsvorsitzenden Ulbricht in Kairo ergreifen könnte und mit welchen Reaktionen der arabischen Staaten dann zu rechnen wäre. Als Folge eines Abbruchs der diplomatischen Beziehungen zur VAR erwartet er eine Aufnahme diplomatischer Beziehungen zwischen der VAR und der DDR sowie eine weitgehende Solidarisierung der arabischen Staaten. Diese würde schwächer ausfallen, wenn zuvor das Problem der Waffenlieferungen an Israel gelöst wäre. Meyer-Lindenberg plädiert dafür, sich auf die Einstellung der Wirtschaftshilfe und die Absage des geplanten Besuchs des Präsidenten Nasser in der Bundesrepublik zu beschränken. Als weitere politische Maßnahme emp- 
fiehlt der Ministerialdirektor, das wirtschaftliche und politische Interesse der Bundesrepublik auf diejenigen arabischen Staaten zu konzentrieren, die in Opposition zu Nasser ständen.

Krapf legt dar, wie ein Beauftragter der Bundesregierung gegenüber jüdischen Persönlichkeiten in den USA die NahostPolitik der Bundesrepublik erläutern sollte. In der Auseinandersetzung mit der DDR, die den Alleinvertretungsanspruch der Bundesrepublik für das deutsche Volk bestreite, komme der VAR als einem der "Hauptansatzpunkte“ der Politik der DDR eine Schlüsselposition zu. Lasse sich die Bundesrepublik aus diesem Staat „herausmanövrieren“, werde sie mit hoher Wahrscheinlichkeit ihre Position in einem großen Teil der nichtgebundenen Welt verlieren. Ein Vordringen des Einflusses der DDR in den arabischen Staaten laufe nicht nur den Interessen der westlichen Verbündeten der Bundesrepublik, sondern auch denen Israels zuwider. Zur Verdeutlichung weist Krapf auf die Stellungnahme der DDR zugunsten der Palästinenser hin. Gegen Kritik an der Bundesregierung führt er schließlich deren Bemühungen um Wiedergutmachung am jüdischen Volk und um die militärische Sicherheit Israels an.

Knoke erörtert die französisch-sowjetischen Beziehungen. Der Botschafterwechsel in Paris von Winogradow zu Sorin deute ebenso wie das erkennbare französische Interesse an Gesprächen über die Deutschland-Frage und die europäische Sicherheit auf eine Intensivierung des Verhältnisses hin. Auch werde von beiden Seiten eine Konferenz zur Lösung der VietnamFrage befürwortet. Beim Aufenthalt des sowjetischen Außenministers Gromyko in Paris am 25. April 1965 solle ein sowjetisches geheimgehaltenes Papier über „Deutschland und die europäische Sicherheit" und das "Problem des Goldstandards“ besprochen werden. Knoke resümiert, daß Staatspräsident de Gaulle wegen der nun im Mittelpunkt stehenden Beziehungen zur UdSSR „nicht mehr an dem Schicksal der europäischen politischen Zusammenarbeit" hänge. Daher könne mit Frankreich als „treibender Kraft" nicht mehr gerechnet werden. Auswärtige Amt

Berger berichtet über die Sorge der niederländischen Regierung hinsichtlich der Differenzen zwischen der Bundesrepublik und der VAR, die auf eine Schwächung des westlichen Einflusses in der VAR und Afrika insgesamt hinausliefen. Im niederländischen Außenministerium werde eine ähnliche Entwicklung wie 
in der VAR auch in Indonesien für möglich gehalten. In Gesprächen „unter vier Augen“ solle die Bundesregierung ihren Standpunkt sowohl gegenüber Präsident Nasser als auch gegenüber Präsident Sukarno mit aller Deutlichkeit vertreten. Hardenberg

Hardenberg nimmt zu den Differenzen mit der britischen Regierung Stellung, die aus dem Verkauf von neun Dornier-Flugzeugen an die International Civil Aviation Organization (ICAO) und an die indonesische Regierung entstanden sind. Da die Flugzeuge zum Ausbau eines zivilen Verkehrsflugnetzes in West-Neuguinea bestimmt seien, habe das Auswärtige Amt auf Anfrage der Dornier-Werke keine Einwände gegen den Vertragsabschluß erhoben. Gegen die Auffassung der britischen Regierung, die auf frühere Absprachen verweise, habe sich das Auswärtige Amt auf den Standpunkt gestellt, daß die Bundesregierung nur dazu verpflichtet sei, während des Malaysia-Konflikts keine militärischen Ausrüstungsgegenstände an Indonesien zu liefern. Hardenberg empfiehlt die Einhaltung der bereits erteilten Ausfuhrgenehmigungen, da die Bundesrepublik sonst schadensersatzpflichtig wäre und die Beziehungen zu Indonesien „auf das äußerste gefährdet" würden. Zudem sei ein rückwirkendes Ausfuhrverbot mit rechtsstaatlichen Grundsätzen unvereinbar. Auswärtige Amt

In Vorbereitung auf den Besuch des Premierministers Wilson in Bonn informiert Grewe, da $\beta$ die britische Regierung die Ansicht vertrete, die „sowjetische Gefahr" sei geringer geworden. Daher sei es möglich, durch Verhandlungen zur Stabilisierung der Verhältnisse in Europa zu gelangen. So erkläre sich die britische Politik zu Fragen wie der Nichtverbreitung von Kernwaffen, der Verringerung der Rheinarmee sowie der Schwächung der Stellung von SACEUR. Wilson müsse entgegengehalten werden, daß die sowjetische Bedrohung vor dem Hintergrund der materiellen Fähigkeiten der UdSSR und nicht ihrer vermuteten Absichten eingeschätzt werden müsse. Eine Schwächung der westlichen militärischen Präsenz in Europa würde zu einem Ungleichgewicht der Kräfte führen, das den Handlungsspielraum des Westens weltweit einengen würde. Zudem stelle die Anwesenheit amerikanischer und britischer Truppen auf dem europäischen Kontinent eine Gegenleistung für die 1954 von der Bundesrepublik übernommenen Rüstungsbeschränkungen bzw. -kontrollen und für den Verzicht auf die Herstellung von Atomwaffen dar. 
111 05.03. Aufzeichnung des Staatssekretärs Carstens

Carstens gibt einen Überblick über Maßnahmen, die noch vor einem Kabinettsbeschluß über den Abbruch der diplomatischen Beziehungen zur VAR zu treffen wären. Er empfiehlt, die drei Westmächte ebenso wie den NATO-Rat zu konsultieren, zumal Frankreich bereits Bedenken zum Ausdruck gebracht habe. Als Schutzmacht für die Interessen der Bundesrepublik in der VAR schlägt Carstens Italien vor. In der VAR lebende deutsche Staatsbürger und die in dortigen Gewässern fahrenden Schiffsbesatzungen aus der Bundesrepublik sollten vor möglichen Repressalien gewarnt werden. Carstens äußert Skepsis hinsichtlich eines Vorschlags des Ministerialdirigenten Böker, den Abbruch der diplomatischen Beziehungen erst für den Fall anzukündigen, daß Präsident Nasser in die DDR reisen oder die VAR in Ost-Berlin ein Generalkonsulat errichten sollte.

112

05.03. Gespräch des Bundeskanzlers Erhard mit den Botschaftern der Drei Mächte

Bundeskanzler Erhard resümiert den Besuch des Staatsratsvorsitzenden Ulbricht in Kairo, der die "Speerspitze" einer sowjetischen Offensive im Nahen Osten darstelle. Um den Alleinvertretungsanspruch der Bundesrepublik aufrechtzuerhalten, erwäge die Bundesregierung den Abbruch der diplomatischen Beziehungen zur VAR. Der amerikanische Botschafter McGhee warnt eindringlich vor einem solchen Schritt, da er die VAR „in die Hände der Kommunisten“ zwänge. Der Westen brauche den Einfluß der Bundesrepublik im Nahen Osten. Der britische Botschafter Roberts und der französische Botschafter Seydoux schließen sich diesen Ausführungen an.

113

05.03. Aufzeichnung des Ministerialdirektors MeyerLindenberg

Meyer-Lindenberg weist darauf hin, wie wichtig es für die Position der Bundesrepublik in den arabischen Staaten sei, die Waffenlieferungen an Israel durch Zahlungen abzulösen. Von der „Umschuldung“ hänge es $a b$, ob sich diese Staaten von der Deutschlandpolitik der VAR distanzieren könnten. Um Präsident Nasser möglichst wenig Raum für Gegenaktionen zu geben, schlägt Meyer-Lindenberg vor, daß die USA, Frankreich, Großbritannien und Italien die noch ausstehenden Lieferungen an Israel vornehmen sollten, das den von der Bundesrepublik zu leistenden Ablösungsbetrag dafür einsetzen könnte.

114

Krapf spricht sich gegen eine Unterbrechung der Verhandlungen mit der Tschechoslowakei aus. Da diese offensichtlich großes Interesse an einem Handelsvertrag habe und zumindest in 
bezug darauf auch hinsichtlich der Einbeziehung von Berlin (West) eine gewisse Kompromißbereitschaft zeige, erscheine die Situation nicht aussichtslos. Zudem sei dem Verhandlungsleiter der Bundesrepublik, Freiherr von Mirbach, Bereitschaft signalisiert worden, über eine vorzeitige Entlassung von in der CSSR inhaftierten deutschen Bürgern sowie andere humanitäre Fragen zu sprechen. Die mit der Rechtsgültigkeit des Münchener Abkommens von 1938 zusammenhängenden Fragen sollten nach Ansicht von Krapf aus den weiteren Verhandlungen ausgeklammert werden. ägyptischen Botschafter Mansour

Carstens informiert über die jüngste Entscheidung der Bundesregierung, auf den Besuch des Staatsratsvorsitzenden Ulbricht in Kairo mit der Einstellung der Wirtschaftshilfe zu reagieren und sich insbesondere nicht am neuen Fünf-Jahres-Plan der VAR zu beteiligen. Ferner würden keine Waffen in Spannungsgebiete geliefert, zu denen auch der Nahe Osten gehöre; bereits vereinbarte Lieferungen sollten im Einvernehmen mit „der

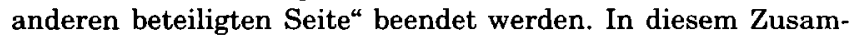
menhang sei Israel die Aufnahme diplomatischer Beziehungen angeboten worden. Die Bundesregierung wünsche, die Beziehungen mit den arabischen Staaten aufrechtzuerhalten. In einer persönlichen Erläuterung hebt der Staatssekretär die Bedeutung des Angebots an Israel für die Bemühungen um eine Einstellung der restlichen Waffenlieferungen hervor. Er betont, ein Botschafteraustausch zwischen der Bundesrepublik und Israel wäre „von Vorteil für alle Seiten, auch für die VAR“. Demgegenüber erinnert Mansour daran, daß die Einladung von Ulbricht eine Reaktion auf die Waffenlieferungen der Bundesrepublik an Israel gewesen sei.

Der britische Außenminister Stewart trägt den Wunsch nach baldiger Beratung des Vorschlags einer ,Atlantic Nuclear Force“ in multilateralem Rahmen vor. Bundesminister von Hassel hebt die Vorteile einer homogenen Bewaffnung einer integrierten NATO-Atomstreitmacht hervor, rät jedoch von einer Ausdehnung des Veto-Rechts auf alle Teilnehmerstaaten für den Fall eines Einsatzes ab und äußert sich kritisch zur Errichtung eines "nuklearen Oberkommandos“. Zum Procedere erklärt Bundesminister Schröder, die Bundesregierung bevorzuge - besonders mit Blick auf eine eventuelle Beteiligung Frankreichs - eine Behandlung des britischen Vorschlags im Rahmen der NATO. Das Projekt einer ANF könne „nur als ein Gegen- oder Modifizierungsvorschlag“ zur MLF angesehen werden. Zur Deutschland-Frage führt Schröder aus, daß eine Bekräftigung der west- 
lichen Position dringlich sei und daher - möglicherweise zum 8. Mai 1965 - eine entsprechende Erklärung und ein Gesprächsangebot an die UdSSR gerichtet werden sollten. Stewart schlägt vor, Einzelheiten einer solchen Initiative ebenso wie mögliche Reaktionen auf sowjetische Gegenvorschläge in der Washingtoner Botschaftergruppe zu besprechen. Abschließend erläutert Staatssekretär Lahr den Wunsch der Bundesregierung nach einer einheitlichen Beschränkung der Laufzeiten für von den NATO-Staaten gewährte Kredite an Ostblock-Staaten, insbesondere an die DDR.

117 marokkanischen Botschafter Boucetta

Boucetta begründet die Vertagung des geplanten Staatsbesuchs des Königs Hassan II. in der Bundesrepublik mit einer "gewissen moralischen Verpflichtung" gegenüber den arabischen Staaten. Er weist darauf hin, daß die Vertagung nicht durch die Spannungen zwischen der Bundesrepublik und der VAR, sondern allein durch die Ankündigung der Aufnahme diplomatischer Beziehungen zu Israel unvermeidlich geworden sei, und betont den Wunsch nach Aufrechterhaltung der "freundschaftlichsten Beziehungen" mit der Bundesrepublik. Erhard erläutert die Hintergründe der Entscheidung für einen Botschafteraustausch mit Israel. Deutschland habe auch „wegen seiner tragischen Geschichte" eine "gewisse moralische Verantwortung“ gegenüber diesem Staat.

Schröder berichtet über die Sondierungen bei den EWG-Staaten über das weitere Vorgehen in der Frage der europäischen politischen Zusammenarbeit. Es zeichne sich eine förmliche Außenministerkonferenz ab, da sich weder über Expertengespräche noch über ein informelles Außenministertreffen Konsens habe finden lassen. Der Bundesminister bittet Erhard um Zustimmung zu einer solchen Konferenz, weist jedoch auf die Schwierigkeiten hin, die durch "tiefgreifende Meinungsverschiedenheiten" in der Frage der Einbeziehung der Verteidigung und hinsichtlich eines europäischen Gemeinschaftsorgans hervorgerufen werden könnten. Lindenberg

Meyer-Lindenberg faßt Reaktionen arabischer Staaten auf die angekündigte Aufnahme diplomatischer Beziehungen zwischen der Bundesrepublik und Israel zusammen. Während in der ägyptischen Presse zunächst die positiven Aspekte - Einstellung der Waffenlieferungen an Israel und Aufrechterhaltung 
der Beziehungen zur VAR - hervorgehoben worden seien, habe Präsident Nasser von einer ,verräterischen Politik“ der Bundesrepublik gesprochen. $\mathrm{Zu}$ möglichen Folgen habe er sich noch nicht geäußert, da zunächst ein gemeinsamer Beschluß der arabischen Staaten herbeigeführt werden solle. Ebenso habe sich Algerien die Antwort auf die „imperialistische Provokation im Nahen Osten" vorbehalten. Marokko habe den Besuch des Königs Hassan II. in der Bundesrepublik zwar vorläufig abgesagt, werde jedoch die Beziehungen keinesfalls abbrechen. Die übrigen arabischen Staaten neigten zum Abbruch der diplomatischen Beziehungen zur Bundesrepublik. Dabei werde SaudiArabien möglicherweise die Stellungnahme der Arabischen Liga nicht abwarten, um nicht Nasser die "gesamtarabische Protagonistenrolle" zu überlassen. Bundeskanzleramt

Mercker hält die Ergebnisse eines Telefonats mit dem Sonderbeauftragten Birrenbach, z.Z. Tel Aviv, fest. Der CDU-Abgeordnete teilte mit, er habe seinen israelischen Verhandlungspartnern Vorschläge zur Übernahme der bestehenden Waffenlieferungsverpflichtungen durch die USA und Großbritannien bei einer Zahlung durch die Bundesrepublik unterbreitet. Zudem habe er Bemühungen der Bundesregierung um eine „annehmbare Lösung" in der Frage der Verjährungsfrist für Gewaltverbrechen in der Zeit des Nationalsozialismus in Aussicht gestellt und darauf hingewiesen, daß die Rückholung von Rüstungsexperten, die außerhalb der NATO an militärischen Projekten tätig seien, angestrebt werde. Schließlich habe er vorgeschlagen, die Verhandlungen zur Aufnahme diplomatischer Beziehungen formell aufzunehmen. Mercker drängte Birrenbach zur Rückkehr, damit die Verhandlungen in Bonn weitergeführt werden könnten.

Böker referiert die Ergebnisse eines Gesprächs mit dem tunesischen Botschafter. Ben Ayed hob hervor, da $\beta$ die Ankündigung der Bundesregierung, diplomatische Beziehungen mit Israel aufzunehmen, in Tunesien Bestürzung ausgelöst habe. Die Bundesregierung habe - „statt Nasser zu bestrafen, wie er es verdient hätte“ - allen 13 arabischen Staaten „eine schallende Ohrfeige erteilt". Ben Ayed informierte über einen Stufenplan für die Reaktionen der arabischen Staaten: Abberufung der Botschafter aus Bonn, Abbruch der Beziehungen und schließlich Aufnahme diplomatischer oder konsularischer Beziehungen zur DDR oder Einrichtung von Handelsvertretungen in Ost-Berlin. 
Abschließend wies der Botschafter auf die verstärkte Dominanz der VAR über die restlichen arabischen Staaten hin und bat um Argumentationshilfen "gegenüber Nasser und den Radikalen“.

Über den Besuch des britischen Premierministers vom 6. bis 9 . März 1965 in Berlin (West) und Bonn teilt Carstens mit, daß Wilson den Wunsch der Bundesregierung nach einem neuen Vorsto $\beta$ in der Deutschland-Frage unterstützt habe. Hinsichtlich des britischen Vorschlags einer ANF sei Übereinstimmung erzielt worden, daß er bei den Planungen der MLF-Arbeitsgruppe in Paris berücksichtigt werden solle. Schwierig hätten sich die Gespräche über den Stand des Devisenausgleichsabkommens vom Juli 1964 gestaltet; kritisiert worden sei die ungenügende Auftragsvergabe nach Großbritannien. Die Bundesregierung ihrerseits habe dringend darum gebeten, keine staatlich verbürgten Kredite an die DDR zu vergeben, weil diese dadurch eine "gefährliche Handelsfreiheit" erhalte und der politisch wichtige Interzonenhandel „ausgehöhlt“ werde.

123 10.03. Aufzeichnung des Ministerialdirektors Sachs

Sachs befaßt sich mit der Laufzeit von Krediten an OstblockStaaten. Der Leiter der Handelspolitischen Abteilung hält fest, daß sich weder Großbritannien noch die EWG-Mitgliedstaaten an die in der Berner Union vereinbarte Frist hielten. Ein Versuch des Bundesministers Schmücker, die EWG-Staaten auf der Ministerratstagung vom 2. März 1965 auf eine einheitliche Linie festzulegen, sei ohne Erfolg geblieben. Eine Neuregelung der Kreditpolitik der Bundesrepublik sei dringlich, da verschiedene Großprojekte in Ostblock-Staaten die Einräumung längerer Kreditfristen erforderlich machten. Sachs unterbreitet den Vorschlag, Ostblock-Staaten Kredite mit einer Laufzeit bis zu acht Jahren einzuräumen. Diese Regelung sei zu revidieren, wenn die deutschen Firmen trotz der verbesserten Kreditbedingungen „nicht zum Zuge kommen" sollten. Auswärtige Amt

Spreti berichtet über ein Gespräch mit dem jordanischen König. Hussein zeigte sich besorgt über die politische Entwicklung, schloß aber die Anerkennung der DDR durch Jordanien aus. Ministerpräsident Tell informierte Spreti über die vorübergehende Rückberufung des jordanischen Botschafters in Bonn, Juma, der an der Außenministerkonferenz der Arabischen Liga teilnehmen solle. Tell schlug vor, die zu unterzeichnenden Abkommen zwischen der Bundesrepublik und Jordanien vor- 
läufig zurückzustellen. Er empfahl ein langsames Vorgehen bei der Aufnahme diplomatischer Beziehungen zwischen der Bundesrepublik und Israel. amerikanischen Botschafter McGhee

Der Botschafter informiert über die Bemühungen der USA, die arabischen Staaten zu einer gemäßigten Reaktion auf die Erklärung der Bundesregierung vom 7. März 1965 zur Lage im Nahen Osten zu bewegen. Der Bundesminister hebt hervor, daß eine wirksame Schadensbegrenzung nur bei Klärung des Verhältnisses zwischen der Bundesrepublik und Israel möglich wäre. Aus den Sondierungen des CDU-Abgeordneten Birrenbach in Tel Aviv ergebe sich, daß die israelische Regierung vor allem an der zugesagten Lieferung von 90 Panzern interessiert sei. Die Bundesregierung habe Informationen erhalten, daß die USA eventuell zu einer Übernahme dieser Lieferung bereit wären. In diesem Fall könnte ein Teil der Panzer, die die Bundesrepublik in den USA für die Bundeswehr bestellt habe, an Israel geliefert werden, das die Zahlungen dafür direkt an die USA leisten würde. Schröder betont, daß ein solches Verfahren nur möglich sei, „wenn damit der Gesamtkomplex abgelöst werde“, und erwartet als Folge eine baldige Aufnahme diplomatischer Beziehungen mit Israel. Er rechtfertigt die Bitte um amerikanische Unterstützung damit, daß die deutsche Seite durch die von den USA initiierten Panzerlieferungen ,in die übelste Patsche der Nachkriegszeit" geraten sei. britischen Abgeordneten Sandys

Der ehemalige Minister für die Beziehungen zum Commonwealth erläutert sein Interesse an den Bemühungen um eine politische Einigung Europas und stellt die Frage, ob nicht Großbritannien stärker einbezogen werden könne und eine Initiative der EWG-Staaten für einen britischen Beitritt zum Gemeinsamen Markt möglich sei. Der Bundesminister hebt zunächst die durch NATO und WEU bereits bestehenden Verbindungen mit Großbritannien hervor. $\mathrm{Zu}$ den Aussichten auf einen europäischen Zusammenschluß und zu den geplanten Konferenzen der Sechs über dieses Thema äußert er sich skeptisch; Aktivitäten zugunsten eines britischen EWG-Beitritts hält er angesichts der ablehnenden Haltung des Staatspräsidenten de Gaulle für aussichtslos. Sandys verweist auf anderslautende Äußerungen des französischen Außenministers Couve de Murville. Er schildert den Stimmungsumschwung in Großbritannien zugunsten der EWG und hält eine Zustimmung zu einem Beitritt für wahrscheinlich, wenn die Sechs eine direkte Aufforderung aussprächen. Schröder weist darauf hin, daß ein solcher Schritt als Ver- 
zögerungstaktik gegen eine europäische politische Union aufgefaßt werden könnte und daher in der CDU angesichts der bevorstehenden Bundestagswahlen nicht konsensfähig wäre.

Lahr referiert die Ergebnisse einer Unterredung mit dem Staatssekretär im Bundesministerium für wirtschaftliche Zusammenarbeit über die Abgrenzung der Zuständigkeiten mit dem Auswärtigen Amt. Vialon forderte die Verhandlungsführung bei entwicklungspolitisch relevanten Gesprächen mit Entwicklungsländern. Auf den Einwand von Lahr, daß dies die Kompetenzen des Bundesministeriums für wirtschaftliche Zusammenarbeit überschreite, entgegnete Vialon, daß nötigenfalls die Geschäftsordnung der Bundesregierung zu ändern sei. Lahr lehnte auch die Forderung von Vialon nach eigenen Entwicklungs-,Missionen“ und nach einem Weisungsrecht gegenüber den Auslandsvertretungen in allen entwicklungspolitischen Fragen ab. Lahr warnt vor den ,ambitiösen Ausweitungsplänen“ des Bundesministeriums für wirtschaftliche Zusammenarbeit und schlägt zunächst eine Besprechung der Bundesminister Schröder und Schmücker vor.

Erhard stimmt dem Vorschlag des Bundesministers zu, Anfang Mai eine förmliche Außenministerkonferenz zur europäischen politischen Zusammenarbeit einzuberufen. Es gehe zunächst darum, die Standpunkte der Beteiligten zu den einzelnen Fragen zu klären, nicht jedoch Meinungsverschiedenheiten - wie etwa bei der Einbeziehung der Verteidigung und der Festlegung auf ein Gemeinschaftsorgan - auszutragen. Ziel der deutschen Initiative sei es, die Staaten durch das politische Gespräch einander näherzubringen.

Redies hält die Ergebnisse der Konferenz der arabischen Außenminister am 15. März 1965 in Kairo fest. Es sei beschlossen worden, sofort die Botschafter aus Bonn abzuberufen und im Falle der Aufnahme diplomatischer Beziehungen zwischen der Bundesrepublik und Israel die Beziehungen zur Bundesrepublik abzubrechen. Keine Einigung sei über die Anerkennung der DDR erzielt worden; einige arabische Staaten würden dies voraussichtlich tun. Mit der Ankündigung, auch die Wirtschaftsbeziehungen abzubrechen, wenn die Bundesregierung ihren "feindseligen Standpunkt gegenüber irgendeinem arabischen Staat" beibehalte, solle eine einheitliche Haltung für den Fall gesichert werden, daß die Bundesregierung die Entwicklungshilfe an einige dieser Staaten einstelle. 

Auswärtige Amt

Knappstein berichtet über eine Sitzung der Washingtoner Botschaftergruppe, in der er Vorschläge zur Deutschland-Frage vorgelegt habe. Er habe erläutert, daß es angesichts der unveränderten sowjetischen Haltung notwendig sei, die Vier-MächteVerantwortung für Deutschland hervorzuheben und der UdSSR „in überzeugender und systematischer Weise" die Position der Westmächte erneut nahezubringen, um etwaigen Fehleinschätzungen vorzubeugen und der Konsolidierung des Status quo entgegenzuwirken. Zu der geplanten Drei-Mächte-Erklärung habe der amerikanische Sonderbotschafter Thompson um Klärung gebeten, wie der nach deutschen Vorstellungen abzugebende Hinweis auf „einen bevorstehenden aktiven Schritt der Westmächte" aussehen solle. Offengeblieben sei auch die Frage, zu welchem Termin eine Deutschland-Erklärung abgegeben werden solle. Der 8. Mai sei vom französischen Botschafter Alphand als ungeeignet bezeichnet worden, weil er Deutschland „an die dunkelsten Tage seiner Geschichte" erinnere und in der übrigen Welt „Gefühle und Gemütsbewegungen wachrufen" werde, die nicht mit der Wiedervereinigung vermischt werden sollten.

Carstens hält die Ergebnisse eines Gesprächs des CDU-Abgeordneten Werner mit dem Beauftragten des Präsidenten Nasser für die Rüstungswirtschaft fest. Mahmoud Khalil habe sich besorgt gezeigt, daß die Bundesrepublik Israel auch nach der Aufnahme diplomatischer Beziehungen „in größtem Umfang“ Wirtschaftshilfe leisten würde. Die VAR biete an, die deutschen Schulen und das deutsche Vermögen nicht zu beschlagnahmen, das Landerecht für die Lufthansa zu garantieren und keine diplomatischen Beziehungen zur DDR aufzunehmen. Dafür solle Bundeskanzler Erhard ein Schreiben „von Mann zu Mann“ an Nasser richten, in dem der angekündigte Botschafteraustausch mit Israel erläutert und Verständnis für die arabische Reaktion gezeigt würde. Erhard solle darauf hinweisen, daß bei einer Anerkennung der DDR durch die VAR ein „unheilvoller Bruch" drohe. Die VAR erbitte zudem eine schriftliche Zusage von Bundesminister Scheel zur baldigen Wiederaufnahme der Wirtschaftshilfe. Während Carstens letzteres ausschließt, sieht er in einem Schreiben des Bundeskanzlers „eine kleine Chance“, diplomatische Beziehungen zwischen der VAR und der DDR zu verhindern. 
132 18.03. Abgeordneter Birrenbach, z. Z. Tel Aviv, an Bundesminister Schröder

Birrenbach gibt ein Gespräch mit dem israelischen Ministerpräsidenten wieder. Eshkol stimmte mit dem Sonderbeauftragten überein, daß die bei einem Abbruch der diplomatischen Beziehungen durch arabische Staaten drohende Beseitigung des Wirtschaftspotentials und des Einflusses der Bundesrepublik aus dem Nahen Osten nicht im beiderseitigen Interesse liege. Eshkol glaubte jedoch, daß die Abwicklung der zugesagten Waffenlieferungen an Israel ohne Auswirkungen bleiben würde, und insistierte besonders auf der Lieferung von Schnellbooten. Birrenbach stellte klar, daß die Schiffe von der Bundesrepublik "weder unmittelbar noch mittelbar" geliefert werden könnten, brachte aber ins Gespräch, ob nicht ein Kauf in anderen Staaten oder die Lieferung deutscher Schiffe über einen Drittstaat erfolgen könnte. Abschließend weist Birrenbach auf das Problem hin, daß die israelische Regierung eine Annullierung der von der Bundesregierung eingegangenen Lieferverpflichtung nicht öffentlich zuzugeben wage, daher auch eine Barablösung abgelehnt habe und in jedem Fall auf Ersatzlieferungen bestehe. Für die weiteren Verhandlungen bittet er um Klärung, ob die Geheimhaltung nicht nur für die Panzerlieferungen, sondern auch für weitere Vereinbarungen die Geschäftsgrundlage gewesen sei. minister Schröder

Birrenbach berichtet von Unterredungen mit dem israelischen Ministerpräsidenten und dem stellvertretenden Verteidigungsminister Peres. Dem Gespräch mit Eshkol war zu entnehmen, daß eine Verlängerung der Verjährungsfrist für Gewaltverbrechen in der Zeit des Nationalsozialismus von israelischer Seite nicht im Zusammenhang mit einem Abkommen zur Beendigung der Waffenlieferungen gesehen werde. Jedoch fand der Vorschlag des Sonderbeauftragten Zustimmung, einen definitiven Beschluß des Bundestages in dieser Frage abzuwarten und erst dann offiziell die Aufnahme diplomatischer Beziehungen einzuleiten. Auf Widerspruch stie $ß$ die Absicht, die Botschaft der Bundesrepublik statt in Jerusalem in Tel Aviv zu errichten. Als Fazit hält Birrenbach fest, daß eine Einigung möglich sei, wenn ein „Ersatzlieferant“ für die von Israel geforderten Schnellboote gefunden würde. Abgelehnt habe er es, sich bereits zur zukünftigen Wirtschaftshilfe an Israel zu äußern.

Böker unterbreitet Vorschläge, wie die Bundesrepublik trotz der Nahost-Krise „Positionen im arabischen Bereich“ wahren könnte. Er rät, den Austausch von Botschaftern mit Israel um 
etwa zwei Monate zu verzögern und diese Zeit zu nutzen, um „Zersetzungserscheinungen“ im arabischen Lager zu fördern und einzelne Staaten aus der Solidarität mit der VAR „herauszubrechen“. Den arabischen Regierungen müßten die Argumente für die Politik der Bundesrepublik gegenüber Israel nahegebracht und verdeutlicht werden, daß eine diplomatische Anerkennung der DDR ein kaum zu überwindendes Hindernis für eine Wiederaufnahme der Beziehungen zur Bundesrepublik bedeuten würde. Mit einigen arabischen Staaten solle ein „intensiver Dialog“ geführt werden, so mit Jordanien durch ein Schreiben des Bundespräsidenten Lübke an König Hussein und mit Saudi-Arabien durch die Entsendung eines hochrangigen Emissärs zu König Feisal. Vordringlich erscheine auch die Eröffnung eines Generalkonsulats in Aden, am „Schnittpunkt des westlichen, Nasserschen und traditionell arabischen Einflusses“. Weitere Möglichkeiten zur Einflußnahme sieht Böker im Jemen, im Sudan, im Irak und in Syrien. Die arabischen Staaten sollten dazu gebracht werden, die Vor- und Nachteile eines Abbruchs der diplomatischen Beziehungen zur Bundesrepublik gründlich abzuwägen. an das Auswärtige Amt

Stein informiert über ein Gespräch des Intendanten der Deutschen Welle, Wesemann, mit dem äthiopischen Kaiser. Haile Selassie habe nicht nur die angekündigte Aufnahme diplomatischer Beziehungen der Bundesrepublik zu Israel, sondern auch die Wirtschafts- und Waffenhilfe positiv aufgenommen. Er habe Unverständnis über die Haltung der arabischen Staaten geäußert und seine Vermittlung insbesondere auch in den afrikanischen Staaten angeboten, die sich dem arabischen Standpunkt anzuschließen drohten. minister Schröder

Birrenbach übermittelt ein Aide-mémoire, in dem das Ergebnis der bisherigen Verhandlungen mit Israel zusammengefaßt sei und das „einen tentativen Versuch" der Einigung darstelle. Der Sonderbeauftragte hebt hervor, daß Israel seine Ablehnung von Ablösungszahlungen für alle Waffenlieferungen nunmehr aufgegeben habe und offenbar auch von der Forderung abgerückt sei, daß die Botschaft der Bundesrepublik in Jerusalem errichtet werden sollte. Offen sei noch die abschließende Regelung der Panzer- und Schiffslieferungen, da die Zustimmung dritter Regierungen eingeholt werden müsse. Er selbst habe die Bereitschaft der Bundesrepublik erklärt, in wenigen Monaten Ver- 
handlungen über die Fortsetzung der Hilfeleistungen an Israel in Form von Wirtschafshilfe und der Lieferung ziviler Güter zu führen. belgischen Außenminister Spaak

Im Mittelpunkt der Unterredung stehen Fragen einer europäischen politischen Union. Die Gesprächspartner betrachten die Aussichten, auf der geplanten Außenministerkonferenz zu substantiellen Ergebnissen zu kommen, angesichts der französischen Haltung als gering. Schröder hält jedoch eine Einigung über regelmäßige Zusammenkünfte und über eine Konferenz der Staats- und Regierungschefs für denkbar. Spaak schätzt eine britische Einbeziehung als schwierig ein, da Großbritannien in einem politischen Europa den sechs EWG-Staaten allein gegenüberstehen könnte. Schröder teilt diese Besorgnis und begrüßt daher die Anzeichen für eine allmähliche Hinwendung von Großbritannien zur EWG. Sie werde von der Bundesrepublik unterstützt, da es andernfalls zu einer „lebensgefährlichen Spaltung in Europa"komme. Spaak äußert sich skeptisch zu der britischen Auffassung, eine Annäherung durch engere Kontakte zwischen der EWG und der EFTA erreichen zu können, und weist darauf hin, daß ein später der EWG beitretender Staat angesichts der fortschreitenden Verflechtung innerhalb der Gemeinschaft "eine wahre Revolution“ werde durchmachen müssen. Abschließend bittet Schröder um Einhaltung der NATO-Richtlinien zur Erteilung von Temporary-Travel-Documents. Spaak sagt dies zu, weist aber auf wachsenden Druck in der belgischen Öffentlichkeit zugunsten einer Lockerung hin. minister Schröder

Birrenbach äußert sich zur Stellungnahme des Auswärtigen Amts zu dem mit der israelischen Regierung ausgehandelten "memorandum of understanding“ über die Ablösung der Waffenlieferungen und erläutert die Hintergründe einzelner Formulierungen. Er hält eine Einigung auf einen endgültigen Text für möglich, so daß lediglich das Problem des Kommuniqués bleibe. Angesichts dieses Sachstandes habe die israelische Seite auf seine Rückberufung nach Bonn „negativ“ reagiert.

Erhard stellt fest, daß das Klima für eine politische Zusammenarbeit der sechs EWG-Staaten sich verbessert habe, und würdigt die belgische Zusage, an der geplanten Außenministerkonferenz in Venedig teilzunehmen. Der belgische Außenminister berichtet dann über Gespräche mit seinem polnischen Amtskol- 
legen. Rapacki habe bekräftigt, daß die Schaffung eines europäischen Sicherheitssystems eine Voraussetzung für die Wiedervereinigung Deutschlands sei. Demgegenüber habe er hervorgehoben, daß es "mindestens eine Parallelität" zwischen der Wiedervereinigung und der Errichtung eines europäischen Sicherheitssystems geben müsse. Erhard zeigt sich wenig zufrieden mit dem Stand der Deutschlandpolitik, die auch angesichts des Zeitfaktors aktiviert werden müsse. Noch werde nach „Hebeln“ gesucht, „urm über den toten Punkt hinwegzukommen“. Bundesminister Schröder hält eine Kombination von defensiven Maßnahmen zur Erhaltung der westlichen Position und offensiven Maßnahmen zur Stärkung des westlichen Einflusses in den osteuropäischen Staaten für erforderlich. Spaak legt abschließend die Schwierigkeiten der Situation im Kongo dar. Erhard erläutert, daß die Bundesrepublik keine Waffen in Spannungsgebiete liefere, sagt aber eine Beteiligung an der multilateralen Wirtschaftshilfe für den Kongo zu. (Entwurf)

Schröder weist darauf hin, daß es im Zuge der Nahost-Krise zur Aufnahme diplomatischer Beziehungen zwischen arabischen Staaten und der DDR kommen könnte. Um der negativen Wirkung dieser Entwicklung zu begegnen und möglicherweise sogar Vorteile daraus zu ziehen, regt er an, Bewegungsfreiheit in der Deutschland-Frage durch die Aufnahme diplomatischer Beziehungen zu den osteuropäischen Staaten zu gewinnen. Die ohnehin notwendige Klärung des Verhältnisses zu den Ostblock-Staaten könnte so im Schatten der Nahost-Krise herbeigeführt werden, ohne daß es zu weiteren negativen Rückwirkungen auf die Nichtanerkennungspolitik der Bundesrepublik käme. Zudem würde dem Versuch des Staatsratsvorsitzenden Ulbricht, die Position der Bundesrepublik in der nichtgebundenen Welt „auszuhöhlen“, nicht defensiv, sondern mit „Selbstbewußtsein und Aktionsbereitschaft" begegnet, indem der DDR im Ostblock Konkurrenz gemacht würde. an das Auswärtige Amt

Ungern-Sternberg informiert über ein Gespräch des Vortragenden Legationsrats I. Klasse Graf von Posadowsky-Wehner mit dem Referatsleiter im Commonwealth Relations Office. Aspin bekundete Verständnis für die von der Bundesregierung ergriffenen Maßnahmen gegen Tansania, die ihre Wirkung nicht zu verfehlen schienen. Als politisch gefährlich erweise sich zunehmend der tansanische Handelsminister Babu, der die Präsidentschaft anstrebe und sich „völlig dem Kommunismus verschrieben" habe. Von einer Unterstützung und Bewaffnung 
paramilitärischer Verbände in Afrika, wie z. B. der „young pioneers" in Malawi, wurde abgeraten. Jedoch befürwortete die britische Seite eine deutsche Lieferung von kleinen Aufklärungsflugzeugen und Patrouillenbooten an Malawi. Zur Situation in Ghana wurde ausgeführt, daß der Staat sich in einer schweren finanziellen Krise befinde, die nur durch Bekämpfung der inneren Inflation und nicht durch eine Aufstockung der Hilfeleistungen bewältigt werden könne. Unerläßlich sei die Bildung einer „gemeinsamen Front“, um zu verhindern, daß Ghana die einzelnen Gläubigerstaaten gegeneinander ausspielen könne.

142 22.03. Abgeordneter Birrenbach, z. Z. Tel Aviv, an das Auswärtige Amt

Der Sonderbeauftragte übermittelt die letzte Fassung des „memorandum of understanding“ über die Ergebnisse seiner Verhandlungen mit Israel. Darin werden die Bemühungen der Bundesrepublik sowohl hinsichtlich der Verlängerung der Verjährungsfristen für Gewaltverbrechen in der Zeit des Nationalsozialismus als auch hinsichtlich der Rückberufung der Rüstungsexperten aus der VAR hervorgehoben. Neben den Zusicherungen zur Ablösung der Waffenlieferungen wird die Bereitschaft der Bundesrepublik herausgestellt, in Kürze über eine Fortsetzung der Hilfeleistungen an Israel in Form von nichtrückzahlbarer Finanzhilfe zu verhandeln, ferner keine Waffen an Israel feindlich gesonnene Staaten zu liefern und schließlich die israelische Position gegenüber der EWG zu unterstützen.

143 23./25.03. Deutsch-norwegische Regierungsbesprechungen

Ministerpräsident Gerhardsen äußert Sorge über die von der EWG für die Kennedy-Runde erstellte Ausnahmeliste zu den geplanten Zollsenkungen, die mehr als $50 \%$ der norwegischen Exporte betreffe. Bundeskanzler Erhard spricht sich für einen weitgehenden Abbau aller Zollschranken aus; Staatssekretär Lahr sagt zu, sich in der EWG für die Beibehaltung der Zollkontingente für Norwegen einzusetzen. Zum „Kekkonen-Plan“ einer atomwaffenfreien Zone in Nordeuropa erklärt Gerhardsen, daß eine solche nur bei reziproken Maßnahmen der UdSSR und einer Einbettung in umfassendere Vereinbarungen in Frage komme. Er zeigt Verständnis für die Auffassung des Bundeskanzlers, daß angesichts des großen konventionellen Übergewichts der UdSSR keine einseitigen Vorleistungen erbracht werden könnten. Bundesminister Schröder erläutert, die Bundesrepublik sei wegen ihrer exponierten Lage ,vielleicht im Hinblick auf die sowjetischen Absichten skeptischer als die Norweger", und betont, daß Schritte zur Abrüstung parallel zu Maßnahmen zur Lösung der deutschen Frage erfolgen müßten. Beweis für die friedlichen Absichten der Bundesrepublik sei die Ostpolitik der letzten Jahre. Bundesminister von Hassel erläu- 
tert die strategischen Vorteile der UdSSR in Mitteleuropa, die ,jedes deutsche Abenteuer" ausschlössen. Gerhardsen teilt das Interesse der Bundesrepublik an einer Erhaltung der NATO, weist jedoch darauf hin, daß Perspektiven für die Friedenssicherung eröffnet werden müßten. In diesem Zusammenhang komme Kontakten mit Ostblock-Staaten eine besondere Bedeutung zu.

Krapf hält den Stand der Verhandlungen mit der Tschechoslowakei fest. Die tschechoslowakische Haltung habe sich deutlich verhärtet: Der Vorschlag für die Einbeziehung von Berlin (West) in das geplante Handelsabkommen sei zurückgezogen und außerdem signalisiert worden, daß über den Austausch von Handelsvertretungen nicht weiter verhandelt werden sollte. Das Angebot, in Prag eine Handelskammervertretung zu eröffnen, habe die Delegation der Bundesrepublik abgelehnt. Krapf betont, daß eine Aufrechterhaltung des Kontakts dennoch von Interesse sei. Jedoch dürfe in künftigen Verhandlungen mit der UdSSR keine Lösung der Berlin-Frage akzeptiert werden, die schlechter sei als die von der ČSSR geforderte und von den übrigen Ostblock-Staaten zugestandene Regelung. Um das tschechoslowakische Interesse an einer Vereinbarung mit der Bundesrepublik zu stärken, solle sich die vorgesehene „Teilliberalisierung" zur Erleichterung von Einfuhren aus osteuropäischen Ländern ebenso wenig auf die CSSR erstrecken wie die neue Regelung zur Kreditpolitik. Auch kulturelle Initiativen sollten vorerst unterbleiben. Amt

Blankenhorn berichtet von Überlegungen des italienischen Staatspräsidenten, während eines Staatsbesuchs in der Bundesrepublik vor Jugendlichen und vor politisch Interessierten für den europäischen Zusammenschluß einzutreten. Der Botschafter informiert dann über die Abschiedsaudienz bei Saragat, der auf die Notwendigkeit hinwies, die Zusammenarbeit zwischen Europa und den USA zu verstärken. Für eine Verbesserung der Ost-West-Beziehungen sah er angesichts der unveränderten sowjetischen Haltung keine Perspektiven. Er hob die Bedeutung des deutsch-britischen Verhältnisses für die weitere Entwicklung in Europa hervor. Hinsichtlich der geplanten Außenministerkonferenz in Venedig rechnete Saragat nicht mit "spektakulären Ergebnissen“; es gehe aber darum, das Problem der politischen Zusammenarbeit „überhaupt einmal wieder im Kreise der Sechs anzupacken". 

Washington

Carstens informiert über die Verhandlungen des Sonderbeauftragten Birrenbach in Tel Aviv und den israelischen Verzicht auf 20 von der Bundesrepublik zu liefernde und zur Umrüstung in Italien stehende Panzer. Er bittet Knappstein, sich im amerikanischen Außenministerium zu erkundigen, ob die USA bereit seien, insgesamt 110 Panzer an Israel zu liefern und zur Abwicklung dieses Geschäfts eine direkte Vereinbarung mit Israel zu treffen. Carstens vermutet, da $\beta$ die Bundesrepublik die Ablösung der noch ausstehenden Waffenlieferung nur durch Barzahlungen an Israel erwirken könne.

Löns informiert über eine Unterredung mit dem österreichischen Außenminister. Kreisky bestritt, daß Österreich die Absicht habe, eine Außenstelle der Bundeskammer der gewerblichen Wirtschaft in Ost-Berlin zu errichten, verwies jedoch auf entsprechende Pläne der österreichischen Bundeswirtschaftskammer. Diese habe aber, so stellten die Gesprächspartner fest, widersprüchliche Informationen über ihre Absichten gegeben. Kreisky sagte zu, in jedem Fall darauf hinzuwirken, daß von der Errichtung einer Vertretung der Bundeswirtschaftskammer in der DDR Abstand genommen werde.

Carstens erörtert die noch offenen Fragen in den Verhandlungen mit Israel. Er spricht sich dagegen aus, die von Israel gewünschten Ersatzlieferungen zu bezahlen. Statt dessen solle für die Ablösung der ausstehenden Waffenlieferungen eine Summe von bis zu 120 Millionen DM gezahlt werden. Eine zusätzlich von Israel geforderte, nicht rückzahlbare Finanzhilfe habe der Sonderbeauftragte Birrenbach abgelehnt. Nach seiner Rückkehr nach Bonn habe er aber angeregt, Israel einen Teil der gewünschten Summe als langfristigen Kredit zu gewähren. Als Richtlinie für die künftige Wirtschaftshilfe an Israel schlägt Carstens vor, keine Geheimabsprachen zuzulassen, sondern die Unterstützung, entsprechend der Entwicklungshilfe, nur auf jährlicher Basis und projektgebunden zu gewähren sowie auf Ausgewogenheit im Verhältnis zur Hilfe an arabische Staaten zu achten. Der israelische Wunsch nach Assoziierung mit der EWG kann nach Ansicht des Staatssekretärs nur durch eine mündliche Wohlwollenserklärung unterstützt werden. Für die Form der zu treffenden Vereinbarungen schlägt Carstens einen Briefwechsel zwischen Bundeskanzler Erhard und Ministerpräsident Eshkol sowie ein gemeinsames Kommuniqué über die Aufnahme diplomatischer Beziehungen vor. 
Lahr verteidigt zwar den Beschluß des Kabinetts, keine Waffen mehr in Spannungsgebiete zu liefern; er teilt dem Vorsitzenden der CDU/CSU-Fraktion im Bundestag aber mit, daß trotz einiger negativer Erfahrungen nicht grundsätzlich auf den Export von Waffen in Entwicklungsländer verzichtet werden sollte. Da eine militärische Ausstattung für die belieferten Staaten ein echtes Bedürfnis oder eine Frage des staatlichen Prestiges sei, werde damit ein verhältnismäßig großer politischer Effekt erzielt. Durch ein grundsätzliches Ausfuhrverbot von Waffen würde zudem die Position der osteuropäischen Staaten gestärkt, die als Lieferanten einspringen könnten. Am Beispiel von Guinea, Nigeria und Madagaskar zeigt Lahr die positiven Auswirkungen militärischer Zusammenarbeit auf die politischen Beziehungen. Generalsekretär Brosio, NATO

Zur Nahost-Krise informiert Carstens, daß mit Israel eine Einigung über die Aufnahme diplomatischer Beziehungen und die Einstellung der Waffenlieferungen erzielt worden sei; offene Fragen gebe es noch hinsichtlich der Kompensation für die Lieferungen. Zur Haltung der arabischen Staaten bemerkt Carstens, noch bestehe die Möglichkeit, daß keiner der Staaten die DDR anerkennen werde. Für sie bleibe die Wirtschaftshilfe der Bundesrepublik „von nicht zu übersehender Bedeutung“. Brosio berichtet, daß auf der kommenden Sitzung des Ständigen NATO-Rats die Lage in Vietnam auf der Tagesordnung stehe und mit amerikanisch-französischen Differenzen zu rechnen sei. Der NATO-Generalsekretär zeigt sich „ernsthaft beunruhigt" über die französische Europa- und NATO-Politik, insbesondere die "unvertretbare Polemik" gegen die USA. Zum Zypern-Konflikt übergehend, bedauert er, daß die USA keine Initiative gezeigt hätten. Angesichts der möglichen sowjetischen Hilfe an die Türkei spricht er sich für eine Erweiterung der multilateralen Verteidigungshilfe aus.

Dröge erläutert, daß hinsichtlich des Alleinvertretungsanspruchs von den „vielen kleinen Freunden“ der Bundesrepublik nicht mehr verlangt werden dürfe als von den Verbündeten. So sei es für die kleineren Staaten kaum einsichtig, daß sie einen Beitritt der DDR zur Weltgesundheitsorganisation verhindern sollten, während die USA und Großbritannien 1963 eine Beteiligung der DDR am Teststopp-Abkommen zugelassen hätten und sie auch für das vorgesehene Astronauten-Bergungsabkommen wünschten. Dröge hält es für erforderlich, auch den Alliier- 
ten gegenüber konsequent zu sein und gegebenenfalls vom Beitritt zu einem multilateralen Abkommen abzusehen, wenn die DDR beteiligt werde.

152 26.03. Aufzeichnung des Ministerialdirektors Krapf

Krapf legt den Stand der Diskussion über den Gomulka-Plan vom 29. Februar 1964 dar. Er hebt hervor, daß die Einbeziehung des westlichen Gebiets der UdSSR ausgeschlossen sei und eine MLF insofern beeinträchtigt würde, als die MLF-Schiffe keine Häfen des vorgesehenen Vertragsgebiets, mithin auch keine deutschen Häfen anlaufen dürften. Der Gomulka-Plan sei zwar von allen NATO-Staaten abgelehnt worden; allerdings hätten mehrere Staaten Interesse an weiteren Gesprächen bekundet. Bei den gegenwärtigen Sondierungen des polnischen Außenministers in Westeuropa habe Premierminister Wilson nun Rapacki „eine Enttäuschung bereitet", indem er die Einbeziehung der in der westlichen UdSSR stationierten Mittelstreckenraketen und eine Verbindung des Plans mit einer Regelung der Deutschland-Frage gefordert habe. Auf Zustimmung sei Rapacki jedoch beim belgischen Außenminister Spaak gestoßen. Mit Blick auf eine mögliche Diskussion in der NATO schlägt Krapf vor, zu erklären, daß ein „wirksames europäisches Sicherheitssystem mit Maßnahmen zur Überwindung der deutschen Spaltung" gekoppelt sein müsse, und auf die Gefahren der polnischen Pläne für das Kräftegleichgewicht in Europa hinzuweisen.

153

29.03. Aufzeichnung des Staatssekretärs Lahr

Lahr faßt ein Gespräch mit dem Abteilungsleiter im französischen Außenministerium, Wormser, zusammen. Auf die Bitte von Lahr, bei der Kreditgewährung an die DDR Zurückhaltung zu üben, erwiderte Wormser, die französische Regierung könne Kredite nicht grundsätzlich verweigern. Der Kreditumfang sei „relativ bescheiden“, und man denke nicht an eine Gleichbehandlung der DDR mit anderen osteuropäischen Staaten. Lahr wies darauf hin, daß auch „bescheidene Anfänge Anlaß zur Besorgnis böten“, weil andere Staaten dem französischen Beispiel folgen könnten.

154

29.03. Botschafter Duckwitz, Neu Delhi, an Staatssekretär Carstens

Duckwitz berichtet, daß „wohlmeinende Freunde der Bundesrepublik" die Entsendung von Bundestagsabgeordneten in die arabischen Staaten während der Nahost-Krise mit Befremden aufgenommen hätten. Es bestehe der Eindruck, daß das Aus- 
wärtige Amt ausgeschaltet worden sei und die Bundesregierung den Ereignissen hilflos gegenüberstehe. Offenbar sei sie selbst nicht von der Richtigkeit ihrer Nahost-Politik überzeugt. Washington

Krapf erklärt sich mit dem amerikanischen Entwurf für eine Drei-Mächte-Erklärung zur Deutschland-Frage grundsätzlich einverstanden und plädiert für eine Veröffentlichung vor dem 8. Mai 1965. Der Ministerialdirektor weist jedoch darauf hin, daß die Bereitschaft der Westmächte, eine aktive Deutschlandpolitik zu betreiben, deutlicher zum Ausdruck kommen sollte. Gegen den von der amerikanischen Botschaft in Moskau angeregten Vorschlag einer Vier-Mächte-Erklärung zum 8. Mai 1965 bestünden jedoch wegen der notwendigen Beteiligung der UdSSR „starke Bedenken“. Krapf teilt mit, das Auswärtige Amt sei um Klärung der französischen Vorstellungen bemüht und werde in diesem Zusammenhang darauf hinweisen, daß es zunächst nur um die Abgabe einer Erklärung gehe, während die konkrete Ausgestaltung einer Deutschland-Initiative später erfolgen könne.

Klaiber berichtet von einer auf persönliche Weisung des Bundeskanzlers Erhard zurückgehenden Demarche beim französischen Staatspräsidenten. Der Botschafter zeigte sich befremdet darüber, daß der französische Außenminister Couve de Murville bei Gesprächen in Rom den 10. Mai 1965 als Termin für eine Außenministerkonferenz zur politischen Einigung Europas abgelehnt habe. Wenn Frankreich nicht positiv für eine europäische politische Zusammenarbeit eintrete, könne eine „schwere Krise" im deutsch-französischen Verhältnis entstehen. De Gaulle begründete die Ablehnung mit der Sorge vor einem Mißerfolg der Konferenz; zunächst müsse nun eine Tagesordnung festgesetzt werden. Spekulationen, daß die verbesserten französisch-sowjetischen Beziehungen die Absage herbeigeführt hätten, seien „völlig unrichtig“. Der Staatspräsident bezweifelte das Interesse der anderen EWG-Staaten an einem politischen Zusammenschluß, weil sie kein „europäisches Europa“, sondern ein von den USA bestimmtes Europa wünschten.

Der Botschafter gibt eine Unterredung mit dem französischen Außenminister wieder. Klaiber bekundete „schwere Enttäuschung" über das Ergebnis der französisch-italienischen Gespräche vom 26. bis 29. März 1965 in Rom. Couve de Murville erklärte dazu, er habe Ministerpräsident Fanfani auf die Not- 
wendigkeit einer Tagesordnung für die geplante Außenministerkonferenz in Venedig hingewiesen. Die italienische Ansicht, da 3 allein ein Treffen die Bemühungen um eine europäische politische Union dokumentiere, halte er für "weder seriös noch präzise". Es gehe darum, zu einer weitgehenden gemeinsamen Außen-, Wirtschafts-, Verteidigungs- und Kulturpolitik sowie zu einer angemessenen Organisation zu gelangen. Der französische Außenminister dementierte jedoch, die Zustimmung zu einer Konferenz von Zugeständnissen in der EWG abhängig gemacht zu haben. Hinsichtlich einer Drei-Mächte-Erklärung zur Deutschland-Frage merkte er an, Staatspräsident de Gaulle habe lediglich einer neuen Initiative zugestimmt. Couve de Murville zeigte sich aber beeindruckt von dem Appell des Botschafters an die „Freundschaftspflicht" und von dem Hinweis, daß die Erklärung nur ein vorbereitender Schritt für eine Deutschland-Initiative sei.

Klaiber informiert über ein Gespräch des Botschaftsrats I. Klasse Fechter mit dem Abteilungsleiter im französischen Außenministerium Lucet. Dieser habe die zögernde Haltung zu einer Außenministerkonferenz der sechs EWG-Staaten mit der mangelnden Bereitschaft einiger Partner zu einem „europäischen Europa" sowie mit der Gefahr eines Fehlschlags erklärt. Fechter habe darauf hingewiesen, daß der Eindruck fehlender französischer Kooperation bei der europäischen Einigung zu einem Umschwung in der offentlichen Meinung der Bundesrepublik führen könne. Negative Reaktionen seien auch bei einer Nichtbeteiligung von Frankreich an der geplanten DeutschlandErklärung zu befürchten. Ausdrücklich habe Lucet die Vermutung zurückgewiesen, daß bei den französischen Überlegungen die Rücksichtnahme auf die UdSSR eine Rolle spiele.

Angesichts der „Befugnisüberschreitungen“ des Vertreters der DDR auf Zypern hält Voigt es für erforderlich, die zyprische Regierung an ihre Vereinbarungen mit der Bundesrepublik zu erinnern. Sollte eine über den üblichen Rahmen hinausgehende Tätigkeit der Handelskammervertretung der DDR zugelassen werden, würde die Bundesrepublik darin eine „Aufwertung des Gewaltregimes" erblicken und sich zu einer Überprüfung ihrer Politik gegenüber Zypern gezwungen sehen. 

an das Auswärtige Amt

Sahm gibt Diskussionen im Ständigen NATO-Rat wieder. Der Staatsminister im britischen Außenministerium, Lord Chalfont, bezeichnete den Abschluß internationaler Abkommen über die Nichtverbreitung und den Nichterwerb von Atomwaffen sowie über den Stopp unterirdischer Atomtests als vordringlich - allerdings nur unter Einbeziehung der UdSSR. Diese sei mit Blick auf die geplante MLF/ANF aber nicht bereit, einem Nichtverbreitungsabkommen beizutreten. Zudem hielt Lord Chalfont es für möglich, auf weiteren Teilgebieten - wie dem „Einfrieren“ von Nuklearwaffen oder regionalen Rüstungskontrollmaßnahmen - Fortschritte zu einer Abrüstung zu erzielen. Staatssekretär Carstens hob die Bedeutung weltweiter Maßnahmen hervor: Ohne die Beteiligung der Volksrepublik China sei ein Beitritt potentieller Nuklearmächte zu einem Nichtverbreitungsabkommen nicht sicherzustellen. Er zeigte sich befriedigt hinsichtlich der Übereinstimmung mit den NATO-Partnern, daß Sicherheitsfragen in Mitteleuropa nur zusammen mit den politischen Problemen zu lösen seien, und forderte dazu auf, sich das sowjetische Interesse an der europäischen Sicherheit für das Ziel der Wiedervereinigung Deutschlands zunutze zu machen.

Carstens berichtet über seine Reise in den Nahen Osten. Er stellt fest, daß die meisten arabischen Staaten voraussichtlich die diplomatischen Beziehungen zur Bundesrepublik abbrechen würden, jedoch ohne die DDR anzuerkennen. Es gebe Anzeichen, daß sich die Araber mit der Existenz Israels abfänden. In einigen Fällen könne die Wiederaufnahme der Beziehungen nach etwa sechs Monaten ins Auge gefaßt werden. Die Haltung der Verbündeten sei wenig solidarisch und ließe sich teilweise als "schlecht verhohlene Schadenfreude“ bezeichnen. Dennoch habe die Nahost-Politik der Bundesregierung auf der Sitzung des Ständigen NATO-Rats vom 31. März 1965 Anerkennung gefunden. Tokio

Krapf bittet Dittmann, den Standpunkt der Bundesregierung zu einer Aufnahme amtlicher Wirtschaftsbeziehungen zur Volksrepublik China klarzustellen. Ein Regierungsabkommen über Wirtschaftsbeziehungen bedeute "keine ins Gewicht fallende Stärkung Pekings“, und es werde nicht erwogen, den Alleinvertretungsanspruch der Volksrepublik China anzuerkennen. Eine Paralle zwischen China- und Deutschland-Frage sei nicht gegeben. 
Carstens informiert Erhard über Schwierigkeiten bei der Ablösung der Waffenlieferungen an Israel. Die Schnellboote könnten nicht, wie vorgesehen, in Italien beschafft werden. Vom Vorschlag des stellvertretenden israelischen Verteidigungsministers Peres, eine französische Werft solle mit Lizenz einer Firma in Bremen die Rümpfe und Antriebsaggregate herstellen, rät Carstens ab. Die Boote seien auch dann eindeutig als Erzeugnisse aus der Bundesrepublik zu identifizieren. Der israelischen Regierung solle daher empfohlen werden, auf „das nächstbeste Modell“ zurückzugreifen.

Lahr spricht sich dafür aus, „als einziges zur Zeit mögliches vertragliches Bindeglied" mit der UdSSR ein Warenabkommen abzuschließen. Die Frage einer Einbeziehung von Berlin (West) solle aus taktischen Gründen nicht im Vorfeld, sondern erst während der Verhandlungen zur Sprache gebracht werden. Um die sowjetische Zustimmung sicherzustellen, müßte ein möglichst attraktives Verhandlungsangebot unterbreitet werden. Darüber hinaus schlägt der Staatssekretär vor, zur Erleichterung der Verhandlungen mit den Ostblock-Staaten bei den drei Westmächten auf eine Änderung der Anordnung der Alliierten Kommandantur vom 21. Mai 1952 hinzuwirken mit dem Ziel, daß Berlin auch ohne entsprechende Klausel als in jedes Abkommen der Bundesrepublik einbezogen gelten solle. Auswärtige Amt

Herwarth berichtet über ein Gespräch mit dem italienischen Außenminister. Fanfani bezeichnete die Verhandlungen mit seinem französischen Amtskollegen Couve de Murville über eine Außenministerkonferenz in Venedig als in der Sache „äußerst hart und enttäuschend“. Die französische Regierung zeige wenig Neigung, auf die belgischen, italienischen und deutschen Vorschläge für eine europäische politische Union einzugehen. Auch den Empfehlungen der Europäischen Beratenden Versammlung zu einer stärkeren Kontrollbefugnis für das Parlament und zur Übertragung der Mittelbewirtschaftung auf die Gemeinschaft stehe Frankreich eher ablehnend gegenüber. Herwarth wies die Möglichkeit einer engen deutsch-französischen Zusammenarbeit in diesen Fragen zu Lasten der anderen Staaten als „indiskutabel“ zurück.

\section{LXXXIV}




\section{Amt}

Berger schildert die niederländische Reaktion auf die Ablehnung der geplanten Außenministerkonferenz der sechs EWGStaaten durch den französischen Staatspräsidenten. Vor allem die Vorgehensweise von de Gaulle errege Anstoß und fordere Zweifel an der Möglichkeit einer gemeinsamen europäischen Politik, zumal sich Frankreich offenbar nicht einmal durch den deutsch-französischen Vertrag vom 22. Januar 1963 in seiner Außenpolitik binden lasse. Bundeskanzler Erhard

Birrenbach berichtet von den gemeinsam mit Ministerialdirigent Pauls geführten Verhandlungen über eine Ablösung der Waffenlieferungen. Ministerpräsident Eshkol verlangte, die zugesagte Wirtschaftshilfe als nicht rückzahlbare Finanzhilfe und nicht nur als Entwicklungsanleihe zu gewähren. In der Weigerung, Schnellboote an Israel zu liefern, sah er eine Diskriminierung, die sich die Bundesrepublik angesichts ihrer „moralischen Verpflichtungen gegenüber Israel einfach nicht erlauben" könne. In einer weiteren Unterredung unter Vorsitz des stellvertretenden Verteidigungsministers Peres kritisierte die israelische Seite, daß die jüngsten Vorschläge der Bundesregierung „in allen Punkten“ von dem am 22. März 1965 erreichten Verhandlungsstand abwichen. In einem „heftigen Wortwechsel“ drohte der Sonderbeauftragte mit dem Abbruch der Verhandlungen und machte die Grenzen der Bereitschaft deutlich, Ersatzlösungen für Vereinbarungen zu finden, die ohnehin „null und nichtig“ seien. Daraufhin schlug Peres vor, das Problem der Schnellboote entweder durch einen französischen Lizenzbau oder durch eine italienische Produktion mit Turbinenaggregaten aus Großbritannien und Dieselmotoren aus der Bundesrepublik zu lösen. Birrenbach hält das ,Alternativangebot in Form von Motoren" trotz erheblicher Mehrkosten für erwägenswert, da keine Genehmigungspflicht der Bundesregierung für diese Lieferung bestehe. Die israelische Seite ziehe hingegen die „französische Variante“ vor.

Carstens informiert über ein Gespräch mit Bundesminister von Hassel, der ihm einen Überblick über die Projekte des Bundesministeriums der Verteidigung in Portugal gab. Hassel führte aus, daß Verzögerungen bei Waffenlieferungen, die aufgrund der vom Auswärtigen Amt erhobenen Bedenken eingetreten seien, zu einer Verstimmung der portugiesischen Regierung geführt hätten. Daher sei der Aufbau verschiedener Stützpunkte der Bundeswehr in Portugal gefährdet. Carstens legte 
dar, daß eine neue Endverbleibsklausel ausgehandelt werden müsse, aus der mit Bestimmtheit hervorgehe, daß die an Portugal gelieferten Waffen nicht in Afrika eingesetzt würden. Dahlgrün

Carstens bittet Dahlgrün um Zustimmung, dem Sudan die Rückzahlung des Ausrüstungshilfe-Kredits in Höhe von 40 Millionen DM für den Fall zu erlassen, daß die diplomatischen Beziehungen zur Bundesrepublik aufrechterhalten würden. Ohnehin sei mit einer Rückzahlung nicht zu rechnen, und angesichts der labilen Lage im Sudan bestehe die Möglichkeit, auf diesem Wege einen weiteren arabischen Staat „aus der Front der radikalen Gruppe herauszubrechen".

Ruete nimmt Stellung zum Vorschlag des Leiters der Handelsvertretung der Bundesrepublik in Budapest, Brückner, mit der ungarischen Regierung eine Erweiterung des Tätigkeitsbereichs der Handelsvertretung zu vereinbaren. Der Ministerialdirigent spricht sich für eine Übernahme von kulturellen Aufgaben sowie von $\mathrm{Pa}$ - und Sichtvermerkbefugnissen durch die Handelsvertretung aus, da dies zur „Höherstufung der beiderseitigen Beziehungen beitrage“. Wegen des Problems der Einbeziehung von Berlin (West) solle die Erteilung von Sichtvermerksbefugnissen jedoch nur mündlich vereinbart werden.

Krapf berichtet von einem Gespräch mit dem französischen Botschafter. Er bedauerte das französische Zögern in den Beratungen über eine Deutschland-Erklärung in der Washingtoner Botschaftergruppe und erläuterte Seydoux den Wunsch, durch eine Drei-Mächte-Erklärung den im unmittelbaren Vorfeld des 8. Mai 1965 als „20jährige Wiederkehr der Beendigung des Krieges" zu erwartenden Bestrebungen der Ostblock-Staaten entgegenzuwirken, „die sowjetische Zone als das ideale Deutschland hinzustellen ". Seydoux wurde darauf hingewiesen, daß eine „bittere Reaktion“ der Öffentlichkeit in der Bundesrepublik zu erwarten sei, wenn bekannt würde, daß eine DeutschlandErklärung am französischen Verhalten gescheitert sei. Bundeskanzler Erhard

Birrenbach informiert über die gemeinsam mit Ministerialdirigent Pauls geführten Verhandlungen mit dem stellvertretenden israelischen Verteidigungsminister Peres. Der Sonderbeauf- 
tragte sieht einen Durchbruch hinsichtlich der künftigen Wirtschaftshilfe für Israel, da nicht mehr über die Art der Hilfe, sondern nur noch über die Möglichkeiten ihrer Verwendung gesprochen worden sei. Auch habe die israelische Seite nicht mehr auf einer Klausel bestanden, die die Wirtschaftshilfe auf eine moralische Verpflichtung der Bundesrepublik zurückführe. Hinsichtlich der Waffenlieferungen zeichne sich eine "carry-over-Klausel" ab, in der die Übereinkunft über eine Umwandlung der Waffenlieferungen festgestellt und Israel eingeräumt werde, im Falle von Schwierigkeiten bei der Umsetzung der Vereinbarung erneut Gespräche aufzunehmen. Auf die Forderung, auch bei Ersatzlieferungen „den dafür angesetzten Betrag auf ein vernünftiges $\mathrm{Ma} \beta$ zu reduzieren", sei die israelische Reaktion nicht endgültig negativ gewesen. Jedoch sei die Bedingung, daß die Panzerlieferungen von den USA nur als „entscheidender Beitrag zum Abschluß der Gesamttransaktion“ übernommen würden, auf Widerspruch gestoßen. Zum israelischen Wunsch nach Assoziierung mit der EWG sei erklärt worden, daß dies derzeit aussichtslos sei und daher nicht unterstützt werden könne. Birrenbach plädiert jedoch dafür, Bereitschaft zu zeigen, sich für Handelserleichterungen zugunsten Israels in der EWG einzusetzen. Schließlich habe die israelische Seite gebeten, neben der geplanten Botschaft der Bundesrepublik in Tel Aviv ein Büro in Jerusalem einzurichten. bach, z. Z. Tel Aviv

Carstens geht von einem großen Interesse der israelischen Regierung an einer Einigung mit der Bundesrepublik aus, nachdem bereits die Ankündigung diplomatischer Beziehungen zu einer Stärkung der israelischen Position geführt habe. Hinsichtlich der in den Verhandlungen angesprochenen „moralischen Verantwortung" der Bundesrepublik verweist Carstens darauf, daß die israelische Regierung 1952 erklärt habe, keine Forderungen mehr ,aufgrund oder in Verbindung mit Schäden, die durch die nationalsozialistische Verfolgung verursacht worden sind“, zu stellen. Der Staatssekretär sieht den Sonderbeauftragten Birrenbach in einer starken Verhandlungsposition, denn das Angebot amerikanischer Panzer, durch das Israel erheblich besser gestellt würde als durch die deutschen Lieferungen, gelte nur bei Zustandekommen einer Gesamtregelung. Falls die israelische Regierung weiterhin "derartige Schwierigkeiten" mache, müßten die Verhandlungen unterbrochen werden.

Ruete hält die Ergebnisse eines Gesprächs mit den Gesandten Hillenbrand (USA), Tomkins (Großbritannien) und Graf d'Aumale (Frankreich) über eine Sitzung des Bundesrates in Berlin 
(West) fest. Hillenbrand betonte im Namen der drei Vertretungen die Notwendigkeit einer rechtzeitigen Konsultation in dieser Frage und signalisierte, da $\beta$ die Sitzung in Berlin voraussichtlich abgelehnt würde. Tomkins und Hillenbrand kritisierten, daß die Risiken, die die Drei Mächte im Zusammenhang mit der letzten Bundestagssitzung in Berlin auf sich genommen hätten, von Teilen der deutschen Öfentlichkeit nicht gewürdigt würden. Hillenbrand bestritt das prinzipielle Recht des Bundestages, in Berlin zusammenzutreten. Er erkundigte sich nach den Absichten der Bundesregierung, Maßnahmen im Interzonenhandel zu ergreifen, falls die Störaktionen auf den Zugangswegen nach Berlin (West) über den 11. April 1965 hinaus fortgesetzt würden.

Rheker gibt eine Unterredung des Ministerialdirektors Krapf mit dem Leiter der jugoslawischen Delegation bei den Wirtschaftsverhandlungen wieder. Lalović erläuterte die Gründe für den geplanten Besuch des Staatspräsidenten Tito in der DDR, den Krapf als Verstoß gegen die 1964 vereinbarte „Wohlverhaltensklausel" ansah. Zu den jugoslawischen Forderungen nach Wiedergutmachung für die Opfer von Verbrechen in der Zeit des Nationalsozialismus erklärte Krapf, daß derartige Leistungen nur solchen Staaten gewährt würden, die die Bundesrepublik "als alleinigen Nachfolger des Deutschen Reiches anerkennten“. Lalović wies darauf hin, daß die DDR die jugoslawischen Ansprüche auf Wiedergutmachung anerkannt und Reparationen gezahlt habe. Er kündigte an, daß Jugoslawien den Internationalen Gerichtshof mit dieser Frage befassen werde.

Steltzer berichtet über Gespräche mit Präsident Nkrumah und dem Staatssekretär im ghanaischen Außenministerium, DeiAnang. Beide erklärten übereinstimmend, daß die Anwesenheit einer Delegation aus der DDR in Accra keine Änderung der ghanaischen Haltung zur Deutschland-Frage bedeute. Steltzer übermittelte die Antwort auf die ghanaischen Kreditwünsche und wies auf Schwierigkeiten bei dem mit deutscher Hilfe erfolgenden Bau einer Fleischfabrik in Ghana hin. Nkrumah zeigte besonderes Interesse an der baldigen Einrichtung eines Bildungsfernsehens in Ghana. Mit Dei-Anang erörtete der Botschafter den geplanten Besuch des ghanaischen Präsidenten in Paris, Bonn, Rom und - „privat“ - in der DDR. Er hob hervor, daß dies ebenso als „Affront" betrachtet werden würde wie ein Aussparen der Bundesrepublik zugunsten der DDR. AbschlieBend hält Steltzer fest, der französische Botschafter Epinat habe der ghanaischen Regierung bereits angedeutet, daß auch Frankreich auf einen Besuch von Nkrumah in der DDR „negativ reagieren“ würde. Steltzer hofft auf deutsch-französische 
Zusammenarbeit in dieser Frage, da die Bundesrepublik anderenfalls „in ganz Afrika einen beträchtlichen Prestigeverlust“ hinnehmen müßte. Birrenbach, z. Z. Tel Aviv

Carstens teilt mit, daß die Bundesregierung über das Angebot diplomatischer Beziehungen und über eine großzügige Ablösung der Waffenlieferungen an Israel nicht hinausgehen werde. Lasse sich Israel darauf nicht ein, werde es die in Aussicht gestellten amerikanischen Panzer nicht erhalten. Der Staatssekretär rechnet auch damit, daß Israel in der Frage der Wirtschaftshilfe einlenken werde. Eine Spezifizierung der künftigen Hilfe sei ebenso abzulehnen wie die "carry-over-Klausel“, nach der im Falle von Problemen bei der Umsetzung der Vereinbarungen die Verhandlungen erneut aufgenommen werden sollten. Schließlich hält es Carstens für bedenklich, im vorgesehenen Schreiben des Bundeskanzlers Erhard an Ministerpräsident Eshkol von „besonderen Beziehungen“ zwischen der Bundesrepublik und Israel zu sprechen. Bundeskanzler Erhard

Der Sonderbeauftragte Birrenbach gibt den Stand der Verhandlungen mit Israel wieder. Die israelische Regierung habe unerwartet angekündigt, die Schnellboote in Frankreich bauen zu lassen; als Hilfe aus der Bundesrepublik wolle sie nur Dieselmotoren in Anspruch nehmen. Ebenso überraschend sei die Erklärung gewesen, daß die USA auf eine Autorisierung durch die Bundesregierung für die Panzerlieferungen an Israel warteten, die aus dem Kontingent für die Bundeswehr bestritten würden. Das Limit von 140 Millionen DM für die Gesamtkosten sei von israelischer Seite im Grundsatz akzeptiert worden. Unter Vorbehalt sei auch die Position der Bundesrepublik zur Wirtschaftshilfe hingenommen worden. Dagegen bestehe Israel nach wie vor auf einer Klausel, nach der die Möglichkeit einer Wiederaufnahme der Gespräche bestünde. Nicht befriedigt hätten die deutsche Stellungnahme zur Lieferung von elektronischen Teilen für die Raketenproduktion an die VAR sowie die Weigerung, in Jerusalem eine Dependance der geplanten Botschaft zu errichten. Besonderen Wert hätten die Gesprächspartner darauf gelegt, in der Veröffentlichung über die Einigung weder von einer „Ablösung“ der Waffenlieferungen zu sprechen noch eine Summe zu nennen. 

Washington

Wieck faßt eine Unterredung des Regierenden Bürgermeisters von Berlin mit Mitarbeitern der Europa-Abteilung im amerikanischen Außenministerium zusammen. Zu den Störaktionen der UdSSR und der DDR auf den Zugangswegen nach Berlin (West) bemerkte Brandt, diese hätten "keine eigentlichen Schäden“ hervorgerufen. Das Verhältnis zwischen Berlin, der Bundesrepublik und den drei Westmächten sei unbeeinträchtigt geblieben. Brandt sprach sich für eine Stabilisierung des Zugangsverfahrens aus. Er bekräftigte das Interesse an einer Verlängerung der Passierschein-Regelung; der Senat werde sich jedoch nicht auf eventuelle Forderungen der DDR einlassen, das Recht des Bundestags auf Zusammenkünfte in Berlin zu beschneiden. Der Ansicht des Regierenden Bürgermeisters, daß ein Stopp des Interzonenhandels im Falle einer Beeinträchtigung der Zugangswege nach Berlin „wirtschaftlich ohne Wirkung“ sei, widersprachen die amerikanischen Gesprächspartner: Es gehe auch um den psychologischen Effekt. Brandt sprach sich für eine Initiative in der Deutschland-Frage aus, hob aber hervor, daß derzeit nicht über die Grenzfragen diskutiert werden könne. Die Osteuropa-Vorschläge des SPD-Abgeordneten Jaksch hielt er für geeignet, die Diskussion ,in die richtige Richtung" zu lenken. Auswärtige Amt

Knappstein informiert über die amerikanische Bewertung der jüngsten sowjetischen Störaktionen im Zusammenhang mit der Bundestagssitzung in Berlin (West). In den USA hätten diese weniger mit Blick auf die UdSSR und die DDR Sorge bereitet als hinsichtlich des Verhältnisses zwischen den Alliierten. Deren Kooperation sei nicht reibungslos gewesen. Der Bundesrepublik werde es „etwas verübelt“, daß der Interzonenhandel, der als Mittel zur Gewährleistung des freien Zugangs nach Berlin (West) bezeichnet werde, ungeachtet der Krise weitergelaufen sei. Kritisch sei auch die Meldung über die geplante Bundesratssitzung in Berlin aufgenommen worden. Positiv vermerkt der Botschafter, daß durch die Zwischenfälle das Deutschland- und Berlin-Problem wieder in das Bewußtsein der Öffentlichkeit gerufen worden sei. Bundeskanzler Erhard

Der Sonderbeauftragte Birrenbach und Ministerialdirigent Pauls übermitteln die Ergebnisse der letzten Verhandlungsrunde mit der israelischen Regierung. Werde die Übernahme der Panzerlieferungen durch die USA geklärt, sei Israel zum 
Verzicht auf die „carry-over-Klausel“ bereit. Entfallen könne auch die gewünschte Erklärung zur Unterstützung der israelischen Position gegenüber der EWG. Die israelische Seite insistiere jedoch auf einer Formel hinsichtlich der besonderen Lage der Deutschen gegenüber den „Juden in aller Welt" und in Israel. Auswärtige Amt

Knappstein berichtet über ein Gespräch des Regierenden Bürgermeisters von Berlin und des SPD-Abgeordneten Erler mit dem amerikanischen Verteidigungsminister. Brandt erläuterte McNamara, daß mit der UdSSR eine Zugangsregelung nach Berlin ausgehandelt werden müsse, da sowjetische militärische Manöver sonst „beliebig“ zur Störung des Verkehrs benutzt werden könnten. Einen Zusammenhang der Störaktionen mit den Vorgängen in Vietnam schlossen Brandt und Erler aus. Beide äußerten sich positiv zum deutsch-französischen Verhältnis, lehnten aber den französischen Vorschlag einer Europäisierung der Deutschland-Frage ab. Zur MLF erklärte Erler, es erscheine sinnvoller, über eine Reorganisation der Nuklearmacht der NATO zu sprechen, bei der die nichtnuklearen Partner ein „faires Mitspracherecht" bei der Strategie und Zielplanung erhielten. Eine weitere Proliferation müsse ebenso verhindert werden wie eine Enttäuschung der „nuklearen have-nots“. McNamara bemerkte daraufhin, daß diese Probleme gerade durch die MLF gelöst werden sollten. Amt

Siegfried gibt eine Unterredung mit dem belgischen Außenminister wieder. Spaak informierte über ein Gespräch mit dem französischen Botschafter in Brüssel, in dem Spitzmuller auf Übernahme des französischen Farbfernsehsystems gedrängt, die Frage einer EWG-Außenministerkonferenz aber nicht erwähnt habe. Spaak äußerte die Vermutung, daß Staatspräsident de Gaulle die Bundesrepublik seit einiger Zeit „zum Narren halte“, um ihre Politik zu „verwirren" und auf den französischen Kurs zu bringen. Der belgische Außenminister zeigte sich besorgt über den „Stillstand“ in der Deutschland-Frage, der die Außenpolitik der Bundesrepublik hemme und bei den Verbündeten wegen mangelnder Erfolgsaussichten von Initiativen zu Ermüdungserscheinungen führe. Siegfried empfiehlt, mit Spaak weiterhin Einvernehmen über die westliche Deutschlandpolitik sicherzustellen, um den in Belgien spürbaren Druck auf erweiterte Beziehungen zur DDR abzuwehren. 

Botschaft in Paris

Meyer-Lindenberg weist die Botschaft an, das französische Informationsministerium auf Bedenken hinzuweisen, die einer Einschaltung der französischen Handelsmission in der Bundesrepublik bei etwaigen Vereinbarungen über die Einführung des von Frankreich entwickelten SECAM-Verfahrens in der DDR entgegenstünden. Ohnehin sei die Einführung eines Farbfernsehsystems in der DDR, das von dem der Bundesrepublik abweiche, „äußerst unerwünscht". Bundeskanzler Erhard

Birrenbach faßt die Ergebnisse der Verhandlungen in Israel zusammen. Erreicht worden sei die Ablösung der Waffenlieferungen durch Zahlung einer "Abstandssumme“, wobei Ersatzlieferungen durch die USA und Frankreich geleistet würden. Keine Absprachen gebe es über die künftige Wirtschaftshilfe an Israel; allerdings sei bereits geklärt, da $\beta$ diese in Form von Anleihen sowie technischer Hilfe und nicht als freie Finanzhilfe geleistet werde. Für Ende Mai sei die Aufnahme diplomatischer Beziehungen vorgesehen. Offen stehe noch der israelische Wunsch, in das vorgesehene Schreiben des Bundeskanzlers Erhard an Ministerpräsident Eshkol einen Passus über die besondere Verantwortung der Bundesrepublik für die Juden in der Welt und in Israel aufzunehmen. Birrenbach teilt nicht die Bedenken, daß diese Formulierung die Grundlage für neue israelische Ansprüche abgeben könnte; mit diesen sei ohnehin zu rechnen. Der Sonderbeauftragte plädiert dafür, sich von der Furcht vor der arabischen Reaktion zu befreien; die Beziehungen zu Israel müßten „ihr eigenes Gewicht haben“. Washington

Ruete informiert über eine Demarche des französischen Botschafters zur Deutschland-Erklärung. Seydoux brachte Erstaunen darüber zum Ausdruck, daß von Botschafter Knappstein bei den Beratungen in der Washingtoner Botschaftergruppe "gewisse Vorbehalte" gegen den französischen Entwurf zum Ausdruck gebracht worden seien, nachdem der Gesandte in Paris, Knoke, dem Text bereits „voll und ohne Einschränkung“ zugestimmt hätte. Die französische Bereitschaft zu der Erklärung werde dadurch in Frage gestellt. In einem weiteren Gespräch mit Seydoux machte Staatssekretär Lahr deutlich, daß Übereinstimmung in der Sache bestehe, die Bundesregierung allerdings durchaus aufgeschlossen sei für britische und amerikanische Änderungswünsche. 

Auswärtige Amt

Knappstein berichtet über Differenzen zwischen Frankreich und den USA bei der Formulierung einer Deutschland-Erklärung der Drei Mächte. Der amerikanische Zusatz zur stärkeren Betonung der Vier-Mächte-Verantwortung sei für Frankreich ebenso unannehmbar wie andererseits für die USA die von Frankreich gewünschte und auch aus deutscher Sicht bedenkliche Erwähnung des notwendigen Einverständnisses der europäischen Nachbarstaaten mit einer Wiedervereinigung Deutschlands. Versuche, eine Kompromißlösung zu finden, seien bisher gescheitert. Offenbar sei Frankreich weder bereit, das "gleichberechtigte" amerikanische Interesse an der Lösung der Deutschland-Frage anzuerkennen, noch die Verpflichtung zur Wiedervereinigung zu bekräftigen. Lediglich die Anwendung des Selbstbestimmungsrechts in beiden Teilen Deutschlands werde vertreten. Es drohe eine Situation, in der die Gegensätze zwischen den Verbündeten in der DeutschlandFrage offen zutage träten.

\section{Klasse Oncken}

Oncken faßt den Inhalt einer Unterredung zwischen Staatssekretär Lahr und dem französischen Geschäftsträger zusammen. Lahr äußerte Unverständnis über die französische Weigerung, dem amerikanischen Zusatzvorschlag bei der Formulierung einer Deutschland-Erklärung zuzustimmen, zumal in Frankreich noch in jüngster Zeit die Vier-Mächte-Verantwortung für Deutschland bekräftigt worden sei. D'Aumale hob hervor, daß in der Washingtoner Botschaftergruppe bereits Einigkeit über den französischen Entwurf bestanden habe, ehe die USA ihre Haltung geändert hätten. Lahr wies darauf hin, daß die Betonung der Interessen der europäischen Völker im französischen Text die Bemühungen der Bundesrepublik erschwere, auch außerhalb von Europa Interesse an der Deutschland-Frage zu wekken. Im übrigen sei es schwierig, den USA das Recht auf Zusatzvorschläge abzusprechen.

Schirmer informiert über ein Gespräch mit dem jordanischen Botschafter. Juma betonte die Notwendigkeit, eine Wiederaufnahme normaler Beziehungen zwischen der Bundesrepublik und Jordanien bereits jetzt vorzubereiten. Er hob hervor, daß aufgrund des jordanischen Einflusses auf der Außenministerkonferenz der Arabischen Liga am 14./15. März 1965 die Anerkennung der DDR sowie die Androhung wirtschaftlicher Maßnahmen gegen die Bundesrepublik und die Westmächte verhin- 
dert werden konnten. Juma schlug vor, in Bonn das geplante Abkommen über Kapitalhilfe noch vor dem zu erwartenden Abbruch der diplomatischen Beziehungen zu unterzeichnen. Schirmer spricht sich dafür aus, diesem Vorschlag zuzustimmen, zumal es sich nur um eine schriftliche Fixierung bereits gemachter Zusagen handele. an Staatssekretär Carstens

Richthofen stellt fest, daß die Aussichten, den angekündigten Abbruch der diplomatischen Beziehungen durch den Sudan abzuwenden, gesunken seien. Jedoch sei angedeutet worden, daß der Bundesrepublik eine Umwandlung der Botschaft in ein Generalkonsulat unter sofortiger Erteilung des Exequaturs angeboten werden solle. Der Botschafter spricht sich für diese Lösung aus, um die entstandene Situation möglichst zu „entdramatisieren“, eine baldige Wiederaufnahme zu erleichtern und zudem die „Kontroll- und Leitfunktion“ der Botschaft über die militärischen und zivilen Hilfsprogramme der Bundesrepublik im Sudan aufrechterhalten zu können. Richthofen weist jedoch darauf hin, daß dies nur eine Alternativlösung sei und er vorerst „uneingeschränkt" um die Vermeidung des Abbruchs der Beziehungen bemüht sei.

Klaiber gibt den Bericht des Abteilungsleiters im französischen Außenministerium, Lucet, über ein Gespräch zwischen dem sowjetischen und dem französischen Außenminister über die europäische Sicherheit und die Deutschland-Frage wieder. Gromyko habe "die alte sowjetische Platte abgespielt" und einen Friedensvertrag mit der Bundesrepublik und der DDR angeregt, in dem auch das „Berlin-Problem auf der Grundlage Berlins als selbständiger Einheit" geregelt werden solle. Sowohl der Bundesrepublik als auch der DDR müsse der Zugang zu Atomwaffen grundsätzlich versperrt bleiben; die Grenze zwischen ihnen müsse ebenso wie die Oder-Neiße-Linie als Staatsgrenze festgeschrieben werden. Hinsichtlich der MLF/ANF habe Gromyko eine „russisch-französische Aktionsgemeinschaft" vorgeschlagen. Couve de Murville habe sich energisch dagegen gewandt, die Deutschland-Frage „durch Kristallisierung der deutschen Teilung" lösen zu wollen, und den engen Zusammenhang mit der europäischen Sicherheit betont. Er habe aber bestätigt, daß hinsichtlich der Grenzen 1945 in Potsdam ein "état de faits" geschaffen worden sei. Auch sei Frankreich, wie die UdSSR, gegen die Beteiligung der Bundesrepublik an einer MLF oder ANF. Ausdrücklich sei auf das französische Interesse hingewiesen worden, gute Beziehungen zur Bundesrepublik zu halten. 

Auswärtige Amt

Der CDU-Abgeordnete berichtet über ein Gespräch mit dem Stellvertreter des ägyptischen Präsidenten. Amer teilte mit, daß der Abbruch der diplomatischen Beziehungen unvermeidlich sein werde, die kulturellen und wirtschaftlichen Beziehungen jedoch trotzdem fortgesetzt werden sollten. Auch sei nicht an eine Anerkennung der DDR gedacht. Amer stellte in Aussicht, die bilateralen Beziehungen auch weiterhin so zu gestalten, ,als wenn der Abbruch nicht stattgefunden haben würde“. Eine Wiederaufnahme der diplomatischen Beziehungen könne unter Umständen bis Anfang September erfolgt sein. Werner berichtet abschließend über die wirtschaftlichen Schwierigkeiten der VAR und stellt fest, daß inzwischen offenbar eine größere Bereitschaft vorhanden sei, sich mit der "speziellen Lage“ der Bundesrepublik gegenüber der arabischen Welt verständnisvoller auseinanderzusetzen. Washington

Carstens übermittelt einen neuen Vorschlag für eine Deutschland-Erklärung der Drei Mächte, der Frankreich jedoch nur im Falle einer amerikanischen Zustimmung vorgelegt werden soll. Er weist die Botschaft zu Sondierungen an, ob der französische Entwurf akzeptabel wäre, wenn darin auf den unveränderten Fortbestand der Vier-Mächte-Verantwortung für Deutschland hingewiesen und - wie vom französischen Außenminister Couve de Murville vorgeschlagen - ein Bezug zur Genfer Direktive vom 23. Juli 1955 hergestellt würde. So könnte dem Wunsch Rechnung getragen werden, das Ziel der Wiedervereinigung zu unterstreichen. Washington

Carstens informiert über eine Unterredung mit dem amerikanischen Botschafter. Er teilte McGhee mit, daß die Bundesregierung einzelne Erklärungen der drei Westmächte erwarte, falls keine Einigung auf eine gemeinsame Deutschland-Erklärung zustande komme. Ferner zeigte er sich besorgt über französische Tendenzen, das nationale Interesse zu sehr hervorzuheben. McGhee äußerte Skepsis zu den Überlegungen des Staatssekretärs, das bisherige Verfahren zur Einbeziehung von Berlin (West) in Verträge dahingehend zu ändern, daß Berlin - falls nicht ausdrücklich anders vereinbart - als in alle Abkommen einbezogen gelte. Auf die Frage von McGhee, ob beim Treffen der vier Außenminister in London über eine Deutschland-Initiative gesprochen werden solle, erwiderte Carstens, die Bundesregierung wolle so lange keine Vorschläge zur Wiedervereinigung 
machen, wie die UdSSR keine Verhandlungsbereitschaft signalisiere. McGhee regte an, wenigstens "prozedurale Vorschläge“ zu unterbreiten.

Blech faßt ein Gespräch des Staatssekretärs Carstens mit dem tansanischen Botschafter zusammen. Kahama trug den Wunsch des Präsidenten Nyerere nach Normalisierung der bilateralen Beziehungen, insbesondere nach Fortsetzung der Wirtschaftshilfe unter Ausschluß der Ausrüstungshilfe, vor. Carstens deutete die Bereitschaft an, die vereinbarte Hilfe weitgehend fortzusetzen; noch stehe jedoch ein entsprechender Kabinettsbeschluß aus. Auf seinen Hinweis, er sei nach wie vor „unglücklich" über die Existenz eines Generalkonsulats der DDR in Tansania, erwiderte Kahama, ein Exequatur sei nicht erteilt worden. Nyerere bemühe sich, die Dienststelle der DDR in Daressalam „schrittweise bis zum vollständigen Verschwinden zu reduzieren".

Klaiber berichtet von einem Gespräch mit dem französischen Außenminister über den Besuch des sowjetischen Außenministers Gromyko vom 25. bis 30. April 1965 in Paris. Couve de Murville betonte, daß der Besuch „völlig unsensationell“ verlaufen sei. Die Verbesserung der Beziehungen und die erzielte Übereinstimmung auf Teilgebieten der internationalen Politik könne nicht zuletzt auch der Bundesrepublik nutzen. In der Deutschland-Frage hätten sich allerdings „die Geister geschieden". Während die UdSSR auf der Zwei-Staaten-Theorie beharre, sei die französische Seite für das Selbstbestimmungsrecht der Deutschen eingetreten und habe eine Anerkennung der DDR abgelehnt. Klaiber bedauerte, daß sowohl diese Stellungnahme als auch eine klare Aussage zur Grenzfrage in dem gemeinsamen sowjetisch-französischen Kommuniqué fehlten, so daß Gromyko in einer Pressekonferenz Übereinstimmung mit Frankreich in diesen Punkten habe behaupten können. Couve sagte eine Richtigstellung zu. amerikanischen Botschafter McGhee

McGhee schildert die Hintergründe für das amerikanische Eingreifen in der Dominikanischen Republik. Er äußert sich kritisch zur französischen Haltung gegenüber der beabsichtigten Deutschland-Erklärung der drei Westmächte. Schröder hält das Schlagwort der „Europäisierung“ insofern für gefährlich, als die Öffentlichkeit dahinter bereits die tatsächliche Lösung des Problems vermute und gleichzeitig "neue Mitspracheberechtigte 
auf der Szene auftauchen könnten". Es sei bedauerlich, daß Frankreich gegenüber der UdSSR und den osteuropäischen Staaten mit einer Anerkennung der Oder-Neiße-Linie und der Unterstützung eines Verbots nuklearer Waffen für die Bundesrepublik operiere. Der Bundesminister befürwortet eine Erörterung der seit dem Vorschlag des Auswärtigen Amts vom 13. August 1963 erarbeiteten Gedanken zu diesem Thema, obwohl ein Konsens wenig wahrscheinlich sei. Solange die Haltung der UdSSR unverändert bleibe, müßten neue Vorschläge, die über einen Appell zur Wiederherstellung der Vier-Mächte-Verantwortung hinausgingen, "unweigerlich zu einer Konsolidierung des Status quo führen". Schröder widerspricht der von McGhee geäußerten Ansicht, die Stagnation der westlichen Deutschlandpolitik sei darauf zurückzuführen, daß die Bundesregierung keine konkreten Vorstellungen entwickelt habe. amerikanischen Botschafter McGhee

Erhard äußert sich zustimmend zum Militäreinsatz der USA in der Dominikanischen Republik und dankt für die Evakuierung von 30 Deutschen. McGhee informiert über die Bemühungen, die amerikanischen Truppen durch eine Friedensstreitmacht der Organisation Amerikanischer Staaten (OAS) zu ersetzen. Er bedauert, daß bislang eine Deutschland-Erklärung der drei Westmächte nicht zustande gekommen sei; eine Aufnahme des französischen Europäisierungsgedankens sei aber unzumutbar. Zu den französischen Vorstellungen stellt Erhard fest, daß dadurch die „gesamte Rechtslage und auch der moralische Anspruch Deutschlands“ zunichte gemacht würden. In einem Europa, wie Staatspräsident de Gaulle es befürworte, „wäre Deutschland nichts anderes als ein französisch-russisches Protektorat".

\section{Klasse Oncken}

Oncken zeigt sich besorgt über den ansteigenden Handel der DDR mit den westlichen Verbündeten und deren wachsende Bereitschaft, der DDR Kredite zu gewähren. Dagegen werde der Ausbau des Interzonenhandels, der nicht nur zur Erhaltung der Verbindungen zwischen den beiden Teilen Deutschlands, sondern auch als Druckmittel im Falle von Berlin-Krisen von Bedeutung sei, dadurch beschränkt, daß keine staatlichen Kreditbürgschaften übernommen würden. Das Bundesministerium der Finanzen und das Bundesministerium für Wirtschaft beabsichtigten, dem Bundeskabinett eine Änderung dieser Haltung ebenso zu empfehlen wie den Wegfall der Widerrufsklausel, die von der DDR durch Vergabe von Großaufträgen an andere Länder umgangen würde. Oncken äußert Bedenken, da dann bei 
kleineren Berlin-Krisen keine Sanktionsmöglichkeiten mehr bestünden. Er weist aber darauf hin, daß die westliche Kreditpolitik es schwer mache, "die IZH-Waffe scharf zu halten“, und empfiehlt, die Außenminister der Drei Mächte zur Fortführung einer restriktiven Handelspolitik gegenüber der DDR zu drängen.

Carstens teilt Shinnar die Entscheidung der amerikanischen Regierung mit, noch keinen bindenden Liefertermin für Panzer an Israel zuzusagen. Shinnar bittet zu prüfen, ob nicht einige für die Bundeswehr vorgesehene Panzer an die USA rückübereignet und "vielleicht nach mehrwöchiger Verschleierungsphase" von den USA an Israel geliefert werden könnten. Hinsichtlich der Aktion "Geschäftsfreund“ erklärt Carstens, die Bundesregierung wolle diese Frage in den Gesamtkomplex der für Israel vorgesehenen Wirtschaftshilfe einordnen. Shinnar hält dagegen an der Auffassung fest, daß die Aktion „Geschäftsfreund" und die in den Besprechungen des Sonderbeauftragten Birrenbach in Tel Aviv erwähnte Wirtschaftshilfe zwei getrennte Vorgänge seien. Carstens betont die Bereitschaft der Bundesregierung, etwa zehn Tage nach Aufnahme der diplomatischen Beziehungen über einen Vorgriff auf die zukünftige Wirtschaftshilfe zu sprechen.

Klaiber gibt Äußerungen des französischen Informationsministers zur deutsch-französischen Zusammenarbeit wieder. Peyrefitte habe vor französischen Journalisten eine "bittere Bilanz" gezogen: Die politische und militärische Kooperation funktioniere nicht, weil die Bundesminister Schröder und von Hassel "von amerikanischen Überlegungen beherrscht" seien. Die Deutschland-Politik der Bundesrepublik sei zwiespältig, weil einerseits die Wiedervereinigung, andererseits gleichzeitig Atomwaffen gefordert würden. Auf die Frage, was Frankreich von der NATO und der SEATO erwarte, habe Peyrefitte geantwortet: „rien“. Außenministern der Drei Mächte in London

Bundesminister Schröder, der britische und der französische Außenminister, Stewart und Couve de Murville, sowie der Staatssekretär im amerikanischen Außenministerium, Ball, einigen sich über den Wortlaut sowie Zeit und Ort der Veröffentlichung einer Deutschland-Erklärung. Schröder erläutert den Wunsch der Bundesregierung, Berlin (West) künftig ohne aus- 
drückliche Erwähnung in alle internationalen Vereinbarungen einzubeziehen. Die Gesprächspartner äußern Bedenken gegen diese Umkehrung der Berlin-Klausel und bitten um die Ausarbeitung eines Memorandums. Um eine Aufwertung der DDR durch Intensivierung des Handels zu verhindern und insbesondere um ihre Abhängigkeit vom Interzonenhandel zu erhalten, schlägt Schröder vor, eine gemeinsame „Strategie“ für den Handel mit der DDR zu entwickeln. Die Gesprächspartner äußern Bedenken gegen dieses Vorhaben.

Carstens informiert die Botschafter in den arabischen Staaten über den Abschluß der Verhandlungen mit Israel und den Termin der Veröffentlichung des gemeinsamen Kommuniqués. Die Botschafter werden angewiesen, den arabischen Staatsoberhäuptern bzw. Regierungschefs am 12. Mai 1965 ein Schreiben des Bundeskanzlers Erhard zu übergeben und sie über den Inhalt des Kommuniqués und des Briefwechsels zwischen Erhard und Ministerpräsident Eshkol zu unterrichten. In diesem Zusammenhang sei der zivile Charakter der Vereinbarungen ebenso hervorzuheben wie die Tatsache, daß keine gegen die arabischen Staaten gerichteten Abmachungen getroffen worden seien. Auf etwaige Fragen nach künftiger Entwicklungshilfe an die arabischen Staaten solle geantwortet werden, daß sich ein Abbruch der diplomatischen Beziehungen zur Bundesrepublik „kaum günstig“ auswirken könne, auch wenn die Leistungen nicht eingestellt würden.

Meyer-Lindenberg hält fest, daß die französische Regierung Großbritannien und den USA vorgeschlagen habe, das Problem der Entflechtung der deutschen Kohle- und Stahlindustrie abzuschließen, da diese Frage „obsolet geworden“ sei. Überlegungen zur Lösung des Entflechtungsproblems gebe es auch bei der Firma Krupp. Sie wolle Aktien in einer Höhe verkaufen, die dem nach der Anordnung der Combined Steel Group vom 4. März 1953 unter Verkaufsauflage stehenden Teil des Firmenkapitals entspräche, und werde keinen weiteren Verlängerungsantrag zur Aussetzung der Verkaufsfrist stellen. Damit wäre die Tätigkeit des Gemischten Ausschusses beendet. In diesem Ausschuß hätte bislang jedoch nur der französische Vertreter Leduc der Auffassung von Krupp Verständnis entgegengebracht, daß lediglich das 1953 vorhandene Aktienkapital der Verkaufsauflage unterstehe. Meyer-Lindenberg schlägt vor, die französische Initiative positiv aufzunehmen und Frankreich über das geplante Vorgehen von Krupp zu unterrichten. 

Lindenberg

Meyer-Lindenberg weist auf die Notwendigkeit hin, zu den zwischen Frankreich und der EURATOM vereinbarten Modalitäten für die Durchführung von Sicherheitskontrollen Stellung zu nehmen, weil ansonsten der Eindruck stillschweigenden Einverständnisses entstünde. Zwar sei mit französischer Verärgerung zu rechnen, wenn die Bundesrepublik Bedenken anmelde; jedoch sollte die Bundesrepublik angesichts „der harten, auf das nationale Interesse" ausgerichteten französischen Haltung in EWG-Fragen ein „Verhandlungspfand" für die Gespräche über die Fusion der Europäischen Gemeinschaften in der Hand behalten. Meyer-Lindenberg schlägt vor, der EURATOM-Kommission ein Aide-mémoire über die deutschen Einwände zuzustellen und Frankreich zuvor in Kenntnis zu setzen. amerikanischen Außenminister Rusk in London

Die Gesprächspartner zeigen sich befriedigt über die am Vortag veröffentlichte Deutschland-Erklärung der drei Westmächte. Schröder äußert Besorgnis darüber, daß Frankreich sich unter dem Stichwort „Europäisierung“ der Deutschland-Frage mit der UdSSR und den osteuropäischen Staaten beispielsweise über die Oder-Neiße-Linie und eine „Denuklearisierung“ der Bundesrepublik verständige, obwohl diese Probleme nicht allein von diesen Staaten geregelt werden könnten. Rusk führt die französische Haltung darauf zurück, daß der von Staatspräsident de Gaulle angestrebte Status in Europa eine Abhängigkeit der Bundesrepublik voraussetze. Die Gesprächspartner klären wechselseitige Mißverständnisse hinsichtlich der Haltung zum MLF-Projekt; der Bundesminister befürwortet eine Fortsetzung der Beratungen in der MLF-Arbeitsgruppe. Zur DeutschlandFrage erklärt er, daß von seiten der Bundesregierung keine weiteren Vorschläge in der Washingtoner Botschaftergruppe zu erwarten seien. Er sei aber bereit, „sehr diskret und auf persönlicher Grundlage bilateral gewisse Fragen der künftigen Entwicklung weiterzuerörtern“. Schröder hebt hervor, daß eine Wiedervereinigung Deutschlands nur möglich sei, wenn die USA ihr ganzes Gewicht für dieses Ziel einsetzten. tunesischen Botschafter Ben Ayed und dem marokkanischen Botschafter Boucetta

Erhard zeigt sich erfreut, daß Tunesien und Marokko - anders als die übrigen arabischen Staaten - die diplomatischen Beziehungen zur Bundesrepublik nicht abgebrochen haben. Er versichert, die Bundesregierung wünsche eine Wiederherstellung des traditionellen deutsch-arabischen Freundschaftsverhältnis- 
ses und werde die Waffenlieferungen an Israel nicht fortsetzen. Die Botschafter betonen, daß keinerlei Zusammenhang zwischen der Entscheidung zur „Aufrechterhaltung der freundschaftlichen Bande " und der Entwicklungshilfe der Bundesrepublik bestehe. Sie mißbilligen den Botschafteraustausch mit Israel, geben jedoch ihrer Freude Ausdruck, daß mit der Einstellung der Waffenlieferungen an Israel gerade das Problem beseitigt sei, das die jüngste Krise im Nahen Osten ausgelöst habe. Brüssel

Lahr gibt ein Gespräch mit dem malischen Außenminister wieder. Ba berichtete über Schwierigkeiten mit Frankreich, das nach positiv verlaufenen Verhandlungen über Wirtschaftshilfe seine Unterstützung plötzlich davon abhängig gemacht habe, daß Mali „bedingungslos" der Westafrikanischen Währungsunion beitrete. Dieser „Rückfall in kolonialistische Methoden“ sei für Mali unannehmbar. Ba bat um Unterstützung, weil ohne französische Zuwendungen das malische Entwicklungsprogramm in Frage gestellt wäre. Lahr erläuterte, daß allein aufgrund unterschiedlicher Prinzipien der Entwicklungshilfe die Bundesrepublik nicht an die Stelle von Frankreich treten könne. Obwohl sich aus politischen Gründen „offensichtlich Vorsicht" empfehle, spricht sich der Staatssekretär für eine Hilfe zum malischen Entwicklungsprogramm aus und bittet um Prüfung der Möglichkeiten. Auswärtige Amt

Schroeder informiert über eine Unterredung mit Präsident Nyerere und dem Staatssekretär im tansanischen Außenministerium, Lukumbuzya. Nyerere äußerte sich zur Auffassung der Bundesregierung, daß die „Beibehaltung einer Zonenvertretung" in Form eines Konsulats der DDR auf Sansibar eine erneute Beeinträchtigung der Beziehungen bedeute. Er habe angenommen, daß dies nach der Eröffnung eines Generalkonsulats der DDR in Daressalam „ohne Belang“ sei. Der Botschafter wies darauf hin, daß ihm zugesagt worden sei, die DDR dürfe nur eine Vertretung in Tansania errichten und dem Generalkonsulat werde kein Exequatur erteilt. Lukumbuzya erklärte, "nach innerstaatlichem tansanischem Recht" sei ein Exequatur erforderlich, das jedoch die gleiche Nichtanerkennungsklausel wie für das Generalkonsulat der DDR in Kairo enthalten werde. Schroeder bemerkte daraufhin, daß diese Haltung die bevorstehende Entscheidung des Bundeskabinetts über die Fortsetzung der Entwicklungshilfe ungünstig beeinflussen könne. Der Bot- 
schafter spricht sich abschließend dafür aus, die Entwicklungshilfe an Tansania fortzusetzen, da ansonsten mit einer "TrotzReaktion“ bis hin zur Anerkennung der DDR zu rechnen sei.

Carstens faßt eine Unterredung mit dem Staatssekretär im Bundesministerium der Verteidigung, Gumbel, zusammen. Ausgehend von der Annahme, daß Frankreich aus der NATO ausscheiden werde, regte Carstens eine Prüfung an, wie die Verteidigung von Deutschland und Europa dann sicherzustellen sei. Gumbel ging davon aus, daß eine deutsch-französische Vereinbarung über eine gemeinsame Verteidigung nicht möglich sein würde, da Frankreich vermutlich das Ausscheiden der Bundesrepublik aus der NATO zur Vorbedingung machen würde. Carstens sprach sich dafür aus, die NATO mit den übrigen Partnern in der bisherigen integrierten Form fortzusetzen und eine befriedigende Zusammenarbeit mit Frankreich zu organisieren. Anderenfalls müßten ,sehr bedeutende organisatorische Veränderungen" in der Bundesrepublik erfolgen.

Sachs hält fest, daß die Ausrüstungshilfe an Äthiopien, neben Waffenlieferungen als „Polizeihilfe“, unter der Rubrik „Fahrzeuge" in der Materialaufgliederung zusätzlich in Großbritannien zu beziehende Schützenpanzer beinhalte. Eine Stornierung dieser Lieferungen würde der Bundesrepublik die Möglichkeit nehmen, den Betrag auf die Devisenhilfe an Großbritannien anzurechnen. Das Bundesministerium der Verteidigung schlage daher vor, Äthiopien den direkten Bezug der Panzer in Großbritannien zu empfehlen. Die Kosten würden von der Bundesrepublik übernommen und auf die Devisenhilfe angerechnet.

Carstens faßt die Ergebnisse von Gesprächen mit Bundesminister von Hassel und dem Staatssekretär im Bundesministerium der Verteidigung, Gumbel, über die Waffenlieferungen an Portugal zusammen. Hassel hob den geringen Umfang der noch ausstehenden Restlieferungen hervor. Gumbel erklärte, die zuständigen Stellen der Bundeswehr drängten darauf, „überschüssiges Material“ abstoßen zu können. Carstens sagte eine Überprüfung der Durchführung von Restlieferungen zu, erklärte aber auch, daß er grundsätzlich die Verschrottung von altem Material einem Verkauf und dadurch hervorgerufenen "politischen Schwierigkeiten größten Ausmaßes" vorziehe. 

Lindenberg

Meyer-Lindenberg befaßt sich mit den Bedenken des Generaldirektors für auswärtige Angelegenheiten bei der EWG, Herbst, gegen die Ausweitung des Assoziierungssystems der Gemeinschaft in Afrika. Er stellt dazu fest, daß das Handelsvolumen mit Lateinamerika trotz der bevorzugten Stellung der assoziierten afrikanischen Staaten schneller gestiegen sei. Grundsätzlich befürwortet er einen allgemeinen Abbau der Zölle und Kontingente, wodurch sich das Problem der Präferenzen von selbst lösen würde. Als Ausgleich sollte die Entwicklungshilfe der EWG an die afrikanischen Staaten verstärkt werden. Obwohl der Ministerialdirektor einräumt, daß die Begrenzung der Assoziierungen auf europäische Länder die Politik der EWG erleichtern würde, spricht er sich für eine Assoziierung auch der Maghreb-Staaten aus. Dafür sprächen sowohl die durch den EWG-Vertrag vom 25. März 1957 bestehende „moralische Bindung" als auch die politische Erwägung, daß anderenfalls eine stärkere Anlehnung dieser als Verbindung zu Schwarzafrika wichtigen Staaten an den Ostblock zu befürchten sei. Hinsichtlich Israels sieht Meyer-Lindenberg keine Möglichkeit zur Änderung der EWG-Politik; allerdings sei das Handelsabkommen für Israel unzureichend. Grundsätzlich seien Handelserleichterungen auf multilateraler Ebene anzustreben, wenn Assoziierungen nicht in Frage kämen. von Hardenberg

Hardenberg legt die pakistanischen Wünsche hinsichtlich einer Ausrüstungshilfe dar, die vor allem in Maschinen und dem Know-how für die Eigenherstellung von Maschinengewehren bzw. für den Schiffbau sowie in einer zusätzlichen Lieferung von Maschinengewehren bestehen soll. Da er im Falle einer Ablehnung eine Belastung der Beziehungen zu Pakistan befürchtet, das bislang dem arabischen Druck auf Revision seiner Deutschland-Politik erfolgreich widerstanden und auch Indonesien günstig beeinflußt habe, plädiert Hardenberg dafür, dem pakistanischen Ersuchen entgegenzukommen. Allerdings sei die Lieferung fertiger Maschinengewehre als Baumuster auf ein Minimum zu beschränken. Auch sollten die Absprachen mit den betreffenden Firmen getroffen werden und „keine finanziellen Verpflichtungen der Bundesregierung" beinhalten.

Schröder erläutert die zwischen der EURATOM-Kommission und Frankreich getroffene Vereinbarung über die Durchführung von Sicherheitskontrollen, die eine „erhebliche Abschwächung" der im EURATOM-Vertrag vom 25. März 1957 vorgese- 
henen Bestimmungen und zudem eine Ausnahmeregelung zugunsten Frankreichs darstelle, die dem Grundsatz der Gleichbehandlung widerspreche. Änderungsversuche seien jedoch aussichtslos und „politisch bedenklich“. Schröder schlägt vor, sich eine Stellungnahme zu der Vereinbarung vorzubehalten, um bei der Verschmelzung der drei Gemeinschaften darauf zurückkommen zu können.

Carstens weist die Botschaft an, bei dem geplanten Gespräch mit Präsident Sukarno das Interesse der Bundesregierung an der Pflege der Beziehungen mit Indonesien zu unterstreichen, das auch in der Bereitschaft des Bundestagspräsidenten Gerstenmaier zu einem Besuch zum Ausdruck komme. Auch solle Befriedigung darüber zum Ausdruck gebracht werden, daß nach Aussagen der indonesischen Minister Oemarjadi und Hasan keine Änderung der Deutschlandpolitik zu erwarten sei. Gleichzeitig sei darauf hinzuweisen, daß eine etwaige Anerkennung der DDR als „ein schwerer Affront gegen Deutschland" und als Bruch bisheriger indonesischer Erklärungen angesehen würde, der auf eine Isolierung von Indonesien innerhalb der afro-asiatischen Staaten hinausliefe. Auch müsse mit einem Abbruch der Beziehungen durch die Bundesrepublik gerechnet werden. französischen Außenminister Couve de Murville

Der Bundesminister erläutert das Interesse an einer Konferenz der Staats- und Regierungschefs der EWG-Staaten. Er betont den "demonstrativen Wert" und hofft auf eine Einigung hinsichtlich regelmäßiger Zusammenkünfte. Zu seinen Gesprächen mit dem sowjetischen Außenminister Gromyko erklärt Couve de Murville, daß die Unterredung am 16. Mai 1965 in Wien nichts Neues erbracht habe. Schröder weist auf die Sorge über die französische Haltung zur Oder-Neiße-Linie hin. Er bittet, die in der Erklärung der drei Westmächte vom 26. Juni 1964 enthaltene Sprachregelung, wonach die Grenzfragen einem Friedensvertrag vorbehalten blieben, einzuhalten. Der französische Außenminister hält die Unzufriedenheit in der Bundesrepublik für einen Ausdruck der verschlechterten Beziehungen, nachdem der deutsch-französische Vertrag vom 22. Januar 1963 „überhaupt nicht funktioniert habe". Es schließt sich eine Diskussion um den Begriff der "Europäisierung“ der Deutschland-Frage an. Während Couve de Murville erklärt, daß eine Wiedervereinigung Deutschlands kaum ohne Beteiligung der angrenzenden Staaten vorstellbar sei, betont Schröder, daß die Bundesrepublik wohl die Interessen, nicht aber ein Mitspracherecht anderer Staaten anerkennen könne. Über die „absolute Priorität“ der Vier-Mächte-Verantwortung müsse Konsens bestehen. 
Staatssekretär Carstens dankt der französischen Regierung für die Übernahme der Schutzmachtvertretung in fünf der zehn arabischen Staaten infolge des Abbruchs der diplomatischen Beziehungen zur Bundesrepublik. Er urteilt, der entstandene "Schaden sei nicht irreparabel“. Offenbar würden weder die VAR noch der Jemen die DDR diplomatisch anerkennen, wenn auch weiterhin mit der Errichtung eines ägyptischen Generalkonsulats in Ost-Berlin zu rechnen sei. Es gebe schon Hinweise, daß einige Staaten die Beziehungen bald wiederherzustellen wünschten. Hinsichtlich der geplanten Konferenz der blockfreien Staaten in Algier hebt Carstens die Gefahr einer Thematisierung der Deutschland-Frage hervor und zeigt sich besorgt über die Politik Indonesiens. Der Abteilungsleiter im französischen Außenministerium, Lucet, teilt den Eindruck des Staatssekretärs, daß der chinesische Einfluß in Tansania groß sei, aber insgesamt für Afrika nicht überschätzt werden solle. Abschließend erläutert Carstens die Probleme bei den unterbrochenen Verhandlungen mit der Tschechoslowakei über den Austausch von Handelsvertretungen. Während er die mit dem Münchener Abkommen von 1938 zusammenhängenden Schwierigkeiten für überwindbar hält, sieht er für die entscheidendere Frage einer Einbeziehung von Berlin (West) noch keine Lösung.

Staatssekretär Carstens informiert über seine Unterredung mit dem Abteilungsleiter im französischen Außenministerium, Lucet. Anschließend berichten Staatssekretär Lahr und der Abteilungsleiter im französischen Außenministerium, Wormser, über ihre Erörterung der Finanzprobleme der EWG. Einigkeit sei über das Verfahren zur Behandlung der Vorschläge der EWG-Kommission erzielt worden. Über die Vorschläge selbst bestünden jedoch Meinungsverschiedenheiten, insbesondere hinsichtlich einer Überweisung der Einnahmen aus den Abschöpfungen und aus dem gemeinsamen Zolltarif an die Gemeinschaft. Nach französischer Auffassung sollten letztere nicht an die Gemeinschaft gehen, sondern unter den Mitgliedern verrechnet werden. Differenzen seien ferner hinsichtlich des Vorschlags der EWG-Kommission für die Finanzierung der Agrarpolitik zu verzeichnen. Auch die Frage einer Ausweitung der Haushaltsbefugnisse des Europäischen Parlaments sei strittig. Frankreich sei allenfalls bereit, Änderungsvorschläge des Parlaments zum Haushalt zuzulassen, über die mit den Räten der Gemeinschaften beraten würde. 

Auswärtige Amt

Knappstein berichtet über die Bewertung der Londoner NATOMinistertagung im amerikanischen Außenministerium. Die Befürwortung der Deutschland-Erklärung der Drei Mächte und die Gespräche des griechischen und des türkischen Außenministers, Kostopoulos und Isik, über Zypern seien die erfreulichsten Entwicklungen der Konferenz gewesen. Angesichts der unklaren französischen Haltung müsse die Planung über die zukünftige Gestaltung des Bündnisses in den Vordergrund gerückt werden. Entsprechende Diskussionsgrundlagen habe der Staatssekretär im amerikanischen Außenministerium, Ball, im NATO-Ministerrat bereits unterbreitet. Aus Sicht des amerikanischen Außenministeriums sei zunächst „unter Wahrung größter Diskretion" eine grundsätzliche Übereinkunft zwischen den USA, Großbritannien und der Bundesrepublik anzustreben.

Lahr hält es „nicht für glücklich“, daß im Zusammenhang mit einer eventuellen Aufnahme diplomatischer Beziehungen zu den Ostblock-Staaten immer Rumänien an erster Stelle genannt wird. Rumänien müsse deutlich gemacht werden, daß dies keine Selbstverständlichkeit sei und auch Gegenleistungen insbesondere in der Frage der Familienzusammenführung erwartet würden. Daher zeigt sich Lahr befriedigt über den bulgarischen Wunsch, der erste Ostblock-Staat mit diplomatischen Beziehungen zur Bundesrepublik zu werden.

Carstens faßt die Ergebnisse einer Ressortbesprechung im Bundeskanzleramt über den Interzonenhandel zusammen. Erörtert wurde die Frage, ob bei einzelnen Geschäften mit der DDR auf eine Widerrufsklausel verzichtet werden könne, da dies die Voraussetzung für langfristige Anlagegeschäfte westdeutscher Firmen in der DDR sei. Carstens wies darauf hin, daß der Zeitpunkt für einen Verzicht auf die Widerrufsklausel ungünstig sei, da die Westmächte gerade zu einer Koordinierung des Handels mit der DDR bewegt werden sollten. Jedoch wurde festgestellt, daß unter den gegebenen Bedingungen „interessante Geschäfte“ in andere westliche Staaten gingen und daher der Interzonenhandel zunehmend „seinen Charakter als Druckmittel“ gegenüber der DDR verliere. Es wurde beschlossen, Gespräche mit den Westmächten aufzunehmen und ihnen mitzuteilen, daß im Einzelfall auf die Widerrufsklausel verzichtet werden solle. Bei einer „ernsteren“ Berlin-Krise müsse der Interzonenhandel etwa durch fristlose Kündigung des Abkommens über den Interzonenhandel - gestoppt werden. 

Lindenberg

Meyer-Lindenberg hält fest, daß angesichts des Abbruchs der diplomatischen Beziehungen durch Algerien eine Überprüfung der Haltung der Bundesrepublik zu den Assoziierungsverhandlungen zwischen Algerien und der EWG notwendig sei. Er rät von Maßnahmen gegen Algerien ab, da diese das ,nicht gewollte Ergebnis" einer Anerkennung der DDR nach sich ziehen könnten und zudem Algerien nicht als einziger der arabischen Staaten „besonders bestraft" werden dürfe. Im Zuge der Verhandlungen zwischen der EWG und Algerien böte sich der Bundesrepublik je nach algerischem Verhalten immer noch die Möglichkeit, ein Assoziierungsabkommen zu verzögern oder zu verhindern.

Lahr faßt die Ergebnisse eines Besuchs in Rumänien zusammen. Der Staatssekretär sieht die besten Voraussetzungen für eine Intensivierung des Verhältnisses im wirtschaftlichen Bereich. Allerdings müsse die Einfuhrpolitik der Bundesrepublik liberalisiert werden. Die rumänische Regierung sei auch gegenüber einem Kulturabkommen positiv eingestellt. Lahr stellt fest, daß Rumänien auf eine „volle Normalisierung“ der Beziehungen hoffe, wenn dies auch nicht ausdrücklich thematisiert worden sei. Der rumänische Außenminister Manescu und Ministerpräsident Maurer hätten sich gegenüber der Familienzusammenführung aufgeschlossen gezeigt, allerdings auf die mit einer Erhöhung der Ausreisegenehmigungen verbundenen wirtschaftlichen Schwierigkeiten hingewiesen. Dafür habe er, Lahr, Gegenleistungen in Aussicht gestellt.

Krapf hält den Stand der Diskussion über das Problem der „Temporary Travel Documents" (TTD) fest. Er informiert über den Beschluß des Politischen Ausschusses der NATO, die seit dem 18. März 1964 bestehende TTD-Regelung zwar nicht zu modifizieren, jedoch „elastischer anzuwenden“. Die Bundesrepublik habe ihren Standpunkt durchsetzen können, daß hohen Funktionären aus der DDR keine TTDs erteilt werden dürften. Schwieriger sei jedoch die Behandlung „nationaler Delegationen und Mannschaften", zumal die Bundesrepublik für internationale Veranstaltungen einer Lockerung der TTD-Sperre zugestimmt habe. Insgesamt stellt Krapf zunehmende Kritik am TTD-System fest. Der Öffentlichkeit in den NATO-Staaten sei kaum verständlich zu machen, daß Deutsche aus der DDR frei in die Bundesrepublik einreisen dürften, in anderen Staaten jedoch den TTD-Beschränkungen unterworfen würden. 

sekretär U Thant, UNO, in New York

Erhard stellt die Notwendigkeit einer Lösung der DeutschlandFrage für den Frieden in Europa heraus. Er hebt die Bereitschaft zu verstärkter Entwicklungshilfe und zur Beteiligung an dem von Präsident Johnson vorgeschlagenen Entwicklungsprogramm für Südost-Asien hervor. U Thant sieht „das Grundproblem in der Welt" in der wirtschaftlichen Lage vieler Staaten und weist auf die Leistungen der UNO auf dem Gebiet der technischen Hilfe hin. Die Auffassung, daß eine Hauptaufgabe der Industrienationen in der Weitergabe ihrer Erfahrungen liege, wird von Erhard geteilt. Sinnvoll seien kleinere Investitionen in Entwicklungsländern, die der Bevölkerung Arbeitsmöglichkeiten böten. amerikanischen Außenminister Rusk in Washington

Rusk erläutert die Anregung des amerikanischen Verteidigungsministers McNamara, ein Gremium für nukleare Zusammenarbeit in der NATO zu bilden. Es handele sich um einen „Vorschlag zu technischen Diskussionen“, der unabhängig von einer MLF zu sehen sei. Zur französischen Haltung gegenüber der NATO erläutert Schröder, Staatspräsident de Gaulle sei ein Gegner der Integration und scheine eine Organisation auf der Grundlage bilateraler Verpflichtungen zu bevorzugen. Dessen propagierte europäische Verteidigungsorganisation befinde sich offenbar noch im Stadium der „psychologischen Vorbereitung“; ein Konzept liege noch nicht vor. Die Partner, die an der NATO festzuhalten wünschten, sollten dies deutlich erklären, um dem Eindruck entgegenzuwirken, daß es nur die Alternative zwischen Reform und Auflösung der Allianz gebe. Der amerikanische Außenminister äußert sich im gleichen Sinn und hebt hervor, daß ein „Bilateralismus“ für die USA nicht in Frage komme. amerikanischen Außenminister Rusk in Washington

Der amerikanische Außenminister schildert den Stand des Vietnam-Konflikts. Alle diplomatischen Bemühungen um Verhandlungen mit der Demokratischen Republik Vietnam (Nordvietnam) seien ergebnislos geblieben. Es gebe keine Anzeichen für ein militärisches Eingreifen der UdSSR oder der Volksrepublik China; zugenommen habe aber die Infiltration nordvietnamesischer Truppenteile in die Republik Vietnam (Südvietnam). Die USA wünschten keinen großen Krieg, würden aber von ihren Verpflichtungen in Vietnam nicht zurücktreten. Die Bombardierung nordvietnamesischer Städte solle diese Entschlossenheit demonstrieren. Die USA seien bemüht, die "sehr schwere und gefährliche Krise" unter Kontrolle zu halten. Der Bundesmini- 
ster hebt die Bedeutung der Konsultation der NATO-Partner hervor und erkundigt sich dann nach der Situation in der Dominikanischen Republik. Rusk informiert über den Beschluß der Organisation Amerikanischer Staaten (OAS), eine Delegation zur Normalisierung der Verhältnisse zu entsenden, und zeigt sich diesbezüglich „mäßig optimistisch“. Washington

Der Staatssekretär im amerikanischen Außenministerium äußert Kritik an der Politik des französischen Staatspräsidenten, die zu einer Zerstörung der NATO zu führen drohe. Den Vorschlag von Ball, Bundeskanzler Erhard möge bei der bevorstehenden deutsch-französischen Zusammenkunft seinen Einfluß geltend machen, hält Bundesminister Schröder für wenig aussichtsreich angesichts der fehlenden Neigung von de Gaulle, „auf die Deutschen Rücksicht zu nehmen“. Statt dessen vertritt er die Ansicht, daß die NATO-Partner ihre Absicht zur Fortsetzung des Bündnisses über das Jahr 1969 hinaus bekräftigen sollten, obwohl Frankreich kaum zur Kooperation bewegt werden könne, da es „keine echten Druckmittel“ gebe. Auf das verbesserte Verhältnis der Bundesrepublik zu den osteuropäischen Staaten angesprochen, erläutert Schröder, daß eine unmittelbare Wirkung zugunsten der Wiedervereinigung davon nicht erwartet werde. Überlegungen zur Möglichkeit einer Aufnahme diplomatischer Beziehungen bedeuteten keine Änderung des Standpunkts hinsichtlich der Alleinvertretung. In bezug auf die Deutschland-Frage wünscht Schröder einen informellen Austausch zwischen der Bundesrepublik und den USA, bevor die Beratungen in der Washingtoner Botschaftergruppe fortgesetzt würden. Man könne „nicht von Anfang an alle Konzessionen sozusagen ins Schaufenster legen“. an das Auswärtige Amt

Ungern-Sternberg informiert über die Besprechungen des Bundesministers Scheel mit dem britischen Außenminister. Stewart bezeichnete die Devisenhilfe als wichtigstes Problem in den deutsch-britischen Beziehungen und erkundigte sich, inwieweit die Vergabe von Aufträgen für die Entwicklungshilfe an Großbritannien zu einer Lösung beitragen könnte. Stewart nahm dann zu einem Beitritt zur EWG Stellung, den er längerfristig als „Notwendigkeit für Großbritannien“ ansehe. Hauptproblem bleibe die Haltung des Staatspräsidenten de Gaulle. Auf die Frage von Scheel, wie er den Vorschlag der britischen Liberalen Partei beurteile, ein dem deutsch-französischen Vertrag vom 22. Januar 1963 ähnliches Abkommen mit der Bundesrepublik abzuschließen, antwortete Stewart ausweichend. 
231 03.06. Gespräch des Bundesministers Schröder mit dem amerikanischen Sicherheitsberater Bundy in Washington

Bundy erläutert die Hintergründe der Situation in der Dominikanischen Republik und konstatiert, die "unmittelbare Gefahr“ sei durch die Anwesenheit lateinamerikanischer Truppen entschärft. Hinsichtlich der Lage in Vietnam stellt er eine Konkurrenzsituation zwischen der UdSSR und der Volksrepublik China fest, wobei letztere ihre Unterstützung für die Demokratische Republik Vietnam (Nordvietnam) bislang auf Worte beschränke. Bundy rechnet mit einem langwierigen Kampf in Vietnam. Auf seine Frage nach der Einschätzung der französischen Politik antwortet der Bundesminister, das Verhältnis zu Frankreich sei bis in die SPD hinein „eine Art Glaubensbekenntnis“. Ein Ausgangspunkt für "vernünftige" Beziehungen sei noch nicht erreicht. Im Hinblick auf die Deutschland-Frage betont Schröder die Gefahren des französischen Eintretens für eine Europäisierung, da dadurch der „Appetit anderer europäischer Länder gereizt werde“. Die Idee, daß ein „Kartell“ kleinerer Staaten eine Regelung herbeiführen könnte, sei „Unsinn". Trotz der durch die französische Haltung bevorstehenden Schwierigkeiten in der NATO ist der Bundesminister von deren Bewährung im Ernstfall überzeugt. Er empfiehlt, gegenüber den französischen Vorstellungen auf Zeit zu spielen, aber keinesfalls zuzulassen, daß das Bündnis „demontiert" werde. amerikanischen Verteidigungsminister McNamara in Washington

McNamara erläutert die amerikanische NATO-Strategie. Während er die nukleare Ausstattung der NATO für ausreichend hält, fordert er mit Blick auf einen Ausbau der konventionellen Bewaffnung eine Erhöhung der Verteidigungsbudgets der Bündnispartner. McNamara hofft auf die baldige Errichtung des von ihm vorgeschlagenen Ausschusses von fünf oder sechs Verteidigungsministern, der über eine stärkere Beteiligung aller Partner an der Planung für einen Einsatz nuklearer Waffen und eine verstärkte Konsultation beraten solle. Darin sieht Erhard eine Möglichkeit der Mitsprache für die Bundesregierung, ,ohne ihre Position ändern zu müssen“. Besorgt äußert er sich über die strategischen und logistischen Konsequenzen eines weiteren französischen Rückzugs aus der NATO, rät aber davon ab, bereits mit Vorbereitungen für den Fall eines französischen Austritts zu beginnen oder mit dem Abzug alliierter Einrichtungen aus Frankreich zu drohen. Beide Gesprächspartner sind überzeugt, daß Staatspräsident de Gaulle seine Verteidigungspolitik nur unter dem „Schutz der amerikanischen Abschreckung" betreiben könne und daher wahrscheinlich im Bündnis bleiben, jedoch die Mitarbeit einstellen werde. Zur 
Situation in Vietnam führt McNamara aus, er rechne nicht mit einem chinesischen Eingreifen; auch die UdSSR werde dies nur tun, um eine Intervention der Volksrepublik China zu verhindern oder die eigene Stellung in der Demokratischen Republik Vietnam (Nordvietnam) zu stärken. amerikanischen Außenminister Rusk in Washington

Die Gesprächspartner befassen sich mit dem Verhältnis zu den osteuropäischen Staaten. Der Bundeskanzler bezweifelt, daß die Schritte zu einer Verbesserung „fast automatisch“ zu einer Wiedervereinigung Deutschlands führen könnten, und stellt fest, daß die Frage einer Aufnahme diplomatischer Beziehungen durch die Bundesrepublik nicht aktuell sei. Er zeigt sich besorgt über den "Wettlauf" westlicher Staaten um den Ausbau der Handelsbeziehungen mit den Ostblock-Staaten. Es bestehe die Gefahr, daß sie zu „Gefangenen ihrer eigenen Kreditpolitik“ würden, weil Rückzahlungen kaum zu erwarten seien. Daher sollten politische Gegenleistungen gefordert werden, wofür die wirtschaftliche Strategie des Westens koordiniert werden müßte. Der amerikanische Außenminister Rusk teilt diese Ansicht, ist aber skeptisch hinsichtlich der Realisierungschancen. Kritisch äußert sich Erhard zur Ostpolitik des Staatspräsidenten de Gaulle, insbesondere zur offenkundigen Übereinstimmung mit der UdSSR hinsichtlich der Oder-Neiße-Linie und des militärischen Status der Bundesrepublik. Er bekräftigt das Vertrauen in den amerikanischen Schutz, für den auch die Haltung der USA im Vietnam-Konflikt Gewähr biete. Johnson in Washington

Der Bundeskanzler sichert die Unterstützung des geplanten amerikanischen Hilfsprogramms in Südostasien zu. Er sieht für die Gespräche mit Staatspräsident de Gaulle am 11./12. Juni 1965 Schwierigkeiten voraus, da es „kaum mehr eine gemeinsame Position“ gebe. Angesichts der bevorstehenden Bundestagswahlen dürfe es nicht zum offenen Konflikt kommen; danach müsse jedoch ein „hartes Gespräch" geführt werden. Zur Lage in Vietnam erläutert Präsident Johnson, er stehe vor der Frage, ob die USA das von der UdSSR in der Demokratischen Republik Vietnam (Nordvietnam) stationierte Kriegsgerät angreifen sollten. Dies könne dazu führen, daß „die Russen die Situation an anderer Stelle aufheizten“. Erhard glaubt, grundsätzlich sei eine feste Haltung am ehesten geeignet, „Abenteuern ein Ende zu setzen“. Johnson zeigt sich interessiert an einem Gedankenaustausch über die „Formierte Gesellschaft“ 
und äußert sich befriedigt über die Kooperation in der Weltraumforschung. Mit Bewunderung habe er auch beobachtet, wie Erhard "mit dem Israelproblem fertiggeworden sei“.

Das Referat „NATO/WEU“ nimmt Stellung zu dem Vorschlag des amerikanischen Verteidigungsministers McNamara, zusätzlich zu den Planungen für die MLF/ANF einen engeren Ausschuß aus vier oder fünf Verteidigungsministern einzurichten. Dieses „select committee“, das Überlegungen zu einer engeren Einbeziehung der Verbündeten bei der nuklearen Planung sowie zur Schaffung eines Konsultationsmechanismus vor der Einsatzfreigabe für nukleare Waffen anstellen solle, werde zwar die „Unzufriedenheit der Nichtbeteiligten“ hervorrufen, jedoch stehe aufgrund des deutschen Verteidigungsbeitrags eine Beteiligung der Bundesrepublik außer Frage. Allerdings dürfe das MLF-Projekt nicht in den Hintergrund gedrängt werden, weil nur diese Streitmacht die Bundesrepublik zum "wirklichen Teilhaber“ nuklearer Mitverantwortung machen würde.

Hauthal informiert über ein Gespräch mit dem Beauftragten des Präsidenten Nasser für die Rüstungswirtschaft. Zum Wunsch der Bundesregierung, das Recht zur Flaggenführung auf den Konsulaten in Alexandrien und Port Said eingeräumt zu bekommen, erklärte Khalil, dies könne sich die VAR gegenwärtig „einfach nicht leisten“, nachdem die Bundesrepublik den Visumzwang eingeführt und den Versuch unternommen hätte, durch bilaterale Gespräche mit einzelnen Staaten die „arabische Einheit zu spalten“. Im übrigen solle die Aufmerksamkeit weniger auf den gegenwärtigen Status der Vertretungen als auf eine Wiederherstellung normaler Beziehungen gelenkt werden. Die VAR sei gesprächsbereit und habe deswegen das angekündigte Generalkonsulat in Ost-Berlin noch nicht eröffnet. Khalil regte an, eine Delegation unter Leitung des CDU-Abgeordneten Werner zu Verhandlungen in die VAR zu entsenden. Auswärtige Amt

Grewe bestätigt Berichte über eine „zunehmende amerikanische Verstimmung" hinsichtlich der NATO-Politik des Staatspräsidenten de Gaulle. Die französische Haltung zum Bündnis gebe Grund zur Sorge, wenn auch nicht damit gerechnet werden müsse, daß Frankreich die NATO vor 1969 verlassen werde. Grewe vermutet vielmehr, daß de Gaulle die Drohung mit einer Kündigung des NATO-Vertrags zur Durchsetzung seiner Wün- 
sche auf Umgestaltung des westlichen Bündnisses zur „klassischen Allianz ohne amerikanische Führung" benutzen wolle. Möglicherweise werde Frankreich in erster Linie das Vetorecht im NATO-Rat nutzen, um ihm mißliebige Entscheidungen - wie solche zu einer stärkeren Integration des Bündnisses - zu verhindern und gemeinsam finanzierte Unternehmungen zu blokkieren.

238 09./10.06. Deutsch-dänische Regierungsbesprechungen

Ministerpräsident Krag tritt für ein Zusammenwirken zwischen EWG und EFTA ein, wie es der britische Premierminister Wilson angeregt habe. Daraufhin erklärt der dänische Außenminister Haekkerup, sowohl bei der EWG-Kommission als auch beim belgischen Außenminister Spaak bereits Unterstützung gefunden zu haben, und kündigt konkretere Vorschläge an. Bundeskanzler Erhard, Bundesminister Schmücker und Staatssekretär Lahr stimmen den Überlegungen der EFTA zu. Die Gesprächsteilnehmer erörtern Vorschläge zur Erleichterung dänischer Agrarexporte in die EWG. Der Bundeskanzler befürwortet einen regen Handelsverkehr mit den Nachbarstaaten und bekräftigt, die Bundesrepublik fühle sich in der „agrarwirtschaftlichen Inzucht" nicht wohl. Befremden äußert Lahr über die dänische Zollerhöhung für Autoimporte aus Staaten außerhalb der EFTA, die nur den Protektionismus der EWGStaaten fördern könne. Beide Seiten stimmen überein, daß eine Verteidigung Europas ohne die USA unmöglich sei, und teilen das positive Urteil über den Vorschlag des amerikanischen Verteidigungsministers McNamara, ein Gremium für nukleare Zusammenarbeit in der NATO zu bilden. Bundesminister Schröder und Staatssekretär Lahr erläutern die Ostpolitik der Bundesregierung und heben das gute Verhältnis zu Rumänien hervor. Zum Wunsch des Bundeskanzlers nach einer Differenzierung zwischen der DDR und den übrigen Ostblock-Staaten in der Handelspolitik bemerkt Haekkerup, der Gesamtumfang des Handels mit der DDR sei gering, für die betroffenen Gewerbezweige jedoch wesentlich. Auswärtige Amt

Blankenhorn berichtet über die positiven Reaktionen in Regierungskreisen und in der britischen Öffentlichkeit auf den Besuch der Königin Elizabeth II. vom 18. bis 28. Mai in der Bundesrepublik. Es würḍen nun Möglichkeiten für eine „fruchtbare Phase $^{u}$ der deutsch-britischen Beziehungen, etwa für eine weitergehende Zusammenarbeit in der Entwicklungshilfe und in der Rüstungswirtschaft, gesehen, ohne daß bislang konkretere Vorstellungen bestünden. Angesichts der wirtschaftlichen Probleme stehe zunächst eine Regelung der Kosten für die Rheinar- 
mee im Vordergrund des britischen Interesses. Blankenhorn spricht sich für eine Intensivierung der beiderseitigen Beziehungen aus, die auch genutzt werden könnten, um den „Divergenzen und Desintegrationserscheinungen " im westlichen Bündnis entgegenzuwirken. Zudem könne dies die deutsche Position gegenüber Frankreich stärken und Möglichkeiten eröffnen, Großbritannien davon abzubringen, Entspannung auf „nicht genehmen Wegen“ zu suchen.

Als Folge einer am 11. Juni 1965 zur Abstimmung stehenden UNO-Resolution für eine Weltabrüstungskonferenz sieht Krapf das Problem der deutschen Beteiligung auf die Bundesrepublik zukommen. Da eine Einladung an „alle Länder" geplant sei, müsse sich die Bundesrepublik darauf vorbereiten, ebenso wie die DDR zur Teilnahme aufgefordert zu werden. Dies würde zwar keine Anerkennung, wohl aber eine Aufwertung der DDR bedeuten, der damit auch der Weg in andere internationale Gremien geebnet würde. Eine Nichtteilnahme der Bundesrepublik wegen der Anwesenheit der DDR werde das Zusammentreten der Konferenz nicht verhindern, aber die Bundesrepublik dem Vorwurf aussetzen, sie stelle sich „der allgemeinen Abrüstung unter dem Vorwand des SBZ-Problems" entgegen. Umgekehrt könne das Forum genutzt werden, um die Deutschland- und Sicherheitspolitik der Bundesrepublik „vor der Weltöffentlichkeit aktiv zu vertreten“. Krapf regt an, sich um eine möglichst große Anzahl von Nichtanerkennungserklärungen der beteiligten Staaten zu bemühen und dadurch die Aufwertung der DDR zu mindern.

241 10.06. Staatssekretär a. D. van Scherpenberg, z. Z. Addis Abeba, an das Auswärtige Amt

Scherpenberg informiert über ein Gespräch mit dem äthiopischen Kaiser. Haile Selassie sprach die Erwartung aus, daß die Deutschland-Frage Gegenstand der bevorstehenden Zweiten Afro-asiatischen Konferenz in Algier sein werde. Scherpenberg wies darauf hin, daß diese Frage nicht in Abwesenheit der Bundesrepublik behandelt werden sollte. Haile Selassie bat um Einwirkung auf die OCAM-Staaten, sich weiterhin in der Organisation für afrikanische Einheit zu engagieren, da ansonsten eine "Radikalisierung der afrikanischen Gruppen“ zu befürchten sei. Mißtrauisch zeigte sich der Kaiser gegenüber der Ausrüstungshilfe der Bundesrepublik an Somalia, die laut Scherpenberg verhindern solle, daß Somalia „zum ausschließlichen Tummelplatz der Russen und Chinesen" würde. Der ebenfalls anwesende Ministerpräsident Habte Wold wies darauf hin, daß an eine 
Änderung der aus der Kolonialzeit stammenden Grenzen innerhalb Afrikas nicht zu denken sei, wenn Afrika nicht in einen „Kampf aller gegen alle“ geraten solle. präsident de Gaulle

Der französische Staatspräsident zeigt Interesse am Vorschlag des amerikanischen Verteidigungsministers McNamara zur Bildung eines nuklearen Konsultationsgremiums innerhalb der NATO, mit dem jedoch auch keine Gewißheit über die Verteidigungsbereitschaft der USA für Europa zu gewinnen sei. Ein direkter Schlag der USA gegen die UdSSR sei wegen des drohenden Gegenschlags unwahrscheinlich. Allenfalls könne mit dem Einsatz der in Europa stationierten taktischen Kernwaffen gerechnet werden, der jedoch eine Zerstörung Westeuropas bedeuten würde. Die Lösung liege allein in der „totalen Abschreckung". Erhard bekräftigt sein Vertrauen in das amerikanische Schutzversprechen, das durch das Vorgehen der USA in Vietnam bestärkt werde. Seine Frage, ob die Force de frappe tatsächlich eine Alternative darstelle, bejaht de Gaulle mit dem Argument, daß deren Abschreckungswirkung wegen der Gewißheit ihres Einsatzes gegen sowjetische Ziele größer sein könnte als die des amerikanischen Potentials. De Gaulle teilt die Auffassung, daß das Bündnis mit den USA erhalten werden müsse, wendet sich aber gegen die Organisationsstruktur der NATO und kündigt ein Ausscheiden Frankreichs für das Jahr 1969 an. französischen Außenminister Couve de Murville

Schröder informiert über den Besuch des Bundeskanzlers Erhard in Washington sowie über die Gespräche mit dem dänischen Ministerpräsidenten in Bonn. Krag habe erwähnt, daß die EFTA ein Gremium zur Vorbereitung einer Annäherung an die EWG bilden wolle. Die Bundesregierung schlage vor, eine entsprechende Arbeitsgruppe auch in der EWG zu bestellen. Der Abteilungsleiter im französischen Außenministerium, Wormser, teilt zu seinen Gesprächen im niederländischen Außenministerium sowie mit dem italienischen Außenminister in Paris mit, die Haltung der niederländischen Regierung sei „sehr extrem“. Sie erwäge, dem Europäischen Parlament ein Vetorecht gegen Verordnungen des Ministerrats einzuräumen und von ihm Vorschläge für eine „moderne“ Steuer zur Finanzierung der EWG ausarbeiten zu lassen. Dagegen habe sich Fanfani auf die Anregung beschränkt, dem Parlament zu einer besseren Nutzung seiner bisherigen Rechte zu verhelfen. Wormser legt dar, da $\beta$ der Ministerrat das entscheidende Gremium bleiben müsse. Dieser könne „eines Tages“ eine Überweisung der Zolleinnahmen an die Gemeinschaft beschließen. Zur Finanzierung des 
Agrarmarkts, über die am 30. Juni 1965 beschlossen werden solle, müsse ein Verteilungsschlüssel gefunden werden, der den finanziellen Möglichkeiten der einzelnen Staaten Rechnung trage. präsident de Gaulle

Erhard berichtet über ein Gespräch mit Ministerpräsdient Pompidou und konstatiert Einigkeit darüber, daß ungeachtet einer Befugniserweiterung für das Europäische Parlament der EWGMinisterrat die „entscheidende Instanz" bleibe. Für die NATO räumt er Reformmöglichkeiten ein, betont jedoch, die Bundesregierung müsse „auf der Integration bestehen“. Der französische Staatspräsident präzisiert seine Konzeption dahingehend, daß Frankreich nach 1969 Beistandspakte mit den USA, Großbritannien und der Bundesrepublik schließen solle. De Gaulle bekundet Zustimmung zu einer Gipfelkonferenz über die europäische politische Zusammenarbeit, ,sobald das Wesentliche in Brüssel geschaffen sei“. Erhard glaubt, daß eine schnelle Einigung über die EWG-Agrarfragen kaum denkbar sei, und spricht sich für eine gemeinsame Erklärung zugunsten der Konferenz „ohne Angaben von Daten oder Bedingungen“ aus. Zur Deutschland-Frage führt er aus, die von französischer Seite befürwortete Europäisierung dürfe nicht zur Verwässerung der VierMächte-Verantwortung führen. Es müsse deutlich „zwischen Verantwortlichen und Interessierten" unterschieden werden. Vor ernsthaften Verhandlungen dürfe es nicht zu einem „Ausverkauf der Positionen" kommen, und daher könne gegenwärtig weder über die Grenzen noch über den militärischen Status Deutschlands gesprochen werden. minister Giscard d'Estaing

Giscard d'Estaing erläutert einen „Kompromißvorschlag“ zur Finanzierung der EWG. Für die von Bundesminister Schmükker geforderten gleichmäßigen Fortschritte bei der Harmonisierung der Umsatzsteuer, der Beseitigung der Binnenzölle und der Einführung gemeinsamer Außenzölle, einer liberalen Handelspolitik sowie eines eigenen Finanzsystems der Gemeinschaft sieht er Konsensmöglichkeiten. Hinsichtlich der geplanten deutsch-französischen Studienkommissionen im Bereich der Wirtschaft wird als erster Gesprächstermin der 25. Juni 1965 in Aussicht genommen. 

präsident de Gaulle

Der französische Staatspräsident bekräftigt die Vier-MächteVerantwortung für Deutschland, wiederholt jedoch, daß eine „europäische Einigung“ über die Wiedervereinigung herbeigeführt werden müsse. Frankreich habe deshalb auf einer entsprechenden Formulierung in der jüngsten Erklärung der Drei Mächte bestanden. De Gaulle vertritt die Ansicht, die UdSSR habe auf das Ziel einer Beherrschung Westeuropas verzichtet und hoffe, die USA für eine Festschreibung des Status quo zu gewinnen. Frankreich dagegen wünsche eine gesamteuropäische Verständigung, die eine deutsche Wiedervereinigung einschließe. Daher sei es "nicht praktisch“, von einer Revision der Grenzen oder einer nuklearen Teilhabe Deutschlands zu sprechen. Erhard tritt für eine Koordinierung der Handelspolitik gegenüber den Ostblock-Staaten sowie für größere Zurückhaltung bei der Kreditgewährung ein und weist besonders hinsichtlich der DDR auf die nachteiligen Konsequenzen der westlichen Geschäftsbereitschaft hin. Er erläutert, daß die Krise im Nahen Osten ihn bewogen habe, „für sich alleine“ den Entschluß zur Aufnahme diplomatischer Beziehungen mit Israel zu fassen. Darauf bestätigt de Gaulle, Erhard habe „gut manövriert“. Die Anregung des Bundeskanzlers, eine Gipfelkonferenz zur europäischen politischen Zusammenarbeit anzukündigen, lehnt er ab. Dies könne erst erfolgen, wenn eine Einigung über die Agrarfragen erzielt sei.

Lahr stellt eine „erfreuliche Annäherung“ des deutschen und französischen Standpunkts zu den EWG-Fragen fest. So bestehe Einigkeit, daß der gemeinsame Agrarmarkt und die Zollunion gleichzeitig zu schaffen seien und daß einige Zeit nach dem Fortfall der internen Zollgrenzen auch die Aufhebung der Steuergrenzen folgen sollte. Beide Seiten wünschten einen Erfolg der Kennedy-Runde und eine Regelung der Agrarfinanzen bis zum 30. Juni 1965. Auch stimmten sie überein, daß bei entsprechendem Finanzbedarf die Zolleinnahmen der Gemeinschaft zufallen sollten und das Europäische Parlament stärker an der Debatte über den Haushalt zu beteiligen sei. Couve de Murville und des Staatspräsidenten de Gaulle

Zu dem von Staatssekretär Lahr vorgelegten Arbeitspapier über die vordringlichen Probleme in der EWG bemerkt der französische Außenminister, daß Frankreich den Punkten zugestimmt habe, die deutsche Interessen beträfen, es hinsichtlich der Finanzregelung aber offenbar zu einem Mißverständnis gekom- 
men sei. Couve de Murville hebt hervor, daß Frankreich bis zum 30. Juni 1965 die Finanzregelung für die restliche Übergangszeit festgelegt wissen wolle und er daher nicht mit dem deutschen Vorschlag einverstanden sei, sich - weil die Lösung der diskutierten Fragen „ein höchst kompliziertes Problem“ sei lediglich auf die Verlängerung der Agrarfinanzierung um ein weiteres Jahr zu verständigen. Staatspräsident de Gaulle stellt zwar eine Annäherung der Standpunkte fest; sollten sich die beiden Regierungen jedoch im Vorfeld der am 28. Juni 1965 beginnenden EWG-Ministerratstagung nicht auf eine gemeinsame Position einigen können, befürchtet er, daß die Verhandlungen "sehr konfus" würden. Angesichts dieser Lage meldet er „zu allen in den beiden Tagen besprochenen Punkten Vorbehalte" an.

Schröder erläutert die Zurückhaltung des Auswärtigen Amts gegenüber einem Staatsbesuch des Präsidenten Stroessner. Er verkennt nicht die paraguayische Unterstützung in der Deutschland- und Berlin-Frage, sieht die Beziehungen jedoch beeinträchtigt durch die paraguayische Haltung zum Auslieferungsersuchen für den ehemaligen Lagerarzt des Konzentrationslagers Auschwitz, Mengele. Angesichts der Presseberichterstattung über diesen Fall glaubt der Bundesminister, daß ein Staatsbesuch von Stroessner ein "unerfreuliches Echo“ haben würde. Keinen Einfluß habe der Fall Mengele allerdings auf die Fortsetzung der Entwicklungshilfe an Paraguay gehabt. Auswärtige Amt

Enders berichtet, daß die tansanische Regierung eine Übernahme der Ausbildung der tansanischen Seepolizei durch die Niederlande prüfe, grundsätzlich jedoch auf einer Rückkehr der Marineberater aus der Bundesrepublik bestehe und zunächst die Entscheidung der Bundesregierung über die Fortsetzung der Seepolizeihilfe abwarte. Der Staatssekretär im tansanischen Präsidialamt habe darauf hingewiesen, daß dem Generalkonsul der DDR, Lessing, kein Exequatur erteilt werde. Enders hält fest, er habe Namata auf anderslautende Aussagen des Präsidenten Nyerere aufmerksam gemacht, die der Erfüllung der tansanischen Wünsche „nicht gerade förderlich“ seien. Der Legationsrat resümiert, Namata sei offenbar schlecht unterrichtet, und es könne nicht damit gerechnet werden, daß er genügend Einfluß habe, eine Exequatur-Erteilung für das DDRGeneralkonsulat in Daressalam zu verhindern. 
Krapf faßt die Ergebnisse einer Staatssekretärbesprechung zu Kontakten mit der DDR zusammen. Zur einseitigen Kündigung der Vereinbarung über die Binnenschiffahrt durch die DDR wurde beschlossen, mit einem Schreiben an die zuständige Abteilung des Verkehrsministeriums der DDR zu reagieren, obwohl die Kontaktaufnahme mit einer oberen DDR-Behörde „nicht erfreulich“ sei. Nicht eingegangen werden solle dagegen auf die Forderung der DDR nach Abschluß eines neuen, durch die Verkehrsministerien auszuhandelnden Tarifvertrags im Eisenbahnverkehr. Bemühungen um eine „Aufwertung der

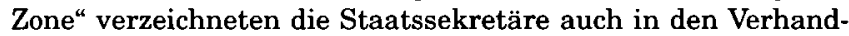
lungen über den Interzonenhandel. Zur Passierschein-Vereinbarung bemerkte Bundesminister Westrick, daß nur eine Verlängerung, keinesfalls aber eine Änderung der Regelung vom 24. September 1964 in Frage käme. Auswärtige Amt

Knappstein informiert über Gespräche des Bundesministers für gesamtdeutsche Fragen mit dem amerikanischen Außenminister und mit Unterstaatssekretär Thompson. Gegenüber Rusk machte Mende auf die Gefahr aufmerksam, daß sich das gestiegene Selbstbewußtsein der Bevölkerung der DDR zu „einer Art von Staatsbewußtsein" entwickeln könnte. Einer Entfremdung zwischen den beiden Teilen der Nation sei nur durch eine Intensivierung der Kontakte zu begegnen. Zum Vorschlag gesamtdeutscher Kommissionen bemerkte Mende, die UdSSR sei nicht bereit, im Rahmen der Vier-Mächte-Verantwortung ein entsprechendes Mandat zu erteilen. Er zeigte sich besorgt, daß die UdSSR und die DDR vor der Bundestagswahl „Unruhe stiften“ könnten, und verwies auf die Kündigung der Bahn- und Wasserstraßentarife. Rusk erläuterte die aus dem Vietnam-Konflikt resultierenden Spannungen zwischen den USA und der UdSSR. Die jetzige sowjetische Regierung scheine "konservativer und engherziger" als ihre Vorgängerin zu sein und stehe dem Ausbau der Beziehungen der USA zu den osteuropäischen Staaten mißtrauisch gegenüber. Thompson äußerte Zweifel an einer sowjetischen Zustimmung zu der mit gesamtdeutschen Kommissionen verbundenen "Verlängerung der Viermächteverantwortung“. ehemaligen britischen Schatzkanzler Maudling

Die Gesprächspartner erörtern die Europa-Politik. Maudling spricht sich sowohl gegen ein „Europa der Vaterländer" als auch gegen Bestrebungen aus, bei der europäischen Einigung „in zu kurzer Zeit zuviel erreichen" zu wollen. Schröder tritt für prak- 
tische Lösungen im Sinne einer wirtschaftlichen, politischen und verteidigungspolitischen Zusammenarbeit der europäischen Staaten ein. Er bezeichnet die französische Haltung gegenüber den USA als „extrem“ und die Konzeption einer rein europäischen Verteidigung als „unmöglich, unnützlich und unvernünftig“. Hinsichtlich der nuklearen Zusammenarbeit hält er, vor allem aus psychologischen Gründen, eine multilaterale Organisation im Sinne der ANF oder MLF für wichtig. marokkanischen Außenminister Benhima

Benhima führt aus, daß für den geplanten Besuch des Königs Hassan II. in Bonn, der im März 1965 wegen der Ankündigung diplomatischer Beziehungen zwischen der Bundesrepublik und Israel "etwas heikel“ erschienen sei, jetzt ein Termin festgelegt werden könne. Zur marokkanischen Haltung in der NahostKrise erläuterte er, die Fortsetzung der diplomatischen Beziehungen zur Bundesrepublik sei „nicht konjunkturell bedingt gewesen". Sie habe ihre Gründe in dem aus der eigenen nationalen Geschichte erwachsenden Verständnis für die Bemühungen um eine Überwindung der Teilung Deutschlands. Das Verhalten der VAR sei nicht auf das „Palästina-Problem“, sondern auf eine Absprache mit der UdSSR zurückgegangen, nach der Präsident Nasser den Auftakt zur Anerkennung der DDR durch eine größere Zahl arabischer und blockfreier Staaten habe geben sollen. Gegen die Annahme eines solchen „kompletten Komplotts“ spricht nach Auffassung von Schröder, daß Nasser seine Haltung zur Anerkennung der DDR geändert habe. Denn Nasser räume den Beziehungen zur Bundesrepublik weiterhin Priorität ein, wolle gleichzeitig aber diejenigen zur DDR soweit wie möglich entwickeln. Amt

Soltmann informiert über ein Gespräch mit dem kenianischen Präsidenten, den er über die Bemühungen unterrichtete, durch das deutsch-britische Devisenausgleichsabkommen einen Weg für weitere Ausrüstungshilfe an Kenia zu finden. Kenyatta berichtete über die Verhinderung eines Besuchs des chinesischen Ministerpräsidenten Tschou En-lai in Kenia. Er bekräftigte, daß er am Prinzip festhalten werde, von einem geteilten Staat jeweils nur einen Teil anzuerkennen. Zur Ablehnung sowjetischer Waffenhilfe erläuterte Kenyatta, er habe dem sowjetischen Stellvertretenden Außenminister Malik erklärt, daß sein Land "kein zweitklassiges Material“ brauche, da es bereits über moderne Waffen verfüge. Angesichts der klaren Haltung des kenianischen Präsidenten gegenüber dem Kommunismus und insbesondere auch gegenüber der DDR spricht Solt- 
mann sich dafür aus, Kenia zum „Schwerpunktgebiet“ in Ostafrika zu machen und Kapitalhilfe in entsprechender Größenordnung vorzusehen.

Als Ergebnis der bevorstehenden Wirtschaftsverhandlungen mit Israel sieht Pauls „Unmut und Enttäuschung“ aufgrund unerfüllbarer israelischer Vorstellungen über jährliche nicht rückzahlbare Beträge von 240 Millionen DM voraus, zugleich aber auch arabische Empörung wegen der Höhe der Kreditzusagen. In jedem Fall müsse der Eindruck vermieden werden, daß es sich bei der Entwicklungshilfe an Israel um eine Wiedergutmachungsleistung handele. Angesichts der Tatsache, daß Israel noch nie etwas zur Unterstützung des Standpunkts der Bundesrepublik in der Deutschland-Frage getan habe, plädiert Pauls zudem dafür, die Israel-Hilfe mit „eindrucksvoller" Unterstützung für einige „besonders bewährte Freunde“ im arabischen Raum zu verbinden. Er empfiehlt, die Finanzhilfe an Marokko und Tunesien zu verdreifachen und diesen Staaten 210 bzw. 145 Millionen DM anzubieten sowie die technische Hilfe an Libyen zu erweitern. Bundesministerium der Finanzen

Lahr bestätigt, daß an Israel eine Zahlung von 75 Millionen DM in Anrechnung auf das Ergebnis der in einigen Monaten stattfindenden Wirtschaftsverhandlungen erfolgen soll. Offen sei noch der Umfang der auf das gesamte Jahr 1965 entfallenden Hilfe. Das Auswärtige Amt schlage 150 Millionen DM vor. Die israelische Forderung, über die bisherige Hilfe hinaus zusätzliche jährliche Zahlungen in Höhe von 200 Millionen DM zu leisten, sei von seiten der Bundesregierung zurückgewiesen worden. Bundeskanzler Erhard habe am 12. Mai 1965 beim Austausch des Briefwechsels anläßlich der Aufnahme diplomatischer Beziehungen deutlich gemacht, daß es nur eine einzige Form von Wirtschaftshilfe geben könne.

Böx informiert über ein Gespräch mit dem Staatssekretär im norwegischen Außenministerium. Boyesen berichtete über die ihm während eines Besuchs in Polen unterbreiteten Disengagement-Pläne. Es werde an einen Vertrag europäischer Mächte über die Nichtverbreitung von Atomwaffen gedacht und eine Annäherung von NATO und Warschauer Pakt angestrebt. Die polnische Regierung sei besorgt, daß anderenfalls eine Vereinbarung zwischen den USA und der UdSSR unter Beteiligung der Bundesrepublik zustande käme, in der "große Gefahren für 
den nationalen Bestand Polens" gesehen würden. Sie trete daher für die Schaffung einer atomwaffenfreien und in einem zweiten Schritt auch rüstungsverdünnten mitteleuropäischen Zone ein und sei auch zu Kontrollen bereit. Böx machte deutlich, daß ein europäisches Sicherheitssystem aus Sicht der Bundesrepublik die Wiedervereinigung Deutschlands voraussetze. Der Botschafter berichtet abschließend, Boyesen sehe in dem vom amerikanischen Verteidigungsminister McNamara angeregten "select committee“ zur Behandlung atomarer Fragen eine Möglichkeit zur Beteiligung an der nuklearen Verantwortung im Bündnis, die „viel besser" als eine MLF/ANF sei.

Krapf referiert den britischen Entwurf eines Abkommens über die Nichtverbreitung von Kernwaffen: Die Nuklearstaaten sollen sich verpflichten, die Verfügungsgewalt über Kernwaffen weder an Nichtnuklearstaaten noch an „irgendwelche Staatengruppen" $z$ übertragen. Ferner sollen die nichtnuklearen Staaten auf die Herstellung von Kernwaffen ebenso verzichten wie auf die Verfügungsgewalt im Rahmen einer Gemeinschaft ohne Zustimmung einer Nuklearmacht. Krapf stellt fest, daß diese Überlegungen dem gegenwärtigen Diskussionsstand ,in keiner Weise mehr Rechnung tragen“. Die Schaffung einer europäischen Atomstreitmacht bleibe zwar möglich, wenn die beteiligten Nuklearmächte das Veto über den Einsatz behielten. Insgesamt aber gingen die vorgesehenen Verpflichtungen einseitig zu Lasten der nichtnuklearen Staaten, während den Atommächten keinerlei Gegenleistungen abverlangt würden. Außerdem könnte eine "Mitunterzeichnung der SBZ“ ähnliche Probleme aufwerfen wie beim Teststopp-Abkommen vom 5. August 1963. Krapf plädiert dafür, dem Vertragsentwurf die Zustimmung zu versagen und bei der Diskussion im Ständigen NATO-Rat hervorzuheben, daß die Bundesrepublik nukleare Bindungen gegenüber dem Ostblock erst nach Klärung der nuklearen Frage in der NATO einzugehen bereit sei.

Plehwe erörtert den Vorschlag regelmäßiger Konsultationen mit der britischen Regierung. Er rät von einer formellen Festlegung ab, da zum einen Großbritannien eher an formlosen Abmachungen interessiert sein dürfte, zum anderen Frankreich darin „ein gezieltes Konkurrenz-Unternehmen" zum deutsch-französischen Vertrag vom 22. Januar 1963 sehen würde. Angesichts des nach dem erfolgreichen Besuch der Königin Elizabeth II. in der Bundesrepublik bestehenden Wunsches nach Festigung der 
Beziehungen regt Plehwe jedoch an, ohne ausdrückliche Vereinbarung eine Vermehrung der Gespräche „auf allen möglichen Ebenen" anzustreben. der Drei Mächte

Erhard sieht in den jüngsten Störmaßnahmen der DDR in Berlin eine "systematische Politik", die Entschlossenheit der drei Westmächte zum Schutz von Berlin (West) zu testen. Er fordert eine über Proteste hinausgehende Reaktion und spricht sich für eine koordinierte, restriktivere Handelspolitik gegenüber der DDR aus. Der französische Botschafter Seydoux unterscheidet zwischen den Hubschrauberflügen der Nationalen Volksarmee über Berlin (West), die die Rechte der Drei Mächte tangierten, und den Maßnahmen beim innerstädtischen und beim TransitVerkehr, die eher die Bundesregierung beträfen. Er stellt fest, daß die Bundesrepublik in den Verhandlungen über den Eisenbahnverkehr durchaus erfolgreich agiert habe. Zum Hinweis des ebenfalls anwesenden Bundesministers Mende auf die schlechte psychologische Stimmung in Berlin (West) wegen der Hubschrauberflüge bemerkt der britische Botschaftsrat Stark, daß seit dem 21. Juni 1965 keine Flüge mehr registriert worden seien.

Krapf nimmt zu polnischen Vorstellungen zur Nichtverbreitung von Kernwaffen Stellung, deren Ziel darin bestehe, die nichtnuklearen europäischen Staaten vom Zugang zu Atomwaffen auch innerhalb multilateraler Organsiationen fernzuhalten. Die Nichtverbreitung von Kernwaffen könne aber nur weltweit geregelt werden. Anderenfalls werde das Problem der europäischen Sicherheit berührt, das ohne gleichzeitige politische Regelungen nicht lösbar sei. Da zudem das westliche Territorium der UdSSR nicht einbezogen werde, bestehe die Gefahr, daß das Kräftegleichgewicht „zuungunsten des Westens" verschoben werde. Krapf schlägt vor, eine Diskussion der - noch nicht offziellen - polnischen Vorschläge im Ständigen NATO-Rat anzuregen und die Verbündeten vorsorglich über die Haltung der Bundesrepublik zu unterrichten.

\section{Lindenberg}

Meyer-Lindenberg hält fest, daß der nigrische Minister für öffentliche Arbeiten, Kaziende, Bundesminister Schröder ein Schreiben des Präsidenten Diori an Bundeskanzler Erhard übergeben habe, in dem um Unterstützung bei der „Unterdrükkung der Subversion in Niger" gebeten werde. Die nigrische 
Regierung sei wiederholt mit der Bitte um Finanzhilfe für den geheimen Nachrichtendienst an die Bundesregierung herangetreten. Meyer-Lindenberg befürwortet eine umgehende Zahlung von 250000 DM an Diori, da der Niger zu den "treuesten Verfechtern der Wiedervereinigung Deutschlands" gehöre und gegen „kommunistisch inspirierte Umsturzversuche" abgeschirmt werden müsse. Damit würde auch ein Beitrag zur „Bekämpfung kommunistischer subversiver Aktivität" in Afrika geleistet. Auswärtige Amt

Blankenhorn berichtet über die WEU-Ministerratssitzung vom 29./30. Juni 1965. Der britische Außenminister Stewart sprach sich für eine stärkere Zusammenarbeit zwischen EWG und EFTA, insbesondere für engere Kontakte auf Ministerebene aus. Der stellvertretende belgische Außenminister Fayat regte die Ausarbeitung entsprechender Vorschläge für die nächste WEU-Ministerratssitzung an. $\mathrm{Zu}$ den Ost-West-Beziehungen bemerkte Bundesminister Schröder, daß das sowjetische Engagement in Vietnam zu einer Reduzierung des außenpolitischen Spielraums der UdSSR geführt habe. Daher werde die DDR nicht mehr daran gehindert, „in Berlin bis hart an die Grenze der Eskalation" zu gehen. Hinsichtlich der Nahost-Politik wies Schröder darauf hin, daß "wesentliche Positionsgewinne der Zone" bislang nicht zu verzeichnen seien, jedoch mit weiteren Versuchen der DDR gerechnet werden müsse, in arabischen Staaten Fuß zu fassen. Im Gegensatz zum Staatssekretär im französischen Außenministerium, Habib-Deloncle, bekundete Schröder Verständnis für das Bestreben der USA, eine „kommunistische Machtergreifung" in der Dominikanischen Republik zu verhindern. Die Minister beschlossen, weitere Überlegungen zur Koordinierung der Zusammenarbeit der WEU-Staaten in Lateinamerika anzustellen.

Zur Vorbereitung des bevorstehenden Gesprächs des Bundesministers Schröder mit dem französischen Botschafter Seydoux faßt Lahr die im EWG-Ministerrat vom 28. bis 30. Juni 1965 in Brüssel zutage getretenen Differenzen über die Finanzierung des gemeinsamen Agrarmarkts zusammen. Die Forderung Frankreichs, sich in einer ,isolierten Entscheidung“ auf fünf Jahre „bedingungslos“ festzulegen, sei für die übrigen Mitgliedstaaten unzumutbar. Die Bundesrepublik halte an der schon bisher gezeigten Verständigungsbereitschaft fest, müsse jedoch eine Berücksichtigung ihrer Interessen hinsichtlich der gemeinsamen Steuerpolitik, der Verhandlungen in der Kennedy-Runde und der Kreditpolitik gegenüber den Ostblock-Staaten und der 
DDR erwarten. Es sei „ein unmöglicher Zustand“, wenn im Jahr der Bundestagswahlen der Eindruck entstehe, die EWG sei in erster Linie eine Vereinigung zur Finanzierung wachsender französischer Agrarüberschüsse. Besonders unverständlich seien die öffentlichen französischen Beschwerden über die Haltung der Bundesregierung. französischen Botschafter Seydoux

Schröder äußert Besorgnis über die mit dem EWG-Ministerrat vom 28. bis 30. Juni 1965 entstandene Krise der Gemeinschaft. Er bittet um Konsultation "nach Maßgabe des deutsch-französischen Vertrages“, bevor Frankreich die angekündigten „politischen, wirtschaftlichen und rechtlichen Konsequenzen" ziehe. Der Botschafter hebt hervor, die französische Regierung habe Konzessionen zugunsten einer Regelung der Agrarfinanzierung gemacht, aber letztlich den Eindruck gewonnen, daß „der Wille zu einer Einigung nicht bestanden habe". Dagegen erklärt der Bundesminister, daß eine Lösung hätte erreicht werden können, wenn über das Stichdatum des 30 . Juni hinaus verhandelt worden wäre. Alle EWG-Staaten wünschten einen Kompromiß, der allerdings auch von anderen Wünschen abhängig sei, so daß es um einen "Gesamtbeschluß" gehen müsse. Seydoux bedauert, daß während der deutsch-französischen Konsultationsbesprechung vom 12. Juni keine Verständigung erzielt worden sei. Auf den Hinweis von Schröder, daß nun erneut die EWG-Kommission „berechtigt und verpflichtet" sei, Vorschläge zu unterbreiten, entgegnet der Botschafter, die bisherigen Initiativen der Kommission „hätten in Paris sehr enttäuscht".

Lahr faßt die Ergebnisse einer Sitzung des Staatssekretärausschusses für Europafragen zusammen. Übereinstimmung bestand in der Einschätzung, daß Frankreich keinesfalls aus der EWG ausscheiden werde. Staatspräsident de Gaulle halte Frankreich für die Führungsmacht der Gemeinschaft und erwarte offenbar, da $\beta$,die Partner bei ihm bald antichambrieren werden". Ein Wettlauf um die Initiative zur Überwindung der Krise müsse jedoch vermieden werden, weil es Aufgabe der EWG-Kommission sei, neue Vorschläge zu unterbreiten. Für die am 26./27. Juli 1965 vorgesehene EWG-Ministerratstagung solle auf eine Erörterung der Handels- und Steuerpolitik gedrängt und eine isolierte Behandlung der Agrarfinanzierung abgelehnt werden. Die Bundesregierung müsse unverändert „ausgewogene Lösungen zum Fortschritt der Gemeinschaft“ fordern. 

Botschaftern der Drei Mächte

Der amerikanische Botschafter führt aus, die Lage in Berlin (West) biete nach Klärung der jüngsten Störungen im Bahnund Schiffsverkehr keinen Anlaß zur Besorgnis. Hinsichtlich Ost-Berlins bekräftigt McGhee, daß die USA ,auf ihrem Recht bestünden", auch wenn es seit einiger Zeit nicht ausgeübt worden sei; noch sei allerdings nicht entschieden, ob und wann die Kontrollflüge über Ost-Berlin wiederaufgenommen würden. Der Bundeskanzler sowie der gleichfalls anwesende Bundesminister Westrick drängen angesichts der Schwierigkeiten bei den Verhandlungen über den Interzonenhandel darauf, eine gemeinsame westliche Handelspolitik gegenüber der DDR zu verfolgen. Der britische Botschafter Roberts informiert über den Umfang der britischen Exporte in die DDR und die seit kurzem verstärkte Inanspruchnahme von Krediten mit fünfjähriger Laufzeit. Für eine Einwirkung durch handelspolitische Maßnahmen sieht er die Bundesrepublik angesichts des erheblich größeren Handelsvolumens mit der DDR in einer "sehr viel stärkeren Position“. Der französische Botschafter Seydoux betont die Notwendigkeit zur Geschlossenheit, um jede „Aufwertung der Zone“ zu vermeiden. Staatspräsident Saragat

Der Bundeskanzler eröffnet die zunächst unter vier Augen stattfindende Unterredung mit einer Beurteilung der EuropaPolitik des französischen Staatspräsidenten. Erhard erklärt, daß „der jetzige Husarenritt de Gaulles nicht ganz ernst zu nehmen" sei, und plädiert für Gelassenheit. Auch der italienische Staatspräsident glaubt nicht, daß de Gaulle die EWG „zerstören“ wolle, da seine „Feindschaft" eher der NATO gelte. Erhard erläutert die französische Haltung, die auf einen Rückzug aus der NATO hinziele. Hinsichtlich der europäischen Politik treten beide Gesprächspartner für Behutsamkeit und Geschlossenheit gegenüber Frankreich ein. Im erweiterten Kreis betont der italienische Außenminister Fanfani sein Befremden über das französische Verhalten während der EWG-Ministerratssitzung vom 28. bis 30. Juni 1965 in Brüssel. Der Bundeskanzler stellt fest, daß die Bundesrepublik durch die Regelung des Getreidepreises im Dezember 1964 den Weg nach Europa geebnet habe. Sie könne für eine Konferenz der Regierungschefs der EWG-Staaten, die von de Gaulle grundsätzlich bereits akzeptiert worden sei, keinen zusätzlichen Preis zahlen. 

französischen Botschafter Seydoux

Gemäß der von Schröder im Gespräch vom 3. Juli 1965 geäußerten Bitte erläutert der Botschafter den Standpunkt Frankreichs zur EWG-Krise. Er hebt hervor, daß die Bundesregierung über die französische Haltung hinsichtlich der Finanzierung der Agrarpolitik informiert worden sei. Frankreich habe gegenüber den Wünschen der übrigen EWG-Staaten großes Entgegenkommen gezeigt, sei dafür aber "schlecht belohnt" worden. Während andere versucht hätten, die Priorität der Finanzregelung zu „verschleiern", halte die französische Regierung daran auch weiterhin fest. Die Verantwortung für die Krise treffe die EWGKommission, die ihre Vorschläge „etwas unzeitgemäß“ vorgelegt und ohne vorherige Konsultation an die Öffentlichkeit gebracht habe. Der Bundesminister bemerkt, daß die Vorschläge bereits drei Monate lang diskutiert und am 12. Mai 1965 im Europäischen Parlament behandelt worden seien. Er bestätigt sodann die Bedeutung der Agrarfinanzierung, betont aber zugleich die Notwendigkeit einer gleichgewichtigen Fortentwicklung der Gemeinschaft. Zudem habe die EWG-Kommission das Recht und die Pflicht, Vorschläge zu unterbreiten, und sei inzwischen mit der Erarbeitung einer Grundlage für weitere Verhandlungen beauftragt worden. Auswärtige Amt

Der Botschafter berichtet von den Beratungen der Ständigen Vertreter bei EWG und EAG über die weitere Zusammenarbeit nach dem französischen Rückzug aus den wesentlichen Gremien der Gemeinschaften. Der italienische Botschafter Venturini und Sachs traten für eine normale Fortsetzung der Konsultationen und Entscheidungen ein, während die Vertreter der übrigen Mitgliedstaaten Zurückhaltung zeigten und lediglich zur Mitwirkung an laufenden Entscheidungsprozessen bereit waren. Der belgische Botschafter van der Meulen äußerte Bedenken gegen eine Beratung des Haushalts auf der EWGMinisterratssitzung am 26./27. Juli 1965 und zweifelte, ob in Abwesenheit einer Delegation überhaupt Ratsbeschlüsse gefaßt werden sollten. Sachs resümiert, daß die Haltung der BeneluxStaaten noch nicht genau eingeschätzt werden könne. amerikanischen Botschafter McGhee

Anläßlich des Besuchs des italienischen Staatspräsidenten informiert der Bundesminister, daß Saragat sowohl zur Deutschland-Frage als auch zu EWG und NATO „absolut positiv" eingestellt sei. Zur geplanten MLF/ANF und zum Vorschlag des amerikanischen Verteidigungsministers McNamara, inner- 
halb der NATO einen Ministerausschuß für nukleare Zusammenarbeit einzurichten, betont Schröder, daß ,die beiden Dinge nichts miteinander zu tun hätten". Ausweichend beantwortet er die Frage nach einem Zusammenhang zwischen dem Deutschland-Problem und einem Abkommen über die Nichtverbreitung von Kernwaffen. McGhee bekräftigt, daß die amerikanische Haltung zur Nichtverbreitung unverändert sei und daß die Wiedervereinigung Deutschlands „doch eine gute Belohnung“ für einen Beitritt der Bundesrepublik wäre. Zur EWG-Krise erläutert Schröder, er halte es für falsch, die EWG-Kommission - wie Frankreich es beabsichtige - zu schwächen, und betont, daß die Bundesrepublik an ihren Forderungen hinsichtlich einer Zollunion, einer Steuerharmonisierung und einer gemeinsamen Außenhandelspolitik festhalte.

Krapf nimmt zum Vorschlag des amerikanischen Verteidigungsministers McNamara Stellung, innerhalb der NATO einen Ministerausschuß für die nukleare Zusammenarbeit einzurichten. Das "select committee" solle eine verstärkte Konsultation gewährleisten und dem NATO-Ministerrat Vorschläge für eine bessere Koordinierung der Einsatzplanung von Kernwaffen und der bestehenden Nachrichtenverbindungen vorlegen. Krapf konstatiert, daß Frankreich auf den Vorschlag negativ reagiert habe. Als Motiv vermutet er, daß die französische Regierung an einer Mitverantwortung der nichtnuklearen Staaten desinteressiert sei, und zwar aus Sorge vor einer engeren Bindung der NATO-Staaten an die USA und vor einer Beschränkung der eigenen Handlungsfreiheit. Für den Fall eines französischen Vetos spricht sich Krapf gegen die Einrichtung des geplanten Gremiums außerhalb des Bündnisses aus, da dies die deutschfranzösischen Beziehungen belasten und zu einer Ersetzung der NATO durch bi- oder multilaterale Zusammenarbeit einzelner NATO-Staaten außerhalb der NATO führen könnte.

Krapf rekapituliert den Stand der Verhandlungen über die MLF/ANF. Auch Großbritannien trete inzwischen für die Unterstellung der geplanten Atomstreitmacht unter den Oberbefehlshaber der NATO ein, halte eine gemischtnationale Bemannung von U-Booten grundsätzlich für denkbar und bestehe nicht mehr auf der Schaffung von zusätzlichen Konsultationsgremien. Voraussetzung sei allerdings aus britischer Sicht eine Regelung zur Nichtverbreitung von Kernwaffen. Krapf schlägt vor, sich für eine Behandlung dieses Themas außerhalb der MLF/ANF-Arbeitsgruppe einzusetzen. 

Auswärtige Amt

Der Botschafter berichtet über ein Gespräch mit dem amerikanischen Außenminister. Knappstein brachte Besorgnis wegen der Diskussionen in den USA über die Nichtverbreitung von Kernwaffen zum Ausdruck. Demgegenüber hob Rusk nachdrücklich hervor, daß es ohne die MLF oder eine andere gleichgewichtige nukleare Organisation keine Nichtverbreitungsregelung geben werde. Er lie $\beta$ jedoch keinen Zweifel daran, daß die von der Bundesrepublik hergestellte Verbindung zwischen einem entsprechenden Abkommen und der Deutschland-Frage nicht akzeptiert werde. Einig waren sich die Gesprächspartner in der Ablehnung des britischen Entwurfs für einen Nichtverbreitungsvertrag. mit dem luxemburgischen Staatsminister Werner

Schröder erklärt, daß zur Lösung der EWG-Krise neue Vorschläge der EWG-Kommission hinsichtlich der Agrarfinanzierung abgewartet werden sollten, und bekräftigt das Interesse an einer ausgewogenen Fortentwicklung der Gemeinschaft. Werner teilt die Ansicht, daß die Kommission nicht ,gedemütigt und in ihren Funktionen gemindert" werden dürfe, hält es jedoch für taktisch wichtig, die Fragen der Einnahmen und der parlamentarischen Kontrolle nicht in die neuen Vorschläge einzubeziehen. Während für die Agrarfinanzen eine definitive Regelung gefunden werden müsse, genüge für die übrigen Probleme die Aufstellung eines Zeitplans. Auf der EWG-Ministerratssitzung am 26./27. Juli 1965 sollten die schon Ende Juni erörterten Themen nicht behandelt werden, wenn auf französischer Seite keine Gesprächsbereitschaft bestehe. Schröder spricht sich dafür aus, daß die Vorschläge der EWG-Kommission vorgetragen, aber erst nach der Sommerpause diskutiert werden sollten.

Zur Vorbereitung der Kabinettssitzung am 14. Juli 1965 faßt Krapf die Ergebnisse einer Staatssekretärbesprechung vom Vortag zum Stand der innerdeutschen Kontakte zusammen. Der Staatssekretär im Bundesministerium für Wirtschaft, Langer, berichtete über die Schwierigkeiten bei den Verhandlungen über ein neues Interzonen-Handelsabkommen, die auf die Ablehnung der bisherigen Währungsgebietsklausel durch die DDR zurückzuführen seien. Der Staatssekretär im Bundesministerium für gesamtdeutsche Fragen, Krautwig, sprach sich für eine feste Haltung in dieser Frage aus, während der Chef des Presse- und Informationsamtes, von Hase, auf die Popularität hinwies, die der Interzonenhandel in der Öffentlichkeit genieße. Krapf wies darauf hin, daß die Westmächte für einen störungs- 
freien Handelsverkehr einträten und daher vermutlich eine entgegenkommendere Haltung befürworteten. Hinsichtlich der Tarifneuregelung im interzonalen Schiffsverkehr durch die DDR machte der Staatssekretär im Bundesministerium für Verkehr, Seiermann, darauf aufmerksam, daß sie nicht nur zu Kostensteigerungen, sondern auch zu Kostenminderungen führen würde.

Klaiber informiert über Äußerungen des stellvertretenden Leiters des französischen Generalsekretariats der nationalen Verteidigung. Maillard habe festgestellt, daß die fehlenden Fortschritte bei der europäischen Einigung auf "gewisse Widersprüchlichkeiten “ der Politik der Partner zurückzuführen seien: So strebe die Bundesrepublik eine umfassende Integration an, ohne „die unausweichlichen politischen und militärischen Konsequenzen" daraus zu ziehen; die Niederlande wünschten die Einbeziehung Großbritanniens und zugleich ein supranationales Europa. Bedauerlich sei ferner, daß keine engere deutschfranzösische Kooperation in Verteidigungsfragen zustande gekommen sei. Frankreich hätte der Bundesrepublik ,nicht offen Atomwaffen anbieten können“, jedoch sei einem einheitlichen europäischen Verteidigungsinstrument der Weg geebnet worden. Eine MLF dagegen, so gibt Klaiber das Fazit von Maillard wieder, gebe der Bundesrepublik „nichts, koste viel Geld und verärgere den General“".

Krapf informiert, daß die Verhandlungen mit der sowjetischen Fluggesellschaft Aeroflot über die Einrichtung einer Direktverbindung zwischen Moskau und Frankfurt/Main abgeschlossen seien. Angesichts der noch immer ausstehenden Stellungnahme der drei Westmächte habe Staatssekretär Lahr Weisung gegeben, ihnen mitzuteilen, daß der Flugverkehr am 1. Oktober 1965 aufgenommen werden könne. Krapf rät davon $a b$, ohne vorherige Zustimmung der Drei Mächte zu handeln, da ihnen die Verantwortung für die Kontrolle des sowjetischen Flugverkehrs über der Bundesrepublik zukomme. Auf die Dringlichkeit einer Entscheidung sei in der Bonner Vierergruppe bereits hingewiesen worden; nötigenfalls müsse dies auf höherer Ebene bekräftigt werden.

Aus einer Unterredung mit dem französischen Außenminister gibt Klaiber Informationen über dessen Gespräche mit Amtskollegen zur EWG-Krise wieder. Gegenüber dem niederländischen Außenminister Luns habe Couve de Murville der EWG-Kommission und Italien die "Hauptschuld" am Scheitern der Ver- 
handlungen im EWG-Ministerrat vom 28. bis 30. Juni 1965 zugewiesen und betont, daß Frankreich die EWG-Kommission nicht als Vermittler akzeptieren könne. Von Luns sei bekräftigt worden, daß eine Beeinträchtigung der Kompetenzen der Kommission sowie der Römischen Verträge "nicht tragbar" sei. Der italienische Außenminister Fanfani habe einen Kompromiß hinsichtlich der Agrarfinanzierung in Aussicht gestellt und gebeten, den geplanten Boykott der EWG-Ministerratstagung am 26./27. Juli 1965 nochmals zu überdenken. Der belgische Außenminister Spaak habe dagegen Verständnis für die französische Haltung gezeigt und den "supranationalen Übereifer" der EWGKommission kritisiert. Klaiber nimmt an, daß der Eindruck einer „Einheitsfront“ der Partner die französische Haltung nur verhärten werde. Er prognostiziert eine Kompromißbereitschaft, sobald Frankreich seine Interessen stärker berücksichtigt fände. bei der NATO in Paris

Carstens übermittelt eine Stellungnahme zum britischen bzw. kanadischen Entwurf eines Vertrags über die Nichtverbreitung von Kernwaffen. Er führt aus, die Bundesrepublik bekenne sich zum Grundsatz der Nichtverbreitung, wünsche aber vor einer Vereinbarung mit der UdSSR eine Klärung der mit der nuklearen Verteidigung zusammenhängenden Fragen innerhalb der NATO. Wie andere nichtnukleare Staaten halte die Bundesrepublik Auflagen auch für die Nuklearmächte für erforderlich und befürworte daher den kanadischen Vorschlag für Sicherheitskontrollen. Die in beiden Vertragsentwürfen vorgesehene Beitrittsmöglichkeit für „alle Staaten“ müsse allerdings wegen der DDR zumindest mit einer „disclaimer-clause“ verbunden werden. Es sei ferner darauf hinzuweisen, daß ein Nichtverbreitungsabkommen das Problem der europäischen Sicherheit und damit die Deutschland-Frage berühre. Schließlich sei davon auszugehen, daß das sowjetische Interesse vorrangig der Verhinderung einer MLF/ANF und weniger einem Nichtverbreitungsabkommen gelte.

Carstens gibt ein Gespräch mit dem Unterstaatssekretär im amerikanischen Außenministerium am 12. Juli 1965 in Paris wieder. Ball äußerte die Erwartung, daß Frankreich die „militärische Integration zu beseitigen" suchen und alsbald die Entfernung militärischer NATO-Einrichtungen von französischem Territorium bzw. ihre Unterstellung unter französisches Kommando verlangen werde. Deshalb wollten die USA schon jetzt mit den Partnern in Überlegungen über die Konsequenzen eintreten. Die amerikanische Regierung erwäge, Frankreich von 
Anfang an mit der Grundsatzfrage nach seiner Stellung zur NATO zu konfrontieren. Carstens betonte die Bedeutung der bisherigen NATO-Organisation, die Verpflichtung zur deutschfranzösischen Konsultation und die Überzeugung, daß Frankreich keine „Umkehrung der Allianzen“ plane.

\section{Amt}

Siegfried informiert über eine Unterredung mit dem belgischen Außenminister am Vortag. Spaak stellte eine „erhebliche Feindseligkeit" Frankreichs gegenüber der EWG-Kommission fest, was die Lage insofern erschwere, als ein Vorschlag zur Überwindung der Krise der Gemeinschaft von der Kommission kommen müsse. Eine Regelung der Agrarfinanzierung bezeichnete er als dringlich, hielt es jedoch für verfrüht, dem Europäischen Parlament größere Befugnisse einzuräumen, da es wegen der Zusammensetzung aus Delegationen der nationalen Parlamente „nicht genügend repräsentativ" sei. Spaak sagte seine Teilnahme an der Sitzung des EWG-Ministerrats am 26./27. Juli $1965 \mathrm{zu}$, obwohl dieser wegen des "leeren Stuhls der Franzosen" nicht beschlußfähig sei. Das Fernbleiben Frankreichs stelle eine Vertragsverletzung dar, aber auch eine Tagung in Abwesenheit einzelner Ratsmitglieder bedeute einen Verstoß gegen den EWGVertrag.

Schröder informiert, daß mit der am 14. Juli 1965 erfolgten Erteilung des Exequaturs die angekündigte Errichtung eines Generalkonsulats der VAR in Ost-Berlin vollzogen sei. Es handele sich um das erste nichtkommunistische Generalkonsulat in der DDR und damit einen „gefährlichen Präzendenzfall". Daher müsse eine "wirksame Gegenmaßnahme" gefunden werden, damit nicht andere Staaten dem „Kairoer Beispiel“ folgen würden. Nach der bereits verfügten Einstellung weiterer Entwicklungshilfe durch die Bundesrepublik und dem Abbruch der diplomatischen Beziehungen durch die VAR komme nur die Schließung der ägyptischen Generalkonsulate in Frankfurt/ Main und Hamburg in Betracht. Zwar werde der ägyptische Präsident Nasser "gefühlsbetont" reagieren, doch sei eine Aufnahme diplomatischer Beziehungen mit der DDR unwahrscheinlich und allenfalls eine Schließung des Konsulats der Bundesrepublik in Alexandrien und des Wahlkonsulats in Port Said zu erwarten. Schröder kommt zu dem Schluß, daß das Bundeskabinett möglichst bald die Aufhebung der Generalkonsulate beschließen sollte. 

Frei in München

Erhard gratuliert zum Wahlerfolg des chilenischen Präsidenten und betont, die Bundesregierung verteidige "die gleichen gesellschaftspolitischen Prinzipien“. Er erkundigt sich nach Möglichkeiten zur Koordinierung der europäischen Entwicklungshilfe an Chile und nach den Aussichten für eine lateinamerikanische Freihandelszone. Frei erläutert das chilenische Wirtschaftsprogramm, bei dem die Inflationsbekämpfung im Vordergrund stehe, und berichtet über politische und soziale Widerstände gegen die beabsichtigte Agrarreform. Die Gesprächspartner sind sich einig, daß sowohl in der Landwirtschaft als auch im Bereich der gewerblichen Wirtschaft vor allem kleine und mittlere Betriebe zu fördern seien. Der chilenische Präsident hebt die Bedeutung der amerikanischen Hilfe für Lateinamerika hervor, bedauert jedoch, „daß die USA zur Stärkung von Militärregimen beitrügen“. Er sieht die „kommunistische Gefahr“ vor allem vor dem Hintergrund der Inflation und der Arbeitslosigkeit. Dieser Gefahr müsse durch gezielte Förderung der demokratischen Parteien und der demokratisch orientierten Gewerkschaftsbewegung in Lateinamerika begegnet werden.

Krapf übermittelt eine Sprachregelung zu den Bemühungen der Bundesregierung, das Verfahren zur Einbeziehung von Berlin (West) in Verträge der Bundesrepublik zu vereinfachen. Durch die vorzeitig bekanntgewordene Anregung gegenüber den drei Westmächten, in künftigen Abkommen auf eine Berlin-Klausel zu verzichten und Berlin (West) stillschweigend als einbezogen zu betrachten, sei in der Öffentlichkeit der "völlig irrige“ Eindruck entstanden, die Bundesregierung habe ihre feste Haltung in dieser Frage aufgegeben. Krapf hebt hervor, daß die angestrebte Verbesserung des Verfahrens gerade der Erhaltung der „lebenswichtigen Verbindung zwischen dem Bund und Berlin“ dienen werde.

Carstens berichtet über ein Gespräch mit dem Unterstaatssekretär im britischen Außenministerium am 12. Juli 1965. Lord Hood erklärte, daß zum Jahresende mit französischen Maßnahmen zum Abbau der integrierten Organisation der NATO zu rechnen sei, und plädierte für eine deutliche Willensbekundung der übrigen Mitgliedstaaten zur Erhaltung der bestehenden Bündnisstrukturen. Er empfahl, mögliche Konsequenzen zu erörtern, hielt jedoch einen französischen Bruch mit der NATO im Sinne einer „Umkehrung der Allianzen“ für unwahrscheinlich. Den amerikanischen Gedanken, „schon bei den ersten fran- 
zösischen Maßnahmen das Gesamtproblem aufzurollen", lehnte Hood ab. Wenn es zu einem Zusammenstoß komme, solle Frankreich die Verantwortung dafür überlassen werden.

Ruete rekapituliert die Haltung zur Nichtverbreitung von Kernwaffen. Nach der "Irischen Resolution“ der UNO-Generalversammlung vom 4. Dezember 1961 habe die Bundesregierung verschiedene Vorschläge der USA unterstützt und lediglich darauf hingewiesen, daß sich diese nicht auf Europa oder Deutschland beschränken und keine Beeinträchtigung der Verteidigungsfähigkeit der NATO verursachen dürften. Im Dezember 1963 habe Bundesminister Schröder erstmals den Standpunkt vertreten, daß „eine weitere Bindung im nuklearen Bereich" erst nach Realisierung der geplanten MLF eingegangen werden könnte. Obwohl die Alliierten Verständnis für diese Haltung hätten, strebten sie angesichts der sowjetischen Ablehnung einer MLF dennoch den baldigen Abschluß eines Nichtverbreitungsabkommens an. Sie beabsichtigten auch keine Verknüpfung mit politischen Fragen, während die Bundesrepublik seit Ende 1964 darauf hinzuwirken suche, ihre Mitwirkung von sowjetischen Gegenleistungen zugunsten der DeutschlandFrage abhängig zu machen. Ruete resümiert, daß die kürzliche öffentliche Bekräftigung dieses Standpunkts durch Schröder „nur eine Ausgangsposition sein“ solle, die nicht aufrechterhalten werden könne.

Schmidt-Horix faßt ein Gespräch mit dem rumänischen Stellvertretenden Außenminister zusammen. Macovei bekräftigte das Einverständnis, Berlin (West) in ein Kulturabkommen einzubeziehen. Hinsichtlich der Familienzusammenführung sagte er eine individuelle Prüfung aller Fälle zu, betonte jedoch die Ablehnung einer „Globallösung“. Der Botschafter beharrte auf der Einhaltung der „eindeutigen Vereinbarungen“ hinsichtlich des Status der Handelsvertretung der Bundesrepublik in Bukarest und gab der Hoffnung Ausdruck, daß diese baldmöglichst $\mathrm{Pa}$ - und Sichtvermerksbefugnisse ausüben könne. Demgegenüber bestritt Macovei eine Absprache über die Ausstellung von Pässen durch die Handelsvertretungen, hob aber hervor, daß Rumänien einer entsprechenden Vereinbarung nicht abgeneigt sei.

Der Botschafter erläutert die Ergebnisse der Verhandlungen mit Rumänien über den Handelsverkehr. Das Warenabkommen vom 24. Dezember 1963 wurde bis zum 31. Dezember 1969 verlängert, und zwar durch Einfügung einer Revisionsklausel, da 
eine Ausnahmeregelung von der EWG-Verordnung über langfristige Abkommen nicht rechtzeitig erreichbar gewesen wäre. Ferner wurde Rumänien die Möglichkeit zur Erhöhung der Exporte in die Bundesrepublik eingeräumt und dabei vertraulich vereinbart, daß eine Lieferung, jeweils zu marktgerechten Preisen" erwartet werde. Schmidt-Horix weist darauf hin, daß den „äußerst hochgespannten Erwartungen“ Rumäniens nicht in vollem Umfang Rechnung getragen worden sei. Er hebt die unveränderte rumänische Bereitschaft hervor, der Bundesrepublik im Westhandel „den ersten Platz" einzuräumen, wenn genügend Absatzmöglichkeiten geboten würden. Der Botschafter hofft, daß sich die Verhandlungsergebnisse auf die noch schwebenden bzw. bevorstehenden Wirtschaftsverhandlungen mit Ungarn, Bulgarien und Polen auswirken. wärtige Amt

Grewe informiert über eine Unterredung mit dem Generalsekretär der NATO. Brosio äußerte, daß sich die britischen und amerikanischen Bemühungen um ein Abkommen über die Nichtverbreitung von Kernwaffen „letztlich gegen die eigenen Verbündeten “ richteten und daher "einen schwerwiegenden Verstoß gegen den Geist der Allianz" bedeuteten. Er stellte jedoch fest, daß außer Frankreich keiner der NATO-Staaten eine offen negative Haltung einnehme. Aufgrund des Hinweises von Brosio, daß Großbritannien seinen Nichtverbreitungsvorschlag am 27. Juli 1965 der Konferenz der 18-Mächte-Abrüstungskommission in Genf vorlegen wolle, hält es Grewe für erforderlich, die Vorbehalte der Bundesregierung gegen die bisherigen Entwürfe „deutlich und entschieden“ zum Ausdruck zu bringen.

Zur Vorbereitung eines Gesprächs des Staatssekretärs Carstens mit den Botschaftern der Drei Mächte informiert Ruete über die innerdeutschen Kontakte und die Lage in Berlin. Er stellt fest, daß der Schiffsverkehr nach Berlin (West) reibungslos verlaufe, während im Eisenbahn-Gütertransport nach der Kündigung der Tarife durch die DDR ein vertragsloser Zustand bestehe. Die Passierschein-Frage werde von der DDR zunehmend in ihre Bemühungen um eine politische Aufwertung einbezogen. Ruete rechnet mit weiteren Störversuchen im Berlin-Verkehr und betont, daß zwischen den drei Westmächten und der Bundesrepublik keine Einigung über Gegenmaßnahmen bestehe. Hinsichtlich einer gemeinsamen Handelspolitik gegenüber der DDR erwartet er weiterhin Schwierigkeiten von britischer Seite. Schließlich weist er darauf hin, daß eine Stellungnahme der Drei Mächte sowohl zur Einbeziehung von Berlin (West) in Verträge der Bundesrepublik als auch zur Vereinbarung der 
Lufthansa mit der sowjetischen Fluggesellschaft Aeroflot über Linienflüge zwischen Frankfurt/Main und Moskau noch ausstehe.

Amt

Giesen schlägt vor, das geplante Luftverkehrsabkommen mit Zypern von einem zyprischen Verzicht auf ein gleichartiges Abkommen mit der DDR abhängig zu machen. Ferner solle die Bundesregierung die Verhandlungen „ruhig scheitern lassen“, wenn der Status der Handelskammervertretung der DDR in Nikosia nicht entsprechend den Wünschen der Bundesrepublik präzisiert würde. Auswärtige Amt

Lüders gibt Informationen des Leiters der Europa-Abteilung im indischen Außenministerium über Gespräche der Staatsministerin Lakshmi Menon in den südosteuropäischen Staaten weiter. Über die Unterredungen mit der türkischen Regierung berichtete Sanyal, daß es gelungen sei, „den starken Einfluß Pakistans auf die Türkei, insbesondere auch in der Kaschmirfrage, zu neutralisieren". In Griechenland sei deutlich gemacht worden, daß Indien für die Unabhängigkeit Zyperns eintrete. Über den Besuch in der Tschechoslowakei sei zu sagen, daß dort große Beunruhigung über die „revisionistischen Forderungen“ der sudetendeutschen Verbände und die „Inaktivität der Bundesregierung“ hinsichlich einer Annullierung des Münchener Abkommens von 1938 herrsche. Sanyal beschloß den Bericht mit Reiseeindrücken aus Ungarn, Rumänien sowie Bulgarien und resümierte, daß mit der geographischen Nähe zur Bundesrepublik die Besorgnis über deren politische Entwicklung wachse. Umgekehrt gelte: „Je weiter man von Mitteleuropa entfernt lebe, desto weniger interessiere man sich für die deutsche Frage."

Der Staatssekretär informiert über eine Unterredung mit dem britischen Botschafter am Vortag. Carstens erläuterte, daß die Bundesrepublik das Prinzip der Nichtverbreitung von Kernwaffen zwar bejahe, jedoch vor dem Beitritt zu einem Abkommen die Beteiligung der nichtnuklearen Mächte an der nuklearen Verantwortung in der NATO gewährleistet sehen wolle. Ferner müsse die UdSSR zu Gegenleistungen in der DeutschlandFrage gedrängt und eine Anerkennungswirkung zugunsten der DDR vermieden werden. Schließlich sei das „Ungleichgewicht" $\mathrm{zu}$ beseitigen, das aus den allein für die Nichtnuklearmächte 
vorgesehenen Beschränkungen erwachse. Roberts zeigte Verständnis, betonte aber, daß es angesichts der sowjetischen Haltung „wohl schwer sein würde“, die Nichtverbreitung mit anderen Themenkomplexen zu verknüpfen.

Hopf informiert über eine Unterredung mit dem Staatsminister im britischen Außenministerium, Lord Chalfont. Der britische Abrüstungsbeauftragte erläuterte Überlegungen zur Ausdehnung des Teststopp-Abkommens vom 5. August 1963 auf unterirdische Versuchsexplosionen. Er berichtete ferner von Bemühungen, über den Vorschlag des Präsidenten Johnson vom Januar 1964 hinaus eine Verringerung von Kernwaffenträgern zu erreichen. Auch die Errichtung von Bodenbeobachtungsposten in Europa sei „weiterhin aktuell“. Den Einwand von Hopf, daß eine MLF/ANF nach Abschluß eines Nichtverbreitungsabkommens kaum noch realisierbar wäre, beantwortete Chalfont mit dem Hinweis, daß er die Nichtverbreitung „zeitlich für dringender" halte als eine gemeinsame Atomstreitmacht. Schröder

Groepper übermittelt eine Analyse zur Bedeutung der Nichtverbreitung von Kernwaffen für die sowjetische Deutschlandpolitik. Demnach würde ein durch Beitritt zu einem Nichtverbreitungsvertrag ausgesprochener Verzicht der Bundesrepublik auf Erwerb von Atomwaffen eine „entscheidende Positionsverbesserung“ für die UdSSR bedeuten, wenn er nicht mit „unwiderruflichen Schritten" zur Wiedervereinigung Deutschlands verbunden wäre. Das Argument, ein entsprechendes Junktim gefährde die Chancen für ein Abkommen, sei nicht stichhaltig. Die UdSSR sei derzeit vor allem deshalb nicht konzessionsbereit, weil sie wisse, daß auch die Westmächte einen umfassenden Atomverzicht der Bundesrepublik „sogar dringend“ wünschten. Falls jedoch die Position der Bundesregierung mehr Unterstützung fände, könnte die UdSSR einen solchen Verzicht mit „entscheidenden und unwiderruflichen Fortschritten in der Deutschlandfrage" honorieren. von Hardenberg

Hardenberg hält den Stand der Sachverständigengespräche mit Äthiopien über einen Ausgleich für die stornierte Ausrüstungshilfe fest. Der äthiopischen Seite sei erklärt worden, daß ihre Erwartungen weit über den Zusagen der Bundesregierung lägen und der Zeitbedarf sowie die Modalitäten für Ersatzlieferungen produktionstechnisch bzw. gesetzlich vorgegeben seien. 
Eine Barauszahlung des ursprünglich für Waffenlieferungen vorgesehenen Betrags sei dagegen „durch die Parlamentsausschüsse untersagt" worden und könne allenfalls in der kommenden Legislaturperiode erneut beraten werden. Auswärtige Amt

Der Botschafter gibt Informationen aus dem amerikanischen Außenministerium und der Abrüstungsbehörde sowie aus der niederländischen Botschaft in Washington wieder. Danach sei zu erwarten, daß auf der kommenden Sondersitzung des Ständigen NATO-Rats am 26. Juli 1965 in Paris der britische Entwurf für ein Abkommen zur Nichtverbreitung von Kernwaffen sowohl von den Niederlanden als auch von den USA verworfen werde. Letztere seien trotz ihres Interesses an einer Regelung nicht bereit, sich zu einer "Opferung des MLF-Gedankens" drängen zu lassen. Für die Stellungnahme der Bundesregierung erachtet es Knappstein als gefährlich, die Deutschland-Frage zu sehr in den Vordergrund zu stellen, und rät zu Argumenten, die auch für andere NATO-Staaten interessant sein könnten. amerikanischen Sonderbotschafter Harriman in München

Harriman versichert, er habe bei seinen Gesprächen mit dem sowjetischen Ministerpräsidenten Kossygin am 15. und 21. Juli 1965 in Moskau erklärt, daß die USA am MLF/ANF-Projekt festhielten, „falls die europäischen Mächte darüber einig würden". Ebenso eindeutig habe er zur Wiedervereinigung Deutschlands Stellung bezogen. Erhard bedauert den seit 1964 eingetretenen Meinungswandel hinsichtlich einer MLF/ANF, der zur "derzeitigen Malaise" geführt und der UdSSR Hoffnung gegeben habe, das Vorhaben verhindern zu können. Zur Lage in Südostasien erläutert Harriman, daß die USA ihre Streitkräfte verstärken wollten, und bittet um Unterstützung für die Republik Vietnam (Südvietnam). Zwar zeige die Bundesrepublik „das meiste Verständnis“, doch müßten alle NATO-Staaten erkennen, „daß in Vietnam um ihren Sieg gekämpft werde“. Erhard weist im Gegenzug auf die Bedeutung einer einheitlichen Kreditpolitik gegenüber der UdSSR hin. Während er sich über die EWG-Krise wenig beunruhigt zeigt, hält er die französischen Vorstellungen zur Zukunft der NATO für besorgniserregend. Hinsichtlich des von Erhard bekräftigten Zusammenhangs einer Regelung zur Nichtverbreitung von Kernwaffen mit der Deutschland-Frage betont Harriman abschließend, daß die amerikanische Regierung diese Auffassung nicht teile. 
Carstens legt eine für die Sitzung des Ständigen NATO-Rats am 26. Juli vorbereitete Stellungnahme zur Nichtverbreitung von Kernwaffen vor. Die Bundesregierung unterstützt das Anliegen, bedauert jedoch, daß ihre Verzichtserklärung von 1954 keine Nachahmung gefunden habe und die Chancen für ein Abkommen inzwischen stark beeinträchtigt seien. Ferner betont sie, daß Beschränkungen auch für die Nuklearmächte vorgesehen und die nichtnuklearen NATO-Staaten vor einer Festlegung gegenüber der UdSSR wirksam an der Verantwortung für die nukleare Verteidigung beteiligt werden sollten. Außerdem wird eine Sicherheitskontrolle sowie eine „disclaimer clause" für die Beitrittsformel eines Vertrags vorgeschlagen und auf den Zusammenhang mit der europäischen Sicherheit hingewiesen. Abschließend gibt Carstens die gesondert abzugebende Erklärung wieder, daß bei der Diskussion von Vorschlägen „mit peinlicher Sorgfalt auf ein allianzkonformes Verfahren" zu achten sei. berg, Washington

Klingeberg nimmt zu den geplanten Maßnahmen zur Verhinderung einer Anerkennung des Olympischen Komitees der DDR und zur Beibehaltung einer gesamtdeutschen Mannschaft bei der Olympiade von 1968 Stellung. Er gibt zu bedenken, daß die Durchführung zu Rückschlägen in der Deutschlandpolitik führen könne und der "schwarze Peter" dem Auswärtigen Amt zufiele. Zweifel hegt er an der Resonanz einer Boykottdrohung der Bundesrepublik, zumal die Chancen auf Mitwirkung hinsichtlich Frankreichs ungewiß und hinsichtlich der USA „äußerst gering" seien. Für bedenklich hält er auch das Vorhaben, die Mitglieder des IOC durch die Auslandsvertretungen um Unterstützung zu bitten, da dies als „Einmischung der Politik in den olympischen Sport" verstanden werden könnte. Erfolgversprechender erscheint ihm eine Initiative über den Präsidenten des NOK für Deutschland, Daume. belgischen Außenminister Spaak in Brüssel

Spaak konstatiert hinsichtlich des Abbruchs der Sitzung des EWG-Ministerrats am 30. Juni 1965, daß der französische Außenminister Couve de Murville entweder „die Nerven zu früh verloren oder präzise Weisungen aus Paris erhalten" habe. Beide Gesprächspartner sehen das Hauptziel Frankreichs in einer Abwertung der EWG-Kommission. Spaak spricht die Möglichkeit eines Beitritts der übrigen vier EWG-Staaten zum deutsch-französischen Vertrag an, der "ein großer Fehler" gewesen sei. Schröder bestätigt das Risiko eines solchen Vorhabens 
und versichert, daß durch die Kontakte mit Frankreich kein Präjudiz geschaffen werden solle und wirtschaftliche Fragen der Gemeinschaft ausschließlich in Brüssel behandelt würden. Spaak befürchtet, daß de Gaulle sowohl der europäischen Politik als auch der NATO „eine tödliche Wunde versetzen“ könnte. Schröder betont die Notwendigkeit, in der NATO so wenig wie möglich über eine Reform zu diskutieren. Auch in der EWG müsse gegenüber Frankreich Entschlossenheit demonstriert werden, keine substantielle Änderung der Römischen Verträge zuzulassen. Eine rechtliche Prüfung habe ergeben, daß auch bei Abwesenheit eines Partners die übrigen EWG-Mitglieder Beschlüsse fassen könnten. Spaak sieht keine Bedenken gegen Beratungen ohne Frankreich, hält aber eine Beschlußfassung ohne französische Beteiligung für problematisch.

Carstens gibt ein Gespräch mit einem Vorstandsmitglied der Firma Strabag wieder. Löhr informierte über eine Unterredung mit dem tansanischen Präsidenten, der es als „höchstes Gebot“ bezeichnet habe, die Einheit zwischen Sansibar und Tanganjika zu erhalten, da letzteres sonst eine „feindliche Festung vor seiner Küste" hätte. Nyerere habe ferner Interesse an guten Beziehungen zur Bundesrepublik geäußert, hinsichtlich des Generalkonsulats der DDR in Daressalam aber hervorgehoben, daß er nicht deswegen die Union mit Sansibar gefährden könne. Carstens erläuterte die Enttäuschung über das Verhalten von Nyerere und die Besorgnis wegen des tansanischen Abgleitens in ein "pro-chinesisches Fahrwasser". Auswärtige Amt

Weinhold berichtet von Gesprächen des Ministerialdirektors Krapf im italienischen Außenministerium. Übereinstimmung bestand hinsichtlich der Bedeutung der NATO-Integration. Die Gesprächspartner wünschten jedoch die Möglichkeit einer „späteren eigenständigen europäischen Verteidigung " nicht auszuschließen und hielten Vorschläge zur Reform der NATO-Organisation für richtig, um der ,Anti-NATO-Politik“ des Staatspräsidenten de Gaulle entgegenzuwirken. Für das MLF-Projekt bevorzugten sie die Konzeption als U-Boot-Flotte und stellten es in einen Zusammenhang mit der Ablehnung französischer Bestrebungen, Frankreich zur einzigen Nuklearmacht Kontinentaleuropas zu machen. Der Vorschlag des amerikanischen Verteidigungsministers McNamara zur Einrichtung eines

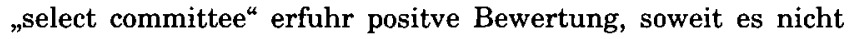
Ersatz für die MLF sein solle und sofern es über die drei NATO- 
Nuklearmächte hinaus von weiteren Staaten gebildet werde. Hinsichtlich der Nichtverbreitung von Kernwaffen wurde der kanadische Abkommensentwurf für akzeptabel gehalten. Außenminister Rusk

Schröder bekundet weitgehende Übereinstimmung hinsichtlich der Nichtverbreitung von Kernwaffen. Er erklärt, die Bundesregierung plane einem Abkommen erst nach Schaffung einer MLF beizutreten, und hebt hervor, daß das „überragende Interesse“ der UdSSR an einer Denuklearisierung Deutschlands und das „überragende Interesse“ der Bundesrepublik an der Wiedervereinigung im Zusammenhang gesehen werden müßten. Auswärtige Amt

Sachs berichtet über die Sitzung des EWG-Ministerrats vom 26./27. Juli 1965. Der belgische Außenminister Spaak sprach sich gegen Abstimmungen in Abwesenheit von Frankreich aus und schlug vor, unvermeidliche Entscheidungen auf schriftlichem Weg zu treffen. Bundesminister Schröder stimmte ebenso wie der italienische Landwirtschaftsminister Ferrari unter dem Vorbehalt $z u$, daß damit kein Präjudiz geschaffen werde, und hob die Notwendigkeit hervor, die EWG „am Leben“ zu erhalten. Der niederländische Außenminister Luns bezeichnete es als „höchst bedenklich“, wenn ein EWG-Staat den Beratungen aus Unzufriedenheit mit den Ergebnissen fernbleibe und zweifelte, ob die „physische Anwesenheit eines Ratsmitgliedes" erforderlich sei. Der Präsident der EWG-Kommission, Hallstein, bezeichnete es als Hauptaufgabe, den Fortbestand und das Funktionieren der Gemeinschaft zu sichern. Der Präsident des Ministerrats, der italienische Außenminister Fanfani, sprach sich für eine Rücksichtnahme auf Frankreich aus, um dessen Rückkehr an den Verhandlungstisch zu erleichtern.

308 27.07. Botschafter Grewe, Paris (NATO), an das Auswärtige Amt

Der Botschafter faßt die Sondersitzung des Ständigen NATORats vom 26. Juli 1965 zusammen. Die Diskussion habe ergeben, daß hinsichtlich des britischen und amerikanischen Vorgehens in der Frage der Nichtverbreitung von Kernwaffen „nicht mit ernsthaftem Widerstand“ der Partner zu rechnen, sondern allenfalls ein Unbehagen erkennbar sei. Der Vorschlag der Bundesregierung, Vertragsentwürfe innerhalb der NATO auszuhandeln, ehe sie auf der Konferenz der 18-Mächte-Abrüstungskommission in Genf vorgelegt würden, sei nicht angenommen worden. NATO-Generalsekretär Brosio habe abschließend auf die 
notwendige Vereinbarkeit mit den Überlegungen zur „nuklearen Frage" in der NATO hingewiesen und die Erwartung ausgesprochen, daß die vier auf der Genfer Konferenz vertretenen NATO-Staaten zwar nicht im Namen der Allianz sprächen, aber die Stellungnahmen der Verbündeten berücksichtigten.

Stelzer berichtet über Außerungen des Leiters der finnischen Handelsvertretung in Köln. Mäkelä erkundigte sich nach den Überlegungen der Bundesregierung hinsichtlich einer Aufnahme diplomatischer Beziehungen mit Rumänien und stellte "scherzhaft" die Frage, ob eine Anerkennung der DDR unter sowjetischem Druck die Voraussetzung für eine Aufwertung der Beziehungen zwischen Bonn und Helsinki sei. Stelzer konstatiert, die Bundesrepublik könne nicht für einzelne OstblockStaaten das gleichzeitige Bestehen diplomatischer Beziehungen mit der Bundesrepublik und der DDR akzeptieren, dies aber für das ,in seiner Bewegungsfreiheit gleichfalls eingeengte“ Finnland ausschließen.

Als Beitrag zur Dienstinstruktion für den Botschafter in Tel Aviv werden die israelischen Bemühungen um eine Assoziierung mit der EWG erläutert. Ein förmlicher Antrag sei nicht gestellt worden, doch habe Israel auch nach Abschluß des Handelsabkommens vom 1. Juli 1964 mit der EWG fortgesetztes Interesse an einer „Assoziierung in Form einer Zollunion oder einer Freihandelszone“ bekundet. Die Bundesrepublik habe zwar das Handelsabkommen unterstützt, sich aber zu einer von Israel wiederholt erbetenen weitergehenden Initiative außerstande gesehen. Eine Assoziierung mit außereuropäischen Staaten sei nach den Grundsätzen der EWG nur in bestimmten Sonderfällen vorgesehen und würde die "wirtschaftliche, finanzielle und organisatorische Kraft" der Gemeinschaft übersteigen. Eine Ausnahme würde einen Präzedenzfall schaffen und komme daher nicht in Betracht. sekretär Carstens

Knappstein informiert über eine Unterredung mit dem amerikanischen Senator Robert Kennedy. Er erläuterte Kennedy, daß die Bundesrepublik einem Abkommen zur Nichtverbreitung von Kernwaffen nur dann beitreten könnte, wenn ihre Beteiligung an der nuklearen Verantwortung in der NATO geregelt und damit ihrem Bedürfnis nach „Sicherheit gegen atomare Aggression und Erpressung “ Rechnung getragen worden sei. Der Senator zeigte Verständnis und bekräftigte das Interesse an einer 
MLF. Er erklärte jedoch, die europäischen Staaten hätten schon einige Jahre mit erfolglosen Verhandlungen über das Projekt verbracht und zu dem Eindruck beigetragen, sie legten auf die MLF „gar keinen Wert mehr“. Abschließend übermittelt Knappstein den Entwurf einer Aufzeichnung, die er Kennedy nachträglich zustellen lassen möchte. Auswärtige Amt

Der Abrüstungsbeauftragte der Bundesregierung gibt ein Gespräch mit dem italienischen Außenminister wieder. Fanfani bezeichnete die Reaktion auf seinen am Vortag auf der Konferenz der 18-Mächte-Abrüstungskommission unterbreiteten Vorschlag, zunächst nur einseitige Verzichtserklärungen der nichtnuklearen Staaten auf den Erwerb von Atomwaffen vorzusehen, als „keineswegs entmutigend“. Schnippenkötter äußerte, daß das Vorhaben ein "gangbarer Ausweg“ sein könnte, insbesondere wenn es um die Entkräftung eventueller Vorwürfe gehe, daß die Bundesrepublik für den Zusammenbruch der Verhandlungen über die Nichtverbreitung von Kernwaffen verantwortlich sei. Auch das Problem der nuklearen Verantwortung in der NATO und der Zusammenhang mit der Deutschland-Frage „könnten damit vielleicht in ein anderes Licht rücken“.

Böx informiert über eine Unterredung mit dem Staatssekretär im norwegischen Außenministerium. Boyesen zeigte kein Verständnis für das Bestreben der Bundesregierung, den Beitritt zu einem Abkommen über die Nichtverbreitung von Kernwaffen von Vorbedingungen, insbesonderere hinsichtlich der Deutschland-Frage, abhängig zu machen, denn „Entspannung sei Voraussetzung für Wiedervereinigung". Auch gegen das MLF-Projekt wandte er sich, zumal es den endgültigen Bruch des Staatspräsidenten de Gaulle mit der NATO heraufbeschwöre. Böx zieht den Schluß, daß Norwegen ,fast vorbehaltlos auf Entspannung zusteuert".

Lahr bittet, dem französischen Ministerpräsidenten Pompidou den Standpunkt der Bundesregierung zur Lage in der EWG zu erläutern. Klaiber solle an die Zugeständnisse erinnern, die die Bundesrepublik hinsichtlich des Agrarmarktes bereits gemacht habe, und den Vorwurf zurückweisen, daß es ihr an „kommunitärem Verantwortungsbewußtsein“ fehle. Er solle ferner Verständnis für die französische Haltung bekunden und eine ruhige Prüfung der jüngsten Vorschläge der EWG-Kommission anregen. Frankreich möge den Verständigungswillen der Partner- 
staaten nutzen und die „Politik des leeren Stuhls“ beenden, die mit dem EWG-Vertrag nicht in Einklang zu bringen sei. Noch könne von einer Krise nicht die Rede sein. Allerdings müsse ein Übergreifen der Auseinandersetzung auf die Beratung institutioneller Fragen vermieden werden, da Bemühungen im Sinne einer Änderung der Römischen Verträge „zum Scheitern verurteilt wären und die Gemeinschaft in Gefahr bringen könnten".

Ruete bewertet den britischen, den amerikanischen und den kanadischen Entwurf für einen Vertrag über die Nichtverbreitung von Kernwaffen. Er stellt fest, daß alle drei Vorschläge die Bildung einer MLF zuließen, freilich nur das amerikanische Konzept deren Europäisierung „unter Einschluß von möglichen Mehrheitsbeschlüssen" erlaube. Die USA gingen allerdings von einer Kontrolle der gesamten Tätigkeit nichtnuklearer Staaten auf atomarem Gebiet durch die IAEO aus. Gegenüber dieser Diskriminierung biete die britische Haltung den Vorteil, daß sie das Problem der Kontrolle einer späteren Vereinbarung vorbehalten wolle. In allen drei Entwürfen seien sowohl die Beitrittsund die Rücktrittsklausel als auch die Depositarmächte-Regelung dem Teststopp-Abkommen vom 5. August 1963 nachgebildet. Die von der Bundesregierung gewünschte „disclaimer clause" habe wenig Chancen, da keiner der Allianzpartner von der Notwendigkeit einer solchen Vertragsbestimmung überzeugt sei. Auswärtige Amt

Knappstein teilt mit, der amerikanische Außenminister habe auf einer Pressekonferenz betont, daß es keine Priorität bezüglich eines Abkommens zur Nichtverbreitung von Kernwaffen und einer Regelung "der nuklearen Organisation der NATO“ gebe, da keinerlei Zusammenhang bestehe. Dies sei die erste öffentliche Stellungnahme eines hohen Regierungsvertreters gegen die von Senator Robert Kennedy verlangte Vorrangigkeit der Nichtverbreitung. Zum italienischen Vorschlag einer Nichtverbreitungsregelung in der Form zeitlich beschränkter einseitiger Verzichtserklärungen habe sich Rusk positiv geäußert, jedoch das Fehlen einer Verpflichtung der Nuklearmächte zur Nichtweitergabe von Atomwaffen bedauert.

$\mathbf{3 1 7}$

03.08. Ministerialdirigent Böker an Generalkonsul Ringelmann, Salisbury

Böker befürchtet, daß sich die Lage in Südrhodesien zuspitzen werde. Zwar sei die Gefahr einer einseitigen Unabhängigkeitserklärung "wohl nicht akut", könnte aber gegebenenfalls zur 
Bildung mehrerer Exilregierungen führen. Dann werde die Frage der internationalen Legitimierung und damit das „Sonderproblem" einer Anerkennung durch die DDR entstehen. Rücksichten auf Großbritannien und die unabhängigen Staaten Afrikas sowie auf die Deutschland-Frage zwängen dazu, ,in Südrhodesien jetzt nicht nach vorn zu drängen" und die Wirtschaftsbeziehungen nicht zu forcieren.

Bach informiert über ein Gespräch mit dem iranischen Verteidigungsminister am 28. Juli 1965. Sanii wiederholte die Bitte des Schah Reza Pahlevi, Lizenzen für den Nachbau des Gewehres G3 und des Maschinengewehres MG1 zu gewähren. Zunächst wünsche der Iran, 10000 Gewehre des ersten und 1000 Gewehre des zweiten Modells kostenlos ,zur Erprobung “ zu erhalten. Ferner würden als „Starthilfe “ für die Eigenproduktion 14,8 Millionen DM benötigt. Darüber hinaus werde um einen Kredit über 21 Millionen DM für die weiteren Kosten gebeten, da diese im derzeitigen iranischen Haushalt noch nicht veranschlagt seien. Bach befürwortet die Ausrüstungshilfe, da eine Ablehnung angesichts der sowjetischen Aktivitäten einen „ernsthaften Rückschlag" für die Bundesrepublik im Iran sowie in der Türkei und Pakistan bedeuten würde.

Dvorak äußert Bedenken gegen die Weisung des Staatssekretärs Carstens, der ungarischen Regierung durch die Handelsvertretung in Budapest einen Entwurf für ein Kulturabkommen zu übermitteln. Er schlägt statt dessen vor, wie im Fall Rumäniens, zunächst zu sondieren, ob Verhandlungsbereitschaft bestehe. Dabei müsse vor allem die Unabdingbarkeit einer Berlin-Klausel hervorgehoben werden. Selbst bei positiver Resonanz sei es zudem ratsam, den Abschluß der Kulturverhandlungen in Bukarest abzuwarten, um einen "möglichst günstigen Präzedenzfall“ zu schaffen. Da Rumänien den Wünschen der Bundesregierung "sehr viel aufgeschlossener" begegne, könne der zu erwartende Verhandlungserfolg gegenüber Ungarn von Nutzen sein. Bundeskanzleramt

Der Leiter des Außenpolitischen Büros im Bundeskanzleramt informiert über ein Gespräch des Bundesministers Westrick mit dem amerikanischen Gesandten. Westrick erklärte, die Bundesregierung müsse auf einem Zusammenhang der DeutschlandFrage mit einem Abkommen über die Nichtverbreitung von 
Kernwaffen bestehen. Es wäre der öffentlichen Meinung nicht vermittelbar, wenn der seltene Fall, daß die UdSSR „etwas Wesentliches von Deutschland wolle", nicht genutzt würde. Hillenbrand bekräftigte die abweichende Auffassung der USA und betonte das beiderseitige Interesse, die Differenzen nicht an die Öffentlichkeit kommen zu lassen. Middelmann

Middelmann gibt eine Unterredung mit dem Direktor der Firma Fritz Werner wieder. Meier teilte mit, er sei von der Armeeführung des Sudan zu einem Besuch eingeladen worden, und bat um Abstimmung für den Fall, daß er auf eine Fortführung der laufenden Ausrüstungshilfe sowie auf die Möglichkeit eines Anschlußabkommens angesprochen werde. Middelmann empfahl zu erklären, daß sowohl für die "vorläufig auf Eis gelegten“" als auch für eventuell neu zu vereinbarende Lieferungen eine Wiederherstellung der diplomatischen Beziehungen Voraussetzung sei.

Seydel berichtet über ein Gespräch mit einem Mitarbeiter der Firma MTP aus Zürich. Kirschsieper informierte, da $\beta 200$ der 350 in der ägyptischen Raketenindustrie tätigen Deutschen in die Bundesrepublik zurückkehren wollten und dafür „sofortige Hilfe" verlangten. Sie seien zum Teil "rabiat" eingestellt und drohten, sich an die Presse zu wenden. Seydel erwiderte, daß ihnen im Rahmen der bestehenden Bestimmungen jede Erleichterung gewährt werden solle. Er sehe jedoch weder eine Verpflichtung noch die Bereitschaft zu finanzieller Hilfe, zumal die Betreffenden ,in der VAR gut verdient hätten“. Kirschsieper prognostiziert, daß das Raketenprogramm „infolge der Unfähigkeit der ägyptischen Stellen" nach dem Weggang der deutschen Experten zusammenbrechen werde.

Böker legt dar, daß die USA die nukleare Zusammenarbeit mit EURATOM den vor 1957 geschlossenen bilateralen Vereinbarungen mit einzelnen Mitgliedstaaten vorzögen. Da aber die Sicherheitskontrollen für die Gemeinschaft allein der EURATOM-Kommission oblägen, stehe diese Haltung den amerikanischen Bestrebungen entgegen, „die möglichst umfassende und weltweite Anwendung von IAEO-Kontrollen zu erreichen". Ob die USA künftig auch eine Anwendung auf EURATOM verlangen würden, hänge u.a. von deren Funktionsfähigkeit $a b$, die jedoch durch die französische Politik gegenüber der Gemeinschaft gefährdet werde. Frankreich habe sich zudem gegen eine 
Nichterneuerung seines Kooperationsabkommens mit den USA gewandt, obwohl eine Überleitung auf EURATOM angesichts deren Kontrollbestimmungen in seinem eigenen Interesse sei. Der Grund liege vermutlich in ,uibergeordneten, ideologischen Erwägungen und dem seit jeher ausgeprägten Autonomiestreben des französichen Atomkommissariats“. Demgegenüber müsse die Bundesrepublik einer Schwächung von EURATOM entgegenwirken und Frankreich davon überzeugen, daß beide Staaten nicht an IAEO-Kontrollen bei der Lieferung von Kernmaterial und -ausrüstungen in das Gebiet der Gemeinschaft interessiert sein könnten.

Böker stellt fest, daß die am 21. September 1965 in New York zusammentretende UNO-Generalversammlung wahrscheinlich wieder den ghanaischen Außenminister zu ihrem Präsidenten wählen werde. Quaison-Sackey werde dann erneut „die Erledigung der Deutschland- und Berlinfrage" durch die UNO anregen. Im Vorjahr habe die Bundesregierung demgegenüber in Übereinstimmung mit den drei Westmächten auf die VierMächte-Verantwortung verwiesen. Der Ministerialdirigent gibt zu bedenken, ob es angesichts der Tatsache, daß eine Erörterung in der UNO auf Dauer ohnehin kaum vermeidbar sei, nicht günstiger wäre, das „Unvermeidliche“ in „ungefährliche oder sogar nützliche Gleise zu lenken“. Er schlägt vor, den blockfreien Staaten in der üblichen Demarche zur DeutschlandFrage zu erklären, daß jede Initiative begrüßt werde, die die Wiedervereinigung auf der Grundlage des Selbstbestimmungsrechts vorsehe. Den möglichen Vorteil sieht Böker vor allem darin, da $\beta$ damit den Ostblock-Staaten und eventuell dem UNO-Generalsekretär U Thant „der Schwarze Peter zugeschoben" würde. Auswärtige Amt

Der Abrüstungsbeauftragte der Bundesregierung gibt Informationen aus der amerikanischen Delegation bei der Konferenz der 18-Mächte-Abrüstungskomission in Genf wieder. Danach werde der amerikanische Entwurf für ein Abkommen über die Nichtverbreitung von Kernwaffen voraussichtlich am 17. August 1965 vorgelegt werden. Änderungen seien nur noch für die Formulierungen zur Kontrollfrage zu erwarten, die weder „offen diskriminierend noch unmittelbar verpflichtend" sein sollten. Aufgrund dieser Modifikation rechneten die USA mit einer Unterstützung durch Großbritannien, Italien und Kanada. Schnippenkötter weist darauf hin, daß die Bundesrepublik als Hauptgegner einer Regelung zur Nichtverbreitung zu erschei- 
nen drohe. Im Hinblick auf die öffentliche Diskussion rät er dringend, den italienischen Vorschlag einseitiger Erklärungen zum Verzicht auf Atomwaffen zu unterstützen.

Schnippenkötter informiert über ein Gespräch mit dem sowjetischen Delegierten bei der Konferenz der 18-Mächte-Abrüstungskommission am 13. August 1965 in Genf. Der Abrüstungsbeauftragte der Bundesregierung betonte das Interesse an einer Abrüstung sowie die bereits bestehenden Beschränkungen für die Bundesrepublik und verwies auf den Zusammenhang mit der Deutschland-Frage. Zarapkin bezeichnete es als wichtigstes Ziel einer Nichtverbreitungsregelung, „daß die Bundesrepublik von Atomwaffen ferngehalten werde", und verlangte einen Verzicht auf das MLF/ANF-Projekt sowie das geplante "select committee“. Diese Forderung, so resümiert Schnippenkötter, sei erst durch die britisch-amerikanische Absicht, die UdSSR zu einer Nichtverbreitungsverpflichtung zu bewegen, ermöglicht worden. Er plädiert dafür, die gegebenen „taktischen Möglichkeiten“ zu nutzen, um dem „weltweit drohenden Vorwurf" zu begegnen, die Bundesrepublik hintertreibe die Nichtverbreitung, sowie der "Taktik der Sowjets" entgegenzutreten, „die die anglo-amerikanische Konzeption für ihre Zwecke skrupellos ausbeuten".

Ruete gibt die Mitteilung des Abteilungsleiters im Bundeskanzleramt, Mercker, wieder, daß die DDR dem Fortbestehen einer Passierscheinstelle für Härtefälle zugestimmt habe, eine Verlängerung der Passierschein-Regelung jedoch auf die Weihnachtszeit beschränken wolle; der Senat von Berlin sei bereit, dies zu akzeptieren. Mercker machte dagegen darauf aufmerksam, daß der für November vorgesehene Besuchszeitraum nicht berücksichtigt worden und somit die Übernahme der bisherigen Besuchszeiten nicht gewährleistet sei. Ruete schließt sich den Bedenken an und hebt hervor, daß ein Abschluß auf dieser Basis die Notwendigkeit häufiger Verhandlungen und dadurch „Dauerkontakte" entstehen ließe, die von der DDR „zur Erpressung und Beunruhigung" der innenpolitischen Verhältnisse in der Bundesrepublik benutzt werden könnten. Offenbar solle ein Gegensatz zwischen einem „entgegenkommenden“ Senat und einer ${ }_{n}$ harten" Bundesregierung provoziert und damit die Situation vor den Bundestagswahlen beeinflußt werden. 

Auswärtige Amt

Knappstein gibt Informationen aus dem amerikanischen Außenministerium wieder. Danach sei eine Bereitschaft erkennbar, auf die Vorschläge der Bundesregierung für eine Änderung des Verfahrens zur Einbeziehung von Berlin (West) in Verträge der Bundesrepublik einzugehen. Gegebenenfalls könnte darauf verzichtet werden, „Berlin ausdrücklich oder in umschriebener Form" zu erwähnen. Das amerikanische Interesse konzentriere sich darauf, sicherzustellen, „daß die Prärogativen der Alliierten Kommandantur in Berlin nicht beeinträchtigt" würden. Daher würde es eine Einigung erleichtern, wenn nicht die Alliierte Kommandantur erklären müßte, daß das Land Berlin als in jeden Vertrag der Bundesrepublik einbezogen gelte, sondern sich darauf beschränken könnte, eine entsprechende Erklärung der Bundesregierung zur Kenntnis zu nehmen. Ferner wäre eine Bestätigung der bisherigen Praxis hilfreich, daß die Alliierte Kommandantur schon vor dem Abschluß von Verträgen über den Wunsch nach Einbeziehung von Berlin (West) unterrichtet werde. bei der NATO in Paris

Zum Vortrag im Politischen Ausschuß des Ständigen NATORats übermittelt Carstens eine Stellungnahme zur geplanten Weltabrüstungskonferenz der UNO. Die Bundesregierung lege Wert darauf, daß eine Beteiligung der DDR vermieden werde. Angesichts des breiten Interesses an einer Mitwirkung der Volksrepublik China solle daher versucht werden, einen Einladungsmodus zu erreichen, der ihr eine Teilnahme ermögliche, ansonsten aber nur die in der UNO und deren Sonderorganisationen vertretenen Staaten erfasse. Sollte dies nicht durchsetzbar sein, dürfe die DDR jedenfalls keine direkt an sie gerichtete Einladung erhalten. Statt dessen solle ein Appell der UNOGeneralversammlung an „alle Länder der Welt" gerichtet werden. Dies gäbe der Bundesrepublik die Möglichkeit, die Teilnehmerstaaten einer Weltabrüstungskonferenz um Abgabe einer „Disclaimer-Erklärung“ zu bitten. Grundsätzlich behalte sich jedoch die Bundesregierung für den Fall einer Beteiligung der DDR die Entscheidung über ihre eigene Mitwirkung vor.

Ruete legt den Entwurf einer Stellungnahme zur Erklärung der drei Westmächte vom 22. Juli 1965 zum Interzonenhandel vor. Die Bundesregierung könne sich der Auffassung, „daß die Verbündeten nie an den laufenden Interzonenhandels-Verhandlungen beteiligt gewesen seien“, nicht anschließen. Wegen des engen Zusammenhangs mit dem Verkehr von und nach Berlin 
(West) seien die drei Westmächte bisher stets einbezogen worden und hätten auch selbst mehrfach Einfluß genommen. Hinsichtlich des Vorschlags der DDR, ein neues Abkommen über den Interzonenhandel ,in neutraler Form“ - ohne Bezugnahme auf die Währungsgebiete und unterzeichnet durch die Verhandlungsführer - abzuschließen, bleibe die Bundesregierung ablehnend. Eine solche Unterschriftsformel könnte als Anzeichen eines Zurückweichens aufgefaßt und von der DDR benutzt werden, um die Forderung nach Herauslösung von Berlin (West) aus dem Abkommen zu untermauern.

Böker faßt die Ergebnisse deutsch-britischer Gespräche vom 7. bis 9. Juli 1965 in London zusammen. Hinsichtlich des Nahen Ostens wurde übereinstimmend der nachlassende Einfluß des Präsidenten Nasser begrüßt, dessen Sturz die britische Seite als wünschenswert bezeichnete. Sie hielt ferner die Gefahr eines militärischen Konflikts für gemindert, schlug jedoch eine Koordinierung der Waffenlieferungen in die Region vor, zumal sowohl die VAR als auch Israel bald Mittelstreckenraketen besitzen könnten und letzteres einen Verzicht auf Produktion oder Erwerb von Atomwaffen ablehne. Hinsichtlich Afrikas stimmten die Gesprächspartner überein, daß im Falle einer einseitigen Unabhängigkeitserklärung Südrhodesiens die weiße Minderheitsregierung von keinem NATO-Staat - „mit der möglichen Ausnahme Portugals" - anerkannt werden würde. Einvernehmen bestand ferner darüber, daß ein Wirtschaftsboykott der Südafrikanischen Republik nicht in Frage komme, das von der UNO beschlossene Waffenembargo jedoch „streng" befolgt werden müsse. Zum Kaschmir-Konflikt informierten die britischen Teilnehmer über vertrauliche Vermittlungsbemühungen, die auf eine Dreiteilung des Gebiets hinausliefen. Sie drängten ferner darauf, Indonesien wegen der „Konfrontationspolitik gegenüber Malaysia" keine Waffen zu liefern, zeigten jedoch Verständnis für die „zur Erhaltung gewisser deutscher Positionen" gewährte Entwicklungshilfe der Bundesrepublik.

Böker berichtet über eine Konferenz vom 22. bis 24. Juni 1965 in der amerikanischen Botschaft in London. Sie habe der Frage gegolten, wie eine militärische Nutzung von spaltbarem Material und von „Kernausrüstungsgegenständen“, die für zivile Zwecke an Drittstaaten geliefert worden seien, verhindert werden könne. In den Beratungen, an denen erstmals auch die Bundesrepublik als möglicher Exportstaat beteiligt worden sei, habe Einigkeit über das Prinzip der "non-proliferation" bestanden. Die deutsche Delegation sei mit der Auffassung, daß generelle Exportkontrollen nur bei Einbeziehung sämtlicher Lieferstaaten sinnvoll seien, auf breite Zustimmung gestoßen. Ferner sei 
eine „genügend vorsichtige“ und revidierbare Liste von in Frage kommenden Ausrüstungsgegenständen erarbeitet worden. Die französische Delegation habe sich gegen ein multilaterales Kontrollsystem ausgesprochen und es hinsichtlich des amerikanischen Vorschlags eines Koordinierungsausschusses „rundweg“ abgelehnt, irgendeine Meldepflicht zu akzeptieren. Die Mehrheit schloß sich der kanadischen Anregung an, daß alle am Sicherheitsverfahren beteiligten Staaten ihre Exporte einander „durch Zirkularnote" mitteilen sollten.

Aus der Sitzung des Bundeskabinetts notiert Carstens, er habe darauf hingewiesen, daß nach der VAR auch Syrien ein Generalkonsulat in der DDR eröffnet habe und Indonesien möglicherweise ähnliche Überlegungen anstelle. Er habe daher den Vorschlag bekräftigt, die ägyptischen Generalkonsulate in der Bundesrepublik zu schließen. Dagegen sei von Bundesminister Westrick die Auffassung des Bundeskanzlers Erhard vorgetragen worden, daß zu einem Zeitpunkt, da eine „gewisse Beruhigung" in den Beziehungen zum Nahen Osten eingekehrt sei, "drastische Maßnahmen" nachteilig wirken könnten. Angesichts der bevorstehenden Reise von Präsident Nasser in die UdSSR würden „neue scharfe Ausfälle“ gegen die Bundesrepublik sehr ungelegen kommen. Da keines der anwesenden Kabinettsmitglieder den Standpunkt des Auswärtigen Amts unterstützt habe, sei die Angelegenheit auf Ende September 1965 vertagt worden.

Der Staatssekretär berichtet über eine Unterredung mit dem britischen Botschafter Roberts, dem französischen Botschafter de Margerie und dem amerikanischen Gesandten Hillenbrand. Carstens informierte über Vorbereitung und Zweck seines bevorstehenden Besuchs in Moskau, über die Vereinbarung der Fluggesellschaften Lufthansa und Aeroflot hinsichtlich einer Direktverbindung zwischen Moskau und Frankfurt/Main sowie über den Stand der Beziehungen zu den arabischen Staaten. Hinsichtlich der Passierschein-Gespräche stellte er fest, daß die Entscheidung für oder gegen einen Abschluß „sehr schwer zu treffen" sei. Er betonte ferner das Interesse an weiteren Beratungen über die mögliche Einführung eines $\mathrm{Pa}$ - und Visumzwangs durch die DDR und über wirtschaftliche Gegenmaßnahmen bei geringeren Störungen im Verkehr mit Berlin (West). 

Auswärtige Amt

Der Abrüstungsbeauftragte der Bundesregierung berichtet über ein Gespräch mit dem Leiter der kanadischen Delegation bei der Konferenz der 18-Mächte-Abrüstungskommission. Burns erläuterte den Vorschlag, bei den Verhandlungen über den amerikanischen Vertragsentwurf zur Nichtverbreitung von Kernwaffen die ,atlantischen Nuklearprobleme“ vorerst zu umgehen. Die Diskussion darüber solle zwischen den USA, Großbritannien und der UdSSR geführt werden; letztere sei davon zu überzeugen, daß ,keine Proliferation an nichtnukleare NATO-Partner stattfinde und daß die sowjetische Sicherheit nicht bedroht werde“. Schnippenkötter wandte ein, daß eine damit gegebene Mitsprache der UdSSR „an die Wurzel der psychologischen Schwierigkeiten" führe. Gegenstand der Genfer Verhandlungen könne nur der Spielraum sein, den ein mögliches Nichtverbreitungsabkommen für die Regelung der Nuklearfragen im Rahmen der NATO lasse. Burns vertrat dagegen die Auffassung, ein Nichtverbreitungsabkommen unter Ausklammerung der Divergenzen um das MLF/ANF-Projekt auszuhandeln, aber erst nach Beseitigung der diesbezüglichen „amerikanisch-deutschensowjetischen Differenzen“ zu unterzeichnen. Amt

Buch stellt fest, daß die dänische Regierung dem Geist der NATO-Zusammenarbeit und den freundschaftlichen Beziehungen mit der Bundesrepublik zuwiderhandele, indem sie die Urlaubsflüge der im Rahmen der UNO-Friedenstruppe auf Zypern eingesetzten Soldaten mit der DDR-Fluggesellschaft Interflug dulde. Zugrunde liege offenbar eine Entscheidung des Außenministers Haekkerup, der damit wieder einmal bis an die Grenze des Zumutbaren gehe. Buch schlägt vor, die „Enttäuschung und Verärgerung“ der Bundesregierung dadurch zum Ausdruck zu bringen, da $\beta$ bei den bilateralen Wirtschaftsgesprächen eine gewisse Zurückhaltung an den Tag gelegt werde.

Behrends erläutert die britische Absicht, im Oktober 1965 für etwa sechs Monate ein Infanterie-Bataillon der Rheinarmee nach Aden zu verlegen. Dies bedeute eine vorübergehende, jedoch nicht unerhebliche Verminderung der Kampfkraft der britischen Verbände, die bereits durch den Abzug von Einheiten nach Zypern und Malaysia geschwächt seien. Des weiteren seien Änderungen bei der Artillerieausstattung geplant, die vor allem auf Kosten der nuklearen Bewaffnung gingen. Als Folge würde die Rheinarmee ab 1966 nur noch über atomare Gefechtsfeldwaffen und nicht mehr über weitreichende taktische Nukle- 
arwaffen verfügen. Anfängliche Vermutungen, Großbritannien strebe eine „Denuklearisierung Deutschlands" an, seien in bilateralen Gesprächen ausgeräumt worden. Dennoch plane die Bundesregierung, ihre Bedenken erneut vorzutragen, weil die nukleare Abschreckung durch die Umstrukturierung für den Bereich der Rheinarmee vermindert werde.

Im Hinblick auf eine Sitzung des Bundesverteidigungsrats informiert Harkort, daß der kenianische Präsident wiederholt und dringlich um finanzielle Unterstützung bei der Modernisierung der Armee gebeten habe. Kenyatta habe sich von den kommunistischen Staaten abgewandt und zum verläßlichsten Bundesgenossen des Westens in Ostafrika entwickelt. Mit der Ausrüstungshilfe wolle er der Opposition in Kenia zeigen, daß er "auf das richtige Pferd gesetzt" habe. Die Waffenlieferung solle Großbritannien übernehmen, ihre Finanzierung jedoch zu 75 Prozent von der Bundesrepublik getragen und über das deutschbritische Devisenausgleichsabkommen abgewickelt werden. Harkort schlägt vor, daß der Bundesverteidigungsrat das Vorhaben in der vorgesehenen Weise genehmigen solle.

Klaiber berichtet über den die EWG-Krise betreffenden Teil eines Gesprächs mit dem französischen Ministerpräsidenten. Mit Zustimmung nahm Pompidou die Erklärungen auf, daß die Bundesregierung weiterhin für eine Ausgewogenheit zwischen Industrie- und Agrarmarkt eintrete und der EWG-Kommission keine Entscheidungen in wesentlichen ökonomischen Fragen der Bundesrepublik überlassen wolle. $\mathrm{Zu}$ den Kommissions-Vorschlägen vom 22. Juli 1965 erklärte er, die Krise könne nicht durch die EWG-Kommission, sondern nur durch den politischen Willen der sechs Mitgliedstaaten überwunden werden. Der Botschafter gibt seinen Eindruck weiter, daß die französische Regierung hinsichtlich des künftigen Mehrheitsprinzips unbesorgt sei, da sie eine Majorisierung „in lebenswichtigen Fragen“ für undurchführbar halte. Sie beschäftige sich jedoch bereits mit der Situation nach dem Ende der Übergangszeit. Klaiber schlußfolgert, Frankreich wolle die EWG nicht zum Scheitern bringen, sondern ihre „supranationale Fortentwicklung“ verhindern. Es werde daher „nach harter Verhandlung“ einem Kompromiß zur Agrarfinanzierung zustimmen, mit dessen Erarbeitung allerdings nicht mehr im laufenden Jahr begonnen werden könne. 

amerikanischen Finanzminister Fowler

Fowler führt aus, daß ihn die erstmals seit 1958 erzielte positive Zahlungsbilanz der USA bewogen habe, eine Währungskonferenz anzuregen, deren Schwerpunkt auf einer "ContingencyPlanung" liegen solle. Seine Europa-Reise diene dem Zweck, die Resonanz bei den Verantwortlichen der in der Zehner-Gruppe und im internationalen Währungsfonds vertretenen europäischen Staaten zu sondieren. Erhard erklärt die Bereitschaft zur Teilnahme an einer ,internationalen Diskussion und Regelung“ und bezeichnet die Schaffung einer neuen Währung als „so unfruchtbar wie Esperanto“. Der ebenfalls anwesende Staatssekretär im amerikanischen Außenministerium, Ball, berichtet anschließend von einem Gespräch mit dem französischen Staatspräsidenten. De Gaulle habe zur Lage in Vietnam erklärt, „daß er mit Kämpfen noch über Jahre rechne“. Er habe die Ansicht vertreten, daß die Volksrepublik China anerkannt werden müsse und die USA mit der UdSSR im Dialog bleiben sollten. Hinsichtlich der NATO habe de Gaulle betont, Integration bedeute Unterordnung, die er nicht hinnehmen werde. Er wolle noch vor 1969 bilaterale Gespräche über die Zukunft der Allianz führen. Auf die Bitte von Ball, den Zeitpunkt möglichst spät zu wählen, habe der französische Staatspräsident nicht reagiert. Auswärtige Amt

Herwarth unterrichtet über ein Gespräch mit dem Leiter der Politischen Abteilung im italienischen Außenministerium. Gaja trat dafür ein, nach der Ablehnung des amerikanischen Entwurfs eines Nichtverbreitungsabkommens durch die UdSSR erneut den der 18-Mächte-Abrüstungskommission in Genf bereits vorliegenden italienischen Vorschlag aufzugreifen. Der darin vorgesehene einseitige Verzicht auf Kernwaffen würde es den "paranuklearen Mächten“ erlauben, der Gefahr zu begegnen, daß ihnen die Verantwortung für einen negativen Verhandlungsverlauf zugeschoben werde. Italien habe zwar nicht die Absicht, Atomwaffen herzustellen, wolle jedoch auch nicht „deklassiert" werden. Es komme darauf an, Zeit zu gewinnen, um Konzessionen der Nuklearmächte zu erreichen und die Interessen der Nichtnuklearmächte zu wahren.

Der Botschafter informiert über den Osteuropa und die UdSSR betreffenden Teil eines Gesprächs mit dem französischen Ministerpräsidenten. Er selbst bat anläßlich des bevorstehenden Aufenthalts des Ministerpräsidenten Cyrankiewicz in Paris, daß hinsichtlich der Oder-Neiße-Linie nichts geschehe, was als französische Unterstützung des polnischen Standpunkts ausge- 
legt werden könnte. Trotz der von Pompidou betonten Besonderheit der Beziehungen mit Polen müsse erwartet werden, daß sich Frankreich bei diesem „heiklen Thema“ mit einem Hinweis auf die Erklärung des Staatspräsidenten de Gaulle vom 25. März 1959 begnüge. Im Hinblick auf den bevorstehenden Besuch des Staatssekretärs Carstens in Moskau wies Pompidou auf die in der UdSSR verbreitete Angst vor dem militärischen Potential der Bundesrepublik und der „deutschen Kriegskunst" hin. Klaiber betonte, daß die Bundesrepublik keine nationale Verfügungsgewalt über Atomwaffen anstrebe und ihr berechtigtes Interesse an nuklearer Mitbestimmung innerhalb der NATO von de Gaulle anerkannt worden sei.

Anläßlich seines Antrittsbesuchs erkundigt sich Ben Natan nach dem Zeitpunkt für die Aufnahme der Wirtschaftsverhandlungen und nach deren Einordnung im Verhältnis zu den früheren finanziellen Leistungen der Bundesrepublik an Israel. Westrick räumt ein, daß hier "tatsächlich ein offener Dissens“ vorliege. Nach Auffassung der Bundesregierung solle die wirtschaftliche Unterstützung im Bundesetat verankert sein und die haushaltsrechtlich nicht abgesicherten Zahlungen im Rahmen der Aktion „Geschäftsfreund“ ablösen. Kurz vor Aufnahme der diplomatischen Beziehungen habe jedoch der Leiter der Israel-Mission, Shinnar, deutlich gemacht, daß Israel zusätzliche Zahlungen erwarte. Seitdem sei mehrfach darauf hingewiesen worden, daß eine „zweigleisige Hilfe" nicht in Frage komme. Ben Natan bekräftigt die Forderung nach zusätzlichen Zahlungen und erklärt sein Einverständnis, mit den Wirtschaftsgesprächen nach den Bundestagswahlen zu beginnen.

\section{Bundeskanzler Erhard}

Der Regierende Bürgermeister von Berlin teilt mit, daß der Verhandlungsspielraum in den Passierschein-Gesprächen ausgeschöpft sei, nachdem die DDR eine Verlängerung der bisherigen Regelung um ein volles Jahr abgelehnt habe. Da die geltende Übereinkunft am 24. September 1965 auslaufe, macht Brandt darauf aufmerksam, daß eine Entscheidung über das Angebot der DDR vom 16. August 1965, die Passierscheinstelle für Härtefälle bis zum 31. Januar 1966 fortzuführen und Verwandtenbesuche zu Weihnachten und Neujahr 1965/66 zuzulassen, getroffen werden müsse. Er schlägt den 21. September 1965 als Termin für das nächste Treffen mit den DDR-Vertretern vor, bei dem dann ein Entschluß der Bundesregierung bekanntgegeben werden müsse. 
Carstens informiert über ein Telefongespräch mit dem Abteilungsleiter im Bundesministerium für wirtschaftliche Zusammenarbeit, Sonnenhol. Dieser erklärte, daß die Öffentlichkeit kein Verständnis für die gleichzeitige wirtschaftliche Unterstützung Indiens und Pakistans habe, da beide Staaten dadurch "mindestens indirekt“ in die Lage versetzt würden, gegeneinander Krieg zu führen. Carstens erwiderte, daß die Fortsetzung der Hilfe aus außenpolitischen Gründen unumgänglich, allerdings zu überlegen sei, wie der Öffentlichkeit diese Entscheidung verständlich gemacht werden könne.

Zur Unterrichtung des Bundeskanzlers Erhard informiert Carstens Bundesminister Westrick über eine Besprechung mit jenen Missionschefs, die aus den arabischen Staaten nach Bonn zurückkehren mußten. Übereinstimmend wurde festgestellt, daß sich die Stimmung gegenüber der Bundesrepublik beruhigt habe. Dennoch sei nicht mit einer baldigen Wiederaufnahme der diplomatischen Beziehungen zu rechnen; Anzeichen für ein "aktives Interesse“ in dieser Richtung gebe es nur im Sudan, in Jordanien und in Algerien. Die Mehrheit werde die weitere Entwicklung der deutsch-israelischen Beziehungen abwarten. Insbesondere müsse eine Ausgewogenheit der Wirtschaftshilfe an Israel und an die arabischen Staaten gewährleistet werden. Initiativen zur Wiederaufnahme der Beziehungen sollten der arabischen Seite überlassen bleiben, jedoch vertrauliche Kontakte $\mathrm{zu}$ "wohlgesonnenen" Staaten gepflegt werden.

In der Aufzeichnung wird eine Besprechung im Rahmen der Bonner Vierergruppe zur Frage der Kreditgewährung an die DDR zusammengefaßt. Die Vertreter Frankreichs und der USA, Tissier und Sutterlin, verwiesen auf ihre bereits vorliegenden Stellungnahmen; von amerikanischer Seite wurde zudem die Notwendigkeit einer restriktiven Haltung bekräftigt. Der britische Botschaftsrat für Handelsfragen erklärte, entgegen den im Arbeitspapier der Bundesregierung vom 19. Juli 1965 geäußerten Befürchtungen beeinträchtige die bisherige westliche Handels- und Kreditpraxis den Interzonenhandel nicht. Folglich bestehe kein Anlaß, britischen Unternehmen die derzeit gewährten Exporterleichterungen zu entziehen. Da das von Galsworthy zugrunde gelegte statistische Material den Vertretern der Bundesrepublik nicht überzeugend erschien, wurde beschlossen, ein gemeinsames, von allen Beteiligten anerkanntes Arbeitspapier zu erstellen. 

amerikanischen Botschafter McGhee

Zu den Äußerungen des französischen Staatspräsidenten auf der Pressekonferenz vom 9. September 1965 führt Schröder aus, de Gaulle wolle hinsichtlich der EWG eine Agrarunion schaffen, die Rolle der Kommission einschränken und weitere Initiativen zur Fortentwicklung der Gemeinschaft hinausschieben. Die Ablehnung einer supranationalen Integration hält der Bundesminister für "nicht indiskutabel" und betont, er sei selbst niemals von einer schnellen politischen Integration überzeugt gewesen. Hinsichtlich der Einführung des Majoritätsprinzips verstehe die Bundesregierung durchaus die Bedenken und trete für eine „politisch vernünftige Interpretation“ im Sinne eines "gentlemen's agreement" ein. Es besteht Übereinstimmung, daß vor dem Abschluß eines Abkommens über die Nichtverbreitung von Kernwaffen die nukleare Frage innerhalb der NATO gelöst werden müsse. McGhee bezeichnet die eingetretene Umkehrung der Prioritäten als „Schande“, betont jedoch, daß in den USA ein Junktim mit der Deutschland-Frage abgelehnt werde. Schröder räumt ein, „er gebe sich hier keineswegs großen Täuschungen hin". Er bemängelt, daß hinsichtlich der Nichtverbreitung nur Einschränkungen für Nichtnuklearmächte vorgesehen seien, die Atommächte sich aber ohne Gegenleistung etwas zusicherten, was ohnehin in ihrem Interesse liege. Damit bliebe der „Machtvorsprung in den Händen einiger weniger".

Klaiber gibt Informationen über das Gespräch des französischen Außenministers mit dem polnischen Stellvertretenden Außenminister am 10. September 1965 weiter. Naszkowski habe die Auffassung vertreten, daß die Bundesrepublik den Besitz von Atomwaffen erstrebe und sowohl daran als auch an einer Beteiligung „an der atomaren Strategie“ gehindert werden müsse. Er habe ferner betont, „Polen leugne nicht, daß sich das Problem der Wiedervereinigung Deutschlands stelle“, halte aber eine Fortdauer der Teilung gegenüber einer Gefährdung der europäischen Sicherheit für das geringere Übel. Hinsichtlich der Oder-Neiße-Linie habe er keine weitergehende Festlegung Frankreichs verlangt, während Couve de Murville geschwiegen habe. Übereinstimmung habe darüber bestanden, daß Sicherheitspläne für Europa so angelegt sein müßten, daß weder die USA noch die UdSSR eine dominierende Rolle spielten. Klaiber äußert abschließend die Ansicht, es gebe keinen Grund zur Beunruhigung: Couve de Murville habe sich „loyal“ verhalten. 

Paris (NATO)

Hartlieb notiert aus einem Gespräch mit dem Gesandten an der amerikanischen Ständigen Vertretung bei der NATO, daß sich Befürworter und Gegner des MLF-Projekts in den USA die Waage hielten. Es sei daher wichtig, daß die Bundesregierung nachdrücklich ihr Interesse betone und es sowohl dem neuen amerikanischen Ständigen Vertreter bei der NATO, Cleveland, als auch dem Botschafter in Bonn, McGhee, nahebringe. Wünschenswert sei ferner eine „political guidance“ der NATO-Botschafter für die militärische Untergruppe der MLF-Arbeitsgruppe. Hartlieb resümiert, Farley sei im Grunde eher skeptisch. Er habe nicht ausgeschlossen, daß erneut eine Situation entstehen könnte, in der es klüger wäre, das Projekt „eine Zeitlang beiseite zu legen“; dem ANF-Projekt gab er keine großen Chancen. Staatssekretäre Carstens und Lahr

Sachs informiert über eine Unterredung mit dem Präsidenten der EWG-Kommission über die Probleme der Gemeinschaft. Hallstein bezeichnete die Lage als Auftakt zu viel schwerwiegenderen Auseinandersetzungen. Hinter der Pressekonferenz des Staatspräsidenten de Gaulle vom 9. September 1965 sei die Einsicht zu vermuten, daß die Zeit nicht für ihn arbeite, sowie der Versuch, einen eventuellen Nachfolger politisch festzulegen. Die Initiative zur Überwindung der durch Frankreich ausgelösten Krise wies Hallstein den Regierungen der übrigen fünf EWG-Staaten und insbesondere der Bundesregierung zu. Ferner legte er dar, daß Mehrheitsentscheidungen des EWG-Ministerrats zulässig und gute Gründe dafür gegeben seien, „nur mit den Fünfen zu einstimmigen Beschlüssen zu kommen“. Hinsichtlich des künftigen Majoritätsprinzips räumte er ein, daß ein "gentlemen's agreement" im Sinne einer einschränkenden Interpretation „nicht an die Existenz der Gemeinschaft rühren“ würde. Auswärtige Amt

Sahm berichtet von der Diskussion im Politischen Ausschuß des Ständigen NATO-Rats am Vortag. Zu den neuen polnischen Abrüstungsvorschlägen wurde angemerkt, daß sie gegenüber dem Gomulka- und Rapacki-Plan keine wesentlichen neuen Elemente enthielten. Angesichts der Bedrohung durch sowjetische Raketen wurde bemängelt, daß eine Erörterung von Plänen ohne Einschluß der UdSSR „akademisch“ sei. Ferner fehle eine Kontrolle der Abrüstung und könne eine auf Mitteleuropa beschränkte Regelung zur Nichtverbreitung von Kernwaffen 
nur wenig Auswirkungen auf das weltweite Problem der Nonproliferation und den Abbau der Ost-West-Spannungen haben. Dennoch wurde eine Fortsetzung des Gedankenaustauschs mit Polen befürwortet. Ständige Vertretung bei der EWG und EAG in Brüssel

Meyer-Lindenberg bittet, der EURATOM-Kommission ein Aidemémoire zu übermitteln, in dem die zwischen ihr und Frankreich getroffene Vereinbarung über die nukleare Sicherheitskontrolle mißbilligt werde. Die Abmachung bringe eine „erhebliche Abschwächung " der im EURATOM-Vertrag vorgesehenen Regelungen mit sich und stelle eine einseitige Ausnahme zugunsten Frankreichs dar, die den französischen Vorsprung auf atomarem Gebiet vergrößere. Die Bundesregierung wolle den Eindruck einer stillschweigenden Zustimmung vermeiden und sich die Möglichkeit offenhalten, bei den Verhandlungen über die Fusion der drei europäischen Gemeinschaften auf das Problem zurückzukommen. Truckenbrodt

Der Ministerialdirigent erörtert die Frage, wie die Einbeziehung von Berlin (West) in ein Warenabkommen mit der UdSSR gewährleistet werden könnte. Er nimmt dabei auf die im Juli 1964 mit den drei Westmächten vereinbarte Regelung Bezug, wonach die Einbindung der Stadt in Abkommen der Bundesrepublik an keine bestimmte Form geknüpft sei, solange eine verbindliche Einigung der vertragschließenden Parteien vorliege. Truckenbrodt konstatiert, daß alle bisher vorgelegten Entwürfe einer Berlin-Klausel an das Abkommen vom 25. April 1958 mit der UdSSR über den Waren- und Zahlungsverkehr anknüpften, über dessen Geltungsbereich jedoch ein offener Dissens bestehe. Er schlägt daher eine „hieb- und stichfeste“ Klausel vor, nach der ein neuer Vertrag in dem Gebiet gelten würde, in dem die bisherigen Vereinbarungen faktisch durchgeführt wurden. Hardenberg

Zur Vorbereitung eines Gesprächs des Staatssekretärs Carstens mit dem Staatssekretär im Bundesministerium der Verteidigung, Gumbel, gibt Hardenberg einen Überblick zum Stand der Ausrüstungshilfe. Portugal lege weiterhin großen Wert auf die Lieferung der zugesagten Flugzeuge, für die jedoch eine Zustimmung Kanadas nicht mehr zu erwarten sei. Das Bundesministerium der Verteidigung habe großes Interesse an dem Vorhaben, da bis zu seinem Abschluß die Arbeiten an den militärischen 
Einrichtungen der Bundeswehr in Portugal ruhten. Es plane daher die Lieferung von Flugzeugen des Typs G 91, die für den "afrikanischen Buschkrieg“ wenig tauglich seien. Pakistan seien Lizenzen zum Bau von Maschinengewehren und Schiffen zugesichert worden. Bezüglich des Sudan sollte der bei Abbruch der diplomatischen Beziehungen verhängte partielle Lieferstopp beibehalten und ein Anschluß-Abkommen über Ausrüstungshilfe erst nach Wiederaufnahme der Beziehungen unterzeichnet werden. Der iranische Wunsch nach Finanzhilfe zur Ausweitung der Waffenproduktion sei bislang auf positive Resonanz gestoßen, jedoch müsse der genaue Umfang der Leistungen noch geklärt werden. Vorbehalte beständen gegen den Verkauf einer größeren Menge von Handfeuerwaffen, weil diese vom Iran eventuell an Jordanien oder Pakistan weitergeliefert werden könnten. Amt

Knoke gibt Informationen über den Besuch des Ministerpräsidenten Harmel und des belgischen Außenministers Spaak am Vortag in Den Haag weiter. Nach Aussage des Generaldirektors im niederländischen Außenministerium, Hartogh, habe Einigkeit darüber bestanden, daß die EWG nicht zu einer ,intergouvernementalen Einrichtung“ umgebaut, auf die Einführung des Majoritätsprinzips nicht verzichtet und die Zuständigkeit der EWG-Kommission nicht eingeschränkt werden dürfe. Ferner müsse die Lösung der Krise im Rahmen der Gemeinschaft und nicht auf zwischenstaatlicher Ebene gefunden werden. Es komme darauf an, Frankreich klarzumachen, daß die fünf übrigen EWG-Staaten am „EWG-Mechanismus" festhalten wollten. Auch in möglichen Verhandlungen zur Agrarfinanzierung sollten sie als „geschlossene Falanx“ auftreten. Amt

Grewe berichtet über die Sondersitzung des Ständigen NATORats vom 17. September 1965. Die Berichte der vier westlichen Delegationsleiter über die Konferenz der 18-Mächte-Abrüstungskommission in Genf hinterließen den Eindruck, daß die Hoffnung auf ein sowjetisches Eingehen auf die westlichen Vorschläge „zwar gedämpft, aber keineswegs aufgegeben worden“ sei. Hinsichtlich einer Weltabrüstungskonferenz legte der britische Abrüstungsbeauftragte Lord Chalfont dar, die von der Bundesregierung vorgeschlagene Einladungsformel sei für viele UNO-Staaten unannehmbar, weil sie den Nuklearmächten eine Sonderstellung einräume und die Teilnahme der Demokratischen Volksrepublik Korea, der Demokratischen Republik Vietnam und der DDR verhindere. Die Vertreter Dänemarks und 
Norwegens plädierten für eine Erweiterung des TeststoppAbkommens vom 5. August 1963. Dies wurde von amerikanischer Seite mit dem Hinweis auf fehlende Möglichkeiten zur Überwachung unterirdischer Atomversuche abgelehnt.

Carstens erläutert die Absicht der Bundesregierung, zu einem neuen Abkommen über den Waren- und Zahlungsverkehr zu kommen, das eine Laufzeit von drei oder vier Jahren haben könne. Kusmin erwidert, „daß die Existenz eines Warenprotokolls allein wenig nütze“, und verweist auf das Außenhandelsgesetz von 1961 und das Röhrenembargo. Bis heute sei die „harte Praxis der zuständigen deutschen Stellen “ unverändert. Wenn das Handelsvolumen auch ohne gültiges Abkommen nicht gesunken sei, so liege das an den direkten Kontakten mit Firmen aus der Bundesrepublik. Dennoch sei die sowjetische Regierung zu neuen Verhandlungen bereit. Die UdSSR müsse aber künftig mehr Waren in der Bundesrepublik absetzen, wenn der Umfang ihrer Importe aufrechterhalten bleiben solle. Nach einer Erläuterung des Außenhandelsgesetzes und der Hintergründe des Röhrenembargos betont Carstens die Notwendigkeit eines Abkommens. Auf eine Diskussion der „Frage des geographischen Geltungsbereichs“ verzichtet er. Auswärtige Amt

Stolzmann berichtet über ein Gespräch mit dem Leiter der Politischen Abteilung im luxemburgischen Außenministerium. Pescatore bezeichnete die Ausführungen des französischen Staatspräsidenten auf der Pressekonferenz vom 9. September 1965 als in der Form unannehmbar. Es sei zu überlegen, ob die EWGStaaten dies „ohne eine bedenkliche capitis diminutio“ hinnehmen könnten. Auch inhaltlich seien die Äußerungen nicht akzeptabel. Mit der Rückkehr zum Nationalismus „negiere de Gaulle unleugbar den Kern und das Wesen der Gemeinschaften“ und verschaffe ähnlichen Strömungen in anderen Staaten gefährlichen Auftrieb. Pescatore betonte, daß das weitere Vorgehen der fünf EWG-Partner Frankreichs unbedingt auf der Basis der Römischen Verträge bleiben müsse. Beratungen außerhalb dieses Rahmens lehne Luxemburg ebenso wie die Bundesregierung ab. 

Amt

Siegfried informiert über eine Unterredung mit dem belgischen Außenminister am Vortag. Angesichts der von Frankreich ausgelösten Krise und der Pressekonferenz des Staatspräsidenten de Gaulle vom 9. September 1965 betonte Spaak die Notwendigkeit einer gemeinsamen Initiative der fünf übrigen EWG-Staaten. Die Gemeinschaft könne nicht ohne „Prestigeverlust und unabsehbaren Schaden länger als sechs Monate immobil bleiben". Mögliche französische Wünsche nach Änderung des EWGVertrags müßten entschieden abgelehnt werden, während eine Interpretation des Vertragstextes offenbleiben könne. Notfalls solle die Gemeinschaft zu fünft fortgesetzt werden, da sie sich nicht zum „Spielzeug Frankreichs“ machen lassen dürfe. Spaak regte eine Sitzung des EWG-Ministerrats ohne Teilnahme der Kommission an, erklärte jedoch, er halte die für Ende Oktober vorgesehene Tagung nicht für ratsam, auch wenn er keinen Einspruch gegen sie erheben wolle. sowjetischen Ersten Stellvertretenden Außenminister Kusnezow in Moskau

Carstens betont, daß die ungelöste Deutschland-Frage das wichtigste Hindernis für eine Verbesserung der bilateralen Beziehungen darstelle. Die Bundesregierung wisse, daß das Problem die sowjetischen Sicherheitsinteressen berühre und wirtschaftliche Implikationen habe. Sie sei bereit, zu erwägen, wie dem Rechnung getragen werden könnte, und halte konkrete gemeinsame Schritte für nötig. Kusnezow bekräftigt demgegenüber die sowjetische Deutschlandpolitik und betont, ,jeder Anschlag auf die Souveränität der DDR, jeder Versuch ihrer gewaltsamen Einverleibung bedeute Krieg". Bezeichnend für die Politik der Bundesregierung sei die Absicht, über eine MLF in den Besitz von Atomwaffen zu gelangen. Unbeantwortet läßt Kusnezow die Frage, ob Bereitschaft zu Gesprächen über die Wiedervereinigung bestehe, wenn die Bundesregierung ihre Beteiligung an einer MLF zur Diskussion stelle. Carstens verweist auf die Erklärung von 1954 über den Verzicht auf die Produktion von Kernwaffen und betont den Gewaltverzicht der Bundesrepublik. Er spricht die Möglichkeit an, Berlin (West) in bilaterale Wirtschafts- oder Kulturabkommen einzubeziehen, und zeigt sich zuversichtlich, daß für beide Seiten befriedigende Lösungen gefunden werden könnten. Kusnezow lehnt jeden Versuch ab, Berlin (West) in ein Abkommen mit der UdSSR „hineinzumogeln“. 
Romanowskij legt dar, daß seit dem Scheitern der Verhandlungen für ein Kulturabkommen im Frühjahr 1961 der bilaterale Kulturaustausch auf der Erledigung noch offener Vorhaben aus der Vereinbarung vom 30. Mai 1959 und auf Absprachen zwischen interessierten Stellen in beiden Staaten basiere. Carstens betont, die Bundesregierung strebe ein neues Kulturabkommen an, doch seien noch Schwierigkeiten "nicht eigentlich kultureller, sondern politischer Art" zu überwinden. Um auch in der Zwischenzeit die kulturellen Beziehungen zu fördern, bittet er um Prüfung, ob nicht im Sommer 1966 eine Architektur-Ausstellung der Bundesrepublik, die bereits im alten Abkommen vorgesehen war, realisiert werden könne. Romanowskij äußert sich dazu sehr zurückhaltend. Er verweist auf fehlendes Ausstellungsgelände in Moskau sowie auf die Vorbereitung von Veranstaltungen zu den 50-Jahr-Feiern der UdSSR im Jahr 1967. sowjetischen Stellvertretenden Außenminister Semjonow in Moskau

Carstens mahnt die Freilassung zweier seit 1961 in der UdSSR inhaftierter Studenten an. Botschafter Smirnow habe ihm bereits vor drei Jahren zugesichert, Naumann und Sonntag würden im Gegenzug zur Auslieferung des wegen Spionage verurteilten Mitarbeiters der sowjetischen Handelsvertretung in Köln, Pripolzew, entlassen werden. Ferner äußert der Staatssekretär die Bitte, die sowjetische Regierung möge aus humanitären Gründen der Repatriierung von Deutschen aus der UdSSR „einen neuen Impuls geben“. Semjonow erwidert, alle aus der Vereinbarung vom 8 . April 1958 resultierenden Verpflichtungen seien erfüllt worden. Abschließend bittet Carstens zu erwägen, ob nicht der Volksbund Deutscher Kriegsgräberfürsorge die Pflege deutscher Soldatengräber in der UdSSR übernehmen und die noch von der deutschen Wehrmacht angelegte Kartei der Grabstätten, die nun in sowjetischem Besitz sei, einsehen dürfe.

\section{Klasse von Plehwe}

Plehwe faßt ein Gespräch des Staatssekretärs Lahr mit dem britischen Botschafter am Vortag zusammen. Roberts erläuterte eine Mitteilung über den Besuch des britischen Außenministers vom 17. bis 21. September 1965 in Warschau. Er führte aus, daß Stewart energisch den Standpunkt vertreten habe, die Frage der Ostgrenzen Deutschlands könne nur in einem Friedensver- 
trag geregelt werden. Die britische Regierung werde diese Haltung offiziell beibehalten, obwohl in Großbritannien, ähnlich wie in anderen westlichen Staaten, „die Oder-Neiße-Linie als die endgültige Westgrenze Polens angesehen" werde. Im übrigen gebe es Hinweise, daß polnische Hoffnungen auf britische Unterstützung in der Grenzfrage durch die Haltung von Stewart enttäuscht worden seien.

Krapf erörtert das „nukleare Problem der NATO“, die Frage der Mitverantwortung der Verbündeten für Kernwaffen. Er konstatiert, daß es für die Bundesrepublik bislang kein Mitspracherecht hinsichtlich des Einsatzes der auf ihrem Territorium stationierten Atomwaffen gebe. Das amerikanische Projekt einer MLF sei dem britischen Vorschlag einer ANF vorzuziehen, da letzterer lediglich eine Umgruppierung vorhandener Streitkräfte und eine ungleichgewichtige Beteiligung der einzelnen Teilnehmerstaaten vorsehe. Ausschlaggebend müsse eine Berücksichtigung deutscher Interessen bei Entscheidungen über einen Kernwaffeneinsatz und die Mitwirkung bei der Entwicklung nuklearer Strategien sein. Zudem sei der Besitz von Atomwaffen über den Abschreckungswert hinaus zum „Statussymbol einer Großmacht" geworden. Die MLF/ANF stelle also für die Bundesrepublik einen Weg dar, ihren Einfluß zu steigern, ohne in Widerspruch zur Politik des Verzichts auf nationale Verfügungsgewailt über Kernwaffen zu geraten. Mögliche Alternativen, wie eine Mitwirkung an der französischen Force de frappe oder der Aufbau einer europäischen Atomstreitmacht, könnten sie nicht in gleichem Maß in den Rang einer an der nuklearen Verantwortung ,maßgeblich beteiligten Macht" erheben.

Schlitter erläutert, wie die Bundesrepublik zur Stabilisierung der gegenwärtigen griechischen Regierung beitragen könne. Im Bereich wirtschaftlicher Hilfen nennt er multilaterale Maßnahmen - so die Unterstützung des griechischen Ersuchens um eine Anleihe bei der Weltbank oder die größtmögliche Beschleunigung des Griechenland-Konsortiums der OECD - und Unterstützung bilateraler Art, wie die Verteidigungshilfe der Bundesrepublik. Er regt ferner an, Mitglieder der griechischen Regierung sowie Journalisten in die Bundesrepublik einzuladen und im Gegenzug qualifizierte deutsche Journalisten und Fernsehteams zu Besuchen in Griechenland zu veranlassen. 

Meyer-Lindenberg

Meyer-Lindenberg nimmt zu dem israelischen Wunsch Stellung, von der Bundesrepublik für die Dauer von acht Jahren jährlich 10 Millionen Dollar für eine atomar betriebene Meerwasserentsalzungsanlage zu erhalten. Er konstatiert, daß eine solche nicht rückzahlbare Finanzhilfe der von der Bundesrepublik angestrebten Normalisierung der wirtschaftlichen Beziehungen zuwiderliefe, da Israel Entwicklungshilfe nach den gleichen Modalitäten wie andere Staaten erhalten solle. Ferner würde eine Beteiligung der Bundesrepublik an einem israelischen Atomprojekt in den arabischen Staaten "nicht ohne erhebliche Reaktionen bleiben“. Allerdings spreche für eine Unterstützung, daß sie „ihren Eindruck auf das Weltjudentum nicht verfehlen " und den Streit um das Jordanwasser beruhigen könnte, während eine Ablehnung die Beziehungen zu Israel belasten würde. Meyer-Lindenberg kommt zu dem Schluß, daß das Projekt unterstützt werden könnte, wenn öffentlich die Bereitschaft zum Bau einer vergleichbaren Anlage in einem arabischen Staat bekundet würde. Es müßte jedoch gewährleistet sein, daß das Projekt keinesfalls militärischen Zwecken diene.

In der Aufzeichnung wird die Entwicklung der NATO-Verteidigungsstrategie von der Maxime der „massiven Vergeltung“ bis zur „abgestuften Abschreckung“ rekapituliert. Im Gegensatz zu Frankreich und Großbritannien habe die Bundesrepublik die von den USA bevorzugte Doktrin der "flexible response“ übernommen. Allerdings gebe es Differenzen über den Zeitpunkt eines Kernwaffeneinsatzes. Während die amerikanische Regierung eine rasche Eskalation vermeiden wolle, vertrete die Bundesregierung wegen der Enge des Raumes und der Dichte der Besiedlung die Auffassung, daß der Verlust größerer Gebiete in einer konventionell geführten Kriegsphase untragbar sei: „Der Zwang zur nuklearen Abwehr könne sich sehr schnell ergeben“, während der konkrete Zeitpunkt oder das Einsatzgebiet nicht im voraus zu bestimmen seien. Gerade diese Unkalkulierbarkeit des Risikos stelle ein wichtiges Element der Abschreckung dar. Für den Verbündeten einer Nuklearmacht bleibe es entscheidend, die lebenswichtigen nationalen Interessen „parallel zu halten“, damit „im Ernstfall der eine für den anderen einstehen" werde.

Vor dem Hintergrund der Pressekonferenz des Staatspräsidenten de Gaulle vom 9. September 1965 bittet Schröder, bei den Regierungen der EWG-Staaten eine Stellungnahme zur Lage der Gemeinschaft abzugeben. Die Bundesregierung sei der 
Ansicht, daß die EWG-Krise nur mit den vertraglich festgelegten Mitteln sowie innerhalb der bereits bestehenden Institutionen gelöst und die Position der EWG-Kommission nicht beeinträchtigt werden dürfe. Das bereits in den Römischen Verträgen verankerte Prinzip der Mehrheitsentscheidungen solle nicht in Frage gestellt, jedoch „vernünftig angewandt" werden. In Fällen, in denen lebenswichtige Interessen eines EWG-Partners zur Entscheidung stünden, sei eine Majorisierung zu vermeiden. Eine Priorität der Agrarpolitik vor den übrigen Bereichen des Gemeinsamen Marktes werde nicht anerkannt. Hinsichtlich des künftigen Vorgehens stimme die Bundesregierung dem belgischen Vorschlag zu, im November 1965 einen „Ministerrat zu Sechs“ abzuhalten. Die Beratungen könnten ohne Beteiligung der EWG-Kommission stattfinden, wenn sie sich auf Fragen der Auslegung und Entwicklung der Römischen Verträge beschränkten.

Ministerialdirektor Krapf informiert über die Gespräche des Staatssekretärs Carstens vom 20. bis 27. September 1965 in Moskau. Die sowjetische Seite habe keine Kompromißbereitschaft gezeigt, jedoch erkennen lassen, daß sie „den Faden nicht abreißen lassen" wolle. Im Hinblick auf den Besuch des Ministerpräsidenten Cyrankiewicz vom 10. bis 16. September in Paris zeigt sich Krapf erfreut, daß das "freundschaftliche deutsch-französische Verhältnis praktisch demonstriert" worden sei. Er erklärt ferner, daß angesichts der verhärteten Haltung der Tschechoslowakei in den Wirtschaftsverhandlungen der vertragslose Zustand trotz guter Handelsbeziehungen „wohl noch lange andauern" werde. Der Leiter der Politischen Abteilung im französischen Außenministerium, Lucet, informiert über den Wunsch der Volksrepublik China, durch „die große Türe" in die UNO aufgenommen zu werden. Er empfiehlt Unterstützung, da andernfalls die Gefahr bestehe, daß eine gesonderte „asiatische Organisation" gegründet würde. Hinsichtlich der Arbeitssprachen im Europarat erklärt sich die französische Seite bereit, die zusätzliche Einführung von Deutsch und Italienisch $z u$ befürworten. Auswärtige Amt

Aus Gesprächen mit dem Unterstaatssekretär im britischen Außenministerium, Lord Hood, und Mitarbeitern der Botschaften der WEU-Staaten in London faßt Blankenhorn die Reaktion auf den französischen Wunsch zusammen, die WEU-Ministerratssitzung am 4./5. November 1965 ohne Beteiligung der EWGKommission und ohne Erörterung wirtschaftlicher Themen durchzuführen. Übereinstimmend werde die Ansicht vertreten, 
daß eine strikte Ablehnung zu einer Krise der WEU führen würde. Ein vorbehaltloses Akzeptieren würde dagegen Großbritannien den bisher im Rahmen der WEU offengehaltenen Zugang zum „Europagespräch“ verschließen. Von belgischer und italienischer Seite sei vorgeschlagen worden, auf eine Teilnahme der EWG-Kommission zu verzichten, Frankreich jedoch zur Einwilligung in eine allgemeine Diskussion wirtschaftlicher Fragen zu bewegen. Die britische Regierung habe eine Annahme des französischen Vorschlags unter der Voraussetzung für möglich erklärt, daß damit kein Präzedenzfall für die kommenden WEU-Ministerratssitzungen geschaffen werde. israelischen Botschafter Ben Natan

Erhard hebt hervor, daß der Entschluß zur Aufnahme diplomatischer Beziehungen mit Israel „allein seine Entscheidung gewesen" sei. Hinsichtlich der geplanten deutsch-israelischen Wirtschaftsgespräche macht er auf die „sehr schwierige Haushaltslage" und den stark beanspruchten deutschen Kapitalmarkt aufmerksam. Der Botschafter betont die von Ministerpräsident Eshkol gehegte Erwartung einer baldigen und vorteilhaften Einigung. Er schildert die Verteidigungsanstrengungen Israels sowie die besondere bevölkerungspolitische Situation als Einwanderungsstaat. Die Unterstützung der Bundesrepublik habe eine große Rolle für den Aufbau und die militärische Sicherheit gespielt; Israel hoffe daher, auch in Zukunft erhebliche Hilfe zu erhalten, ,wenn auch in anderer Form“. Zu der von Ben Natan betonten Notwendigkeit einer Meerwasserentsalzungsanlage erklärt der Bundeskanzler, daß deren Realisierung als Aufgabe eines Konsortiums mehrerer Staaten ein „Projekt mit weltweiter Leuchtkraft" sein könnte.

Der Staatssekretär gibt eine Unterredung mit dem sowjetischen Stellvertretenden Außenminister am 24. September 1965 in Moskau wieder. Carstens versuchte, Semjonow für eine konstruktive Haltung hinsichtlich einer Einbeziehung von Berlin (West) in Verträge der Bundesrepublik zu gewinnen. Er vertrat den Standpunkt, daß die Bundesrepublik lediglich die außenpolitische Vertretung wahrnehme, so wie die Schweiz das souveräne Liechtenstein vertrete. Semjonow ging darauf ebensowenig ein wie auf den Vorschlag, zu der im Handelsabkommen von 1958 gefundenen Lösung zurückzukehren. Zum Eindringen sowjetischer Flugzeuge in den Luftraum von Berlin (West) erklärte er, es habe sich um eine Reaktion auf "Provokationen“ gehandelt. Carstens entgegnete, die Bundestagssitzung in Berlin sei gegen niemanden gerichtet und als Ausdruck der Zusammengehörigkeit „der natürlichste Vorgang von der Welt“ gewe- 
sen. Semjonow stellte fest, daß in den bilateralen Beziehungen seit 1958 keine Fortschritte erzielt worden seien. Carstens betonte, entspannungspolitische Maßnahmen könnten nicht auf der Basis der Teilung Deutschlands getroffen werden. Die UdSSR müsse erkennen, „daß der Wiedervereinigungswille des deutschen Volkes immer stärker werden würde“.

Carstens faßt eine Ressortbesprechung im Bundeskanzleramt über den Stand der Passierschein-Gespräche zusammmen. Während Senator Schütz für eine Unterzeichnung des von der DDR am 16. August 1965 eingebrachten Vorschlags über eine neue Regelung eintrat, sprachen sich Carstens und Bundesminister Krone gegen eine Annahme aus. Der Chef des Presse- und Informationsamtes, von Hase, erklärte, eine Annahme sei der Bevölkerung in der Bundesrepublik „noch schwerer verständlich zu machen als Ablehnung “. Unter Hinweis auf die Haltung des Bundeskabinetts wandte sich auch Bundesminister Westrick dagegen, „in die Knie" zu gehen, und gab die gleichfalls ablehnende Stellungnahme des Bundeskanzlers Erhard wieder. Der Staatssekretär im Bundesministerium für gesamtdeutsche Fragen, Krautwig, referierte die Beurteilung des Bundesministers Mende, der ein Eingehen auf die Vorschläge für möglich halte. Er erläuterte jedoch als seine persönliche Ansicht, daß in Abstimmung mit den Verhandlungen über den Interzonenhandel weiterverhandelt werden solle. Es wurde beschlossen, das am 2. Oktober vorgesehene Passierschein-Gespräch mit einer Wiederholung der bisherigen Position aufzunehmen.

375 30.09. Staatssekretär Lahr, z. Z. Colombo, an das Auswärtige Amt

Lahr teilt mit, daß in den Verhandlungen mit Ceylon eine Einigung über die Wirtschaftshilfe, nicht jedoch über den Status der DDR-Vertretung in Colombo erreicht worden sei. Der ceylonesische Ministerpräsident habe zwar deren Zulassung durch seine Amtsvorgängerin Bandaranaike bedauert, jedoch auf das großzügige Kreditangebot der DDR verwiesen und lediglich zugesagt, bei gegebenem Anlaß die Herabstufung des Generalkonsulats in eine Handelsvertretung vorzusehen. Der Staatssekretär informiert ferner, daß Unstimmigkeiten über den ceylonesischen Entwurf für das Kommuniqué beständen. Er, Lahr, habe daran erinnert, daß der Bundesregierung eine eindeutige Erklärung zur Deutschland-Frage zugesichert worden sei, die gleichzeitig mit dem Abkommen über Wirtschaftshilfe abgegeben werden müsse. Demgegenüber habe Senanayake die Notwendigkeit innenpolitischer Rücksichten betont, jedoch eine Zusage für einen späteren Zeitpunkt gemacht. Lahr empfiehlt, die Vereinbarung auf dieser Basis unterzeichnen zu dürfen. Zur Absiche- 
rung sollten die künftigen Verhandlungen über Kapitalhilfe so geführt werden, daß Ceylon vor Abgabe der zugesagten Deutschland-Erklärung keine Ansprüche geltend machen könne. Auswärtige Amt

Sachs informiert über die Sitzung der Ständigen Vertreter bei EWG und EURATOM vom Vortag. Der italienische Ständige Vertreter berichtete aus einem Gespräch des Außenministers Fanfani mit seinem französischen Amtskollegen anläßlich der UNO-Generalversammlung in New York, daß Couve de Murville offenbar nicht über die Vorstellungen des Staatspräsidenten de Gaulle zur Lösung der EWG-Krise unterrichtet sei. Er habe ausweichend geantwortet, jedoch nachdrücklich die Notwendigkeit betont, den EWG-Vertrag den „nationalen Realitäten“ anzupassen. Anschließend stellten die Ständigen Vertreter fest, daß auf der EWG-Ministerratstagung am 25./26. Oktober 1965 eine grundsätzliche Einigung über die im Memorandum der EWGKommission vom 22. Juli 1965 aufgeworfenen Fragen erzielt werden müsse. Frankreich solle vorab darüber unterrichtet werden, daß es kein „préalable politique" für die Agrarfinanzierung geben werde. Venturini regte an, neben den im Memorandum der Kommission erwähnten Themen auch die KennedyRunde auf die Tagesordnung zu setzen. Eine Mehrheit votierte dafür, eine harte Haltung gegenüber Frankreich einzunehmen, das offensichtlich eine "Artischockentaktik" verfolge, um die Partnerstaaten „von Konzession zu Konzession zu treiben“.

Erhard betont, die im Bundestagswahlkampf erwähnte Möglichkeit eines Treffens mit Präsident Johnson bedeute keineswegs, daß eine Begegnung mit dem französischen Staatspräsidenten „erst in zweiter Linie" stehe. Er spricht eine Meldung der Nachrichtenagentur UPI über mutmaßliche französische Vorstellungen an, künftig nur die Bundesrepublik einem integrierten NATO-Kommando zu unterstellen und ihr kein Mitspracherecht bei der Nuklearplanung einzuräumen. Die Mitteilung des Leiters der Politischen Abteilung im französischen Außenministerium, Lucet, während der deutsch-französischen Konsultationsbesprechung vom 29. September 1965, daß „hie und da“ in der französischen Regierung ähnliche Überlegungen angestellt würden, und seine Verweigerung eines Dementis gäben Anlaß zur Sorge. Eine Sonderstellung der Bundesrepublik in der NATO sei von de Gaulle bislang nicht angesprochen worden und auch gar nicht möglich. Seydoux hält die Pressemeldung für „absolut unrichtig“ und erläutert, daß ihr ein offizielles Dementi 
unverdiente Bedeutung verschaffen würde. Mit Blick auf die EWG-Krise erinnert der Bundeskanzler abschließend an die Zusage von de Gaulle zu einem Treffen der Regierungschefs oder der Außenminister der EWG-Staaten „auf politischer Ebene und ohne jede Verbindung mit Brüssel“. an das Auswärtige Amt

Obermayer übermittelt die Stellungnahme des Leiters der Europa-Abteilung im niederländischen Außenministerium, Hartogh, zur EWG-Krise. Die Niederlande seien gegen jede Vereinbarung zur Nichtanwendung des künftig erweiterten Majoritätsprinzips für Entscheidungen des Ministerrats, da dieses für die kleineren Staaten das "wichtigste demokratische Element" im EWG-Vertrag sei. Auch eine Diskussion über die Stellung der EWG-Kommission werde abgelehnt. Der Vorschlag des belgischen Außenministers Spaak, eine Sitzung des EWG-Ministerrats ohne Teilnahme der Kommission abzuhalten, werde für akzeptabel gehalten, wenn es nur darum ginge, die „Gravamina Frankreichs“ zu behandeln. Zur Regelung der Agrarfinanzierung müsse jedoch die EWG-Kommission hinzugezogen werden. italienischen Botschafter Venturini

Der italienische Ständige Vertreter bei EWG und EURATOM vertritt die Ansicht, daß die Bundesregierung in der EWG-Krise den Schlüssel für die weitere Entwicklung in der Hand habe. Der Bundeskanzler sieht keine Möglichkeit für eine Änderung der Römischen Verträge und ist bezüglich des künftigen Mehrheitsprinzips der Auffassung, daß eine Majorisierung in lebenswichtigen Fragen vermieden werden müsse. Das Vorgehen des französischen Staatspräsidenten erklärt er damit, daß de Gaulle keinesfalls ,auch nur ein Eckchen an nationaler Souveränität abzugeben" bereit sei. Erhard hebt seine bisherigen Bemühungen um eine politische Einigung Europas hervor, die nicht „als reife Frucht vom Brüsseler Baume fallen“ werde. Er betont, daß die EWG-Krise im Rahmen der Gemeinschaft und nicht durch bilaterale deutsch-französische Kontakte gelöst werden müsse. Ein Einlenken Frankreichs sei am ehesten zu erwarten, wenn die übrigen EWG-Staaten in ihrer Haltung festblieben.

Lahr informiert über ein Gespräch mit dem israelischen Botschafter über die geplanten Wirtschaftsverhandlungen. Ben Natan vertrat die Auffassung, daß die Aktion „Geschäftsfreund“ unabhängig von der am 12. Mai 1965 zugesagten Wirtschafts- 
hilfe fortgesetzt werden müsse. Letztere sei zum einen als Wiedergutmachung, zum anderen als Abgeltung für nicht ausgeführte Waffenlieferungen zu sehen, die jedoch nicht abgeschlossen sei. Die künftige Unterstützung müsse daher „mindestens teilweise als unentgeltliche Leistung (grant) und nicht als Kredit“ erfolgen. Lahr wies diese Argumentation zurück und bekräftigte das Vorhaben, nicht zwischen einer Regierungshilfe gemäß der Absichtserklärung des Bundeskanzlers Adenauer vom 14. März 1960 und einer Wirtschaftshilfe zu unterscheiden, sondern die Zahlungen "den nunmehr gegebenen Umständen anzupassen“. Er erläuterte die Grundsätze für die Entwicklungshilfe der Bundesrepublik und betonte, daß Israel aufgrund seiner besonderen Bedeutung bereits in der „Spitzengruppe“ der geförderten Staaten rangiere. Ben Natan stellte abschließend fest, daß sich "außerordentlich weitreichende Meinungsverschiedenheiten" abzeichneten.

Böker berichtet über ein Gespräch mit dem tunesischen Botschafter. Ben Ayed erkundigte sich, ob arabische Staaten seit dem Ende der Nahost-Krise eine Annäherung an die Bundesrepublik gesucht hätten, und sprach sich dafür aus, im Einzelfall „eine goldene Brücke zu bauen“. Interessiert zeigte er sich vor allem an einer Wiederaufnahme der diplomatischen Beziehungen mit Algerien. Sie erfordere nur eine „kleine Geste" seitens der Bundesrepublik und könne Vorbild für andere arabische Staaten sein. Ben Ayed erläuterte, daß Tunesien auf eine Reform der Arabischen Liga dränge, da es „die Schulmeisterei durch Nasser gründlich satt" habe. Er äußerte Sorge über die Entwicklung in Libyen, das zu einer Bedrohung für Tunesien werden könnte, wenn es „von der VAR verschluckt" würde.

Lahr faßt Gespräche mit dem Staatssekretär im niederländischen Außenministerium, de Block, und dem stellvertretenden belgischen Außenminister zusammen. Fayat erläuterte den Vorschlag, Frankreich nach der am 25./26. Oktober 1965 stattfindenden EWG-Ministerratssitzung zu einem Ministerrat ohne Beteiligung der EWG-Kommission einzuladen. Sollte sich dabei herausstellen, daß mit französischer Mitarbeit in absehbarer Zeit nicht zu rechnen sei, würde Belgien zur „Fortführung der EWG zu fünf" bereit sein. Lahr stimmte unter der Voraussetzung zu, daß keine die Anwesenheit der EWG-Kommission erfordernden Sachfragen besprochen würden. Er zieht den Schluß, daß die Benelux-Staaten nunmehr auch ohne Frankreich zur Fortsetzung der EWG bereit seien, und wertet dies als Beweis des Vertrauens in die „europäische Gesinnung“ der Bun- 
desrepublik. Dies sei um so bedeutsamer, als in einer reduzierten Gemeinschaft mehr als die Hälfte des Wirtschaftspotentials bei der Bundesrepublik läge.

Krapf erläutert die Schwierigkeiten bei der Wiederaufnahme der Wirtschaftsverhandlungen mit Ungarn. Diese werde durch Differenzen um ein Schreiben des ungarischen Protokollchefs vom 7. Juni 1965 belastet, in dem die Zuständigkeit der Handelsvertretung der Bundesrepublik in Budapest für Angelegenheiten von Berlin (West) bestritten worden sei. Krapf plädiert dafür, daß das ungarische Schreiben zurückgesandt und gleichzeitig mündlich ein Terminvorschlag für die Wirtschaftsgespräche unterbreitet werden solle. Damit würde sowohl der Entschlossenheit der Bundesrepublik Ausdruck verliehen, hinsichtlich der Einbeziehung von Berlin (West) keine Abstriche am Abkommen vom 10. November 1963 mit Ungarn hinzunehmen, als auch dem ungarischen Prestigebedürfnis Rechnung getragen. Demgegenüber sei das Risiko, daß Ungarn „möglicherweise unter sowjetischem Druck auf einer harten Haltung" bestehen würde, angesichts des großen Interesses an den Verhandlungen mit der Bundesrepublik gering. (Entwurf)

Schröder zeigt sich beunruhigt über die Bemühungen der DDR, „das Alleinvertretungsrecht für Deutschland zu usurpieren". Er regt eine Aussprache über die erforderlichen Konsequenzen an und übermittelt Vorschläge für eine „aktive Auseinandersetzung“. Danach soll die Widersprüchlichkeit der DDR-Politik offengelegt und insgesamt weniger defensiv vorgegangen werden. So müsse die Forderung nach Wiedervereinigung „Vorrang vor Grenz- und Heimatrechts-Fragen" haben. Der Alleinvertretungsanspruch solle stärker als Ausdruck eines „elementaren Volkswillens" dargestellt werden, da die rechtliche Argumentation zu abstrakt wirke. Ferner sei eine stärkere Bündelung der Aktivitäten und eine offensivere Zurückweisung der DDR-Propaganda im internationalen Bereich vonnöten. Schließlich müsse die Informationspolitik "volkstümlicher" gestaltet und dem „inneren Verbundenheitsgefühl“ des deutschen Volkes gröBere Aufmerksamkeit gewidmet werden. Daher sollten politische Sachverständige in die technischen Kontakte mit der DDR einbezogen werden. 
Harkort faßt Überlegungen zur Ausrüstungshilfe an Äthiopien zusammen. Nachdem die Bundesregierung beschlossen habe, keine Waffen mehr in Spannungsgebiete zu liefern, sei Äthiopien die Lieferung anderen Materials bzw. eine Barablösung in Aussicht gestellt worden. Dazu habe der Auswärtige Ausschuß des Bundestags festgelegt, daß die Mittel nicht für Waffenkäufe in dritten Staaten benutzt werden dürften. Harkort weist darauf hin, daß demgegenüber der Bundesverteidigungsrat der Finanzierung kenianischer Rüstungsaufträge in Großbritannien zugestimmt habe, was zu einer ernsthaften Verstimmung in Äthiopien führen könne. Er schlägt vor, auch äthiopische Beschaffungen in Großbritannien zu ermöglichen. Dies würde zudem die Erfüllung der Devisenverpflichtungen der Bundesrepublik gegenüber Großbritannien beschleunigen. Vertretung bei der NATO in Paris

Für die Sitzung des Politischen Ausschusses des Ständigen NATO-Rats am folgenden Tag übermittelt Schnippenkötter eine Stellungnahme zum sowjetischen Entwurf für ein Abkommen über die Nichtverbreitung von Kernwaffen. Nach Ansicht der Bundesregierung würden bei einer Annahme sowohl eine gemeinschaftliche Verfügungsgewalt über Atomwaffen innerhalb der NATO unmöglich als auch bereits bestehende Formen der nuklearen Kooperation verboten. Dies betreffe etwa die in den Athener "guidelines“ festgelegte Konsultation über den Einsatz von Kernwaffen, aber auch die Abkommen zwischen den NATO-Staaten und den USA über den Austausch von Atominformationen. Da der sowjetische Entwurf auf eine fast " vollständige Denuklearisierung der NATO-Streitkräfte“ abziele, sei er als Verhandlungsgrundlage unannehmbar.

Lahr berichtet über eine Unterredung mit dem israelischen Botschafter. Ben Natan brachte „tiefe Enttäuschung“ über die Ausgangsposition der Bundesregierung für die Wirtschaftsverhandlungen zum Ausdruck. Er begründete die Forderung nach zusätzlicher Wirtschaftshilfe damit, daß Israel Grund zu der Annahme gehabt habe, die militärische Unterstützung werde „sich immer weiter fortsetzen“. Ferner habe es aus dem Gespräch des Bundeskanzlers Adenauer mit Ministerpräsident Ben Gurion am 14. März 1960 in New York einen zwar „nicht rechtlich perfektionierten, so doch moralischen und politischen ${ }^{\text {“ }}$ Anspruch auf fortlaufende Leistungen ableiten können. Als israelisches Verhandlungsziel nannte Ben Natan die volle Ausschöpfung des seinerzeit zugesagten Betrags von 2 Milliarden DM durch jährliche Zahlung von 150 Millionen DM und eine 
zusätzliche fünfjährige Hilfe von 200 Millionen DM pro Jahr. Lahr bestritt, daß für die Ausrüstungshilfe „Kontinuität“ in Anspruch genommen werden könnte, und erläuterte, die Bundesregierung könne Verpflichtungen der genannten Art schon aus haushaltsrechtlichen Gründen nicht eingehen.

Klaiber informiert über die Reaktion des französischen Außenministers auf die Stellungnahme der Bundesregierung zur EWG-Krise. Couve de Murville erklärte, Frankreich habe niemals eine Änderung der Römischen Verträge hinsichtlich der EWG-Kommission verlangt. Diese solle sich jedoch an ihre vertraglichen Grundlagen halten und ihrer "politischen Ambitionen" entsagen. Zufrieden zeigte sich Couve de Murville darüber, daß die künftig vorgesehenen Mehrheitsentscheidungen im EWG-Ministerrat nicht zur Majorisierung eines Mitgliedstaats führen sollten. Ohne Widerspruch nahm er die Auffassung zur Kenntnis, daß der Agrarfinanzierung keine Priorität zukomme und zunächst die Entwicklungsperspektiven für die EWG in anderen Bereichen zu klären seien. Positiv beurteilte er den belgischen Vorschlag für eine Ministerratskonferenz ohne Teilnahme der EWG-Kommission und bemerkte, daß die deutsche und die französische Haltung „nicht allzuweit" voneinander entfernt seien.

Frank erörtert mögliche französische Reaktionen für den Fall, daß die Bundesrepublik der geplanten MLF beiträte. Er vermutet „Repressalien“ auf dem Gebiet der Ost- und Deutschlandpolitik, wobei „der Fächer der Möglichkeiten“ bis zu einer Anerkennung der DDR reiche. Grund für die negative Haltung Frankreichs sei die erwartete Beeinträchtigung der angestrebten Wiederherstellung des europäischen Gleichgewichts und die Relativierung des mit der Force de frappe erreichten Vorsprungs vor den übrigen europäischen Staaten auf nuklearem Gebiet. Frankreich habe der Bundesrepublik niemals eindeutig Alternativen zur MLF in Aussicht gestellt. Auch sei fraglich, ob es ihr bei einer nuklearen Zusammenarbeit ein effektives Mitspracherecht einzuräumen bereit wäre und einer "Verklammerung der französischen Abschreckung mit der amerikanischen“ zustimmen würde. Lindenberg

Meyer-Lindenberg befaßt sich mit den Auswirkungen einer etwaigen südrhodesischen Unabhängigkeitserklärung. Großbritannien werde eine solche nicht hinnehmen, jedoch eher mit

\section{CLXXIV}


politischen und wirtschaftlichen als mit militärischen Mitteln reagieren. Zu überprüfen seien daher die Konsequenzen eventueller UNO-Sanktionen auf die Wirtschaftsbeziehungen der Bundesrepublik mit Südrhodesien. Meyer-Lindenberg weist auf die eventuelle Bildung einer oder mehrerer Exilregierungen hin, die auch das Problem einer Anerkennung durch die DDR aufwerfen könnte. Er spricht sich für die baldige Entsendung eines neuen Generalkonsuls nach Salisbury aus, um mit dessen Rückberufung ,im Bedarfsfall eine sichtbare politische Demonstration“ durchführen zu können. Auswärtige Amt

Knappstein berichtet über eine Unterredung mit dem amerikanischen Außenminister über die geplante Weltabrüstungskonferenz. Der Botschafter trug Bedenken hinsichtlich einer Teilnahme der DDR vor, da eine solche einen schweren Rückschlag für die Deutschlandpolitik der Bundesrepublik bedeuten würde, und erklärte, die Bundesregierung behalte sich gegebenenfalls die Entscheidung über ihre eigene Mitwirkung vor. Er erläuterte ferner den Vorschlag einer Einladungsformel, die der Volksrepublik China die Teilnahme ermöglichen und lediglich die DDR, die Volksrepublik Korea (Nordkorea) und die Demokratische Republik Vietnam (Nordvietnam) ausschließen würde. Rusk hob hervor, daß die USA bemüht seien, das Projekt zu verhindern. Es sei zu erwarten, daß die Volksrepublik China eine Einladung ablehnen werde und andere Staaten dann von der Nutzlosigkeit einer Konferenz überzeugt werden könnten. Rusk sicherte zu, bei einem Zustandekommen unter Beteiligung der DDR eine „disclaimer“-Erklärung abzugeben. Auswärtige Amt

Blankenhorn informiert über eine Unterredung des Gesandten Freiherr von Ungern-Sternberg mit dem britischen Vertreter bei den Europäischen Gemeinschaften. O'Neill habe auf das Interesse der EFTA an einem „Brückenschlag“ zur EWG bzw. an einem ständigen Kontakt zwischen den beiden Organisationen hingewiesen. Substantielle Möglichkeiten für eine Verbesserung der Zusammenarbeit würden derzeit nicht gesehen; hinsichtlich der Zollpolitik warte die EFTA zunächst die Ergebnisse der Kennedy-Runde ab. Ferner habe O'Neill erläutert, daß an eine Aufhebung des zur Verbesserung der Zahlungsbilanz eingeführten britischen Sonderzolls erst im Lauf des Jahres $1966 \mathrm{zu}$ denken sei. 
Der Leiter der Rechtsabteilung berichtet, der israelische Botschafter habe das Problem der Wiedergutmachung für Gesundheitsschäden von Opfern aus der Zeit der Herrschaft des Nationalsozialismus zur Sprache gebracht. Thierfelder stellt fest, da $\beta$ Israel im Abkommen vom 10. September 1952 auf Entschädigungsleistungen dieser Art verzichtet habe und solche daher von der Bundesregierung abgelehnt würden. Ben Natan habe betont, daß hier der „legalistische Weg“ nicht der richtige sei. Er werde sich nachdrücklich für eine Lösung des Problems einsetzen, beabsichtige jedoch keine Verknüpfung mit den bevorstehenden Wirtschaftsverhandlungen. Thierfelder hält die juristischen Gründe einer Ablehnung für gewichtig, sieht jedoch auch bedeutende politische Argumente für ein Entgegenkommen. Dabei könne eine Verbindung mit den Wirtschaftsgesprächen für die Bundesrepublik sogar von Interesse sein, um bei der Bemessung der Leistungen der Bundesrepublik auf wirtschaftlichem Gebiet die freiwilligen Zahlungen an "Gesundheitsgeschädigte“ als Entlastung des israelischen Haushalts zu berücksichtigen. bei der EWG und EAG in Brüssel

Lahr bittet, dem Mitglied der EURATOM-Kommission Sassen die Bedenken gegen die Absprachen der EURATOM-Kommission mit Frankreich über die Anwendung der Sicherheitskontrollen zu erläutern. Die Bundesregierung habe auf einen förmlichen Rechtsvorbehalt verzichtet, um die mit der Vereinbarung erreichte faktische Verbesserung der Kontrollen nicht zu gefährden. Sie wolle jedoch einen allgemeinen Vorbehalt einlegen, um bei den Verhandlungen über die Fusion der europäischen Gemeinschaften darauf zurückkommen zu können. Die Befürchtung, daß Frankreich die geplante Übergabe eines entsprechenden deutschen Aide-mémoires an die EURATOM-Kommission dazu nutzen könnte, die USA von der Unwirksamkeit des EURATOM-Sicherheitssystems zu überzeugen, werde nicht geteilt, weil Frankreich die Alternative - Kontrollen durch die Internationale Atomenergie-Organisation - erst recht ablehne. Auch Rückwirkungen auf die amerikanische Haltung seien angesichts der Geheimhaltung des Aide-mémoires der Bundesregierung nicht zu befürchten.

Klaiber informiert über ein Gespräch des niederländischen Botschafters mit dem französischen Staatspräsidenten. Baron Bentinck habe den Eindruck gewonnen, daß de Gaulle zwar den Gedanken einer Revision der Römischen Verträge aufgegeben habe, jedoch eine Neuinterpretation hinsichtlich des künftigen 
Majoritätsprinzips und der Stellung der EWG-Kommission für nötig halte. De Gaulle habe sich bereit erklärt, mit den EWGPartnern über die gemeinsame Handelspolitik gegenüber den Ostblock-Staaten, über die Kennedy-Runde und über die Steuerharmonisierung zu sprechen. Dabei seien die politischen Grundsatzentscheidungen von den Regierungen zu treffen, während die EWG-Kommission zu Fragen der praktischen Umsetzung herangezogen werden könnte. Schließlich habe de Gaulle seine Besorgnis wegen der „deutschen Dynamik“ im industriellen Bereich erkennen lassen. Auswärtige Amt

Grewe zieht aus Äußerungen des amerikanischen Ständigen Vertreters bei der NATO den Schluß, daß sich die Haltung der USA hinsichtlich der Nichtverbreitung von Kernwaffen geändert habe. Da die UdSSR ohnehin nicht mehr an der Weitergabe nuklearer Kenntnisse interessiert sei, so habe Cleveland erläutert, bestehe das Hauptproblem nunmehr darin, die potentiellen Nuklearmächte durch besondere Vereinbarungen und Garantien vom Erwerb atomarer Waffen abzuhalten. Es sei jedoch „höchst zweifelhaft“, ob Staaten wie Indien, Israel und Japan zum Beitritt zu einem Nichtverbreitungsabkommen bewegt werden könnten. Weil eine sowjetische Mitwirkung in dieser Hinsicht wenig nütze, lohne es sich jedenfalls nicht, dafür "große politische Preise“ zu zahlen.

Lahr faßt die Ergebnisse seiner Besprechungen mit der italienischen Regierung am 19. Oktober 1965 in Rom zusammen. Einigkeit bestand über die Notwendigkeit, Frankreich zu einer baldigen Rückkehr in die EWG zu bewegen, ohne jedoch durch Konzessionen eine „Belohnung für Vertragsbruch“ zu gewähren. Die Stellung der EWG-Kommission solle nicht beeinträchtigt werden; hinsichtlich des erweiterten Majoritätsprinzips werfe Frankreich ein "faux problème" auf, weil ein Mißbrauch des künftigen Verfahrens ohnehin in niemandes Interesse liege. Die italienischen Gesprächspartner unterstützten die deutschen Überlegungen zur Beilegung der EWG-Krise und legten ihre Vorstellungen hinsichtlich einer Regelung der Agrarfinanzierung dar. Eine "gewisse Zurückhaltung“ zeigten sie gegenüber der Kennedy-Runde. 

Auswärtige Amt

Knappstein informiert über ein Gespräch des Gesandten von Lilienfeld mit dem Sicherheitsberater des amerikanischen Präsidenten. Bundy habe das Interesse an einer Beteiligung der nichtnuklearen Staaten der NATO - insbesondere der Bundesrepublik - an der Verantwortung für die atomare Verteidigung bekräftigt. $\mathrm{Er}$ habe sich offen für verschiedene Formen der nuklearen Mitwirkung gezeigt, allerdings eine Berücksichtigung der britischen Interessen, der Haltung des amerikanischen Kongresses und des ablehnenden französischen Standpunkts für notwendig gehalten. Dabei habe er erkennen lassen, daß in den USA nur dann Chancen zur Durchsetzung einer MLF oder ANF beständen, wenn sich die europäischen Partner einig seien. Bundy habe daher angeregt, nach Regelungen zu suchen, die von der Zustimmung des Kongresses unabhängig seien, etwa in Richtung einer stärkeren Einbeziehung der Bundesrepublik in die nukleare Planung der NATO. Allerdings müsse in jedem Fall der Anschein eines „deutsch-amerikanischen Alleingangs" vermieden werden. sowjetischen Botschafter Smirnow

Carstens protestiert gegen die von sowjetischen Diplomaten in einem Ausschuß der UNO-Generalversammlung erhobenen Behauptungen, daß die Bundesrepublik ein MilitärhilfeAbkommen mit Südrhodesien besitze und Ausbildungshilfe leiste. Er erhebt ferner Einspruch gegen die Teilnahme des sowjetischen Gesandten Kudrjawzew an einem von DDR-Journalisten gegebenen Empfang in Bonn aus Anlaß des 16. Jahrestages der Gründung „dieses Gebildes“. Smirnow entgegnet, weder er noch seine Mitarbeiter könnten derartige „rein private“ Einladungen ablehnen. Er stellt fest, daß die Erklärung von Carstens als „Einmischung in seine Rechte als diplomatischer Vertreter“ zu werten sei. Botschafter Allardt, Madrid

Meyer-Lindenberg bittet um Stellungnahme zu der israelischen Anfrage, ob die Bundesrepublik in Spanien die Möglichkeit einer Aufnahme diplomatischer Beziehungen sondieren könne. Israel sei auch bereit, sich zunächst mit konsularischen oder "beschränkt diplomatischen“ Beziehungen zu begnügen. Der Ministerialdirektor erläutert, daß sich die Bundesregierung angesichts der Erfahrungen der Nahost-Krise nicht unbedingt als geeigneten Vermittler für Israel betrachte. Da jedoch die

\section{CLXXVIII}


Wirtschaftsverhandlungen die israelischen Erwartungen voraussichtlich nicht vollständig erfüllen würden, könnte Entgegenkommen in anderen Bereichen wünschenswert sein. minister Schröder

Blankenhorn informiert über eine Demarche beim britischen Außenminister. Stewart erläuterte seine jüngsten Stellungnahmen zur Frage einer integrierten Atomstreitmacht der NATO. Er betonte, daß der britische ANF-Vorschlag nach wie vor Bestand habe; mit der MLF könne sich Großbritannien jedoch „nicht befreunden“. Als mögliche Ersatzlösung bezeichnete Stewart das vom amerikanischen Verteidigungsminister McNamara vorgeschlagene „select committee“. Ferner bekräftigte er das Interesse an einem Abkommen über die Nichtverbreitung von Kernwaffen, versicherte jedoch, er habe „niemals daran gedacht", einem solchen Priorität vor einer Lösung der nuklearen Probleme innerhalb der NATO einzuräumen.

Bräutigam bewertet die deutschlandpolitischen Ausführungen des französischen Außenministers am 29. September 1965 vor der UNO-Generalversammlung in New York und stellt ihnen Äußerungen des Bundesministers Schröder gegenüber. Er stimmt mit Couve de Murville darin überein, daß das Selbstbestimmungsrecht Grundlage einer Wiedervereinigung sein und diese im Zusammenhang mit der europäischen Sicherheit stehen müsse. „Ernste Vorbehalte“ hält er jedoch hinsichtlich der französischen Thesen für nötig, daß die Überwindung der deutschen Teilung durch eine Einigung zwischen Ost und West herbeizuführen und von einer Beseitigung der Teilung Europas abhängig sei. Bräutigam sieht darin eine Aushöhlung der VierMächte-Verantwortung sowie eine Auflösung des Junktims zwischen Deutschland-Frage und europäischer Sicherheit. Er macht darauf aufmerksam, daß das Dankschreiben von Schröder vom 30. September an Couve de Murville den Eindruck erwecken könnte, die Bundesregierung sei sich der Differenzen mit Frankreich nicht bewußt. britischen Botschafter Roberts

Roberts betont das Interesse an einem Besuch von Schröder in London und schlägt als Termin die erste Hälfte des Novembers 1965 vor. Er gibt die positive Resonanz auf den Vorschlag der Bundesregierung zur Intensivierung der bilateralen Kontakte weiter. Schröder befürwortet ein „bewegliches System von Zusammenkünften“. Als Thema künftiger Gespräche verweist 
der Botschafter auf die Nichtverbreitung von Kernwaffen, deren gleichzeitige Diskussion im Rahmen der NATO und der UNO das Problem aufwerfe, „beide Pferde am Zügel“ zu halten. Hinsichtlich Südrhodesiens erläutert er, daß Großbritannien im Fall einer Unabhängigkeitserklärung nicht intervenieren, jedoch wirtschaftliche Sanktionen verhängen werde.

Der Botschafter rekapituliert die spanische Vermittlungsaktion in der VAR während der Nahost-Krise im Februar 1965. Er stellt fest, daß die spanische Regierung die geringe Anerkennung ihrer Bemühungen mit Enttäuschung vermerkt habe, zumal nach ihrer Ansicht das Mögliche erreicht worden sei. Die Mängel der Aktion sieht Allardt in der unzureichenden Vorbereitung: Das spanische Außenministerium und der Vermittler, Abteilungsleiter de Nerva, seien über die Vorstellungen der Bundesregierung zur Lösung der Nahost-Krise zu wenig unterrichtet gewesen. Zudem fehle in Spanien Verständnis für eine Politik, die zugunsten von drei Millionen „nicht wohlgesonnener Israelis" die traditionelle Freundschaft von 100 Millionen Arabern gefährde. Der Botschafter resümiert, de Nerva habe sich bei den Gesprächen in Kairo korrekt verhalten, jedoch seien seine öffentlichen Erklärungen „ebenso überflüssig wie der Sache schädlich" gewesen. Nachteilig dürfte ferner gewirkt haben, daß die Position der Bundesregierung seinerzeit ,gewissen Schwankungen" unterworfen gewesen sei. I. Klasse Luedde-Neurath

Luedde-Neurath faßt die Ergebnisse der deutsch-britischen Gespräche am 21./22. Oktober 1965 in London über die Osteuropa-Politik zusammen. Die britische Delegation habe das sowjetische Sicherheitsbedürfnis als ernsthaft bewertet. Die UdSSR fürchte die Bundesrepublik ,als den Schwanz, der mit dem amerikanischen Hund wackeln könne“. Ferner habe sie die innenpolitische Bedeutung einer Verbesserung der britischsowjetischen Beziehungen betont. Darüber hinaus sei die Wichtigkeit eines Ausgleichs zwischen der Bundesrepublik und der Tschechoslowakei festgestellt worden, weil darin der "Angelpunkt für eine Emanzipierung der Tschechoslowakei“ und eine Differenzierung innerhalb des Ostblocks liege. Kein Verständnis zeigte die britische Seite für die Betonung eines „Rechts auf Heimat". 
Scheel befaßt sich mit der künftigen Politik gegenüber den arabischen Staaten. Da eine Neuordnung der Beziehungen „am zweckmäßigsten in bilateralen Verhandlungen " erfolge, sei eine eigene entwicklungspolitische Konzeption für jeden der Staaten sowie für den gesamten arabischen Raum einschließlich Israels notwendig. Scheel regt deshalb eine Abstimmung der NahostPolitik zwischen dem Bundesministerium für wirtschaftliche Zusammenarbeit und dem Auswärtigen Amt an. Lindenberg

Meyer-Lindenberg informiert über ein Gespräch mit dem pakistanischen Botschafter. Rahman Khan drängte auf eine baldige Bekanntgabe des Beitrags der Bundesrepublik innerhalb des Pakistan-Konsortiums. Auf seine Bitte, Ausfuhrgenehmigungen wenigstens für die vor Beginn des indisch-pakistanischen Konflikts abgeschlossenen Waffengeschäfte sowie $100000 \mathrm{Schu} ß$ Übungsmunition zu erteilen, erwiderte Meyer-Lindenberg, daß prinzipiell an keine der am Kaschmir-Konflikt beteiligten Parteien Waffen geliefert werden sollten. Rahman Khan regte an, Bundeskanzler Erhard möge bei der nächsten Zusammenkunft mit Präsident Johnson die Kaschmir-Frage ansprechen, weil die Bundesrepublik und die USA eine Vermittlerrolle übernehmen könnten. Er erkundigte sich ferner, ob Interesse an einem Besuch des Präsidenten Ayub Khan in der Bundesrepublik bestehe. Meyer-Lindenberg erläuterte „diskret ${ }^{\text {“ }}$, daß ein solcher Besuch in näherer Zukunft Komplikationen mit sich bringen würde und daher erst später vorgesehen werden sollte.

Schmidt-Horix berichtet über die Wirtschaftsverhandlungen in Sofia. Auf bulgarischer Seite bestehe nicht nur der Wunsch nach Aufnahme diplomatischer Beziehungen, sondern auch nach einer Verdoppelung des Handelsvolumens. In dem unterzeichneten Warenprotokoll habe jedoch nur eine Erhöhung der bulgarischen Ausfuhren um 20 Prozent zugestanden werden können, da die Einbindung der Bundesrepublik in die EWG bindende Abnahmezusagen unmöglich mache. Der Botschafter macht jedoch darauf aufmerksam, daß sich offensichtlich andere EWGStaaten gegenüber den bulgarischen Exportwünschen aufgeschlossener zeigten und daß das Bundesministerium für Wirtschaft der politischen Bedeutung einer Ausweitung des Handels mit den Ostblock-Staaten „nur zögernd“ Rechnung trage. Zum möglichen Abschluß eines Kulturabkommens teilt er mit, daß Bulgarien keine Berlin-Klausel akzeptieren wolle, jedoch einen Notenwechsel über einen technisch-wissenschaftlichen Aus- 
tausch angeregt habe, der auch kulturelle Bereiche abdecken würde. Er plädiert für die Annahme dieses Vorschlags, auch wenn die „Form nicht befriedigt“. israelischen Botschafter Ben Natan

Ben Natan teilt mit, daß seine Gespräche mit Staatssekretär Lahr über Wirtschaftshilfe an Israel „feststeckten“. Nach israelischer Auffassung sei in den Verhandlungen im April 1965 über die Aufnahme diplomatischer Beziehungen die Grundlage für eine zusätzliche „wesentliche“ Zahlung geschaffen worden. Die nun von Lahr vertretene Position, die geheimgehaltene Aktion "Geschäftsfreund" solle eingestellt und statt der bisher festen Beträge nur eine projektgebundene Entwicklungshilfe gewährt werden, sei ebenso unannehmbar wie das Argument, die Leistungen an Israel müßten in einem angemessenen Verhältnis zur Entwicklungshilfe für die arabischen Staaten stehen. Westrick weist auf die angespannte Haushaltslage hin und legt dar, seitens der Bundesregierung sei bereits im Frühjahr betont worden, daß „man in der Zukunft nicht doppelgleisig, sondern eingleisig fahren müsse“. Israel habe zudem zugesagt, nach der Abwicklung des Wiedergutmachungsabkommens von 1952 keine weiteren Forderungen zu erheben. Ben Natan schlägt als Kompromißlösung vor, die Bundesrepublik solle ein Jahr in "Geschäftsfreund-Art" 70 bis 80 Millionen DM zahlen und daneben eine projektgebundene Wirtschaftshilfe in etwa gleicher Höhe leisten; im zweiten Jahr könne der „GeschäftsfreundAnteil" geringer werden und danach vielleicht völlig auslaufen. So könne schließlich „die aller Welt offenliegende Entwicklungshilfe das einzige Geleise bleiben". I. Klasse Schirmer

Schirmer informiert über ein Gespräch mit dem jordanischen Presseattaché, der im Auftrag des früheren Botschafters in Bonn, Juma, anfragte, ob die Bundesregierung der Eröffnung eines jordanischen Generalkonsulats in den ehemaligen Botschaftsräumen zustimmen würde. Schirmer erläuterte, daß zwar Interesse an einer Wiederaufnahme der diplomatischen Beziehungen bestehe, nicht aber an "Ersatzlösungen“. Grundsätzlich sei die Bundesrepublik wenig geneigt, zwischenstaatliche Beziehungen auf der Ebene von Generalkonsulaten zu pflegen, da ${ }_{n}$ diese Formel von der SBZ mangels völkerrechtlicher Anerkennnung " angewandt werde. Dajany habe demgegenüber betont, daß die Eröffnung eines Generalkonsulats als ein erster Schritt zur Wiederherstellung des Status quo ante gesehen werden müsse.

\section{CLXXXII}



an Ministerialdirektor Krapf

Braun berichtet über ein Gespräch mit dem ehemaligen amerikanischen Ständigen Vertreter bei der NATO. Finletter äußerte die Ansicht, Staatspräsident de Gaulle mache die NATO, „wo und wie er könne, kaputt“, und bedauerte das nachlassende Eintreten der Bundesrepublik für eine MLF. Braun begründete letzteres damit, daß die Bundesregierung „als alleiniger Bannerhalter" für die auch innerhalb der Allianz umstrittene MLF habe auftreten müssen. Dies habe sich ungünstig auf die öffentliche Meinung in den USA ausgewirkt. Finletter bekräftigte dagegen den amerikanischen Willen zur Realisierung des Projekts. Er bestätigte den Eindruck des Botschafters, daß die amerikanische Regierung wenig Interesse an Abrüstungsfragen habe, es ihr in erster Linie um die „Atomzähne in der NATO" gehe und sie deshalb die MLF nicht durch irgendwelche Absprachen gefährden wolle. Die Bundesregierung solle sich also weder wegen der Nichtverbreitung von Kernwaffen noch wegen der Weltabrüstungskonferenz Sorgen machen, sondern vielmehr ihre Wünsche hinsichtlich einer Festigung der Zusammenarbeit mit den USA ,in deutlicher Form" vorbringen.

Lahr faßt die französische Reaktion auf die EWG-Ministerratssitzung vom 25./26. Oktober 1965 zusammen. Die Legalität dieser Zusammenkunft werde bestritten. Der Staatssekretär warnt vor dem französischen Vorschlag, das Majoritätsprinzip abzuschaffen und Verhandlungen auf bilateraler Ebene zu führen. Frankreich wolle lediglich „die jeweils weichste Stelle ausfindig machen" und den einen gegen den anderen ausspielen. Eine mögliche französische Forderung nach personellem Wechsel in der EWG-Kommission lehnt er aus Gründen der Kontinuität und der Wahrung von Rechten der EWG-Mitgliedstaaten ab. Skeptisch äußert er sich zu der vertraglich möglichen Vorstellung, daß das EWG-Präsidium alle zwei Jahre alternieren solle. Abschließend stellt Lahr fest, daß die "negativen Elemente“ in der französischen Haltung weiterhin überwiegen, und sich in der Frage der Mehrheitsbeschlüsse sogar eine Verhärtung der Position zeige. französischen Außenminister Couve de Murville in Paris

Couve de Murville berichtet über seinen Aufenthalt in Moskau vom 28. Oktober bis 2 . November 1965. Die sowjetische Regierung sei von einem „extremen“ Mißtrauen gegenüber der Bundesrepublik und den USA beherrscht. Sie frage sich vor allem, was sich hinter den Diskussionen um eine integrierte NATO- 
Atomstreitmacht verberge. Ein Gespräch mit der UdSSR über diese Frage wäre daher nützlich. Schröder legt demgegenüber dar, daß ohne sowjetische Zugeständnisse bei der Überwindung der deutschen Teilung Vorleistungen weder hinsichtlich der Ostgrenzen noch der Bündniszugehörigkeit noch der nuklearen Mitsprache erbracht werden dürften. Couve de Murville hält dem entgegen, daß ein „westeuropäisches Atomverteidigungssystem" nicht im Interesse Europas und der Bundesrepublik liege, denn es würde den USA erlauben, sich im Kriegsfall nicht zu engagieren. Er bedauert, daß das enge deutsch-amerikanische Verhältnis die französischen Bemühungen um eine größere Bewegungsfreiheit in der Allianz unterlaufe, da es den USA ermögliche, ,,sich auf die anderen gegen Frankreich“ zu stützen und somit in Westeuropa „die Politik zu dirigieren“. in Paris

Angesichts der einseitigen Unabhängigkeitserklärung der rhodesischen Regierung erklärt der Generalsekretär im französischen Außenministerium, Alphand, daß Frankreich weder diplomatische Beziehungen zu Rhodesien aufnehmen noch bestehende amtliche Kontakte weiterführen werde. Zudem werde es die britischen Wirtschaftssanktionen unterstützen. Staatssekretär Carstens erläutert die Haltung der Bundesregierung zum Kaschmir-Konflikt. Sie wolle weiterhin Indien und Pakistan bei der Vergabe von Wirtschaftshilfe gleichmäßig behandeln. Es wäre allerdings verhängnisvoll, wenn diese Leistungen für eine Finanzierung der militärischen Auseinandersetzung verwendet würden. Das Scheitern des Putsches am 30. September 1965 in Indonesien werten Carstens und Alphand als Rückschlag für die Volksrepublik China. Zur Nahost-Politik legt der Staatssekretär dar, daß die DDR zwar gewisse „Geländegewinne" habe verbuchen können, es jedoch nicht zu einer Aufnahme diplomatischer Beziehungen mit einem arabischen Staat gekommen sei. Vielmehr interessierten sich einige arabische Regierungen mittlerweile für eine Normalisierung der Beziehungen zur Bundesrepublik. Carstens äußert die Bitte, Frankreich möge diese Bestrebungen unterstützen. Generalsekretär Brosio in Paris

Schröder erläutert, daß die Bundesregierung unverändert an einer stärkeren Beteiligung der nichtnuklearen Staaten an der NATO-Strategie und Zielplanung festhalte. Sie wolle daher intensiv an dem von amerikanischer Seite vorgeschlagenen "special committee" mitarbeiten, sehe jedoch eine befriedigende Lösung des Problems nur in einem gemeinsamen nuklearen Waffensystem. Schröder äußert die Auffassung, daß Frankreich

\section{CLXXXIV}


zumindest bis 1969 Mitglied der NATO bleiben wolle. Spätestens von diesem Zeitpunkt an solle nach französischen Vorstellungen der NATO-Vertrag in eine „Kumulation“ von bilateralen Absprachen mit möglichen "Sonderarrangements, eventuell sogar Deutschland betreffend", umgewandelt werden. Brosio vertritt dagegen die Ansicht, Frankreich wolle nicht den Vertrag, sondern lediglich die NATO-Organisation verlassen. Wie abschließend einvernehmlich festgestellt wird, müsse daher geprüft werden, auf welchen rechtlichen Grundlagen die militärische Integration in der NATO beruhe. französischen Außenminister Couve de Murville in Paris

Couve de Murville stellt fest, daß Frankreich erst nach Beilegung der EWG-Krise wieder an Verhandlungen des EWG-Ministerrats teilnehmen werde. Voraussetzung dafür sei eine Regelung der Agrarfinanzierung, des Prinzips der Mehrheitsentscheidungen, das ab dem 1 . Januar 1966 auch auf die Landwirtschafts- und Handelspolitik angewendet werden solle, sowie der Frage des Verhaltens der EWG-Kommission. Hinsichtlich der Kommission regt der französische Außenminister eine Überprüfung der „inzwischen gewonnenen guten oder schlechten Gewohnheiten" an, für die die geplante Fusion der Exekutiven eine gute Gelegenheit bieten würde. Bezüglich des Majoritätsprinzips befürwortet er eine Revision des EWG-Vertrags. Die Mehrheitsregelung sei nur dann anwendbar, wenn die beteiligten Staaten zu einer politischen Zusammenarbeit gefunden hätten, wie sie bereits 1960 von Frankreich vorgeschlagen worden sei. Den Hinweis von Schröder, daß das Majoritätsprinzip vernünftig gehandhabt werden müsse, weil eine Überstimmung einzelner Partner in wichtigen Fragen "sehr töricht" wäre, bezeichnet Couve de Murville als theoretisch. Es könne nicht darauf vertraut werden, $d a ß$ in Zukunft „keiner einem anderen schaden wolle“.

417 13.11. Abgeordneter Birrenbach an Bundesminister Schröder

Aus Gesprächen während seines Aufenthaltes in den USA vom 30. Oktober bis 10 . November 1965 zieht der CDU-Abgeordnete den Schluß, daß die amerikanische Haltung zur geplanten integrierten NATO-Atomstreitmacht unentschieden sei. Während Außenminister Rusk und Staatssekretär Ball das Projekt befürworteten, habe Verteidigungsminister McNamara die Position vertreten, daß die sowjetischen Mittelstreckenraketen durch das amerikanische nukleare Potential "gedeckt" seien und daher keine Notwendigkeit für ein neues Waffensystem bestehe. Als Gegenargumente seien zudem die ablehnende französische 
Haltung und der voraussichtliche britische Wunsch nach einem Vetorecht beim Einsatz der Streitmacht angeführt worden. Birrenbach betont, wie eng das Problem einer integrierten NATOAtomstreitmacht mit dem der Nichtverbreitung von Kernwaffen "verzahnt" sei. Abschließend weist er eindringlich darauf hin, daß es für eine zukünftige nukleare Mitsprache ausschlaggebend sein werde, den noch unentschlossenen Präsidenten Johnson bei den bevorstehenden deutsch-amerikanischen Gesprächen für die Position der Bundesregierung zu gewinnen.

Sattler erörtert die Gestaltung der Kulturbeziehungen zur UdSSR nach dem Auslaufen der unter dem Abkommen vom 30. Mai 1959 geschlossenen Vereinbarungen. Er plädiert dafür, zunächst keine Vorkehrungen für einen Kulturaustausch ohne vertragliche Grundlage zu treffen, um nicht das sowjetische Interesse am Abschluß einer neuen Vereinbarung zu mindern. Verhandlungen wären aussichtsreich, sobald die Alliierten sich damit einverstanden erklärten, daß Berlin (West) auch ohne ausdrückliche Klausel in alle Abkommen der Bundesrepublik einbezogen sein würde. Sollte jedoch trotz fehlenden Übereinkommens ein Kulturaustausch durchgeführt werden, so empfiehlt Sattler eine vom Auswärtigen Amt zu steuernde „Fall-zuFall-Regelung“ auf der Basis „strikter Reziprozität", die langfristige Planungen auf sowjetischer Seite unmöglich machen würde. Sattler schließt nicht aus, daß die UdSSR versuchen könnte, durch Einladung von Künstlern aus Berlin (West) „Propaganda für die Dreistaatentheorie“ $z u$ betreiben. Schröder

Groepper informiert über eine Unterredung mit dem sowjetischen Stellvertretenden Außenminister. Als wichtigsten Punkt hebt er hervor, daß Semjonow auf die Frage nach der Reaktion der sowjetischen Regierung auf die Schaffung einer integrierten NATO-Atomstreitmacht mit dem Hinweis auf „Gegenmaßnahmen" geantwortet habe. Der Botschafter sieht darin die Bestätigung einer in der Presse wiedergegebenen Äußerung des Ministerpräsidenten Kossygin, die UdSSR wolle im Falle der Gründung einer solchen Streitmacht andere sozialistische Staaten atomar ausrüsten. Keinerlei Bewegung habe sich in deutschlandpolitischen Positionen gezeigt. Die Frage, ob die UdSSR zu Entgegenkommen auf diesem Gebiet bereit sei, wenn die Bundesrepublik ihre Teilnahme an einer NATO-Atomstreitmacht zurückstelle, wurde von Semjonow verneint; er gab sogar zu verstehen, daß eine solche Verbindung „nach Erpressung“ aussehe. Nach Einschätzung von Groepper hoffe die sowjetische Regie-

\section{CLXXXVI}


rung offensichtlich, daß sich das Problem einer deutschen nuklearen Mitsprache „demnächst ohnehin und somit ohne jede Konzession ihrerseits“ erledigen werde.

Aus einer Unterredung des CDU-Abgeordneten Barzel mit der israelischen Außenministerin gibt Pauls wieder, daß sich Meir betont emotional über die besondere geschichtliche Verantwortung Deutschlands für die Sicherung der „bloßen Existenz“ Israels geäußert habe. Der Botschafter weist daher darauf hin, daß Israel im Falle enttäuschter Erwartungen hinsichtlich der Wirtschaftshilfe die Juden in New York und weltweit „mobil machen" könnte und die Bundesrepublik damit zum Nachgeben zwingen würde. Eine reduzierte Wirtschaftshilfe an Israel werde zudem kaum von arabischer Seite honoriert werden. Pauls schlägt vor, hinsichtlich der Leistungen für 1966 im Rahmen der Aktion "Geschäftsfreund" die Geheimhaltung aufzugeben und sich überdies an einem internationalen Projekt zur Entsalzung von Meerwasser zu beteiligen. Den arabischen Staaten könnten unter der Voraussetzung einer Verbesserung der Beziehungen zur Bundesrepublik ähnliche Hilfen in Aussicht gestellt werden.

Carstens schildert den „Fall Huyn“. Offensichtlich auf dem Wege einer Indiskretion gelangte die von Ministerialdirigent Frank auf einer Referentenbesprechung am 21. Oktober 1965 vertraulich mitgeteilte Information, Großbritannien sei ein Vorschlag zur Intensivierung der bilateralen Konsultationen unterbreitet worden, an Bundestagsabgeordnete. Diese wandten sich an das Auswärtige Amt mit der Frage, warum der Bundestag nicht vorab über den Abschluß des „Konsultationspakts“ unterrichtet worden sei. Alle Teilnehmer an der Besprechung - mit Ausnahme des Legationsrats Graf Huyn - erklärten schriftlich, keine Informationen weitergegeben zu haben. Als daraufhin erwogen wurde, Huyn vom Dienst zu suspendieren, bat dieser um seine sofortige Entlassung aus dem Beamtenverhältnis. Anschließend teilte er dem Auswärtigen Amt mit, er habe gegen den Konsultationsvorschlag so schwere Bedenken gehabt, daß er den CSU-Abgeordneten Freiherr zu Guttenberg gebeten habe, Bundeskanzler Erhard von dieser Entwicklung der Außenpolitik zu unterrichten. Carstens sieht darin lediglich Schutzbehauptungen, die einer Prüfung nicht standhielten. 

minister Wilson in London

Schröder bemerkt zur Situation in der EWG, über die auch Wilson Besorgnis äußert, daß Frankreich eine "ziemlich kräftige“ Änderung des EWG-Vertrags anstrebe, vor allem hinsichtlich des Majoritätsprinzips und der Aufgaben der EWG-Kommission. Bezüglich der Lage in der NATO rechnet Schröder damit, daß Frankreich bis 1969 eine Politik verfolgen werde, die den Schutz des Bündnisses beizubehalten gestatte. Es werde wohl zu langwierigen Gesprächen über eine Reform kommen. In diesem Zusammenhang stelle sich die Frage nach nuklearer Mitbestimmung bzw. nach einer NATO-Atomstreitmacht, die in absehbarer Zukunft entschieden werden müsse. Das Verhalten gegenüber Frankreich sollte durch eine „Kombination von Takt und Festigkeit" gekennzeichnet sein. Während die Möglichkeit einer französischen Beteiligung an einer nuklearen Integration der NATO erhalten bleiben solle, dürfe die Lösung der Probleme nicht nur unter dem Gesichtspunkt der französischen Wünsche gesehen werden. britischen Außenminister Stewart in London

Mit Blick auf Rhodesien äußert Stewart die Hoffnung, daß die weiße Minderheitsregierung nicht lange die Macht behalten werde, wenn sich möglichst alle Staaten den Wirtschaftssanktionen anschlössen. Auf die Frage nach der britischen Haltung zur nuklearen Integration der NATO antwortet Stewart, daß weiterhin das Modell einer ANF befürwortet werde. Schröder plädiert dagegen für eine Kombination von MLF und ANF, die sich aus Schiffen und U-Booten zusammensetzen solle und auch um eine französische Komponente erweitert werden könnte. In Abweichung vom ANF-Konzept schlage die Bundesregierung eine "Gesamtfinanzierung" der Streitmacht vor. Stewart begründet die britische Ablehnung der MLF damit, daß Frankreich vermutlich noch weniger zu einer Teilnahme bereit sein würde als im Fall einer ANF. Auf seiner bevorstehenden Reise nach Moskau wolle er sich auch über die sowjetische Haltung zur Nichtweitergabe von Kernwaffen informieren. Nach britischer Auffassung müsse vermieden werden, daß infolge von Diskussionen innerhalb der NATO Fortschritte in Richtung auf ein Nichtverbreitungsabkommen unterblieben. britischen Außenminister Stewart in London

Stewart äußert sich positiv zu der Anregung, die deutsch-britischen Konsultationen zu intensivieren und dabei „ein allzu formelles oder gar schwerfälliges Verfahren" zu vermeiden. Zum Thema der nuklearen Integration der NATO übergehend, 
bezeichnet er das "special committee“ als möglichen ersten Schritt zu einem Konsultationsgremium innerhalb der Allianz. Er bestätigt, daß mit dem Konzept einer ANF eine „Abgabe“ der britischen nationalen Streitkräfte an die NATO verbunden wäre. Der Einsatz der „Abschreckungswaffe“ müsse jedoch den USA vorbehalten bleiben, da Mehrheitsbeschlüsse gleichbedeutend mit einer Weitergabe von Kernwaffen wären. Während Stewart die militärische Notwendigkeit für eine MLF anzweifelt, hält Schröder eine gemeinsam neu zu errichtende Streitmacht für überzeugender als eine rein organisatorische Umgruppierung von Verbänden. Zudem seien die Waffensysteme, die in eine ANF eingebracht werden sollten, zur Abwehr der sowjetischen Mittelstreckenraketen ungeeignet. Stewart macht darauf aufmerksam, da $\beta$ es schwierig sein werde, der sowjetischen Regierung die Schaffung einer neuen Atomstreitmacht unter Beteiligung der Bundesrepublik als „Umorganisation“ zu erklären. Die NATO-Staaten dürften nicht dazu beitragen, ein Nichtverbreitungsabkommen zu verhindern, das wiederum Ausgangspunkt für weitere Vereinbarungen mit der UdSSR sein könne. Hinsichtlich der EWG stellt Stewart fest, daß Großbritannien dem Interesse an einem größeren europäischen Markt „genügend Ausdruck gegeben“ habe. der Finanzen

Lahr weist darauf hin, da $\beta$ in den Wirtschaftsverhandlungen mit Israel die Gefahr eines „Eklats“ drohe, wenn die auf israelischer Seite noch für 1965 erwartete und durch die Bundesregierung grundsätzlich gebilligte Wirtschaftshilfe in Höhe von 75 Millionen DM erst Anfang 1966 gezahlt würde, wie dies vom Bundesministerium der Finanzen aufgrund der Haushaltslage vorgeschlagen worden sei. Die Kreditanstalt für Wiederaufbau sei in der Lage, den Betrag vorzufinanzieren, wenn die Bundesregierung andere Fälligkeiten abdecke. Einem entsprechenden Antrag des Bundesministeriums für wirtschaftliche Zusammenarbeit an das Bundesministerium der Finanzen schließe sich das Auswärtige Amt an. Auswärtige Amt

Knappstein berichtet, daß aus amerikanischer Sicht das BerlinProblem nicht akut sei und daher während des bevorstehenden Besuchs des Bundeskanzlers Erhard in Washington nicht thematisiert werden solle. Die UdSSR habe diese Frage zugunsten der Beziehungen zu den USA zurückgestellt, und der Spielraum der DDR sei wegen ihrer zunehmenden wirtschaftlichen Abhängigkeit von der Bundesrepublik eingeschränkt. Der Botschafter hält fest, daß dem Wunsch der Bundesrepublik, das Verfahren 
über die Einbeziehung von Berlin (West) in Abkommen zu ändern, Verständnis entgegengebracht werde. Allerdings dürften die Rechte der Alliierten Kommandantur nicht beeinträchtigt werden.

Carstens faßt die Ergebnisse einer Ressortbesprechung über eine neue Passierschein-Vereinbarung zusammen. Es wurden Bedenken gegen eine Erklärung erhoben, die der Staatssekretär beim Ministerrat der DDR, Kohl, verlesen wolle. Darin werde gefordert, daß keine „Anschläge gegen den humanitären Geist dieses Abkommens" erfolgen dürften. Ferner wurde auf fehlende Verbesserungen gegenüber dem Verhandlungsstand vom August 1965 hingewiesen. Carstens selbst legte das Für und Wider einer Passierschein-Regelung unter außenpolitischen Gesichtspunkten dar und kam zu dem Schluß, daß ein negatives Votum nicht gerechtfertigt sei. Schröder

Groepper sieht in der aktuellen sowjetischen Pressekampagne gegen die Bundesrepublik keine grundsätzliche „Verhärtung“ der offiziellen Politik, sondern lediglich - und dies auch nur im Vergleich mit den letzten Monaten der Amtszeit des Ministerpräsidenten Chruschtschow - eine Verschärfung der Methode. Die Zielsetzung der sowjetischen Deutschland-Politik, nämlich die Festschreibung der Teilung, sei seit 1955 unverändert, und ihr dienten Bemühungen um „Normalisierung“ der Beziehungen ebenso wie „Hetz- und Diffamierungskampagnen“. Unter Hinweis auf frühere Krisen argumentiert Groepper, daß die jetzige sowjetische Regierung eher zurückhaltender vorgehe als Chruschtschow, da sie auf Mittel verzichte, die die Gefahr der Eskalation in sich trügen. Ziel der gegenwärtigen Kampagne der UdSSR sei offenbar, die amerikanischen und britischen Gegner einer nuklearen Integration der NATO zu stärken und die Bundesrepublik „so mürbe“ zu machen, daß sie von sich aus auf nukleare Mitsprache verzichte und einem Nichtverbreitungsabkommen beitrete.

Schlitter informiert über den griechischen Wunsch nach Erweiterung der Wirtschaftshilfe durch das OECD-Konsortium. Auch solle Frankreich gedrängt werden, sich an den Sitzungen des Assoziationsausschusses der EWG zu beteiligen, um die Angleichung der griechischen Landwirtschaft an die Gemeinschaft voranzutreiben. Der Botschafter berichtet weiterhin über ein Gespräch mit dem Abteilungsleiter im griechischen Außenmini- 
sterium, Tetenes, den er davon unterrichtete, daß die Bundesrepublik keine zusätzliche Finanzhilfe leisten könne. Tetenes verwies auf die "bedrohliche“ Wirtschaftslage und betonte, daß Griechenland stets die deutschlandpolitischen Positionen der Bundesrepublik unterstützt habe.

Im Hinblick auf die EWG-Krise stimmen Schröder und Rumor überein, daß im Rahmen des EWG-Vertrags weiterverhandelt werden müsse. Rumor spricht sich gegen bilaterale Gespräche aus und rät dazu, vor Erörterung der jüngsten französischen Vorschläge zunächst die Antwort Frankreichs auf die Einladung zu einer außerordentlichen Sitzung des EWG-Ministerrats abzuwarten. Bezüglich des Problems der nuklearen Teilhabe in der NATO hebt Schröder hervor, daß die Bundesrepublik und Italien eine gleichberechtigte Behandlung anstreben sollten. Nach seinen Gesprächen in Großbritannien befragt, betont er, in der Frage der nuklearen Integration der NATO habe es große Fortschritte gegeben; der britische Außenminister Stewart habe vor dem Unterhaus erklärt, er sei „zufrieden“ mit seinem deutschen Amtskollegen. Rumor macht darauf aufmerksam, daß die italienische Presse von fast völlig unterschiedlichen britischen und deutschen Positionen berichtet habe. Daran zeige sich, daß der Austausch vertraulicher Mitteilungen zwischen den Regierungen wichtig sei, um „derartige deformierte Wiedergaben“ $\mathrm{zu}$ berichtigen. Auswärtige Amt

Sachs berichtet über den in Vorbereitung der EWG-Ministerratstagung am 29./30. November 1965 gefaßten Beschluß der Ständigen Vertreter, ein Aide-mémoire zum weiteren Vorgehen gegenüber Frankreich vorzulegen, das entweder in Form eines Briefes der französischen Regierung zugeleitet oder im Rahmen des Kommuniqués veröffentlicht werden könne. Darin solle das Bedauern darüber ausgedrückt werden, daß Frankreich auf die Einladung zu einer außerordentlichen Ministerratssitzung nicht geantwortet habe, und herausgestellt werden, daß eine Lösung der Krise im Rahmen des EWG-Vertrags gefunden werden müsse. Änderungen des Vertrags oder des Majoritätsprinzips könne nicht zugestimmt werden. Sachs teilt ferner mit, daß die Minister politische Fragen unter Ausschluß der EWG-Kommission und des Ratssekretariats erörtern werden. 
432 23.11. Botschafter von Tannstein, Tunis, an das Auswärtige Amt

Tannstein informiert über Bemühungen zur Wiederaufnahme diplomatischer Beziehungen zwischen der Bundesrepublik und arabischen Staaten. Dem algerischen Botschafter in Tunis habe er mitgeteilt, daß die Bundesregierung einer entsprechenden Initiative Algeriens positiv gegenüberstehen würde. Allali habe sich zwar zurückhaltend geäußert, den Vorschlag jedoch persönlich befürwortet. Tannstein berichtet ferner von Andeutungen aus dem Umkreis des Präsidenten Bourguiba, daß wohl schon in absehbarer Zeit mehrere arabische Staaten, darunter auch der Libanon, Saudi-Arabien und Syrien, in dieser Frage an die Bundesregierung herantreten würden. Daraus schließt der Botschafter, daß die tunesische Regierung schon aus eigenem Interesse versuchen werde, Algerien zu einer Wiederaufnahme diplomatischer Beziehungen zu bewegen. an das Auswärtige Amt

Braun äußert Bedenken gegen den kanadischen Vorschlag, im Rahmen der UNO ein Konsortium zur Finanzierung der UNOTruppen auf Zypern zu gründen. Zwar befürwortet auch er eine festere finanzielle Grundlage für die Zypern-Aktion, sieht aber die Lösung des Problems darin, Staaten, die sich bisher noch nicht beteiligt haben, zu Zahlungen heranzuziehen. Ein Konsortium habe dagegen zur Folge, seine Mitglieder auf Beiträge festzulegen, die höher sein würden als die bisher freiwillig gezahlten. Braun weist darauf hin, daß die Leistungen der Bundesrepublik für die Zypern-Aktion ohnehin die von der UNO festgesetzte Quote überstiegen, und macht auf die größere politische Wirkung freiwilliger Zahlungen aufmerksam.

Krapf schildert die Konsultation in der Bonner Vierergruppe über die Passierschein-Vereinbarung vom 25. November 1965. Seitens des Auswärtigen Amts wurde erklärt, daß die neue Regelung Fragen des Berlin-Status und alliierte Interessen nicht berühre. Die Vertreter der Drei Mächte erhoben den Vorwurf, die Unterzeichnung der Vereinbarung sei so kurzfristig angesetzt worden, daß eine ordnungsgemäße Konsultation unmöglich gewesen sei. So sei die Alliierte Hohe Kommission nicht in der Lage gewesen, rechtzeitig die erforderliche Einwilligung zu geben. Krapf stellt dazu fest, daß dieser Vorfall erneut die Neigung der Drei Mächte zeige, ihre Vorbehaltsrechte in "dozierender Weise" wahrzunehmen. Dies sei um so unerfreulicher, als keine Einwände gegen den Inhalt der Vereinbarung bestanden hätten. 
Schröder informiert über die Probleme der Einbeziehung von Berlin (West) in Verträge der Bundesrepublik. Die bisherige Regelung, daß die Zugehörigkeit von Berlin (West) hinsichtlich des Geltungsbereichs eines Vertragstextes im Vertragstext „hinreichend klar" zum Ausdruck kommen müsse, habe z.B. Abkommen mit der Tschechoslowakei und der UdSSR verhindert. Dieses Verfahren solle dahingehend geändert werden, daß Berlin (West) als in alle Verträge der Bundesrepublik einbezogen gelte, sofern nicht seitens der Bundesregierung oder der Alliierten das Gegenteil erklärt werde. Eine solche Regelung hätte den Vorteil, die These von Berlin (West) als Land der Bundesrepublik zu stützen. Schröder bittet Erhard, in diesem Sinne mit den Alliierten weiterverhandeln zu dürfen.

\section{Lindenberg}

Meyer-Lindenberg faßt Beratungen der Nahost-Experten der NATO zusammen. Die Entwicklung im Nahen Osten im vergangenen halben Jahr werde als positiv für den Westen eingeschätzt. Die gemäßigten Kräfte seien stärker geworden, wenngleich Präsident Nasser weiterhin einen "Unruhefaktor" darstelle. Die Gefahr einer militärischen Auseinandersetzung mit Israel um das Jordanwasser habe sich verringert, und auch die UdSSR zeige in ihrer Nahost-Politik eine größere Zurückhaltung. Einigkeit habe darüber bestanden, daß den westlichen Interessen am besten durch Nichteinmischung in innerarabische Streitfragen gedient sei. Auswärtige Amt

Grewe informiert über die erste Sitzung des „special committee“ der NATO. Es wurden drei Arbeitsgruppen eingerichtet, von denen die für nukleare Planung die wichtigste sei. Sie solle wohl das verwirklichen, was der amerikanische Verteidigungsminister McNamara mit seinem Vorschlag vom Mai 1965 für ein "select committee" beabsichtigt habe. Nach „mühsamen" Verhandlungen wurde beschlossen, daß dieser Arbeitsgruppe neben den USA, Großbritannien, Italien und der Bundesrepublik auch die Türkei angehören solle. In der Sachdiskussion betonten McNamara und sein britischer Amtskollege Healey, das Hauptproblem liege in der Reaktion auf lokal begrenzte Angriffe, die die Allianz zum "selektiven und sich steigernden Einsatz" von Kernwaffen nötigen könnten. Während Healey die Ansicht vertrat, daß die Erarbeitung strategischer Konzeptionen Vorrang vor der Schaffung einer neuen Streitkraft habe, erklärten der 
italienische Verteidigungsminister Andreotti und Bundesminister von Hassel, das „special committee“ könne nicht eine integrierte NATO-Atomstreitmacht ersetzen.

Krapf legt dar, daß er gegenüber dem sowjetischen Geschäftsträger Kudrjawzew „aufs schärfste“ gegen einen Artikel des sowjetischen Journalisten Schukow in der Tageszeitung „Prawda" protestiert habe, weil Bundespräsident Lübke mit Verbrechen aus der Zeit der Herrschaft des Nationalsozialismus in einen „unmittelbaren“ Zusammenhang gebracht worden sei. Aufgrund dieser schweren Beleidigung und Verleumdung sei der sowjetischen Botschaft zudem eine Protestnote übersandt worden. Schröder

Pauls teilt mit, daß der Vorschlag der Bundesregierung über den Umfang zukünftiger Wirtschaftshilfe vom israelischen Kabinett als unzureichend empfunden werde. Vielleicht setze sich sogar die Position durch, daß Verhandlungen überhaupt abgelehnt werden sollten. Für diesen Fall befürchtet Pauls eine israelische Kampagne gegen die Bundesrepublik, die auch die in Großbritannien und den USA lebenden Juden einbeziehen würde. Ebenso könnten Informationen über die bisher im Rahmen der geheimgehaltenen Aktion „Geschäftsfreund“ gezahlten 650 Millionen DM publik gemacht werden. Dann habe die Bundesrepublik „die arabische Meute “ am Hals. Statt nach „fürchterlichem Wirbel" nachgeben zu müssen, sei es daher vorzuziehen, das vorliegende Angebot als einen Eröffnungsvorschlag für die Wirtschaftsverhandlungen zu bezeichnen und die israelische Regierung rechtzeitig über diese geänderte Auffassung zu informieren.

Lahr gibt ein Gespräch mit dem israelischen Botschafter am 29. November 1965 wieder. Ben Natan übermittelte die Antwort auf das Angebot der Bundesregierung für eine zukünftige Wirtschaftshilfe. Danach müsse vor allem das „Abkommen Adenauer/Ben Gurion" bis zum Gesamtbetrag von 2 Milliarden DM erfüllt werden. Gegenstand kommender Gespräche könne folglich nicht die Rate von 75 Millionen DM sein, die bereits Ende September 1965 fällig gewesen wäre, sondern das, was zusätzlich über diesen Betrag hinausgehe. Lahr legte demgegenüber dar, daß es sich bei der Absichtserklärung vom 14. März 1960 nicht um ein bindendes Abkommen gehandelt habe und die bislang geleisteten Zahlungen keiner „Automatik“ wie einem Fäl- 
ligkeitstermin unterworfen gewesen seien. Am 12. Mai 1965 habe Bundeskanzler Erhard sich von der israelischen These der "Zweigleisigkeit" distanziert und Verhandlungen über eine einheitliche Wirtschaftshilfe zugesichert. Lahr unterbreitete den persönlichen Vorschlag, die 75 Millionen DM noch 1965 als Vorleistung auf ein dann 1966 zu erzielendes Verhandlungsergebnis zu zahlen. Eine Fortsetzung der Zahlungen im Rahmen der geheimgehaltenen Aktion „Geschäftsfreund“, wie sie Ben Natan vorschlug, lehnte er ab. Auswärtige Amt

Blankenhorn informiert, daß politisch einflußreiche jüdische Persönlichkeiten entschlossen seien, die öffentliche Meinung in Großbritannien gegen eine Einbeziehung der von der Bundesrepublik zugesicherten Wiedergutmachungsleistungen in das Haushaltssicherungsgesetz für 1966 zu mobilisieren. Sie hätten ihm gegenüber die Ansicht vertreten, daß die auf Wahlgeschenken beruhende Haushaltskrise nicht auf Kosten der ,jüdischen Geschädigten" gelöst werden könne. Blankenhorn macht darauf aufmerksam, daß es für das Ansehen der Bundesrepublik günstiger sei, die geplanten Maßnahmen sofort rückgängig zu machen, als dem internationalen Druck nachgeben zu müssen.

Mit Blick auf die NATO-Ministerratstagung vom 14. bis 16 . Dezember 1965 wird das Ergebnis der Beratungen zur TTDFrage in der Bonner Vierergruppe dargelegt. Es wurde beschlossen, der - laut Beschluß des IOC künftig eigenständigen - DDROlympiamannschaft Temporary Travel Documents zu erteilen; ausgenommen seien jedoch Teilnehmer an nichtolympischen Wettkämpfen. Des weiteren sollten Stellvertretende Minister der DDR einreisen dürfen, da sie gewissermaßen die Funktionen von Abteilungsleitern wahrnähmen und es sich demnach nicht um Politiker, sondern um hohe Beamte handele. In der Frage der „Rentnerreisen“, die die DDR gestatte, wenn „SBZPässe" benutzt würden, sei Einigung erzielt worden, diese Papiere nicht anzuerkennen. Als Reisedokumente sollten außer Temporary Travel Documents vielmehr „besondere Blätter“ mit dem Visum und Angaben zur Person dienen.

Der Abrüstungsbeauftragte der Bundesregierung legt dar, da die geplante Einrichtung einer integrierten NATO-Atomstreitmacht aufgrund des internationalen Meinungsbildes und der mangelhaften Unterstützung des Projekts durch den Bundestag schwierig sei. Er schlägt vor, die Bundesregierung solle zwar 
eine Beteiligung an der nuklearen Ziel- und Einsatzplanung innerhalb der NATO anstreben, jedoch vorläufig den Wunsch nach Mitbesitz an einem integrierten Waffensystem zurückstellen. Sie solle sich bereit erklären, in einem Vertrag zur Regelung des Nuklearproblems auf den Erwerb von Kernwaffen zu verzichten und erst nach einer Wiedervereinigung einem Nichtverbreitungsabkommen beitreten zu wollen. Bundesministerium der Finanzen

Lahr befürwortet Verhandlungen mit Zypern über die Einrichtung einer Flugverbindung mit der Bundesrepublik - trotz der zyprischen Entscheidung, die Landerechte für die DDRFluggesellschaft "Interflug" um zwei Jahre zu verlängern. Die Bundesrepublik dürfe der DDR das Feld nicht endgültig überlassen, sondern solle "den Kampf" aufnehmen. Dabei müsse hingenommen werden, daß für eine gewisse Zeit zwei deutsche Luftfahrtgesellschaften die Insel anflögen. Habe es sich erst gezeigt, daß das Angebot der „Lufthansa“ das der „Interflug“ in den Schatten stelle, bestehe die Aussicht, daß sich Zypern in zwei Jahren zugunsten alleiniger Landerechte für die „Lufthansa" entscheiden werde. maligen amerikanischen Hohen Kommissar McCloy

McCloy teilt mit, daß in den USA die Abrüstungsbehörde sowie Teile von Senat und Presse einen Vertrag über die Nichtverbreitung von Kernwaffen befürworteten. Er selbst hält ein solches Abkommen für unnütz, da weder die UdSSR Kernwaffen weitergeben noch die Bundesrepublik über Atomwaffen verfügen wolle. Zudem gefährde es den Zusammenhalt in der westlichen Allianz und damit die Erfolge der Nachkriegspolitik. Die Bundesrepublik brauche für ihr Prestige nukleare Gleichberechtigung und Mitverantwortung. Diese Argumente solle Bundeskanzler Erhard offen und eindringlich gegenüber Präsident Johnson vorbringen, der zwar "nicht sehr“ für die MLF sei, jedoch der NATO und der Bundesrepublik „sympathisch" gegenüberstehe. Da die MLF allerdings im Augenblick nicht durchsetzbar sei, habe es wenig Sinn, an „Buchstaben oder früher diskutierten Lösungen" zu hängen.

Der Mitarbeiter der Abteilung für die Wahrnehmung der Interessen der Bundesrepublik Deutschland bei der französischen Botschaft informiert über den Besuch des CDU-Abgeordneten Gewandt in Bagdad. Von französischer Seite seien die inoffiziellen Gespräche mit dem Irak begrüßt worden. Der irakische 
Wirtschaftsminister Hilali habe gegenüber Gewandt die „mittelbare Schuld“ Deutschlands an der Gründung Israels aufgrund der Vertreibung und Ermordung der Juden hervorgehoben. Durch die Waffenlieferungen und die Aufnahme diplomatischer Beziehungen zwischen der Bundesrepublik und Israel seien alle deutschfreundlichen Araber beleidigt worden. Diese Verärgerung könne leichter überwunden werden durch eine Geste der Freundschaft seitens der Bundesregierung, wie etwa einer verstärkten Hilfe für palästinensische Flüchtlinge.

Frank faßt eine Unterredung des Bundesministers Schröder mit dem britischen Botschafter vom Vortag zusammen. Roberts teilte mit, daß der sowjetische Außenminister Gromyko in Moskau gegenüber seinem britischen Amtskollegen Stewart deutlich gemacht habe, daß die UdSSR jede Form eines Zugangs der Bundesrepublik zu Kernwaffen, sei es innerhalb einer integrierten Atomstreitmacht oder im Rahmen des "special committee“, entschieden ablehne. Während Stewart auf den legitimen Anspruch der nichtnuklearen NATO-Mitgliedstaaten auf atomare Teilhabe hingewiesen habe, sei von Gromyko betont worden, ein Zugang der Bundesrepublik zu Atomwaffen würde die Aussichten auf einen Vertrag über die Nichtverbreitung von Kernwaffen zunichte machen. Roberts fügte hinzu, aufgrund eines Gesprächs mit Ministerpräsident Kossygin habe Stewart dennoch den Eindruck erhalten, die "Tür" zu einem solchen Abkommen sei „nicht geschlossen worden“.

Harkort schildert Bemühungen einer italienischen Firmengruppe, den Auftrag zum Bau des Wasserkraftwerks „Mantaro“ in Peru zu erhalten, obwohl bereits ein deutsch-britisches Konsortium Liefervorverträge, die auch durch die Bundesregierung finanziell abgesichert seien, geschlossen habe. Die italienische Seite habe offensichtlich Kenntnis von dem deutsch-britischen Angebot erhalten und es daher unterbieten können. Trotz der Bemühungen des Auswärtigen Amts, auf diplomatischem Wege das Konsortium zu unterstützen, müsse damit gerechnet werden, daß eine Entscheidung zugunsten des italienischen Angebots oder einer öffentlichen Ausschreibung getroffen werde. Harkort schlägt vor, der peruanischen Regierung deutlich zu machen, daß ein solcher Beschluß auch die Entwicklungshilfe der Bundesrepublik für Peru beeinträchtigen könne. 

Auswärtige Amt

Knappstein berichtet, daß in den USA die Hoffnung, doch noch ein Abkommen über die Nichtverbreitung von Kernwaffen zu erreichen, gestiegen sei. Die UdSSR scheine erkannt zu haben, daß die Gefahr einer Weitergabe von Atomwaffen gerade außerhalb Europas durch ein Abkommen gebannt werde und eine gewisse Form der nuklearen Teilhabe das Risiko einer „echten“ Proliferation innerhalb der NATO, vor allem an die Bundesrepublik, verringern könne. Zwar seien die sowjetischen Äußerungen widersprüchlich, doch könne nicht ganz ausgeschlossen werden, daß die UdSSR künftig nur die Schaffung einer neuen Streitmacht im Sinne der MLF als unvereinbar mit einer vertraglichen Regelung bezeichnen und Entgegenkommen hinsichtlich des „special committee“ oder der ANF zeigen werde. Auswärtige Amt

Grewe teilt mit, daß der kanadische und der belgische Ständige Vertreter bei der NATO, Ignatieff und de Staercke, eine Deutschland-Initiative seitens des NATO-Ministerrats angeregt hätten. Er selbst habe darauf aufmerksam gemacht, daß vergleichbare Vorschläge der Bundesregierung bislang daran gescheitert seien, daß die drei Westmächte die Einführung von "Substanz" in die Verhandlungen forderten. Der britische Ständige Vertreter Shuckburgh und sein amerikanischer Kollege Cleveland hätten zwar erkannt, wie kompliziert dieses Problem sei, trotzdem habe Cleveland auf mögliche Vorteile eines Angebots "bedingungsloser" Verhandlungen hingewiesen. Grewe schließt nicht aus, daß sich in den USA ein Stimmungswandel zugunsten einer neuen Deutschland-Initiative anbahnen könnte. Auswärtige Amt

Grewe berichtet von einer „informellen Erörterung“ der Ständigen Vertreter bei der NATO über mögliche Hilfeleistungen an Griechenland und die Türkei. Es habe sich gezeigt, daß aufgrund der Zypern-Politik dieser beiden Staaten nur die USA und die Bundesrepublik zur Unterstützung bereit seien. Von amerikanischer und deutscher Seite sei die Zweckmäßigkeit weiterer Verteidigungshilfe mit der Notwendigkeit begründet worden, die Verteidigung der Süd-Ost-Flanke der NATO zu sichern und Griechenland sowie die Türkei an die Allianz zu binden. 

amerikanischen Botschafter McGhee

Schröder teilt mit, während seines Aufenthaltes vom 18. bis 20 . November 1965 in London habe er vom britischen Außenminister erfahren, daß immer noch der Vorschlag einer ANF favorisiert werde. Hinsichtlich des Verhältnisses zwischen Großbritannien und der EWG habe er gegenüber Stewart betont, daß alles, was getan werden könne, um den britischen Willen zur Mitarbeit auszudrücken, gut und nützlich sei. Mit einem neuen Antrag auf Beitritt sei jedoch in nächster Zukunft nicht zu rechnen. Zur geplanten zeitlichen Streckung von Wiedergutmachungsleistungen an Israel erklärt Schröder, angesichts der geringfügigen Verzögerung dürften die jüdischen Organisationen jetzt nicht „unangemessen pressen“. Die Denkschrift der Evangelischen Kirche in Deutschland sowie den Briefwechsel der deutschen und polnischen katholischen Bischöfe zur OderNeiße-Linie wertet er als Zeichen guten Willens, jedoch nicht als Indiz für einen politischen Wandel. Schröder

Groepper berichtet von einer Besprechung mit den Botschaftern der drei Westmächte. Erläutert wurde die Aussage des Ministerpräsidenten Kossygin, wenn die NATO der Bundesrepublik Zugang zu Atomwaffen verschaffe, werde die UdSSR nicht umhin können, der DDR die gleichen Möglichkeiten einzuräumen. Es bestand Einigkeit, daß die sowjetische Regierung das westliche Interesse an einem Nichtverbreitungsabkommen als Hebel benutzen wolle, um ein nukleares Mitspracherecht der Bundesrepublik zu verhindern. Es gebe in der UdSSR die Befürchtung, daß eine nuklear bewaffnete Bundesrepublik die DDR angreifen und somit einen Krieg zwischen den beiden Großmächten auslösen werde. Die Botschafter stimmten darin überein, daß der Westen einen „effektiven Zugang“ der Bundesrepublik zu Kernwaffen niemals zulassen werde; davon müsse auch die UdSSR überzeugt werden.

Aus Gesprächen mit Ministerpräsident Manescu und Außenminister Maurer zieht Lahr den Schluß, daß die Gründe für die schleppende Entwicklung der Familienzusammenführung in der rumänischen Unzufriedenheit über den Umfang der Handelsbeziehungen und in der unerwartet großen Zahl der Auswanderungswünsche seitens der deutschen Minderheit lägen; ein Junktim zwischen der Familienzusammenführung und einer Aufnahme diplomatischer Beziehungen gebe es dagegen nicht. Der rumänischen Regierung müsse klargemacht werden, 
daß Fortschritte im beiderseitigen Verhältnis ohne ein Entgegenkommen bei der Familienzusammenführung nicht erreichbar seien.

Amt

Werz berichtet, ein hoher Beamter des indonesischen Außenministeriums habe ihn im Auftrag des Heeres um Hilfeleistung für Indonesien gebeten. Er habe erwidert, daß zunächst Klarheit über den politischen Kurs Indonesiens bestehen müsse, bevor größere Kredithilfen zugesagt werden könnten. Daraufhin sei ihm zugesichert worden, daß die anti-kommunistische Ausrichtung konsequent fortgesetzt werde. Werz wies darauf hin, daß die Eröffnung eines indonesischen Generalkonsulats in OstBerlin jede Kreditgewährung unmöglich machen und zum Abbruch der Beziehungen führen würde. Auswärtige Amt

Carstens berichtet von der Debatte im Ministerkomitee des Europarates, die er selbst mit einer Darstellung der Beziehungen zu den osteuropäischen Staaten eröffnete. Zwar gebe es kein Entgegenkommen in der Frage der Wiedervereinigung, doch sei im Falle der Handelsabkommen mit Ungarn, Polen, Rumänien und Bulgarien die Einbeziehung von Berlin (West) gelungen. Zur Denkschrift der Evangelischen Kirche Deutschlands, zum Schreiben der polnischen Bischöfe und zur Antwort der deutschen Bischöfe äußerte er die persönliche Ansicht, daß sie „eindrucksvolle Zeugnisse “ für den in der Bundesrepublik wie in Polen vorhandenen Wunsch nach Versöhnung seien. Der österreichische Außenminister Kreisky stellte fest, daß der Prozeß der nationalen "Individualisierung" in Osteuropa fortschreite und sich die Kontakte zu westeuropäischen Staaten verstärkten. Dies sei jedoch kein Anzeichen für eine Demokratisierung.

Ungerer legt dar, der Leiter der „Direktion Sicherheitskontrolle“ der EURATOM-Kommission habe ihn am 9. Dezember 1965 darauf hingewiesen, daß es in den USA ein größeres Interesse an weltweiten Lösungen auf dem Gebiet der atomaren Sicherheitskontrolle als an einer Förderung der europäischen Kernindustrie gebe. Zur Wirksamkeit der EURATOM-Kontrollen teilte Fernand Spaak mit, daß es durchaus möglich sei, in Romans und Annecy - den beiden französischen Produktionsstätten, in denen Brennelemente sowohl für militärische als auch für friedliche Zwecke hergestellt würden - zu kontrollieren, ob für zivile Verwendung deklariertes Material militärisch genutzt werde. 
Spaak schilderte die Bemühungen um Zusammenarbeit zwischen IAEO und EURATOM. Ziel sei es, beide Organisationen „kompatibel“ zu machen, um gegenüber den USA darauf hinweisen zu können, daß keine Veranlassung bestehe, die EURATOM-Kontrollen durch solche der IAEO zu ersetzen.

\section{Klasse Luedde-Neurath}

Luedde-Neurath gibt Überlegungen aus einer Referentenbesprechung vom Vortag wieder, ob und in welchem Umfang die USA, die verschärfte Ausfuhrbestimmungen im Warenverkehr mit der Volksrepublik China befürworteten, über den angewachsenen China-Handel der Bundesrepublik in Kenntnis zu setzen seien. Es wurde festgestellt, daß aufgrund einer Vereinbarung vom Herbst 1965, in der sich die amerikanische Regierung bereit erklärte, über größere Geschäftsabschlüsse mit der DDR zu informieren, eine Unterrichtung wohl unumgänglich sei, doch sollten Mitteilungen nur im Rahmen der COCOM-Verpflichtungen und keineswegs über einzelne Geschäfte erfolgen. Auch lägen restriktivere Exportbestimmungen im China-Handel als Gegenleistung für Ausfuhrbeschränkungen in die DDR nicht im Interesse der Bundesrepublik. Allerdings müßten angesichts der amerikanischen Haltung im Handel mit der DDR "gewisse Rücksichten“ genommen werden. Auswärtige Amt

Carstens berichtet über einen deutschlandpolitischen Meinungsaustausch der vier westlichen Außenminister vom Vortag. Bundesminister Schröder hob hervor, daß die UdSSR eine „Entnuklearisierung" der Bundesrepublik sowie eine systematische "Aushöhlung“ der Beziehungen zwischen dem Bundesgebiet und Berlin (West) anstrebe. Der amerikanische Außenminister Rusk und der Staatssekretär im britischen Außenministerium, Gore-Booth, vertraten die Ansicht, daß die Volksrepublik China zur Zeit das größte Problem für die UdSSR darstelle. Die sowjetische Konzentration auf die Deutschland-Frage diene dazu, von dieser Tatsache abzulenken und das „unübersichtlich werdende Verhältnis" zu den osteuropäischen Staaten unter Kontrolle zu halten. Schröder teilte mit, im Falle einer Wiedervereinigung sei die Bundesrepublik hinsichtlich der Grenze zu Polen, des militärischen Status Gesamdeutschlands sowie wirtschaftlicher und finanzieller Leistungen zu "Opfern" bereit. Etwaige Verhandlungen mit der UdSSR müßten aufgrund der ViermächteVerantwortung für Deutschland jedoch gemeinsam mit den drei Westmächten geführt werden. 
460

14.12. Legationsrat I. Klasse Bock, Belgrad, an das Auswärtige Amt

Der Leiter der Abteilung für die Wahrnehmung der Interessen der Bundesrepublik Deutschland bei der französischen Botschaft teilt mit, daß während eines Arbeitsessens der Botschafter der NATO-Staaten in Belgrad der fehlende Informationsaustausch über die Gewährung von finanziellen und wirtschaftlichen Hilfen an Jugoslawien bedauert und der Wunsch nach möglichst vollständiger Unterrichtung geäußert wurde. Übereinstimmend wurde das große Interesse des Westens am Erfolg des spezifisch jugoslawischen Modells der "sozialistischen Marktwirtschaft" herausgestellt, um somit liberale Tendenzen in den Volkswirtschaften anderer osteuropäischer Staaten zu begünstigen.

461

15.12. Gespräch des Bundesministers Schröder mit dem amerikanischen Außenminister Rusk in Paris

Rusk regt eine westliche Erklärung zur Deutschland-Frage an, die weniger an die sowjetische Regierung gerichtet sei, sondern vielmehr der Öffentlichkeit im Westen und in den OstblockStaaten die Vorzüge einer deutschen Wiedervereinigung näherbringen solle. Die Teilung Deutschlands stelle das Hauptproblem im Verhältnis zwischen den militärischen Bündnissen und eine große Belastung für die Verteidigungshaushalte dar. Auf die Frage nach dem Verhältnis zu Polen antwortet Schröder, daß die polnische Regierung die Handelsvertretung in Warschau nicht als Partner für politische Gespräche betrachte und daher deren Handlungsspielraum einschränke. Das Schreiben der polnischen Bischöfe habe vornehmlich psychologische und keine kurzfristig politische Bedeutung. Rusk teilt mit, daß die USA ihr Engagement in Vietnam personell und finanziell verstärken müßten; dies werde die Diskussion über die Zahl der amerikanischen Truppen in Europa anregen. Für die bevorstehende Debatte im Kongreß wäre es daher nützlich, wenn die Bundesrepublik die Entsendung von technischem und medizinischem Personal nach Vietnam zusagen würde. Schröder entgegnet, daß ein „Dienst außerhalb der Bundesrepublik“ nicht angeordnet werden und daher nur auf der „Basis absoluter Freiwilligkeit“ erfolgen könne.

462

15.12. Gespräch des Bundesministers Schröder mit dem italienischen Schatzminister Colombo in Paris

Colombo berichtet über ein Gespräch, das er am 8. Dezember 1965 als Präsident des EWG-Ministerrats mit dem französischen Außenminister führte. Couve de Murville habe die Bereitschaft in Aussicht gestellt, dem EWG-Haushalt zuzustimmen, jedoch hinsichtlich der Zollsenkung um zehn Prozent, die zum 1. Januar 1966 in Kraft treten solle, ein Moratorium von zwei 
bis vier Monaten für weitere Beratungen vorgeschlagen. Ferner habe er die Möglichkeit einer französischen Teilnahme an einer außerordentlichen EWG-Ministerratstagung in Luxemburg angedeutet. Der Hinweis von Colombo, eine Einladung der französischen Regierung könne von deren Zustimmung zum EWGHaushalt und zur Zollsenkung abhängig gemacht werden, stößt bei Schröder auf Skepsis. Zu den Personalfragen bemerkt Colombo, daß Frankreich dieses Thema anläßlich der Fusion der Exekutiven anschneiden werde und wahrscheinlich an die Einführung eines Rotationsprinzips in der EWG-Kommission denke.

Ministerialdirektor Sattler unterbreitet Vorschläge für einen Kulturaustausch mit der UdSSR nach Auslaufen der Vereinbarungen vom 30. Mai 1959. Da aufgrund der sowjetischen Ablehnung einer Berlin-Klausel kein neues Abkommen abgeschlossen werden könne, sollten kulturelle Spitzenorganisationen bzw. die "Zentrale Austauschstelle Bonn“ des Auswärtigen Amts die Organisation übernehmen. Es sei auf möglichst weitgehende Reziprozität und einen „ausgeglichenen Saldo“ zwischen deutschen und sowjetischen Veranstaltungen zu achten. Dieses Verfahren gestatte der UdSSR, ohne Vereinbarung mit der Bundesregierung in Berlin (West) kulturell präsent zu sein. Ein Boykott, wie vom Berliner Senatsdirektor Hartkopf befürchtet, sei unwahrscheinlich. Die sowjetische Seite, so Legationsrat I. Klasse Peckert, sei durchaus bereit, Berlin (West) faktisch einzubeziehen, solange dies ihre politische Position nicht präjudiziere. Hartkopf betont dennoch die Notwendigkeit einer geregelten Teilhabe von Berlin (West). Sattler erwägt eine Beendigung des Kulturaustauschs in ein bis zwei Jahren, falls die Einbeziehung der Stadt nicht gelingen sollte.

Ruete befaßt sich mit der Übernahme von $\mathrm{Paß}$ - und Sichtvermerksbefugnissen durch die Handelsvertretung in Bukarest bzw. die rumänische Handelsvertretung in Frankfurt/Main. Im Oktober 1963 sei vereinbart worden, die Ausübung solcher Befugnisse "stillschweigend" zu dulden. Im Verlauf des Jahres 1965 habe die rumänische Regierung der Handelsvertretung der Bundesrepublik das Recht zur Ausstellung und Verlängerung von Pässen sowie jegliche Zuständigkeit für Berlin (West) abgesprochen und nur die Ausgabe von Visa zugestanden. Inzwischen habe sie erkennen lassen, daß keine Einwände gegen Sichtvermerksbefugnisse auch für Berlin (West) bestünden, die Paßbefugnisse sich jedoch auf die Reisedokumente von Personen aus dem Bundesgebiet beschränken müßten. Dies hält Ruete für nicht hinnehmbar. Es müsse darauf bestanden werden, daß auch Pässe von Reisenden aus Berlin (West) und aus 
der DDR bearbeitet werden könnten. Die rumänische Regierung solle in einem „vorsichtig“ geführten Gespräch davon überzeugt werden, daß es in der Praxis der $\mathrm{Pa}$ - und Visaerteilung nicht zu Konflikten kommen werde. amerikanischen Außenminister Rusk in Washington

Zur Lage der EWG legt Erhard dar, daß sich Lösungen der Agrarfinanzierung andeuteten. Mit Blick auf die westliche Allianz führt Rusk aus, daß der von französischer Seite geäußerten Auffassung entgegenzuwirken sei, der NATO-Vertrag müsse 1969 neu verhandelt werden. Das Bündnis könne nicht durch bilaterale Vereinbarungen ersetzt werden. Sollte sich Frankreich zurückziehen, so werde dies keine Folgen für den Fortbestand der NATO haben. Zur Arbeit im "special committee“ äußert sich Rusk optimistisch; die Probleme der Bundesrepublik würden dort in vollem Umfang berücksichtigt. Erhard versichert, die Bundesregierung werde sich in ihrer Haltung zur NATO nicht durch Frankreich beeinflussen lassen. Für Staatspräsident de Gaulle seien Integration und Supranationalität "wesensfremd“; Frankreich habe sich ja aus diesem Grund auch aus der EWG zurückgezogen. Der amerikanische Verteidigungsminister weist auf die aus dem Vietnam-Konflikt resultierenden Belastungen für die Wirtschaft der USA hin. Der Kongreß werde im Januar 1966 „bohrende Fragen“ nach der Unterstützung durch die Verbündeten stellen. Es bestehe daher der Wunsch, so McNamara, dieses Problem mit den Alliierten „eingehender als bisher" zu erörtern. Johnson in Washington

Erhard betont, für den Fall, daß eine Wiedervereinigung in realistische Nähe rücke, bestehe Gesprächsbereitschaft über Themen wie die Grenze zu Polen und den nuklearen Status Deutschlands. Zur Frage der nuklearen Teilhabe in der NATO bekundet Johnson Unverständnis, daß einige Staaten trotz der Stärke der Allianz eine zusätzliche Organisation wünschten. Großbritannien scheine ein „Spielzeug mit U-Booten“ zu wollen, und die Bundesrepublik glaube wohl, Geld "loswerden" zu müssen. Erhard überreicht eine Aufzeichnung über die Konzeption einer integrierten Atomstreitmacht. Er führt aus, daß nur eine multilaterale Lösung die Abschreckungskraft der NATO erhöhe. Es müsse deutlich werden, daß eine „umfassendere nukleare Verantwortung" im Entstehen sei. Die Zustimmung der Bundesregierung zu einem Abkommen über die Nichtverbreitung von Kernwaffen setze eine Klärung dieser Frage voraus. Erhard macht auch auf die politische Dimension aufmerksam und verweist auf eine Bemerkung des Staatspräsidenten de 
Gaulle, wonach ein Staat ohne das Recht auf Mitsprache bei der Verteidigung des eigenen Territoriums über keine echte Souveränität verfüge. Abschließend sprechen sich Johnson und Erhard für eine engere Zusammenarbeit auf dem Gebiet der Raumfahrt aus. Washington

Der amerikanische Außenminister Rusk dementiert Meldungen über Friedensfühler der Vietcong. Die nordvietnamesische Regierung beharre vielmehr auf der Erfüllung ihres VierPunkte-Programms, von dem zumindest der geforderte amerikanische Rückzug aus der Republik Vietnam (Südvietnam) unannehmbar sei. Der amerikanische Verteidigungsminister erläutert dann das personelle und materielle Engagement der USA in Vietnam. Er schließt ein Eingreifen der Volksrepublik China solange aus, wie es den USA nicht um eine Niederwerfung der Demokratischen Republik Vietnam (Nordvietnam), sondern nur um die Wiederherstellung der „Freiheit Südvietnams" gehe. Zu den NATO-Problemen führt McNamara aus, $\mathrm{daß}$ auch im Falle einer „radikalen“ französischen Entscheidung die volle Einsatzfähigkeit des Bündnisses erhalten bliebe; das elektronische und logistische System könne außerhalb Frankreichs wiederaufgebaut werden. Zur EWG-Krise führt Bundesminister Schröder aus, daß ein Kompromiß gefunden werden müsse, der den „vitalen Fragen“ Rechnung trage, dem EWGVertrag jedoch nichts Wesentliches - wie etwa das Majoritätsprinzip - nehme. in Washington

Zur Fortführung der Planungen für eine nukleare Integration der NATO plädiert der amerikanische Außenminister für geheime Gespräche zwischen den USA, der Bundesrepublik und Großbritannien. Er spricht sich gegen den Vorschlag des Bundesministers Schröder aus, zunächst zu einer deutsch-amerikanischen Verständigung zu kommen, bevor der Kontakt mit weiteren Bündnispartnern gesucht werde. Schröder erläutert, der britische ANF-Vorschlag sei zur Grundlage des den USA gerade übergebenen Memorandums gemacht worden, obwohl nach Auffassung der Bundesregierung die MLF das bessere System sei, da es die „überzeugendere Abschreckungswirkung “ darstelle. Bei der Überführung des britischen Nuklearpotentials in die NATO sei ausschlaggebend, daß dieses zuvor einem gemeinsamen Waffensystem innerhalb des Bündnisses unterstellt werde. Rusk weist darauf hin, daß die Bundesrepublik de facto bereits über ein weitgehendes Mitspracherecht hinsichtlich des Einsatzes von Atomwaffen verfüge. 

Johnson in Washington

Johnson äußert sich zustimmend zur deutschen Aufzeichnung über den Aufbau einer integrierten NATO-Atomstreitmacht. Im Rahmen des Offset-Abkommens erwarteten die USA Aufträge seitens der Bundesrepublik in Höhe von 100 Millionen Dollar bis zum 1. Januar 1966. Der Präsident verweist auf den durch den Vietnam-Konflikt angewachsenen Verteidigungshaushalt und betont, er wisse sonst nicht, wie "alles“ weitergehen solle. Erhard erwidert, das Abkommen sei Teil der deutsch-amerikanischen Zahlungsbilanz, die für die USA "stark aktiv" sei. Er könne die gewünschte Zusage nicht abgeben, da im Bundeshaushalt "kein Pfennig mehr manipulierbar" sei. Unter Hinweis auf die Notwendigkeit, im kommenden Jahr die Zahl amerikanischer Soldaten in Vietnam zu verdoppeln, und mit der Zusicherung, keine Truppen aus der Bundesrepublik nach SüdostAsien zu verlegen, bittet Johnson nachdrücklich um die Entsendung einer Sanitätseinheit der Bundeswehr von 200 Mann und eines 1000 Mann starken Baubataillons nach Vietnam. (EWG/EAG)

Sachs berichtet über die Besprechung der EWG-Außenminister in Schloß Val Duchesse. Der Präsident des Ministerrats, Colombo, informierte über seine Gespräche mit dem französischen Außenminister in Rom. Couve de Murville habe für seine Person Entgegenkommen bezüglich des Agrarhaushalts und einer französischen Teilnahme an einer außerordentlichen Ministerratstagung in Luxemburg gezeigt. Er habe kritisiert, daß sich die EWG-Kommission als „europäische Regierung“ geriere, und gefordert, daß sie politisch bedeutsame Vorschläge erst nach Rücksprache mit den nationalen Regierungen unterbreite. Colombo berichtete weiter, er habe Couve verdeutlicht, daß die übrigen EWG-Mitgliedstaaten am Prinzip der Mehrheitsentscheidungen festzuhalten beabsichtigten. Der belgische Außenminister Spaak stellte fest, daß eine positive französische Haltung zu den Zoll- und Budgetfragen durch die Bereitschaft der übrigen EWG-Staaten zu einer Ministerratstagung unter Ausschluß der Kommission in Luxemburg gefördert werden könnte. Staatssekretär Lahr stimmte einer solchen Zusammenkunft zu, auf der über das Majoritätsprinzip und die Rolle der EWG-Kommission gesprochen werden sollte.

471

20.12. Vortragende Legationsrätin I. Klasse von Puttkamer an das Bundesministerium für Wirtschaft

Vor dem Hintergrund der Beratungen auf der Konferenz über eine Kontrolle von Kernmaterial-Ausfuhren durch die Internationale Atomenergie-Organisation (IAEO) vom 22. bis 24. Juni 
1965 in London übermittelt Puttkamer den Vorschlag für eine Stellungnahme der Bundesregierung. Es wird angeregt, daß sich die exportierenden Staaten gegenseitig über Lieferungen von nuklearem Material unterrichten sollten, nicht jedoch über gewährte finanzielle Hilfen. Zwar dürften nach deutschem Recht weder die Vertragspartner noch Einzelheiten der Lieferung genannt werden, jedoch sei die Bundesregierung bereit, die für wirksame Kontrollen erforderlichen Änderungen am Außenwirtschaftsgesetz vorzunehmen. Dementiert wird die von Südafrika aufgestellte Behauptung, daß die Bundesrepublik nun die UdSSR in den Kreis der auf der Londoner Konferenz vertretenen Exportstaaten einbezogen sehen wolle. Meyer-Lindenberg

Meyer-Lindenberg resümiert Gespräche, die er und Vortragender Legationsrat I. Klasse Schirmer am 14./15. Dezember 1965 in Paris mit dem ägyptischen Botschafter Naggar und Botschaftsrat Charaf führten. Es bestand Einvernehmen, daß eine Wiederaufnahme diplomatischer Beziehungen erst nach Wiederherstellung des politischen Vertrauens möglich sein würde. Dieser Prozeß, bei dem es keine politischen oder wirtschaftlichen Bedingungen geben dürfe, solle in Etappen erfolgen, von denen die erste - die Aufnahme von Gesprächen auf persönlicher Basis - bereits erreicht sei. Weiterhin seien einseitige Maßnahmen zur Verbesserung der politischen Atmosphäre sinnvoll. Die ägyptischen Gesprächspartner verwiesen auf jüngste deutschlandpolitische Erklärungen des Präsidenten Nasser und schlugen ein Vorgehen gegen ägyptische Emigrantenorganisationen in der Bundesrepublik vor. Die Anregung, Nasser eine Zusammenstellung der an Israel gelieferten Waffen zukommen zu lassen, wurde von Schirmer unter dem Hinweis, ein „Wiederaufwärmen“ des „Waffenkomplexes“ könne nur schaden, abgelehnt.

Ruete informiert über die NATO-Ministerratssitzung vom 14 . bis 16. Dezember 1965 in Paris. Die Partner seien bemüht gewesen, eine Verschärfung der Gegensätze mit Frankreich zu vermeiden. Eine lebhafte Debatte habe es über das „special committee" gegeben, in dem Frankreich nicht vertreten sei, weil es selbst keine nuklearen Informationen zur Verfügung stellen wolle. Da es sich nun von der Diskussion ausgeschlossen sehe, habe der französische Außenminister Couve de Murville versucht, einen Beschluß über die Beendigung der Tätigkeit des "special committee“ Mitte 1966 herbeizuführen. Dies hätten die NATO-Partner jedoch abgelehnt. Als positive Ergebnisse der Konferenz wertet Ruete, daß der Wille zum Festhalten an der 
NATO ausdrücklich unterstrichen worden sei und sich der NATO-Ministerrat erneut für eine Lösung der DeutschlandFrage auf der Grundlage des Selbstbestimmungsrechts ausgesprochen habe.

Lahr gibt zwei Unterredungen mit dem israelischen Botschafter wieder. Am 13. Dezember 1965 habe Ben Natan als Voraussetzung für die Aufnahme von Wirtschaftsverhandlungen eine schriftliche Bestätigung der israelischen Auslegung des „Abkommens Adenauer/Ben Gurion“ vom 14. März 1960 verlangt. Nachdem dies abgelehnt worden sei, habe Ben Natan am 22. Dezember 1965 auf eine solche Vorbedingung verzichtet und den Beginn der Gespräche für Januar 1966 vorgeschlagen. Die Bundesrepublik solle jedoch möglichst bald für 1965 weitere 75 Millionen DM zahlen - nach einer ersten Leistung in gleicher Höhe, die im Rahmen der geheimgehaltenen Aktion "Geschäftsfreund" bereits im Juni 1965 erfolgt sei. Israel wolle auch diese zweite Zahlung nicht publik machen, werde aber für 1965 keine Forderungen mehr stellen. Lahr empfiehlt daher, die Summe von 150 Millionen DM als „Präjudiz“ für 1966 anzusetzen.

Ruete faßt eine Mitteilung des CDU-Abgeordneten Blumenfeld über dessen Gespräche in Prag zusammen: Die tschechoslowakische Regierung wolle bestehende Schwierigkeiten in den Verhandlungen - auch im Hinblick auf den Geltungsbereich eines Handelsabkommens sowie einer Vereinbarung über den Austausch von Handelsvertretungen - überwinden. Eine Erklärung der Bundesregierung zum Münchener Abkommen von 1938 sei nicht als Vorbedingung für den Abschluß einer Vereinbarung genannt worden. Ein Entgegenkommen in dieser Frage könnte jedoch dazu beitragen, letzte Hindernisse bei der Einbeziehung von Berlin (West) aus dem Weg zu räumen. Ruete schlägt vor, weitere Vorbesprechungen mit der Vertretung tschechoslowakischer Außenhandelsgesellschaften in Frankfurt/Main zu führen und nach Einigung über die wesentlichen Fragen die Verhandlungen wieder aufzunehmen.

Carstens teilt mit, wie er den französischen Botschafter Seydoux über den Besuch des Bundeskanzlers am 20./21. Dezember 1965 in Washington unterrichtet habe. Erhard habe wirtschaftliche und medizinische Unterstützung für die südvietnamesische Regierung in Aussicht gestellt. Der Beitritt der Bundesrepublik zu einem Nichtverbreitungsabkommen sei von einer Lösung der nuklearen Probleme in der NATO abhängig gemacht worden, zu einer Absprache hinsichtlich einer integrierten 
NATO-Atomstreitmacht sei es allerdings nicht gekommen. Schließlich habe Erhard darauf hingewiesen, daß die Verhandlungen der Kennedy-Runde angesichts des Auslaufens des Trade Expansion Act am 30. Juni 1967 beschleunigt werden müßten, wenn nicht eine „einzigartige“ Chance für den Abbau von Handelsschranken verlorengehen solle. Amt

Groepper gibt Informationen über eine Unterredung des amerikanischen Botschafters in Moskau mit dem sowjetischen Außenminister weiter. Die Frage von Kohler, ob eine Konsultation der Bundesrepublik durch die USA über atomare Fragen von der UdSSR bereits als Zugang zu Atomwaffen gewertet werde, habe Gromyko bejaht. Der Außenminister habe sich für die Fortsetzung von Verhandlungen über die Nichtverbreitung ausgesprochen, jedoch betont, daß die sowjetische Gesprächsbereitschaft beendet wäre, wenn der Bundesrepublik der Weg zu Kernwaffen eröffnet würde. Auswärtige Amt

Knappstein berichtet von einer Unterredung mit dem amerikanischen Sonderbotschafter Thompson. Dieser unterrichtete ihn über einen sowjetischen Vorschlag zum Austausch von Manöverbeobachtern zwischen NATO und Warschauer Pakt bzw. zwischen USA und UdSSR. Als seine persönliche Ansicht erklärte Knappstein, daß der Bundesregierung vermutlich ein Austausch von Beobachtern zwischen den Bündnissen „keineswegs

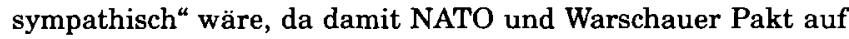
eine Stufe gestellt würden. Zudem stelle sich die Frage der Teilnahme von Offizieren aus der DDR. Zu einem bilateralen amerikanisch-sowjetischen Austausch äußerte Knappstein die Vermutung, daß die militärischen Erkenntnisse in keinem Verhältnis zu dem politischen Schaden stünden, der durch ein Wiederaufleben von Gerüchten um ein „Zusammenspiel“ von USA und UdSSR in Europa hervorgerufen würde.

Osterheld faßt Gespräche des Bundeskanzlers vom 20. Dezember 1965 mit Persönlichkeiten des amerikanischen öffentlichen Lebens in Washington zusammen. Die Vertreter der jüdischen Organisation „B'nai Brith“ setzten sich für eine Ausweitung der Wirtschaftshilfe an Israel ein und äußerten Sorge über eine Kürzung der Wiedergutmachungsleistungen. Erhard sicherte zu, daß in „Härtefällen“ Regelungen gefunden würden. Der ehe- 
malige Außenminister Acheson befürwortete eine nukleare Teilhabe der Bundesrepublik. Für ein Abkommen über die Nichtverbreitung von Kernwaffen sollten keine Zugeständnisse an die UdSSR gemacht werden. Zur Wiedervereinigung Deutschlands bemerkte Acheson, daß die Bundesregierung die Initiative übernehmen müsse. An dem Thema interessiert seien nur noch die USA und die Bundesrepublik. Es solle daher "unauffällig" versucht werden, über die schlechte britische Finanzlage, die ohne Hilfe aus der Bundesrepublik wohl nicht gefestigt werden könne, das Engagement Großbritanniens wieder zu wecken. minister Schröder

Duckwitz plädiert für eine Wende in der Deutschland- und Ostpolitik, da die bisherige Linie des Antikommunismus das Ziel der Wiedervereinigung nicht nähergebracht habe. Um die notwendige Zustimmung der UdSSR zu einer Überwindung der Teilung zu erreichen, müsse vor allem ihren Interessen Rechnung getragen werden. Daher solle der UdSSR ein Friedensund Freundschaftsvertrag mit einem wiedervereinigten Deutschland sowie großzügige wirtschaftliche Hilfe angeboten werden. Auf militärischem Gebiet müßten die Sicherheitsbedürfnisse aller osteuropäischen Staaten gegen "tatsächliche

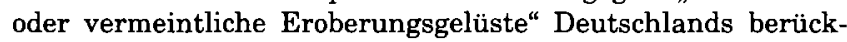
sichtigt werden. Die Schaffung einer atomwaffenfreien Zone in Mitteleuropa sei aus diesem Grund überlegenswert, die Zugehörigkeit eines wiedervereinigten Deutschlands zur NATO „undenkbar“. Duckwitz rät ferner dazu, die ohnehin nicht mehr revidierbare Oder-Neiße-Linie anzuerkennen und eine Ungültigkeitserklärung zum Münchener Abkommen von 1938 abzugeben. Hinsichtlich der Beziehungen zu den westlichen Verbündeten mißt er den USA eine „überragende Rolle“ zu, fordert aber auch eine engere Zusammenarbeit mit Großbritannien. Das Verhältnis zu Frankreich werde dagegen unter Staatspräsident de Gaulle, der der Bundesrepublik einen „inferioren Platz“ zugedacht habe, problematisch bleiben, überhaupt sei der deutschfranzösische Vertrag von 1963 ein Fehler gewesen. 


\section{Literaturverzeichnis}

AAPD 1963

AAPD 1964

AChter Gesamtbericht 1964/65

ADAP, D, II

AdenaUtr, Erinnerungen II

ADENAUER, Erinnerungen IV

AdG

AlPHAND, L'étonnement

AMTSBLATT DER EUROPÄISCHEN

GEMEINSCHAFTEN

L'Année Polttique 1959

L'Année Politique 1963

L'Année Politique 1964
Akten zur Auswärtigen Politik der Bundesrepublik Deutschland, Bde. I-III, hrsg. im Auftrag des Auswärtigen Amts vom Institut für Zeitgeschichte, bearbeitet von Rainer A. Blasius, Mechthild Lindemann und Ilse Dorothee Pautsch, München 1994.

Akten zur Auswärtigen Politik der Bundesrepublik Deutschland, Bde. I-II, hrsg. im Auftrag des Auswärtigen Amts vom Institut für Zeitgeschichte, bearbeitet von Rainer A. Blasius, Wolfgang Hölscher und Daniel Kosthorst, München 1995.

Achter Gesamtbericht über die Tätigkeit der Gemeinschaft (1. April 1964 - 31. März 1965), hrsg. von der Kommission der Europäischen Wirtschaftsgemeinschaft, [Brüssel] 1965.

Akten zur deutschen auswärtigen Politik 19181945. Serie D (1937-1945). Bd. II: Deutschland und die Tschechoslowakei (1937-1938), BadenBaden 1950.

Konrad Adenauer, Erinnerungen 1953-1955, Stuttgart 1966.

Konrad Adenauer, Erinnerungen 1959-1963. Fragmente, Stuttgart 1968.

Archiv der Gegenwart (bis 1955: Keesing's Archiv der Gegenwart), zusammengestellt bzw. begründet von Heinrich von Siegler, $1931 \mathrm{ff}$.

Hervé Alphand, L'étonnement d'être. Journal 1939-1973, [Paris] 1977

Amtsblatt der europäischen Gemeinschaften (EGKS, EWG, Euratom), Brüssel 1958 ff.

L'Année Politique 1959. Revue chronologique des principaux faits politiques diplomatiques, économiques et sociaux de la France et de la Communauté et bilan des organisations européennes du 1er janvier au 31 décembre 1959 , Paris 1960.

L'Année Politique économique, sociale et diplomatique en France 1963, Paris 1964.

L'Année Politique économique, sociale et diplomatique en France 1964, Paris 1965. 
AUSSENPOLITIK DER DDR I

AUSSENPOLITIK DER DDR II

AUSSENPOLITIK DER DDR VII

AUSSENPOLITIK DER DDR XI

AUSSENPOLITIK DER DDR XII

AUSSENPOLITIK DER DDR XIII

BEMUUHUNGEN I
Dokumente zur Außenpolitik der Regierung der Deutschen Demokratischen Republik, Bd. I: 7. Oktober 1949 bis 25. März 1954, hrsg. vom Deutschen Institut für Zeitgeschichte, Berlin (Ost) 1954.

Dokumente zur Außenpolitik der Regierung der Deutschen Demokratischen Republik, Bd. II: 25. März 1954 bis 14. Mai 1955, hrsg. vom Deutschen Institut für Zeitgeschichte, Berlin (Ost) 1955 .

Dokumente zur Außenpolitik der Regierung der Deutschen Demokratischen Republik, Bd. VII: 1. Januar bis 31. Dezember 1959, hrsg. vom Deutschen Institut für Zeitgeschichte, Berlin (Ost) 1960.

Dokumente zur Außenpolitik der Regierung der Deutschen Demokratischen Republik, Bd. XI: 1. Januar bis 31 . Dezember 1963, hrsg. vom Deutschen Institut für Zeitgeschichte und vom Institut für Internationale Beziehungen in der Deutschen Akademie für Staats- und Rechtswissenschaft "Walter Ulbricht", Berlin (Ost) 1965.

Dokumente zur Außenpolitik der Regierung der Deutschen Demokratischen Republik 1964. Bd. XII, hrsg. vom Institut für Internationale Beziehungen an der Deutschen Akademie für Staatsund Rechtswissenschaft "Walter Ulbricht" in Zusammenarbeit mit der Abteilung Rechts- und Vertragswesen des Ministeriums für Auswärtige Angelegenheiten der Deutschen Demokratischen Republik, Berlin (Ost) 1966.

Dokumente zur Außenpolitik der Regierung der Deutschen Demokratischen Republik 1965. Bd. XIII, hrsg. vom Institut für Internationale Beziehungen an der Deutschen Akademie für Staats- und Rechtswissenschaft "Walter Ulbricht" in Zusammenarbeit mit der Abteilung Rechts- und Vertragswesen des Ministeriums für Auswärtige Angelegenheiten der Deutschen Demokratischen Republik, Berlin (Ost) 1969.

Die Bemühungen der Bundesrepublik um Wiederherstellung der Einheit Deutschlands durch gesamtdeutsche Wahlen. Dokumente und Akten, I. Teil: Oktober 1949-Oktober 1953, hrsg. vom Bundesministerium für gesamtdeutsche Fragen, 4. Auflage, Bonn 1958. 
BIRRENBACH, Sondermissionen

BLANKENHORN, Verständnis

BONN-WARSCHAU

BT ANLAGEN

BT Stenographische Berichte

BULLETIN

BULLETIN DER EWG

CARSTENS, Erinnerungen

Charter of the United Nations

Couve de Murville, Politique Étrangère

Department of State Bulletin

Deutsch-isRaelischer Dialog I/1

DocUments on Disarmament 1945-1959

Documents on Disarmament 1961
Kurt Birrenbach, Meine Sondermissionen. Rückblick auf zwei Jahrzehnte bundesdeutscher Außenpolitik, Düsseldorf/Wien 1984.

Herbert Blankenhorn, Verständnis und Verständigung. Blätter eines politischen Tagebuchs 1949 bis 1979, Frankfurt a.M./Berlin/Wien 1980.

Bonn-Warschau 1945-1991. Die deutsch-polnischen Beziehungen. Analyse und Dokumentation, hrsg. von Hans-Adolf Jacobsen und Mieczyslaw Tomala, Köln 1992.

Verhandlungen des Deutschen Bundestages. Anlagen zu den Stenographischen Berichten, Bonn $1950 \mathrm{ff}$.

Verhandlungen des Deutschen Bundestages. Stenographische Berichte, Bonn $1950 \mathrm{ff}$.

Bulletin des Presse- und Informationsamtes der Bundesregierung, Bonn $1951 \mathrm{ff}$.

Bulletin der Europäischen Wirtschaftsgemeinschaft, hrsg. vom Sekretariat der Kommission der Europäischen Wirtschaftsgemeinschaft, Brüssel $1958 \mathrm{ff}$.

Karl Carstens, Erinnerungen und Erfahrungen, hrsg. von Kai von Jena und Reinhard Schmoekkel, Boppard am Rhein 1993.

Charter of the United Nations. Commentary and Documents, hrsg. von Leland M. Goodrich und Edvard Hambro, 2. Auflage, London 1949.

Maurice Couve de Murville, Une politique étrangère, Paris 1971.

The Department of State Bulletin. The Official Weekly Record of United States Foreign Policy, Washington D.C. $1939 \mathrm{ff}$.

Der deutsch-israelische Dialog. Dokumentation eines erregenden Kapitels deutscher Außenpolitik, hrsg. von Rolf Vogel, Teil I/1: Politik, München/New York/London/Paris 1989.

Documents on Disarmament 1945-1959, hrsg. vom Department of State, Washington D.C. 1960 .

Documents on Disarmament 1961, hrsg. von der United States Arms Control and Disarmament Agency, Washington D.C. 1962. 
Documents on Disarmament 1962

DOCUMENTS ON DISARMAMENT 1963

DOCuMENTS ON Disarmament 1964

Documents on Disarmament 1965

Dokumente zur Berlin-Frage 1944-1966

\section{DOKUMENTE DES GETEILTEN} Deutschland, Bd. 1

\section{DzD I}

DzD II

DzD III

DzD IV

EBAN, Autobiography

FÜNFTER GESAMTBERICHT 1961/62
Documents on Disarmament 1962, hrsg. von der United States Arms Control and Disarmament Agency, Washington D.C. 1963.

Documents on Disarmament 1963, hrsg. von der United States Arms Control and Disarmament Agency, Washington D.C. 1964.

Documents on Disarmament 1964, hrsg. von der United States Arms Control and Disarmament Agency, Washington D.C. 1965.

Documents on Disarmament 1965, hrsg. von der United States Arms Control and Disarmament Agency, Washington D.C. 1966.

Dokumente zur Berlin-Frage 1944-1966, hrsg. vom Forschungsinstitut der Deutschen Gesellschaft für Auswärtige Politik e.V., Bonn, in Zusammenarbeit mit dem Senat von Berlin, 3. Auflage, München 1967.

Dokumente des geteilten Deutschland. Quellentexte zur Rechtslage des Deutschen Reiches, der Bundesrepublik Deutschland und der Deutschen Demokratischen Republik, Bd. 1, hrsg. von Ingo von Münch, 2. Auflage, Stuttgart 1976.

Dokumente zur Deutschlandpolitik. I. Reihe: Vom 3. September 1939 bis 8. Mai 1945, hrsg. vom Bundesministerium für innerdeutsche Beziehungen, Frankfurt a.M. $1984 \mathrm{ff}$.

Dokumente zur Deutschlandpolitik. II. Reihe: Vom 9. Mai 1945 bis 4. Mai 1955, hrsg. vom Bundesministerium des Innern, Neuwied $1992 \mathrm{ff}$.

Dokumente zur Deutschlandpolitik. III. Reihe: Vom 5. Mai 1955 bis 9. November 1958, hrsg. vom Bundesministerium für gesamtdeutsche Fragen, 4 Bde., Frankfurt a.M. 1961-1969.

Dokumente zur Deutschlandpolitik. IV. Reihe: Vom 10. November 1958 bis 30 . November 1966, hrsg. vom Bundesministerium für innerdeutsche Beziehungen, 12 Bde., Frankfurt a.M. 1971-1981.

Abba Eban, An Autobiography, London 1978.

Fünfter Gesamtbericht über die Tätigkeit der Gemeinschaft (1. Mai 1961-30. April 1962), hrsg. von der Kommission der Europäischen Wirtschaftsgemeinschaft, [Brüssel] 1962. 
DE GAULLE, Discours et messages, Bd. 3

DE GaUlLE, Discours et messages, Bd. 4

DE GAULLE, Lettres, notes et carnets. Juin 1958-décembre 1960

DE GAULLE, Lettres, notes et carnets. Janvier 1961-décembre 1963

DE GAULLE, Lettres, notes et carnets. Janvier 1964-juin 1966

DE Gaulle, Mémoires d'espoir. Le renouveau 1958-1962

Gerstenmaier, Streit und Friede

GrEwE, Rückblenden

HANSARD

Huxn, Sackgasse

Krone, Aufzeichnungen

LAHR, Zeuge

McGheE, An Ambassador's Account

Mende, Wende

MosKaU-BonN
Charles de Gaulle, Discours et messages. Bd. 3: Avec le renouveau. Mai 1958-juillet 1962, [Paris] 1970.

Charles de Gaulle, Discours et messages. Bd. 4: Pour l'effort. Août 1962-décembre 1965, [Paris] 1970.

Charles de Gaulle, Lettres, notes et carnets. Juin 1958-décembre 1960, [Paris] 1985.

Charles de Gaulle, Lettres, notes et carnets. Janvier 1961-décembre 1963, [Paris] 1986.

Charles de Gaulle, Lettres, notes et carnets. Janvier 1964-juin 1966, [Paris] 1987.

Charles de Gaulle, Mémoires d'espoir. Le renouveau 1958-1962, [Paris] 1970.

Eugen Gerstenmaier, Streit und Friede hat seine Zeit. Ein Lebensbericht, Frankfurt a.M./ Berlin/Wien 1981.

Wilhelm G. Grewe, Rückblenden 1976-1951, Frankfurt a.M./Berlin/Wien 1979.

Parliamentary Debates (Hansard). House of Commons, Official Report. Fifth Series, London [1965 f.].

Hans Graf Huyn, Die Sackgasse. Deutschlands Weg in die Isolierung, Stuttgart-Degerloch 1966.

Heinrich Krone, Aufzeichnungen zur Deutschland- und Ostpolitik 1954-1969, in: Untersuchungen und Dokumente zur Ostpolitik und Biographie (Adenauer-Studien III), hrsg. von Rudolf Morsey und Konrad Repgen, Mainz 1974, S. 134-201.

Rolf Lahr, Zeuge von Fall und Aufstieg. Private Briefe 1934-1974, Hamburg 1981.

George McGhee, At the Creation of a new Germany. From Adenauer to Brandt. An Ambassador's Account, New Haven/London 1989.

Erich Mende, Von Wende zu Wende 1962-1982, München/Berlin 1986.

Moskau-Bonn. Die Beziehungen zwischen der Sowjetunion und der Bundesrepublik Deutschland 1955-1973. Dokumentation, hrsg. von Boris Meissner, 2 Bde., Köln 1975. 
NeUNTER GESAMTBERICHT 1965/66

OSTERHELD, Außenpolitik

OSTERHELD, Kanzlerjahre

Public PAPers, Johnson 1963/64

Public Papers, Johnson 1965

Public PaPers, Johnson 1966

Public Papers, Kennedy 1962

Public Papers, Kennedy 1963

SHINNAR, Bericht

Sechster Gesamtbericht 1962/63
Neunter Gesamtbericht über die Tätigkeit der Gemeinschaft (1. April 1965-31. März 1966), hrsg. von der Kommission der Europäischen Wirtschaftsgemeinschaft, [Brüssel] 1966

Horst Osterheld, Außenpolitik unter Bundeskanzler Ludwig Erhard 1963-1966. Ein dokumentarischer Bericht aus dem Kanzleramt, Düsseldorf 1992.

Horst Osterheld, „Ich gehe nicht leichten Herzens..... Adenauers letzte Kanzlerjahre. Ein dokumentarischer Bericht, 2. Auflage, Mainz 1987.

Public Papers of the Presidents of the United States. Lyndon B. Johnson. Containing the Public Messages, Speeches, and Statements of the President. November 22, 1963 to December 31, 1964, Washington D.C. 1965.

Public Papers of the Presidents of the United States. Lyndon B. Johnson. Containing the Public Messages, Speeches, and Statements of the President. January 1 to December 31, 1965, Washington D.C. 1966.

Public Papers of the Presidents of the United States. Lyndon B. Johnson. Containing the Public Messages, Speeches, and Statements of the President. January 1 to December 31, 1966, Washington D.C. 1967.

Public Papers of the Presidents of the United States. John F. Kennedy. Containing the Public Messages, Speeches, and Statements of the President. January 1 to December 31, 1962, Washington D.C. 1963.

Public Papers of the Presidents of the United States. John F. Kennedy. Containing the Public Messages, Speeches, and Statements of the President. January 1 to November 22, 1963, Washington D.C. 1964.

Felix E. Shinnar, Bericht eines Beauftragten. Die deutsch-israelischen Beziehungen 19511966, Tübingen 1967.

Sechster Gesamtbericht über die Tätigkeit der Gemeinschaft (1. Mai 1962-31. März 1963), hrsg. von der Kommission der Europäischen Wirtschaftsgemeinschaft, [Brüssel] 1963. 
Siebenter Gesamtbericht 1963/64

SPAAK, Combats inachevés

SPD-FRAKTION 1964-1966

StrausS, Erinnerungen

Teheran - Jalta - PotsdaM

UN General Assembly, 20th Session, Fourth Committee

UN General Assembly, 19th Session, Plenary Meetings

UN General Assembly, 20th Session, Plenary Meetings

United Nations Resolutions, I/1

United Nations Resolutio:is, I/2

United Nations Resolutions, I/3

United Nations Resolutions, I/8

United Nations Resolutions, $1 / 10$
Siebenter Gesamtbericht über die Tätigkeit der Gemeinschaft (1. April 1963-31. März 1964), hrsg. von der Kommission der Europäischen Wirtschaftsgemeinschaft, [Brüssel] 1964.

Paul-Henri Spaak, Combats inachevés. Bd. 2: De l'espoir aux déceptions, [Paris] 1969.

Die SPD-Fraktion im Deutschen Bundestag. Sitzungsprotokolle 1961-1966, bearb. von Heinrich Potthoff, 2. Halbband: 1964-1966, Düsseldorf 1993.

Franz Josef Strauß, Die Erinnerungen, Berlin 1989.

Teheran, Jalta, Potsdam. Die sowjetischen Protokolle von den Kriegskonferenzen der "Großen Drei“, hrsg. von Alexander Fischer, Köln 1968.

United Nations. Official Records of the General Assembly. Fourth Committee. Twentieth Session. Summary Records, New York 1966.

United Nations. Official Records of the General Assembly. Plenary Meetings. Nineteenth Session. Verbatim Records of Meetings, New York 1964.

United Nations. Official Records of the General Assembly. Plenary Meetings. Twentieth Session. Verbatim Records of Meetings, New York 1967.

United Nations Resolutions. Series I: Resolutions Adopted by the General Assembly, hrsg. von Dusan J. Djonovich. Bd. 1: 1946-1948, New York 1973.

United Nations Resolutions. Series I: Resolutions Adopted by the General Assembly, hrsg. von Dusan J. Djonovich. Bd. 2: 1948-1949, New York 1973.

United Nations Resolutions. Series I: Resolutions Adopted by the General Assembly, hrsg. von Dusan J. Djonovich. Bd. 3: 1950-1952, New York 1973.

United Nations Resolutions. Series I: Resolutions Adopted by the General Assembly, hrsg. von Dusan J. Djonovich. Bd. 8: 1960-1962, New York 1974.

United Nations Resolutions. Series I: Resolutions Adopted by the General Assembly, hrsg. von Dusan J. Djonovich. Bd. 10: 1964-1965, New York 1974. 
United Nations Resolutions, II/4

United Nations Resolutions, II/5

UNTS

U.S. TREATIES

VIERERKONFERENZ

WILSON, The Labour Government

YEARBOOK OF THE UNITED NATIONS 1964

ZehNTER Gesamtbericht 1966/67
United Nations Resolutions. Series II: Resolutions and Decisions of the Security Council, hrsg. von Dusan J. Djonovich. Bd. 4: 1960-1963, New York 1989.

United Nations Resolutions. Series II: Resolutions and Decisions of the Security Council, hrsg. von Dusan J. Djonovich. Bd. 5: 1964-1965, New York 1989.

United Nations Treaty Series. Treaties and International Agreements Registered or Filed and Recorded with the Secretariat of the United Nations, [New York] 1946/47 ff.

United States Treaties and Other International Agreements, hrsg. vom Department of State, Washington D. C. $1950 \mathrm{ff}$.

Die Viererkonferenz in Berlin 1954. Reden und Dokumente, Berlin 1954.

Harold Wilson, The Labour Government 19641970. A Personal Record, London 1971.

Yearbook of the United Nations 1964, hrsg. vom Office of Public Information United Nations, New York 1966.

Zehnter Gesamtbericht über die Tätigkeit der Gemeinschaft (1. April 1966-31. März 1967), hrsg. von der Kommission der Europäischen Wirtschaftsgemeinschaft, [Brüssel] 1967. 


\section{Abkürzungsverzeichnis}

\begin{tabular}{|c|c|c|c|}
\hline $\begin{array}{l}\text { AA } \\
\text { ABC-Waffen }\end{array}$ & $\begin{array}{l}\text { Auswärtiges Amt } \\
\text { atomare, biologische und }\end{array}$ & BKO & $\begin{array}{l}\text { Berlin Kommandatura } \\
\text { Order }\end{array}$ \\
\hline & chemische Waffen & $\mathrm{BM}$ & Bundesminister(ium) \\
\hline Abg(eo) & Abgeordnete(r) & BMAT & $\begin{array}{l}\text { Bundesminister(ium) für } \\
\text { Arbeit und Sozialordnung }\end{array}$ \\
\hline $\begin{array}{l}\text { Abt. } \\
\text { a.D. }\end{array}$ & $\begin{array}{l}\text { Abtellung } \\
\text { außer Dienst }\end{array}$ & BMF & $\begin{array}{l}\text { Bundesminister(ium) der } \\
\text { Finanzen }\end{array}$ \\
\hline AEG & $\begin{array}{l}\text { Allgemeine Elektrizitäts- } \\
\text { Gesellschaft }\end{array}$ & BMI & $\begin{array}{l}\text { Bundesminister(ium) des } \\
\text { Innern }\end{array}$ \\
\hline AFCENT & $\begin{array}{l}\text { Allied Forces Central } \\
\text { Europe }\end{array}$ & BML & $\begin{array}{l}\text { Bundesminister(ium) für } \\
\text { Ernährung, Landwirt- }\end{array}$ \\
\hline $\mathrm{AG}$ & Aktiengesellschaft & & schaft und Forsten \\
\hline $\begin{array}{l}\text { AHK } \\
\text { a.i. }\end{array}$ & $\begin{array}{l}\text { Alliierte Hochkommission } \\
\text { ad interim }\end{array}$ & BMV & $\begin{array}{l}\text { Bundesminister(ium) für } \\
\text { Verkehr }\end{array}$ \\
\hline AIRCENT & $\begin{array}{l}\text { Allied Air Forces Central } \\
\text { Europe }\end{array}$ & BMVtdg. & $\begin{array}{l}\text { Bundesminister(ium) der } \\
\text { Verteidigung }\end{array}$ \\
\hline AK & Arbeitskreis & BMWi & $\begin{array}{l}\text { Bundesminister(ium) für } \\
\text { Wirtschaft }\end{array}$ \\
\hline ANF & Atlantic Nuclear Force & BMZ & $\begin{array}{l}\text { Bundesminister(ium) für } \\
\text { wirtschaftliche Zusammen- }\end{array}$ \\
\hline $\operatorname{Anl}(g)$ & Anlage(n) & & arbeit \\
\hline Anm. & Anmerkung & BND & Bundesnachrichtendienst \\
\hline ANZUS-Pakt & $\begin{array}{l}\text { Australia-New Zealand- } \\
\text { United-States-Pakt }\end{array}$ & $\begin{array}{l}\text { BR I } \\
\text { BRD }\end{array}$ & Botschaftsrat I. Klasse \\
\hline AP & Associated Press & & land \\
\hline ATO & Allied Travel Office & BT & Bundestag \\
\hline AWV & $\begin{array}{l}\text { Außenwirtschaftsverord- } \\
\text { nung }\end{array}$ & $\begin{array}{l}\text { bzw. } \\
\text { ca. }\end{array}$ & $\begin{array}{l}\text { beziehungsweise } \\
\text { circa }\end{array}$ \\
\hline $\mathrm{AZ}$ & Aktenzeichen & CCPIT & China Council for the \\
\hline BAOR & British Army on the Rhine & & $\begin{array}{l}\text { Promotion of International } \\
\text { Trade }\end{array}$ \\
\hline BASC & Berlin Air Security Centre & CDU & Christlich-Demokratische \\
\hline Bd./Bde. & Band/Bände & & Union Deutschlands \\
\hline $\mathrm{BDI}$ & $\begin{array}{l}\text { Bundesverband der deut- } \\
\text { schen Industrie }\end{array}$ & C.E.C.A. & $\begin{array}{l}\text { Communauté Européenne } \\
\text { du Charbon et de l'Acier }\end{array}$ \\
\hline BEA & $\begin{array}{l}\text { British European } \\
\text { Airways Corporation }\end{array}$ & CENTO & $\begin{array}{l}\text { Central Treaty Organisa- } \\
\text { tion }\end{array}$ \\
\hline $\begin{array}{l}\text { Ber. } \\
\text { Betr./betr. }\end{array}$ & $\begin{array}{l}\text { Bericht } \\
\text { Betreff/betreffend }\end{array}$ & CNL & $\begin{array}{l}\text { Comité National } \\
\text { de Libération }\end{array}$ \\
\hline $\mathrm{BKC} / \mathrm{L}$ & $\begin{array}{l}\text { Berlin Kommandatura } \\
\text { Commandant/Letter }\end{array}$ & COCOM & $\begin{array}{l}\text { Coordinating Committee } \\
\text { for East-West Trade Policy }\end{array}$ \\
\hline
\end{tabular}




\begin{tabular}{|c|c|c|c|}
\hline COMECON & $\begin{array}{l}\text { Council for Mutual Eco- } \\
\text { nomic Aid/Assistance }\end{array}$ & EURATOM & $\begin{array}{l}\text { Europäische Atomgemein- } \\
\text { schaft }\end{array}$ \\
\hline ČSSR & Československá Sociali- & \multirow{3}{*}{$\begin{array}{l}\text { etc. } \\
\text { EVG }\end{array}$} & et cetera \\
\hline & stická Republika & & \multirow{2}{*}{$\begin{array}{l}\text { Europäische Verteidi- } \\
\text { gungsgemeinschaft }\end{array}$} \\
\hline CPP & Convention People's Party & & \\
\hline CSU & Christlich-Soziale Union & evtl. & eventuell \\
\hline D & (Ministerial-)Direktor & \multirow[t]{2}{*}{ EWG } & \multirow{2}{*}{$\begin{array}{l}\text { Europäische Wirtschafts- } \\
\text { gemeinschaft }\end{array}$} \\
\hline DB & Drahtbericht/ & & \\
\hline & Deutsche Bundesbahn & f. & folgende \\
\hline DC & Disarmament Commission & \multirow[t]{2}{*}{ FAZ } & \multirow{2}{*}{$\begin{array}{l}\text { Frankfurter Allgemeine } \\
\text { Zeitung }\end{array}$} \\
\hline $\mathrm{DDR}$ & Deutsche Demokratische & & \\
\hline & Republik & \multirow[t]{2}{*}{ FDP } & \multirow{2}{*}{$\begin{array}{l}\text { Freie Demokratische } \\
\text { Partei }\end{array}$} \\
\hline DE & Drahterlaß & & \\
\hline \multirow{2}{*}{$\begin{array}{l}\text { DEA/DEAG } \\
\text { DED }\end{array}$} & Deutsche Erdöl AG & \multirow[t]{2}{*}{ FLN } & \multirow{2}{*}{$\begin{array}{l}\text { Front de Libération } \\
\text { Nationale }\end{array}$} \\
\hline & Deutscher Entwicklungs- & & \\
\hline \multirow{2}{*}{$\mathrm{Dg}$} & $\begin{array}{l}\text { dienst } \\
\text { (Ministerial-)Dirigent }\end{array}$ & FRG & $\begin{array}{l}\text { Federal Republic } \\
\text { of Germany }\end{array}$ \\
\hline & das heißt & Frhr. & Freiherr \\
\hline \multirow{3}{*}{$\begin{array}{l}\text { Dipl.-Ing. } \\
\text { d.J./d. Jhrs. } \\
\text { d.M. }\end{array}$} & Diplomingenieur & FS & \multirow{2}{*}{$\begin{array}{l}\text { Fernschreiben } \\
\text { General Agreement on } \\
\text { Tariffs and Trade }\end{array}$} \\
\hline & dieses Jahres & GATT & \\
\hline & dieses Monats & geh. & geheim \\
\hline DM & Deutsche Mark & \multirow{2}{*}{$\begin{array}{l}\text { gem. } \\
\text { gez. }\end{array}$} & gemäß \\
\hline $\begin{array}{l}\text { Dok. } \\
\text { dpa }\end{array}$ & $\begin{array}{l}\text { Dokument } \\
\text { Deutsche Presseagentur }\end{array}$ & & gezeichnet \\
\hline DR & Deutsche Reichsbahn & GG & $\begin{array}{l}\text { Grundgesetz (der Bundes- } \\
\text { republik Deutschland) }\end{array}$ \\
\hline DRK & Deutsches Rotes Kreuz & \multirow{2}{*}{$\begin{array}{l}\text { ggf./ggfs. } \\
\text { GmbH }\end{array}$} & \multirow{2}{*}{$\begin{array}{l}\text { gegebenenfalls } \\
\text { Gesellschaft mit } \\
\text { beschränkter Haftung }\end{array}$} \\
\hline DRV & $\begin{array}{l}\text { Demokratische Republik } \\
\text { Vietnam }\end{array}$ & & \\
\hline EAG & $\begin{array}{l}\text { Europäische Atomgemein- } \\
\text { schaft }\end{array}$ & GNS & $\begin{array}{l}\text { Gemeinsame Nuklear- } \\
\text { Streitmacht }\end{array}$ \\
\hline EEC & $\begin{array}{l}\text { European Economic } \\
\text { Community }\end{array}$ & h. & hora/Stunde \\
\hline EFTA & $\begin{array}{l}\text { European Free Trade } \\
\text { Association }\end{array}$ & HPA & $\begin{array}{l}\text { Handelspolitischer } \\
\text { Ausschuß }\end{array}$ \\
\hline EGKS & $\begin{array}{l}\text { Europäische Gemeinschaft } \\
\text { für Kohle und Stahl }\end{array}$ & Hrsg./hrsg. & $\begin{array}{l}\text { Herausgeber/ } \\
\text { herausgegeben }\end{array}$ \\
\hline EKD & $\begin{array}{l}\text { Evangelische Kirche in } \\
\text { Deutschland }\end{array}$ & $\mathrm{HV}$ & Handelsvertretung \\
\hline ENDC & & $\begin{array}{l}\text { i.A. } \\
\text { IAEO }\end{array}$ & $\begin{array}{l}\text { im Auftrag } \\
\text { International Atomic }\end{array}$ \\
\hline & ment Committee & & Energy Organisation \\
\hline ENEA & $\begin{array}{l}\text { European Nuclear } \\
\text { Energy Agency }\end{array}$ & ICBM & $\begin{array}{l}\text { Inter-Continental Ballistic } \\
\text { Missile }\end{array}$ \\
\hline
\end{tabular}




\begin{tabular}{|c|c|c|c|}
\hline IDA & International Development & Mrs. & Misses \\
\hline & Association & MRBM & Medium Range Ballistic \\
\hline i.G. & im Generalstab, & & Missile \\
\hline & im Generalstabsdienst & Mrd. & Milliarde(n) \\
\hline IMF & $\begin{array}{l}\text { International Monetary } \\
\text { Fund }\end{array}$ & MTP & $\begin{array}{l}\text { Maschinen, Turbinen, } \\
\text { Pumpen }\end{array}$ \\
\hline insbes. & insbesondere & NAP & Nichtangriffspakt \\
\hline IOC & $\begin{array}{l}\text { International Olympic } \\
\text { Committee }\end{array}$ & NASA & $\begin{array}{l}\text { National Aeronautics } \\
\text { and Space Administration }\end{array}$ \\
\hline $\begin{array}{l}\text { i.V. } \\
\text { IWF }\end{array}$ & $\begin{array}{l}\text { in Vertretung } \\
\text { Internationaler Währungs- }\end{array}$ & NATO & $\begin{array}{l}\text { North Atlantic Treaty } \\
\text { Organisation }\end{array}$ \\
\hline IWS & $\begin{array}{l}\text { fonds } \\
\text { Integriertes Waffensystem } \\
\text { (NATO) }\end{array}$ & NBC & $\begin{array}{l}\text { National Broadcasting } \\
\text { Corporation }\end{array}$ \\
\hline IZH & Interzonenhandel & NF & Nouveaux Francs \\
\hline km & Kilometer & $\mathrm{NfD}$ & $\begin{array}{l}\text { Nur für den Dienst- } \\
\text { gebrauch }\end{array}$ \\
\hline KP & Kommunistische Partei & No. & Number \\
\hline KPCh & $\begin{array}{l}\text { Kommunistische Partei } \\
\text { Chinas }\end{array}$ & NOK & $\begin{array}{l}\text { Nationales Olympisches } \\
\text { Komitee }\end{array}$ \\
\hline KPD & $\begin{array}{l}\text { Kommunistische Partei } \\
\text { Deutschlands }\end{array}$ & Nr. & Nummer \\
\hline KPdSU & $\begin{array}{l}\text { Kommunistische Partei der } \\
\text { Sowjetunion }\end{array}$ & $\begin{array}{l}\text { NS } \\
\text { NTSC }\end{array}$ & $\begin{array}{l}\text { Nationalsozialismus } \\
\text { National Television System }\end{array}$ \\
\hline KPI & $\begin{array}{l}\text { Kommunistische Partei } \\
\text { Italiens }\end{array}$ & NV & $\begin{array}{l}\text { Committee } \\
\text { Nichtverbreitung }\end{array}$ \\
\hline LANDCENT & $\begin{array}{l}\text { Allied Land Forces Central } \\
\text { Europe }\end{array}$ & NVA & $\begin{array}{l}\text { Nichtverbreitungs- } \\
\text { abkommen }\end{array}$ \\
\hline LR I & Legationsrat I. Klasse & o.a. & oben angeführt \\
\hline LS & Legationssekretär & o.ä. & oder ähnlich \\
\hline $\begin{array}{l}\mathrm{m} \\
\mathrm{M}\end{array}$ & $\begin{array}{l}\text { Meter } \\
\text { Monsieur }\end{array}$ & OAS & $\begin{array}{l}\text { Organisation of American } \\
\text { States }\end{array}$ \\
\hline $\mathrm{MD}$ & Ministerialdirektor & OAU & $\begin{array}{l}\text { Organisation for African } \\
\text { Unity }\end{array}$ \\
\hline MdB & Mitglied des Bundestages & & \\
\hline m.d.B. & mit der Bitte & OCAM & $\begin{array}{l}\text { Organisation Commune } \\
\text { Africaine et Malgache }\end{array}$ \\
\hline $\begin{array}{l}\text { MDg } \\
\text { m.E. } \\
\text { MEV }\end{array}$ & $\begin{array}{l}\text { Ministerialdirigent } \\
\text { meines Erachtens } \\
\text { Megaelektronenvolt }\end{array}$ & OECD & $\begin{array}{l}\text { Organisation for Economic } \\
\text { Cooperation and } \\
\text { Development }\end{array}$ \\
\hline MEZ & mitteleuropäische Zeit & OEEC & Organisation for European \\
\hline MG & Maschinengewehr & & Economic Cooperation \\
\hline Mio. & Million(en) & o.g. & oben genannt \\
\hline MLF & Multilateral Force & o.J. & ohne Jahr \\
\hline Mr. & Mister & ORR & Oberregierungsrat \\
\hline
\end{tabular}




\begin{tabular}{|c|c|c|c|}
\hline ORTF & $\begin{array}{l}\text { Office de Radiodiffusion- } \\
\text { Télévision Française }\end{array}$ & UdSSR & $\begin{array}{l}\text { Union der Sozialistischen } \\
\text { Sowjetrepubliken }\end{array}$ \\
\hline \multirow[t]{2}{*}{ O.T.A.N. } & \multirow{2}{*}{$\begin{array}{l}\text { Organisation du Traité } \\
\text { de l'Atlantique Nord }\end{array}$} & UK & United Kingdom \\
\hline & & UN & United Nations \\
\hline PAA & Pan American Airways & \multirow[t]{2}{*}{ UNCTAD } & \multirow{2}{*}{$\begin{array}{l}\text { United Nations Conference } \\
\text { on Trade and Development }\end{array}$} \\
\hline PAL & Phase Alternating Line & & \\
\hline PKI & Partai Komunis Indonesia & \multirow[t]{2}{*}{ UNESCO } & \multirow{2}{*}{$\begin{array}{l}\text { United Nations Education- } \\
\text { al, Scientific and Cultural } \\
\text { Organisation }\end{array}$} \\
\hline PVAP & $\begin{array}{l}\text { Polnische Vereinigte } \\
\text { Arbeiterpartei }\end{array}$ & & \\
\hline \multirow{2}{*}{$\begin{array}{l}\text { RAU } \\
\text { rd. } \\
\text { ROK }\end{array}$} & $\begin{array}{l}\text { République Arabe Unie } \\
\text { rund }\end{array}$ & UNFICYP & $\begin{array}{l}\text { United Nations Forces } \\
\text { in Cyprus }\end{array}$ \\
\hline & $\begin{array}{l}\text { rund } \\
\text { Republic of Korea } \\
\text { siehe }\end{array}$ & UNICEF & $\begin{array}{l}\text { United Nations } \\
\text { International Children's } \\
\text { Emergency Fund }\end{array}$ \\
\hline S. & Seite & \multirow[t]{2}{*}{ UNO } & \multirow{2}{*}{$\begin{array}{l}\text { United Nations } \\
\text { Organisation }\end{array}$} \\
\hline SAC & Strategic Air Command & & \\
\hline SACEUR & $\begin{array}{l}\text { Supreme Allied } \\
\text { Commander Europe }\end{array}$ & UNR & $\begin{array}{l}\text { Union pour la Nouvelle } \\
\text { République }\end{array}$ \\
\hline SBZ & $\begin{array}{l}\text { Sowjetische } \\
\text { Besatzungszone }\end{array}$ & UNRWA & \multirow{3}{*}{$\begin{array}{l}\text { United Nations Relief and } \\
\text { Works Agency for Palestine } \\
\text { Refugees in the Near East } \\
\text { United Press International } \\
\text { United States }\end{array}$} \\
\hline s.E. & seines Erachtens & & \\
\hline SEATO & $\begin{array}{l}\text { South-East Asia Treaty } \\
\text { Organisation }\end{array}$ & US & \\
\hline \multirow{2}{*}{$\begin{array}{l}\text { SECAM } \\
\text { SED }\end{array}$} & Sequentielle à mémoire & \multirow{2}{*}{$\begin{array}{l}\text { USA/U.S.A. } \\
\text { usw. } \\
\text { u.U. }\end{array}$} & \multirow{2}{*}{$\begin{array}{l}\text { United States of America } \\
\text { und so weiter } \\
\text { unter Umständen }\end{array}$} \\
\hline & $\begin{array}{l}\text { Sozialistische Einheits- } \\
\text { partei Deutschlands }\end{array}$ & & \\
\hline \multirow[t]{2}{*}{ SHAPE } & Supreme Headquarters & v. & von \\
\hline & $\begin{array}{l}\text { Allied Powers Europe } \\
\text { siehe oben }\end{array}$ & VAR & $\begin{array}{l}\text { Vereinigte Arabische } \\
\text { Republik }\end{array}$ \\
\hline sog. & sogenannt & vgl. & vergleiche \\
\hline \multirow[t]{2}{*}{ SPD } & Sozialdemokratische & v.J. & vorigen Jahres \\
\hline & Partei Deutschlands & \multirow[t]{2}{*}{ VLR I } & \multirow{2}{*}{$\begin{array}{l}\text { Vortragender Legationsrat } \\
\text { I. Klasse }\end{array}$} \\
\hline \multirow{5}{*}{$\begin{array}{l}\text { StS/St.S. } \\
\text { SU } \\
\text { s.Zt. } \\
\text { t } \\
\text { TASS }\end{array}$} & Staatssekretär & & \\
\hline & Sowjetunion & $\mathrm{VN}$ & Vereinte Nationen \\
\hline & seinerzeit & $\mathrm{VN} / \mathrm{CH}$ & $\begin{array}{l}\text { Charta der Vereinten } \\
\text { Nationen }\end{array}$ \\
\hline & Tonne & Vorg. & Vorgang \\
\hline & $\begin{array}{l}\text { Telegrafnoe Agentstvo } \\
\text { Sovetskogo Sojuza }\end{array}$ & VR & Volksrepublik \\
\hline TO & Tagesordnung & VRCh & Volksrepublik China \\
\hline \multirow{2}{*}{ TTD } & Temporary Travel & VS & $\operatorname{Verschlußsache(n)}$ \\
\hline & Document & VS-v/vsv & VS-vertraulich \\
\hline u.a. & unter anderem & WAK & Weltabrüstungskonferenz \\
\hline u.a.m. & und anderes mehr & WEU & Westeuropäische Union \\
\hline
\end{tabular}




$\begin{array}{llll}\text { WHO } & \text { World Health Organisation } & \text { Ziff. } & \text { Ziffer } \\ \text { ZAB } & \text { Zentrale Austauschstelle } & \text { zit. } & \text { zitiert } \\ & \text { Bonn } & \text { ZK } & \text { Zentralkomitee } \\ \text { z.B. } & \text { zum Beispiel } & \text { z.Z./z.Zt. } & \text { zur Zeit } \\ \text { z.b.V. } & \text { zur besonderen } & & \\ & \text { Verwendung } & & \end{array}$


